\title{
Synthesis, Characterization and Application of \\ Ruthenium-Containing Polymers
}

Xianguo Wu, M.Sc.

A thesis submitted to the Faculty of Graduate Studies and Research in partial fulfillment of the requirements for the degree of Doctor of Philosophy

Department of Chemistry

Carleton University

Ottawa, Ontario

August 2008

(C) Copyright 


$\begin{array}{ll}\begin{array}{l}\text { Library and } \\ \text { Archives Canada }\end{array} & \begin{array}{l}\text { Bibliothèque et } \\ \text { Archives Canada }\end{array} \\ \begin{array}{l}\text { Published Heritage } \\ \text { Branch }\end{array} & \begin{array}{l}\text { Direction du } \\ \text { Patrimoine de l'édition }\end{array} \\ \begin{array}{l}\text { 395 Wellington Street } \\ \text { Ottawa ON K1A 0N4 } \\ \text { Canada }\end{array} & \begin{array}{l}\text { 395, rue Wellington } \\ \text { Ottawa ON K1A 0N4 } \\ \text { Canada }\end{array}\end{array}$

Your file Votre référence ISBN: 978-0-494-43915-9 Our file Notre référence ISBN: 978-0-494-43915-9

NOTICE:

The author has granted a nonexclusive license allowing Library and Archives Canada to reproduce, publish, archive, preserve, conserve, communicate to the public by telecommunication or on the Internet, loan, distribute and sell theses worldwide, for commercial or noncommercial purposes, in microform, paper, electronic and/or any other formats.

The author retains copyright ownership and moral rights in this thesis. Neither the thesis nor substantial extracts from it may be printed or otherwise reproduced without the author's permission.
AVIS:

L'auteur a accordé une licence non exclusive permettant à la Bibliothèque et Archives Canada de reproduire, publier, archiver, sauvegarder, conserver, transmettre au public par télécommunication ou par l'Internet, prêter, distribuer et vendre des thèses partout dans le monde, à des fins commerciales ou autres, sur support microforme, papier, électronique et/ou autres formats.

L'auteur conserve la propriété du droit d'auteur et des droits moraux qui protège cette thèse. $\mathrm{Ni}$ la thèse ni des extraits substantiels de celle-ci ne doivent être imprimés ou autrement reproduits sans son autorisation.
In compliance with the Canadian Privacy Act some supporting forms may have been removed from this thesis.

While these forms may be included in the document page count, their removal does not represent any loss of content from the thesis.
Conformément à la loi canadienne sur la protection de la vie privée, quelques formulaires secondaires ont été enlevés de cette thèse.

Bien que ces formulaires aient inclus dans la pagination, il n'y aura aucun contenu manquant.

\section{Canada}




\begin{abstract}
Near-infrared (NIR) light covers the wavelength from $750 \mathrm{~nm}$ to $2500 \mathrm{~nm}$. Materials, interacting or emitting light in this region, have drawn increasing interests due to their unique electrical and optical properties. In theory, electrochromic (EC) materials which can reversibly change their absorption at telecommunication wavelengths $(980$, 1330 and $1550 \mathrm{~nm}$ ) at different oxidation states are potentially useful in optical switching and attenuation. The device application requires these NIR materials be incorporated as thin films.
\end{abstract}

This thesis research focuses mainly on the synthesis, characterization and application of a series of dicarbonylhydrazine ruthenium complexes and polymers. Different strategies have been applied to the synthesis of NIR-active film-forming materials: crosslinking the functionalized ruthenium complexes, complexation of ligand polymers and polymerization of the ruthenium complex monomers.

Crosslinking of the functionalized dendric DCH-Ru complex is a simple way to form the films with high resistance to solvents and thermal degradation. All the complex polymers in the mixed-valence state show intense and broad absorption in the NIR region. Direct polymerization of the DCH-Ru monomers produces the complex polymers with controlled molecular weights, compositions and good solubility for film casting. The application of these complex polymers in electrochromic variable optical attenuator devices has been demonstrated. A high dynamic range of optical attenuation of $30 \mathrm{~dB}$ at $1550 \mathrm{~nm}$ has been achieved with a hybrid device using a dendric $\mathrm{DCH}-\mathrm{Ru}$ complex in solution and $\mathrm{WO}_{3}$ thin film as complimentary NIR electrochromic materials. 


\section{Acknowledgements}

Pursuing a Ph.D is a struggling time in my life. Without the help from so many people, this work could not be done.

First of all, I like to thank my supervisor, Dr. Zhiyuan Wang, for all of his guidance, understanding and support throughout my graduate study. What I have learned from him will benefit the rest of life.

Second, I want to thank those old students who have left this lab. They treated me like their brothers. Whenever I needed help, they would give out their hands without my asking. Their care and love was especially important to me when I was alone at that time. And my thanks also go to the people currently in this lab. Although they are younger, they are just like most others who worked in this lab before. As a student in organic chemistry, I have to spend a lot of time in purifying stuff. But most people from this lab don't need to be purified. They would try what they could to help others. The list of the name could be too long, but the names have already stored in my memory.

And there are many others out of this lab I need to thank. I can't forget to thank the technicians working on NMR and MS at Carleton U. and Ottawa U. They have done a lot of work to help me to finish my job.

Finally, I thank my wife and my parents for their support all the time. 


\section{Table of Contents}

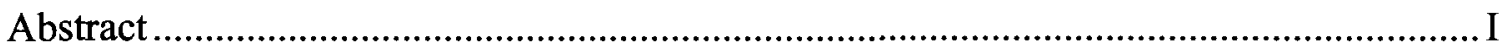

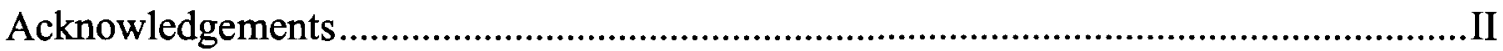

Table of Contents ...................................................................................................... III

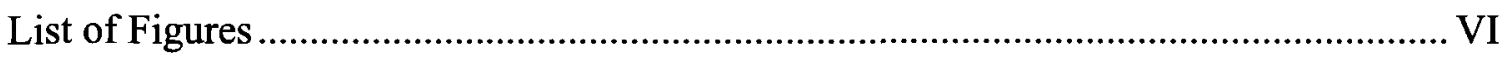

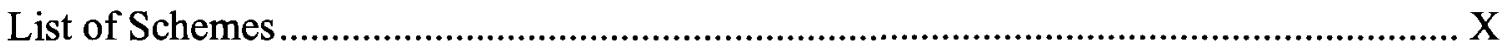

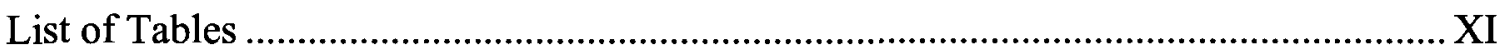

List of Abbreviations ..........................................................................................

Chapter I Introduction to Near-Infrared Materials and Applications ............................ 1

I.1. Near-Infrared Active Metal Oxides .......................................................... 2

I.2. Near-Infrared Active Organic Compounds ................................................ 3

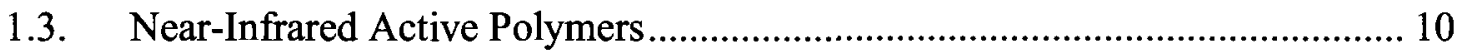

I.4. Near-Infrared Active Metal Complexes................................................... 16

I.5. Electrochromic Variable Optical Attenuator (ECVOA) ................................ 24

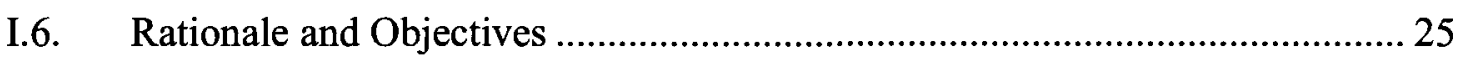

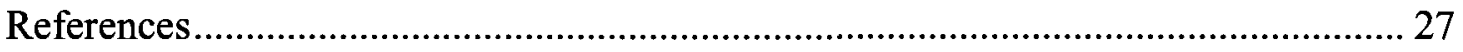

Chapter II Design, Synthesis and Application of [G]-1 DCH-Ru Complexes ............... 34

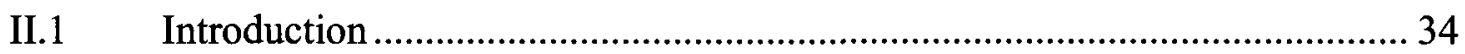

II.2 Synthesis and Characterization of [G]-1 DCH-Ru complexes...................... 36

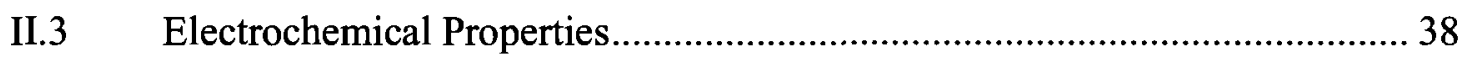

II.4 UV-vis-NIR Spectroscopic Properties .............................................. 41

II.5 NIR Electrochromic Variable Optical Attenuator................................... 42

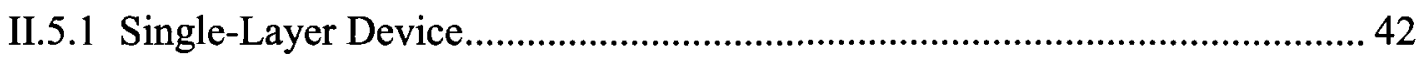


II.5.2 Hybrid Single-Layer Device .................................................................. 44

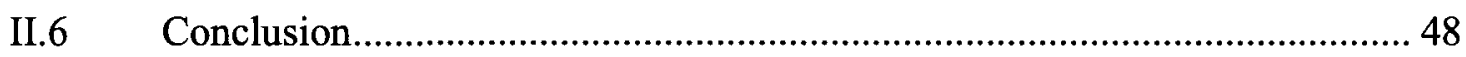

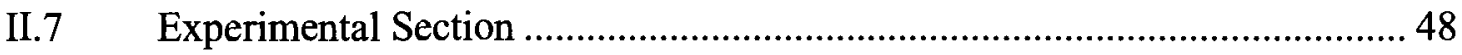

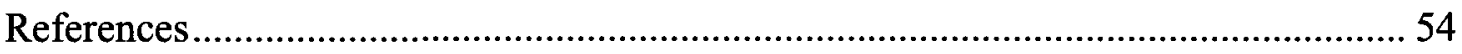

Chapter III Synthesis and Characterization of Biurea-Ruthenium Complex.................... 57

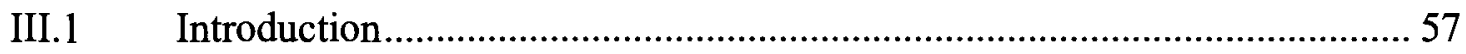

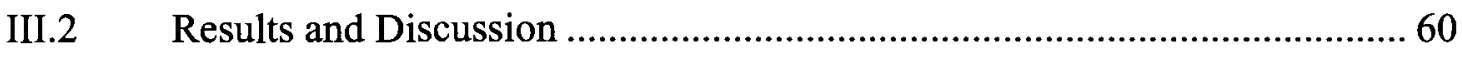

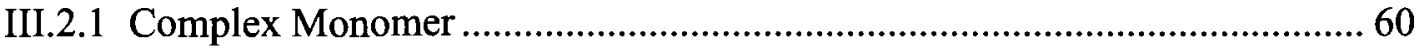

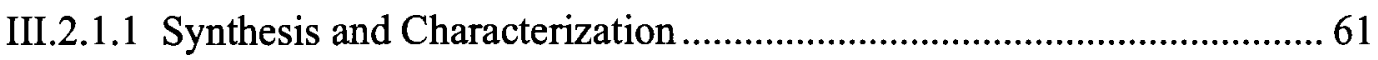

III.2.1.2 Electrochemical Properties .................................................................... 61

III.2.1.3 Spectroelectrochemical Properties .................................................. 62

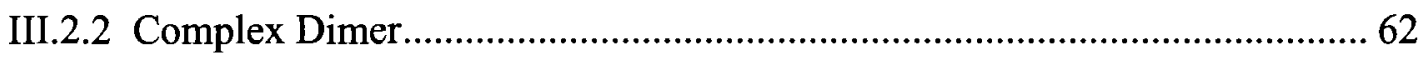

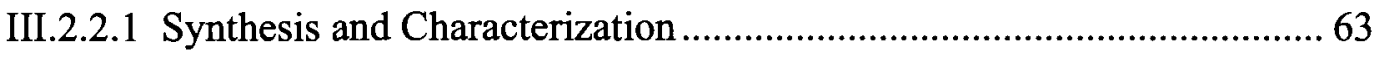

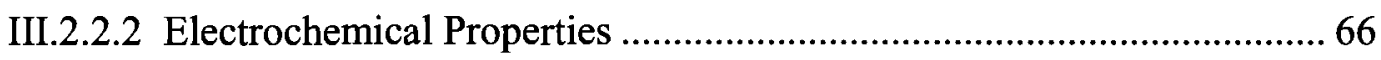

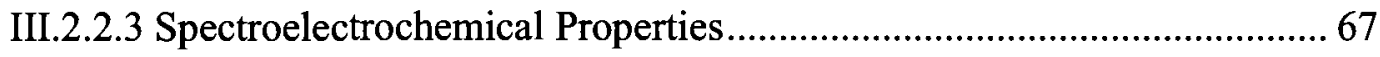

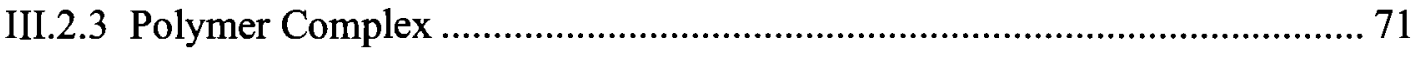

III.2.3.1 Synthesis and Characterization .............................................................. 71

III.2.3.2 Electrochemical Properties ..................................................................... 73

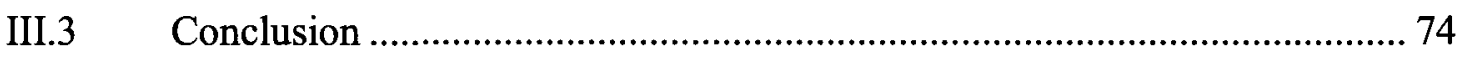

III.4 Experimental Section ......................................................................... 75

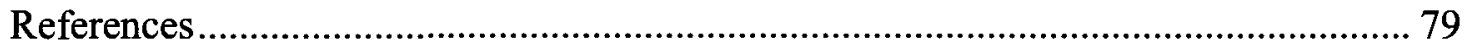

Chapter IV Ru-Containing Polymers by Suzuki Cross-Coupling Polymerization.......... 81

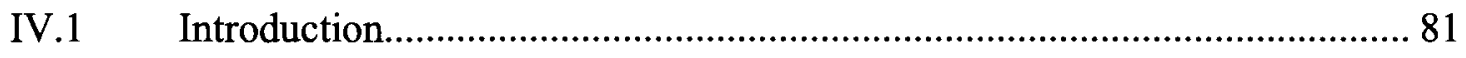


IV.2 Design and Synthesis of AB monomers ......................................................... 84

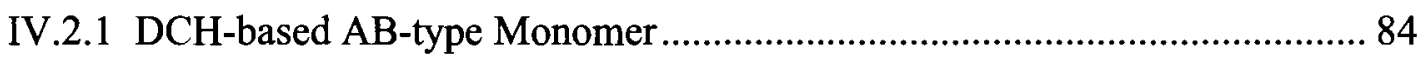

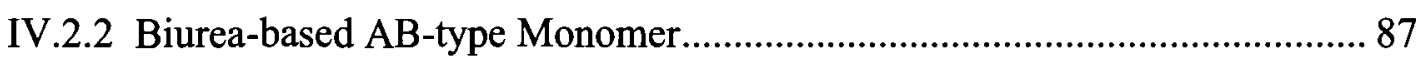

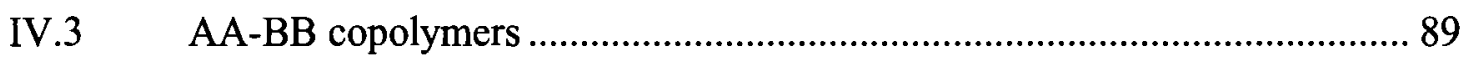

IV.3.1 Synthesis and Characterization of Poly(DCH-Ru-alt-triglycol)..................90

IV.3.2 Synthesis and Characterization of Poly(fluorene-co-DCH-Ru) .................. 93

IV.3.3 Solution Property .................................................................................. 96

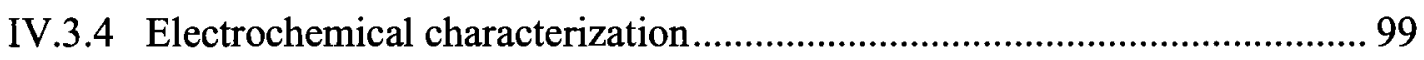

IV.3.5 UV-vis-NIR Spectroscopic Study.......................................................... 101

IV.3.6 Photoluminescent and Electroluminescent Properties............................... 103

IV.3.7 Thermal Properties................................................................................... 109

IV.3.8 Electrochromic Properties ……………………….............................. 110

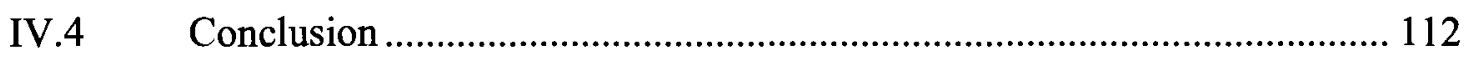

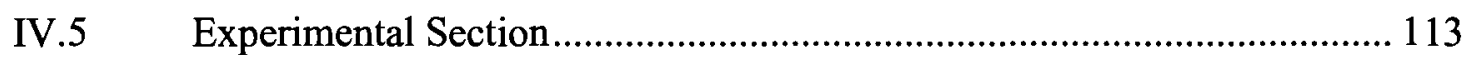

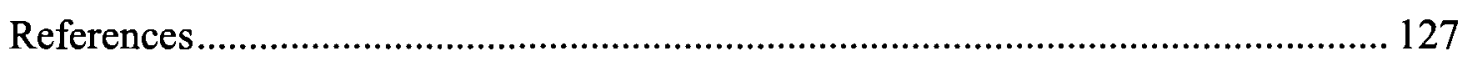

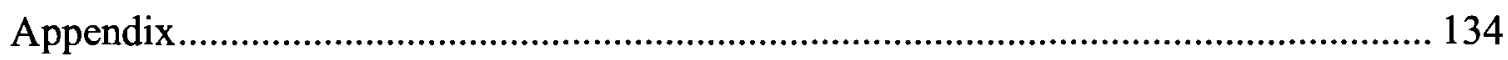

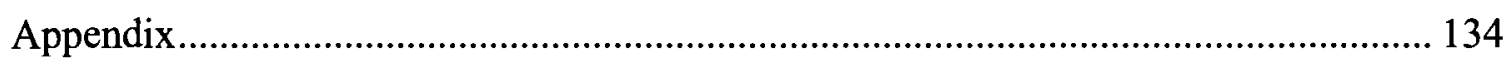




\section{List of Figures}

Figure I.1. Absorption of $\mathrm{WO}_{3}$ films under different reduction potential. ..................... 3

Figure I.2. Examples of NIR electrochromic polymers..................................... 11

Figure I.3. Evolution of energy levels with p-doping (top) and n-doping (bottom) in a conjugated polymer with non-degenerated ground states......................... 13

Figure I.4. Spectroelectrochemistry for PEDOT film on ITO ..................................... 14

Figure I.5. Spectroelectrochemistry of a thin PEDOP film (a: $-0.887 \mathrm{~V}, \mathrm{j}:-0.37 \mathrm{~V}) \ldots 14$

Figure I.6. $\left[\left\{R u(b p y)_{2}\right\}_{2} \mu-P h_{2} d c h\right]^{2+}$ (L.21): general structure, typical $\mathrm{CV}$ and absorption spectra in three different oxidation states. .............................. 23

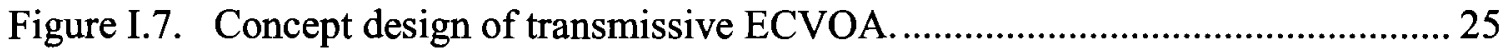

Figure II.1. IR spectra of ligands II.1-5 ( $\mathrm{KBr}$ pallets)....................................... 38

Figure II.2. $\mathrm{CV}$ of II.4-Ru $(\mathrm{R}=\mathrm{Ph})$ in $0.1 \mathrm{M} \mathrm{TBAH} / \mathrm{ACN}($ scanning rate of $200 \mathrm{mv} / \mathrm{s}) .39$

Figure II.3. Relationship between the total Hammett parameter and redox potentials (• $\left.E_{1}, \circ E_{2}\right)$

Figure II.4. UV-vis-NIR spectra of DCH-Ru complex $2 \mathrm{~d}(\mathrm{R}=\mathrm{Ph})$ at different oxidation states

Figure II.5. NIR ECVOA device configuration..................................................... 45

Figure II.6. The X-ray pattern of ITO/ $\mathrm{WO}_{3}$ and blank ITO glass. 45

Figure II.7. The relation between the applied voltage and attenuation at $1550 \mathrm{~nm}$ of device A: ITO / $\mathrm{WO}_{3} / \mathrm{Fc} / \mathrm{ITO}(\boldsymbol{\bullet})$ and B: ITO / $\mathrm{WO}_{3} / \mathrm{DCH}-\mathrm{Ru} / \mathrm{ITO}(\bullet)$.

Figure II.8. The transmittance vs time curves of devices A and B under $2.0 \mathrm{~V}$.

Figure III.1. Cyclic voltammogram of monomer complex (III.1-Ru) in $0.1 \mathrm{M}$ 
TBAH/ACN $(200 \mathrm{mV} / \mathrm{s})$

Figure III.2. Spectroelectrochemical spectrum of monomer complex (III.1-Ru) in

0.1M TBAH/ACN solution 62

Figure III.3. IR spectra of dimer ligand (III.2) and its complex (III.2-Ru). 63

Figure III.4. ${ }^{1} \mathrm{H}$ and ${ }^{13} \mathrm{C}$ NMR spectra of dimer ligand (III.2). 64

Figure III.5. ESI-MS spectrum of dimer complex (III.2-Ru). 65

Figure III.6. Cyclic voltammogram of dimer complex (III.2-Ru) in $0.1 \mathrm{M}$

TBAH/ACN solution. 66

Figure III.7. Spectroelectrochemical spectra of dimer complex (III.2-Ru) in_0.1M

TBAH/ACN solution. 68

Figure III.8. ${ }^{1} \mathrm{H}$ NMR and ${ }^{13} \mathrm{C}$ NMR spectra of polymer ligand (III.3). 72

Figure III.9. Cyclic voltammogram of complex polymer (III.3-Ru) in $0.1 \mathrm{M}$

TBAH/ACN solution. 74

Figure IV.1. IR spectra of ligands IV.2 and IV.3 (KBr pellet). 85

Figure IV.2. ${ }^{1} \mathrm{H}$ NMR spectra of IV.2 and IV.3 in DMSO- $d_{6}$ 85

Figure IV.3. Calculated geometric structure of $\left[\left\{R u(b p y)_{2}\right\}_{2} \mu-P h_{2} d c h\right]^{2+}$ by

Spartan ES as a model compound for $[\mathrm{IV} .3-\mathrm{Ru}]^{2+}$ 87

Figure IV.4. Calculated geometric structure of $\left[\left\{R u(b p y)_{2}\right\}_{2} \mu-(N H P h)_{2} d c h\right]^{2+}$ as

a model compound for [IV.10-Ru $]^{2+}$ by Spartan ES 89

Figure IV.5. IR spectra of compound IV.11 and its complex IV.11-Ru...................... 91

Figure IV.6. ${ }^{13} \mathrm{C}$ NMR spectrum of monomer IV.11-Ru.................................... 91

Figure IV.7. IR spectra of starting monomers IV.16, IV.17 and IV.11-Ru and product IV.20 in $\mathrm{KBr}$. 
Figure IV.8. ${ }^{1} \mathrm{H}$ NMR spectrum $\left(300 \mathrm{MHz}\right.$, DMSO- $\left.d_{6}\right)$ of IV. 20. 95

Figure IV.9. Reduced viscosities as a function of polymer concentration in DMF without or with salt $\left(0.01 \mathrm{M} \mathrm{NH}_{4} \mathrm{PF}_{6}\right)$ at $30^{\circ} \mathrm{C}$ : (B) IV.18, salt free;(X) IV.18, with salt; (!) IV.19, salt free; ( $\forall$ ) IV.19 with salt; (,)IV.20, salt free; (-) IV.20, with salt.

Figure IV.10. GPC traces of DCH-Ru copolymers using $2 \mathrm{mM} \mathrm{NH}_{4} \mathrm{PF}_{6}$ in DMF as $\mathrm{n}$ eluant : 1) IV.18, 2) IV.19, 3) IV.20. 99

Figure IV.11. Cyclic voltammograms of monomers and copolymers IV.18, IV.19 and IV.20 in 0.1 M TBAH/ACN solution at room temperature (polymers are coated on electrode). 100

Figure IV.12. UV-vis-NIR spectra of starting monomers and copolymer products. in $\mathrm{ACN}$ at a concentration of $0.020 \mathrm{mg} / \mathrm{ml}$. 102

Figure IV.13. Fluorescent spectra of fluorene ( $\lambda_{e x}=280 \mathrm{~nm}$, inserted figure) and PFO (inserted figure, $\lambda_{e x}=330 \mathrm{~nm}$ ) in toluene and Ru copolymers in ACN at c $=2.14 \times 10^{-5} \mathrm{M}\left(\lambda_{e x}=330 \mathrm{~nm}\right)$ : (a) fluorene; (b) PFO; (c) IV.18; (d) IV.19; (e) IV.30. 104

Figure IV.14. PL spectra of three copolymers in ACN at $\mathrm{c}=0.10 \mathrm{mg} / \mathrm{mL} \ldots \ldots \ldots \ldots \ldots \ldots . . .106$

Figure IV.15. EL spectra of LED devices containing polymers IV.18, IV.19 and IV.20 with a configuration of ITO/polymer/Au. 108

Figure IV.16. EL performance of copolymer IV.20 in film at a chickness of $80 \mathrm{~nm}$ : (a) current vs time; (b) brightness (radiance) vs time. 109

Figure IV.17. TGA traces of PFO and three copolymers. 110

Figure IV.18. Current (dot line) and transmission (solid line) changes of IV.20 film 
(thickness: $325 \pm 5 \mathrm{~nm}$ ) at $1600 \mathrm{~nm}$ at a constant potential of $+600 \mathrm{mV}$ and $-600 \mathrm{mV}$ in $0.1 \mathrm{M} \mathrm{TBAH} / \mathrm{THF}$

Figure IV.19. Change of transmittance at $1600 \mathrm{~nm}$ of the film of copolymer IV.20 film (thickness: $325 \pm 5 \mathrm{~nm}$ ) coated on ITO glass (electrolyte: $0.1 \mathrm{M}$ $\mathrm{NH}_{4} \mathrm{PF}_{6} / \mathrm{THF}$ ) as a function of switching speed (5s, 10s and 20s); pulse potentials: $\pm 600 \mathrm{mV}$ 


\section{List of Schemes}

Scheme III.1. (a) Poly(2,2'-bipyridine-5,5'-diyl), (b) Copolymer with quarter(3octylthiophene), (c) Copolymer with benzobisoxazole, (d) Polyamides, (e) Polyesters. 58

Scheme III.2. General reaction routes to prepare (a) polyhydrazides and (b) polybiurea.... .58

Scheme III.3. Structures of monomer, dimer and polymer complexes and their ligands. 59

Scheme III.4. Proposed oxidation mechanism of NH group in $\left[\left\{\mathrm{Ru}(\mathrm{bpy})_{2}\right\}_{2} \mu-\mathrm{Ph}, \mathrm{NH}\left(\mathrm{C}_{3} \mathrm{H}_{7}-\mathrm{n}\right) \mathrm{dch}\right]\left(\mathrm{PF}_{6}\right)_{2}$

Scheme III.5. Proposed redox process of dimer complex (III.2-Ru) .............................. 70

Scheme IV.1. Accepted mechanism of Suzuki-coupling reaction..................................... 81

Scheme IV.2 General representation of SPC with the AA/BB-type or AB-type polymerization. $\mathrm{X}$ and $\mathrm{Y}$ represent aromatic units, typically benzene derivatives.

Scheme IV.3. Synthesis of Ru-containing polymer by Suzuki cross-coupling Polymerization 83

Scheme IV.4. Synthesis of AB ligand and thecomplex................................................ 84

Scheme IV.5. Synthesis of Biurea-based AB-type ligand. ................................................. 88

Scheme IV.6. Synthesis of monomer IV.11-Ru complex and BB monomer IV.14 .......90

Scheme IV.7. Suzuki cross-coupling polymerization of IV.11-Ru and IV.14 ............... 93

Scheme IV.8. Preparation of poly(fluorene-co-DCH-Ru) by Suzuki cross-coupling in $\mathrm{ACN}$ at a concentration of $0.020 \mathrm{mg} / \mathrm{ml}$ 


\section{List of Tables}

Table I.1. Organic NIR-absorbing and electrochromic compounds. 4

Table I.2. Examples of dinuclear metal complexes with MMLC-related NIR

Absorption

Table I.3. Examples of dinuclear metal complexes with IVCT-related NIR

Table II.1. Syntheses of 1,3,5-benzenetris(2'-substituted carbohydrazides) II.1-5 and the corresponding DCH-Ru complexes II.(1-5)-Ru.

Table II.2. Electrochemical oxidative potentials of complexes in 0.1M TBAH/ACN solution (scanning rate of $200 \mathrm{mv} / \mathrm{s}$ ). 39

Table II.3. Optical data of complexes at different oxidative states. 42

Table III.1. Electrochemical data of monomer and dimer complexes. 70

Table III.2. Spectroelectrochemical data of three complexes................................... 70

Table IV.1. Intrinsic viscosity and GPC data of copolymers IV.18, IV.19 and IV.20... 97

Table IV.2. Electrochemistry data ${ }^{\mathrm{a}}$ of monomers and copolymers taken in $0.1 \mathrm{M}$ TBAH/ACN.

Table IV.3. Photophysical properties of monomer 11 and three copolymers in A. 103

Table IV.4. Measured Ru content by colorimetric method. 103

Table IV.5. Thermal stability results of PFO and copolymers IV.18, IV.19 and IV.20 under $\mathrm{N}_{2}$. 110 


\section{List of Abbreviations}

PDQ

CAN

BPA

BPY

CB

CE

CV

$\mathrm{DCH}$

DMF

DMF

DMSO

DMSO- $d_{6}$

DSC

EC

ECVOA

Fc

GPC

HOMO

ICP

ITO

LMCT

LUMO
Pentacenediquinone

Acetonitrile

4,4'-Isopropylidenediphenol

Bipyridine

Conducting Band

Color efficiency

Cyclic Voltammetry

Dicarbonylhydrazine

$\mathrm{N}, \mathrm{N}$-dimethylformamide

$\mathrm{N}, \mathrm{N}$-dimethylformamide

Dimethylsulphoxide

Deuterated Dimethylsulfoxide

Differential scanning calorimetry

Electrochromic

Electrochromic Aariable Optical Attenuator

Ferrocene

Gel Permeation Chromatography

Highest Occupied Molecular Orbital

Inductively Coupled Plasma

Indium Doped Tin Oxide

Ligand-to-Metal Charge Transfer

Lowest Unoccupied Orbital 


\begin{tabular}{ll} 
LVCT & Intervalence Charge Transfer \\
MLCT & Metal-to-Ligand Charge Transfer \\
MMCT & Metal-to-Metal Charge Transfer \\
NHE & Normal Hydrogen Electrode \\
NIR & Near-Infrared \\
PDA & N,N'-diphenyl-1,4-phenylenediamine \\
PDBF & Poly(dibenzofulvene) \\
PDEQ & Poly(5,8-bis(2,3-dihydrothieno[3,4-b][1,4]dioxin- \\
& 5-yl)quinoxaline) \\
PEDOP & Poly(3,4-ethylenedioxypyrrole) \\
PEDOT & Poly(3,4-ethylenedioxythiophene) \\
PSS & Poly(styrene sulfonate) \\
SPC & Suzuki polycondensation \\
TBAH & Tetra-n-butylammonium Hexafluorophosphate \\
TEAP & Tetraethylammonium Perchlorate \\
TG & Tungsten Oxide \\
THF & Thermogravimetry \\
TMS & Tetrahydrofuran \\
WO & Tetramethylsilane \\
VB & Vanadium Oxide \\
VOA & Valence Band \\
\hline
\end{tabular}




\section{Chapter I Introduction to Near-Infrared Materials and Applications}

The infrared part of the electromagnetic spectrum covers the range from roughly $300 \mathrm{GHz}(1 \mathrm{~mm})$ to $400 \mathrm{THz}(750 \mathrm{~nm})$. It can be divided into three parts: Far-infrared, Mid-infrared and Near-infrared.

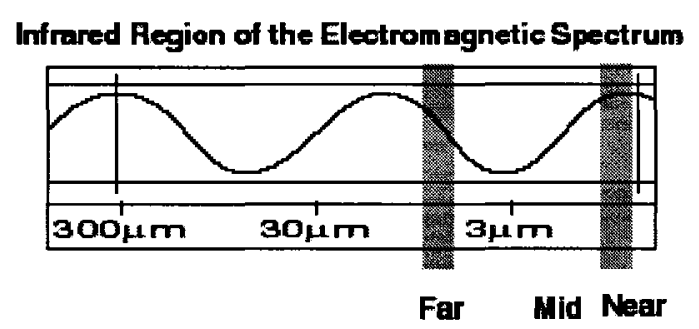

Far-infrared, from $300 \mathrm{GHz}(1 \mathrm{~mm})$ to $30 \mathrm{THz}(10 \mu \mathrm{m})$. The lower part of this range may also be called microwaves. This radiation is typically absorbed by so-called rotational modes in gas-phase molecules, by molecular motions in liquids, and by phonons in solids. The wavelength range from approximately $200 \mu \mathrm{m}$ up to a few $\mathrm{mm}$ is often referred to as "sub-millimetre" in astronomy, reserving far infrared for wavelengths below $200 \mu \mathrm{m}$.

Mid-infrared, from 30 to $120 \mathrm{THz}$ (10 to $2.5 \mu \mathrm{m}$ ). Hot objects (black-body radiators) can radiate strongly in this range. It is absorbed by molecular vibrations, where the different atoms in a molecule vibrate around their equilibrium positions. This range is sometimes called the fingerprint region since the mid-infrared absorption spectrum of a compound is very specific for that compound.

Near-infrared, from 120 to $400 \mathrm{THz}(2,500$ to $750 \mathrm{~nm})$. Physical processes that are relevant for this range are similar to those for visible light. Visible light (and nearinfrared light) is typically absorbed and emitted by electrons in molecules and atoms that move from one energy level to another. The light we see with our eyes is really a very 
small portion of the electromagnetic spectrum. A rainbow shows the optical (visible) part of the electromagnetic spectrum; infrared (if you could see it) would be located just beyond the red side of the rainbow with ultraviolet appearing just beyond the violet end.

Materials, either inorganic or organic, interacting or emitting light in this region have drawn increasing interests because their electric and optical properties are unique and suitable for a number of applications in photonics ${ }^{1,2}$, optical communications ${ }^{3}$, biotechnology ${ }^{4}$, spacecraft thermal control and military application ${ }^{5}$. For example, autofluorescence and absorption from tissue and water are minimized in the near-infrared region, and the NIR light penetrates deeper into tissues and causes less damage to the cells ${ }^{6}$. In telecommunication, the wavelengths of 980,1300 and $1500 \mathrm{~nm}$ are desirable because silica-based optical fibres have a minimum optical loss for data transmission.

This chapter covers a brief historical review on some important classes of NIR materials and application in variable optical attenuators, and finally the rationale and objectives for this thesis research.

\section{I.1. Near-Infrared Active Metal Oxides}

Metal oxides such as tungsten oxide $\left(\mathrm{WO}_{3}\right)^{7}$ and vanadium oxide $\left(\mathrm{V}_{2} \mathrm{O}_{5}\right)^{8}$, can become NIR-absorbing when being reduced. The thin film of the reduced $\mathrm{WO}_{3}$ or $\mathrm{V}_{2} \mathrm{O}_{5}$ absorbs broadly in the NIR region, also called "cathodically colored" in the NIR region. The absorbance in the NIR region is associated to the degree of reduction or ion insertion coefficient and as well film morphology ${ }^{9}$. As shown in figure $\mathrm{I} .1$, the $\mathrm{WO}_{3}$ film absorbs weakly around $400 \mathrm{~nm}$, but strongly from 400 to $1600 \mathrm{~nm}$ upon reduction ${ }^{10}$. However, 
some inherent drawbacks, such as high cost for film preparation and long switching time ${ }^{11}$, limit these materials for large-scale film production and industrial applications.

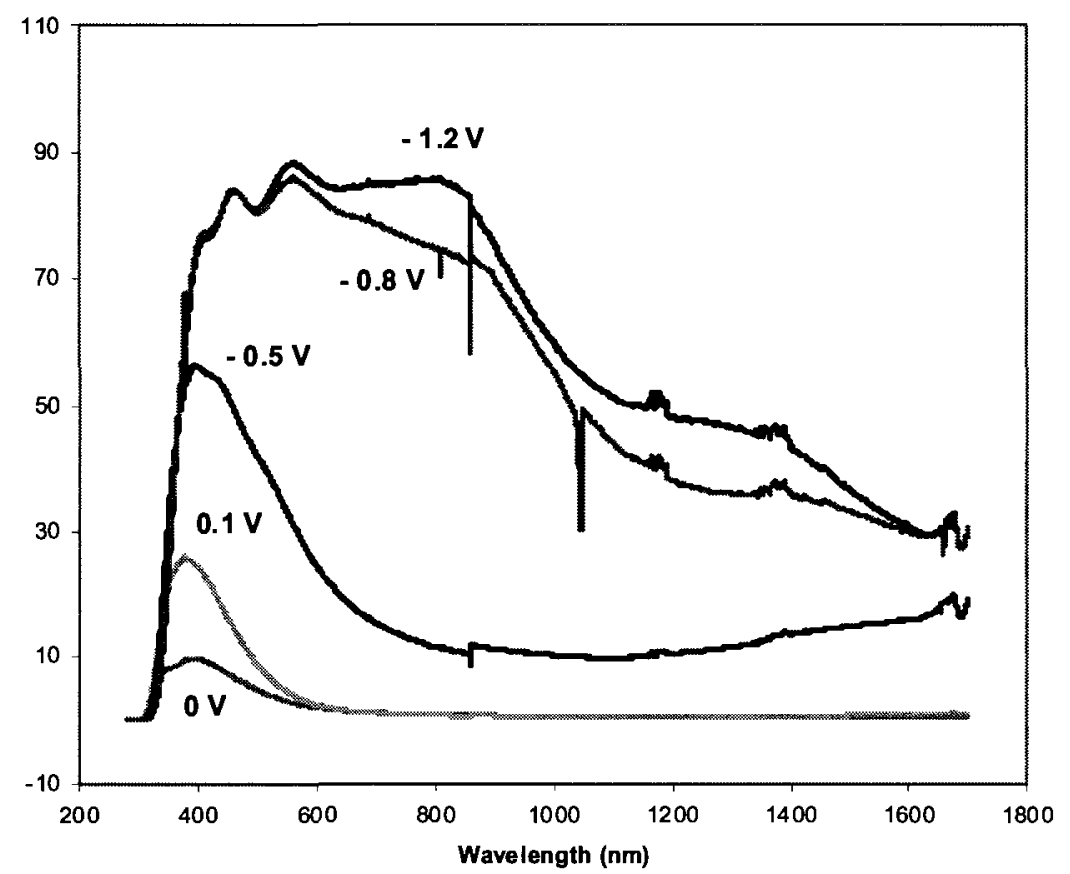

Figure I.1. Absorption of $\mathrm{WO}_{3}$ films under different reduction potentials.

\section{I.2. Near-Infrared Active Organic Compounds}

Organic NIR-absorbing or electrochromic materials include mainly organic dyes and conducting polymers. Compared to inorganic NIR materials, organic materials are readily to be modified to have a wide range of the electrical/optical properties, easy to process, and cost effective ${ }^{12}$. Applications in optical recording, display, laser printer, laser filter, infrared photography and medical applications have been realized. The existing reviews cover mainly the NIR-absorbing organic materials with the maximum absorptions below $1000 \mathrm{~nm}^{13-15}$. Thus, the following review will focus on those exhibiting the long-wavelength NIR absorption and electrochromism $(1000-2000 \mathrm{~nm})$. 
Near-Infrared Dyes

Table I.1. Organic NIR-absorbing and electrochromic compounds.

\begin{tabular}{|c|c|c|c|c|c|}
\hline No. & Structure & $\begin{array}{c}\text { Radical } \\
\text { state }\end{array}$ & $\begin{array}{c}\lambda_{\max } \\
(\log \varepsilon)^{\mathrm{a}}\end{array}$ & solvent & Ref \\
\hline \multirow{3}{*}{ I.1 } & & & $\begin{array}{c}1615 \\
(4.34)\end{array}$ & & \\
\hline & & cation & $\begin{array}{c}1572 \\
(4.45)\end{array}$ & $\mathrm{CH}_{2} \mathrm{Cl}_{2}$ & 17 \\
\hline & & & $\begin{array}{c}1312 \\
(4.48)\end{array}$ & & \\
\hline 1.2 & & cation & $\begin{array}{l}1120 \\
(<4)\end{array}$ & $\mathrm{H}_{2} \mathrm{O}$ & 19 \\
\hline \multirow{2}{*}{ I.3 } & & & $\begin{array}{c}1140 \\
(3.59)- \\
1700\end{array}$ & $\left(\mathrm{H}_{2} \mathrm{O}\right)$ & 20 \\
\hline & & & $\sim 1300$ & (film) & 30 \\
\hline I.4 & & anion & $\begin{array}{c}1560 \\
(4.20)\end{array}$ & DMF & \\
\hline I.5 & & anion & $\begin{array}{c}1335 \\
(4.50)\end{array}$ & DMF & \\
\hline I.6 & & anion & $\begin{array}{c}1305 \\
(4.49)\end{array}$ & THF & 22 \\
\hline
\end{tabular}


I.7<smiles>CC(C)CN=Cc1cccc(C=NCCN2CC=NCCN3CCN=CC4=CN(CCN=Cc5cccc(C=NC(C)C)c5)CCN=CC(=CC=C4)N(CC2)C3)c1</smiles>

I.8<smiles>CN(C)Cc1ccc(/C(=N\N=c2\sc3ccccc3n2C)c2ccc(N(C)C)cc2)cc1</smiles>

$\begin{array}{cccc}\text { anion or } & 1345, & \mathrm{CH}_{3} \mathrm{CN} & 23 \\ \text { dianion } & 1180\end{array}{ }^{24}$

$\begin{array}{llll}\text { cation } & 1000, & & \\ & 1150\end{array} \mathrm{CH}_{3} \mathrm{CN} \quad 16$

I.9<smiles>CCn1c(/C=C/c2c3ccccc3c(-c3ccccc3)c3ccccc23)ccc1C1=C([O-])/C(=C2/C(=O)C=C/C2=C\c2c3ccccc3c(-c3ccccc3)c3ccccc23)[N+](C)(C)C1</smiles>

cation

1000 , 1630

$\mathrm{CH}_{2} \mathrm{Cl}_{2}$ 27 $1230-$

I.10<smiles>[X]C(=O)CCS(=O)(=O)c1cc2c(c([N+](=O)[O-])c1)-c1c(cc([N+](=O)[O-])cc1[N+](=O)[O-])C2=C(C#N)C#N</smiles>
$\begin{array}{cc} & 1260 \\ \text { neutral } & (3.67- \\ & 3.53)\end{array}$

NIR-absorbing organic molecules generally have -conjugated structures, such as phthalocyanine, naphthalocyanine, polymethine, phenylmethane, quinone and azo dyes. However, only those that can undergo reversible redox reaction are suitable for electrochromic application. NIR electrochromism is more likely observed in molecules with relatively stable radicals generated during the redox reaction, either cationic radicals or anionic radicals ${ }^{16}$. 
Intense NIR absorption arising from the radical cations is likely obtained in the electron-efficient systems when oxidized or from dicationic salts when reduced. Examples of the former are systems containing two $\pi$ - bridged triphenylamines (I.1, Table I.1 $)^{17}$. They can reversibly undergo two one-electron oxidization processes to form radical monocations and dications. Their radical monocations are characterized by an intense and sharp band at $734 \mathrm{~nm}$ and a broad (covering from 1000 to over $2500 \mathrm{~nm}$ ) and relatively intense $\left(\varepsilon>10^{4} \mathrm{M}^{-1} \mathrm{~cm}^{-1}\right)$ intervalence charge-transfer (IVCT) band in the NIR region, which is attributed to a photoinduced intramolecular electron-transfer between the two redox centers. The spectroelectrochemistry of dendric hexaarylbenzene containing six triarylamines has also been studied by Nöll, showing the absorbance of the radical trication being about one order of magnitude lower than those of bistriarylamines ${ }^{18}$. Viologens, 1,1'-disubstituted-4,4'-bipyridinium salts, are a family of parent dications. Although the electrochromism of their radical cations has mostly been studied in the visible region for display application ${ }^{13,15}$, a weak NIR absorption $\left(\varepsilon<10^{4} \mathrm{M}^{-1} \mathrm{~cm}^{-1}\right)$ at $1120 \mathrm{~nm}$ has also been reported for 1-methyl-1'-alkyl-substituted viologens when the alky group is long enough $(n=16$ or 18$)\left(\right.$ I.2, Table I.1) ${ }^{19}$. The observed NIR absorption is due to the radical dimers formed in one-electron reduction.

On the other hand, intense NIR absorption is also observed in electron-deficient conjugated systems including aromatic imides, quinones and Schiff base cryptans when reduced. The Miller group did extensive research and found that the molecular stacking plays an important role in NIR absorption of the radical anions such as disodium $N, N$ bis(p-sulfonatophenyl)naphthalenedicarboximide $\quad\left(\mathbf{I . 3}\right.$, Table $\quad$ I.1) ${ }^{20}$. In $N, N-$ dimethylformamide (DMF), it existed as a monomeric radical anion, and no absorption 
above $800 \mathrm{~nm}$ was observed. In water, it formed $\pi$-stacked radical dimers and a relatively intense band appeared at 1140 . With higher $\pi$-stacking aggregates in brine, the absorption band was further shifted to $1700 \mathrm{~nm}$. They also studied the electrochromic properties of the anion radicals of diquinone compounds. Semiquinones I.4 and I.5 (Table I.1) ${ }^{21}$ were found to absorb intensely and sharply at $1560 \mathrm{~nm}$ and $1335 \mathrm{~nm}$ in DMF solution, respectively, which was ascribed to $\pi^{*}-\pi^{*}$ excitations from the delocalized anions. Both compounds have two reversible redox couples at less negative potentials, originating from two one-electron reactions, $\mathrm{X} \leftrightarrow \mathrm{X}^{--}$and $\mathrm{X}^{--} \leftrightarrow \mathrm{X}^{2-}$. The absorption bands varied with electron-donating or electron-withdrawing substituents, a blue shift for the former and a red shift for the latter. Strong NIR absorption peaking at $1305 \mathrm{~nm}$ in tetrahydrofuran (THF) with a shoulder was also observed in an organoboron compound, 4,4'bis(dimesitylboryl)biphenyl (I.6, Table I.1), ${ }^{22}$ when reduced to anion radical, which was assigned to $\pi^{*}-\pi^{*}$ transition, i.e. SOMO to LUMO. Another type of compound in this class is Schiff base cryptand (I.7, Table I.1), which can be electrochemically ${ }^{23}$ or chemically ${ }^{24}$ reduced to form monoanion, dianion and trianion. Its reduction is not quite reversible due to the presence of several chemical equilibriums. Both the monoanion and dianion showed the same spectra in the visible and NIR region with absorption at 1345 $\mathrm{nm}$ plus a shoulder at $1180 \mathrm{~nm}$, which behaved similar to the single strand $\left(\mathrm{CH}_{3}\right)_{2} \mathrm{CH}-\mathrm{N}=\mathrm{CH}-$ meta- $\mathrm{C}_{6} \mathrm{H}_{4} \mathrm{CH}=\mathrm{N}-\mathrm{CH}\left(\mathrm{CH}_{3}\right)_{2}$.

Cyanines are a type of conjugated system that contains neutral nitrogen and positively charged nitrogen in their parent states. Thus, they can produce radicals in both one-electron reduction and one-electron oxidation, and both radicals are expected to display long-wavelength absorption in long-length cyanine ${ }^{25}$. However, the redox 
reversibility highly depends on their structures, and relatively intense long-wavelength absorption is only observed in the radical cations, due to their higher stability than the opposite radical anions. Closed-shell polymethine cyanines are well-known for their systemic shift of the absorption with the extension of the polymethine chains. A number of cationic cyanine salts have been reported to absorb intensely at $1000-2000 \mathrm{~nm}^{25,26}$. However, the NIR electrochromism involving the radicals has not received much interest, probably due to lower absorptions restricted in the region below $1000 \mathrm{~nm}$ and the decreased stability of the radical ions with long polymethine chains. Relatively intense absorption at longer wavelength was reported in the mixed cyanine system. The violene/cyanine compound (I.8, Table I.1) ${ }^{16}$ displayed a broad band at $800-1300 \mathrm{~nm}$ when reduced to radical cation. The squaraine-based cyanine $(\text { I.9, Table I.1 })^{27}$, is featured with a donor-bridge-acceptor structure. Its radical cation, resulting from single-electron oxidization, revealed an intense and sharp band at $1000 \mathrm{~nm}$ and a broad and less intense band at $\sim 1630 \mathrm{~nm}$ due to the intramolecular electron transfer. The cyclic voltammograms of both cyanines showed two reversible one-electron oxidation waves with a one-electron reduction wave with limited reversibility for the latter cyanine.

Some molecules containing a strong donor and an acceptor linked by a nonconjugated spacer show contrary electrochromic behavior and are less studied in comparison with the conjugated organic systems. A representative example is the $\sigma$-bondbridged diad system (I.10, Table I.1) ${ }^{28}$, having trialkyltetrathiafulvalene as a strong $\pi$ donor and trinitrofluoren-9-dicyanomethylene as a strong $\pi$-acceptor. Such a system has a very low energy gap between highest occupied molecular orbital (HOMO) and lowest unoccupied orbital (LUMO) (about $0.3 \mathrm{eV}$ ) and in solution displays relatively intense 
NIR absorption bands peaking at $1230-1260 \mathrm{~nm}$ in the neutral state. Both ester- and amide-bridged systems showed high electrochemical reversibility, especially for the latter. The NIR absorption bands disappeared after being reduced or oxidized to the radicals, resulting from the loss of donor or acceptor ability.

Nevertheless, there are two major problems associated with ionic organic dyes for electrochromic applications: aggregation and instability of radicals. The aggregation of radicals in solution causes complication in understanding of their electrochemical and spectral properties $^{29}$. One of the solutions to the aggregation problem is to absorb dyes onto a solid surface like a silver halide crystal in order to make the aggregation process irreversible. However, this could make the fabrication of electrochromic devices quite inconvenient. An alternative solution is to stabilize the radicals with ionic polymers to form films. ${ }^{30}$ However, the films formed are highly anisotropic in NIR absorption, and the film sizes are determined by the area of the electrodes used. Another major problem is the instability of the radical ions formed in redox reactions, especially for radical anions. They easily undergo degradation in air because of their high reactivity towards oxidation, therefore the redox reactions have to be carried out with protection of inert gases and at low temperatures, e.g. $-20{ }^{\circ} \mathrm{C}^{31}$. As for radical cations of cyanines, some of them can undergo rapid dimerization to from stable dication products, which makes the electrochemical process irreversible ${ }^{32,33}$. Although this problem can be partially fixed through structural modification, such as substituting the methine carbons with bulky alkyl groups $^{34}$, the NIR electrochromic property for cyanines are rarely reported. 


\subsection{Near-Infrared Active Polymers}

The advantage of polymers over small organic molecules is their ease to form films by solution processes for application in devices. Polymeric electrochromic materials that are active in the NIR region can be divided into two categories: nonconjugated polymers and conjugated polymers. The non-conjugated electrochromic polymers are generally constructed from electrochromic chromophores by incorporating into or grafting onto polymer backbones. Viologens are a popular class of chromophores used to build non-conjugated electrochromic polymers, owing to their ease to undergo nucleophilic substitution reaction with high yields. For example, viologen can be incorporated into a polymer backbone by the reactions of equimolar 4,4'-bipyridyl and $\alpha, \alpha^{\prime}$-dibromo-p-xylene in dry acetonitrile (poly(xyly1 viologen), Figure I.2) ${ }^{35}$. Viologens can also be easily grafted to chlorinated poly(oxyethylene) ${ }^{36}$ and polymeric microspheres $^{37}$ with controllable degrees of functionalization. However, the electrochromic properties of these viologen polymers are usually restricted within the UV-vis spectral region. Recently, Nakano and Yade reported that the oxidized oligo- and poly(dibenzofulvene) (PDBF, Figure I.2) ${ }^{38}$, made from anionic polymerization of 1,1diphenylethylene, displayed intense and broad absorption bands centered from $1400 \mathrm{~nm}$ to $1600 \mathrm{~nm}$ depending on the degree of polymerization. The authors ascribed the NIR absorption to the intramolecular charge resonance of $\pi$-stacked structure. Unfortunately, the oxidization of such polymers is irreversible, which makes them not suitable for NIR electrochromic applications. Our lab recently synthesized a series of polymers containing NIR electrochromic chromophore, pentacenediquinone (PDQ), by copolymerization of bis(4-fluorophenyl)sulfone, $\quad 4,4^{\prime}$-isopropylidenediphenol $\quad$ (BPA) and 1,8- 
dinitropentacenediquinone. Similar to pentacenediquinone, the resulting poly(PDQ-BPSco-BPA) (Figure I.2) displayed two absorption bands in N,N-dimethylformamide (DMF) peaking at 1170 and $1396 \mathrm{~nm}$ when reduced to radical anions. In the solid state, their absorption intensities varied with respect to the thicknesses of films as well as the molar ratios of PDQ in polymers. Although these polymers behave high thermal stability (degradation temperature $>375{ }^{\circ} \mathrm{C}$ ), high electrochemical reversibility for the first two reduced steps and long-term stability for their anion radicals (no optical loss for 7 days), their optical contrasts need to be improved and switching time needs to be reduced for use in optical attenuators in the NIR region.

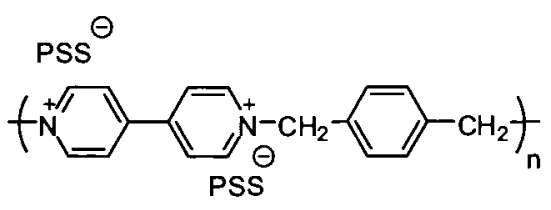

poly(xylyl viologen)/PSS

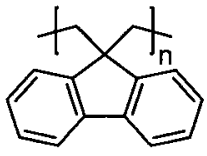

PDBF

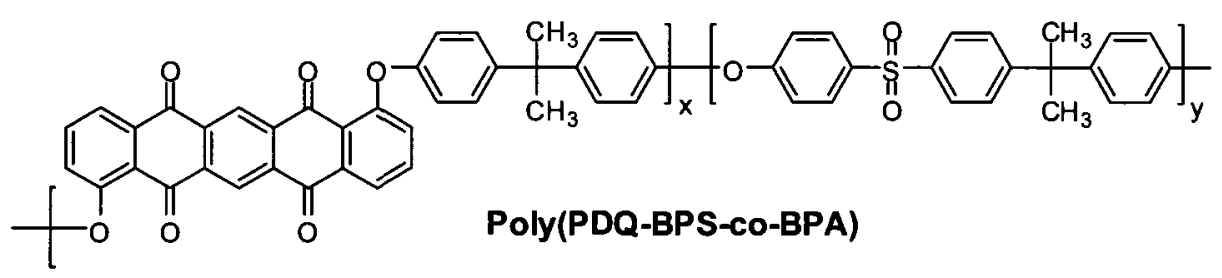

Figure I.2. Examples of NIR electrochromic polymers.

In a conjugated polymer, the lowest-energy optical transition is directly related to its bandgap, i.e., the lowest energy required for electronic excitation from the valence band (VB) (highest occupied band) to the conducting band (CB) (lowest unoccupied band). The optical transition relies on the structure of the conjugated polymer (intrinsic bandgap) as well as the doping level. For conjugated polymers, doping is generally referred to the process of oxidation ("p-doping") or reduction ("n-doping") with ion 
insertion or expulsion of counter ions, although the latter is less common than the former due to the increased instability at the reduced state. As a result, all conjugated polymers are potentially electrochromic materials. The doping process is depicted in figure I.3. ${ }^{39}$ Considering a conjugated polymer with non-degenerated ground states, which is the case for most aromatic conjugated polymers, either p-doping or n-doping will create new energy levels (polaron and bipolaron) between the valence band (highest occupied band) and the conducting band (lowest unoccupied band), which will give rise to the appearance of low-energy transitions. With the increase of the doping level, the original bandgap (difference of the energy level of the conducting band and the valence band) will be replaced by a lower bandgap. At a high doping level, the bipolaron bands will overlap with the $\pi$ bands to produce metallic-like states. Experimentally, the bandgap of a conjugated polymer is determined by the onset of the absorption band ("optical bandgap") or the difference of the onset electrochemical potential for oxidation and for reduction ("electrochemical bandgap"). As a result, the reduction in bandgap will shift the absorption to higher wavelengths, which makes conjugated polymers able to achieve electrochromism in the long-wavelength region. On the other hand, as the shift in absorbance owing to doping is limited, the position of the shifted absorption band is highly dependent on the absorbance of a conjugated polymer at its undoped state (intrinsic bandgap). Hence, a long wavelength absorption in the visible region at the neutral state is required for a conjugated polymer to achieve absorption in the NIR region at the doped state. In other words, intrinsically low-bandgap polymers with $\mathrm{E}_{\mathrm{g}} \leq 1.8-1.9$ $\mathrm{eV}(\sim 650-700 \mathrm{~nm})^{40}$ are desired to realize NIR electrochromism once being doped. 


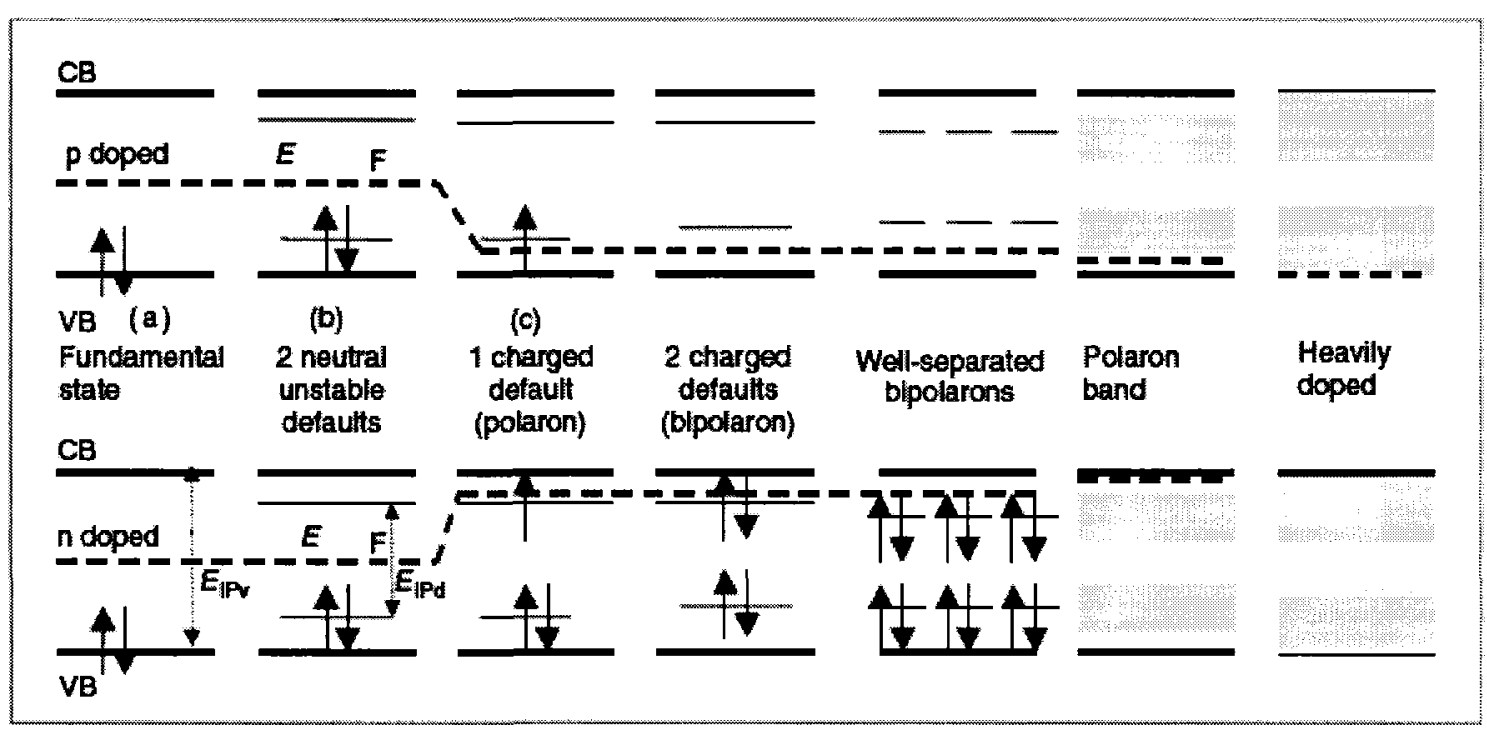

Figure I.3. Evolution of energy levels with p-doping (top) and n-doping (bottom) in a conjugated polymer with non-degenerated ground states.

Conjugated polymers have been studied as electrochromic materials, owing to their several advantages, such as high colouration efficiency, low switching time ${ }^{41-42}$, availability of multiple colours in the same material ${ }^{43}, 44$, fine tunability of the band gap ${ }^{45}$ and film-forming property ${ }^{46}$. However, NIR electrochromism was only considered as an accompanied phenomenon as most of the studies focused on their electrochromic properties and applications in the visible region ${ }^{14,15,47-49}$.

Polyaniline displays absorption maximum at $\sim 1900 \mathrm{~nm}$ at its emeraldine state (a partially oxidized state) with intensity and peak values depending on the applied potentials and the degree of protonation, which is attributed to the transition of VB to the lowest polaron level ${ }^{50,51}$. The fully reduced or oxidized state shifts the absorption band to higher energy but with relatively broad absorption in the above region, i.e. a relatively low optical contrast in the NIR region, which diminishes the value of polyaniline as an active material for NIR display and optical attenuation. The band gap of polyaniline is 
easily changed through structural modification, because the introduction of substituents onto the nitrogen generally reduces the conjugation of the polymer chains, resulting in a blue shift of the absorption band ${ }^{52}$ or phenyl ring ${ }^{53}$.

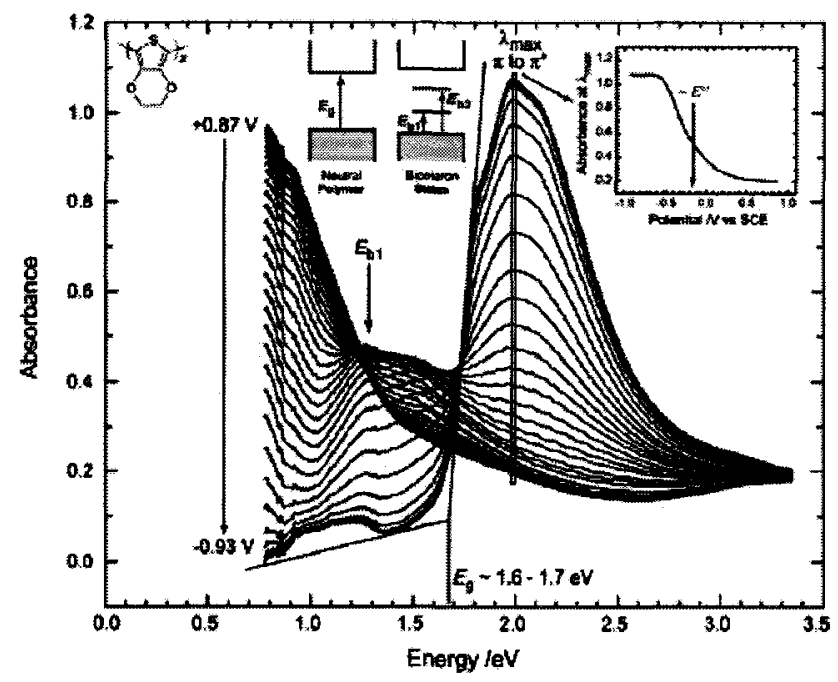

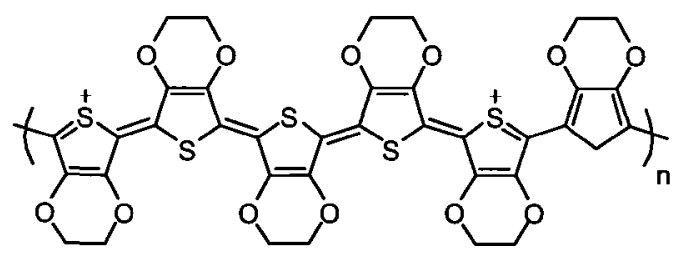

PEDOT (bipolaronic state)

Figure I.4. Spectroelectrochemistry for PEDOT film on ITO.

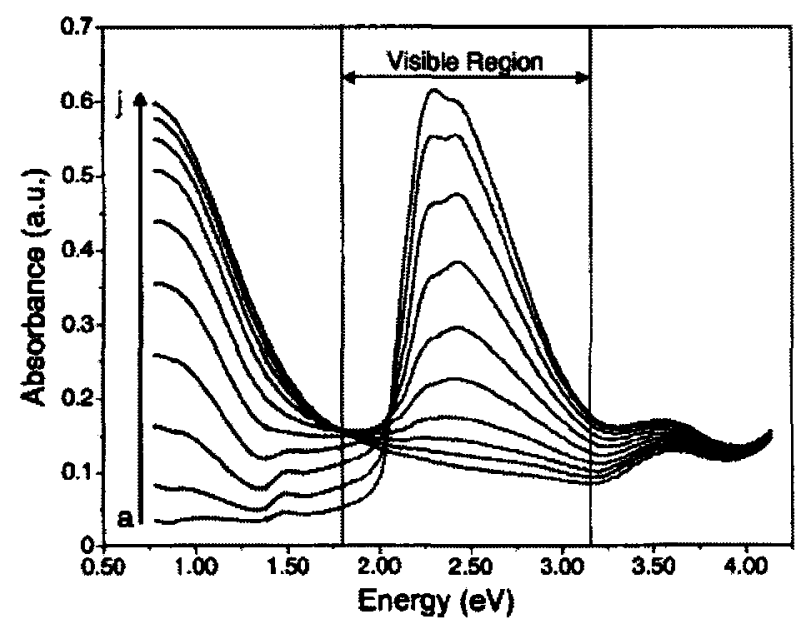

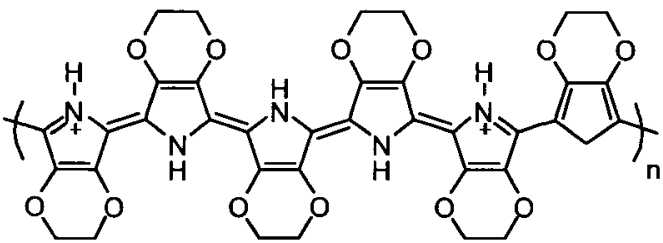

PEDOP (bipolaronic state)

Figure I.5. Spectroelectrochemistry of a thin PEDOP film (a: $-\mathbf{0 . 8 8 7} \mathrm{V}, \mathrm{j}:-\mathbf{0 . 3 7} \mathrm{V})$.

p-Doped polythiophene shows broad absorption from 1000 to $2500 \mathrm{~nm}^{54}$, as well as good environmental stability at both the p-doped and neutral state ${ }^{55}$. However, due to its rigid structure it is insoluble in most solvents and is not easily to be processed. This problem can be solved by introduction long-chain, or bulky, or polar groups, or 
incorporating it with surfactants like poly(styrene sulfonate) (PSS) ${ }^{56,57}$. The structural modification also varies the band gaps of the polymers and hence the absorption wavelengths at their doped states. A representative is poly(3,4-ethylenedioxythiophene) (PEDOT), which was first developed by Bayer $\mathrm{AG}^{58}$ and studied in detail for its electrochromic property by the Reynolds' group. The doped PEDOT is more stable under ambient conditions than the neutral PEDOT. As shown in Fig. $1.4^{15}$, the polymer absorbs at $621 \mathrm{~nm}(2.0 \mathrm{eV})$ in the neutral state $(-0.93 \mathrm{~V})$ due to a $\pi-\pi$ interband transition. When being oxidized, the decrease in absorption in the visible region is accompanied by the increase in absorption at $\sim 1.25$ and $\sim 0.80 \mathrm{eV}$ due to the formation of polaronic charge carriers. Further oxidization results in bipolarons with the enhanced NIR absorption at $0.80 \mathrm{eV}$, which matches one of the telecommunication wavelengths of $1550 \mathrm{~nm}$.

The p-doped polypyrrole film has the NIR absorption band peaking at $\sim 1240 \mathrm{~nm}^{59}$ and can undergo an electrochromic switch with a fast stepping time $(\sim 100 \mathrm{~ms})^{47}$. However, the electrochromic property of polypyrrole is not fully exploited, mainly due to the degradation of the film during redox process ${ }^{13}$. The substituted polypyrroles with a higher stability have been obtained. An interesting example is poly $(3,4-$ ethylenedioxypyrrole) (PEDOP) (Figure I.5), which has a lower bandgap $(2.0 \mathrm{eV})^{60,61}$ than polypyrrole $(2.7 \mathrm{eV})^{62}$. Its film displays a dual electrochromism in both visible and NIR regions similar to PEDOT with a lower energy transition at $\sim 0.77 \mathrm{eV}(1600 \mathrm{~nm})$. Because of its low oxidization potential $(-0.15$ to $+0.05 \mathrm{~V}$ vs SCE), it shows a high stability under ambient conditions in the doped state.

A great number of low bandgap copolymers based on thiophene and EDOT have also been prepared ${ }^{64-65}$, and some of them display excellent electrochromic properties in 
the NIR region, such as poly(5,8-bis(2,3-dihydrothieno[3,4-b][1,4]dioxin-5yl)quinoxaline) (PDEQ) ${ }^{66}$. Being commercially available, PEDOT is at present the most desirable material for NIR electrochromic device application, although there is a cost issue for its monomer ${ }^{67}$.

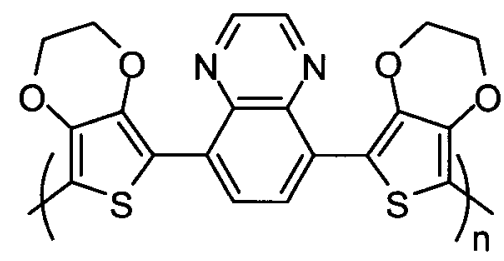

PDEQ

\section{I.4. Near-Infrared Active Metal Complexes}

NIR-absorbing metal complexes have gained much attention owing to some unique features such as electrochromism, large extinction coefficient, easy modification of the ligands, good solubility and processability. Mono- and multi-nuclear complexes have been reported with absorptions in the NIR region.

For mono-nuclear complexes to absorb close to the NIR region, it generally requires a large planar ligand system for electrons to delocalize to a large extend to achieve low-energy $\pi-\pi *$ transfer. Nickel-dithiolene complexes are one of the few types of mono-nuclear complexes whose absorption can be tuned to match the telecommunication wavelengths. 1,2-Dithiolene is a bidentate ligand consisting of two sulfur atoms connected via an unsaturated carbon-carbon backbone. Since the first report on nickel-dithiolene complexes by Schrauzer and Mayweg in $1962^{68}$, metal-dithiolene complexes have drawn much attention for use as NIR dyes, mostly in lasers ${ }^{69}$ and photocurrent detectors ${ }^{70}$, conducting and magnetic materials ${ }^{71}$. It has been found that the absorption maxima of the nickel dithiolene complexes can go up to $1500 \mathrm{~nm}$ or even 
beyond by increasing the electron-donating ability of the sbustituents and the coplanarity of the ligand ${ }^{69}$. For example, the N,N'-diethyl-6,6'-tetrahydroquinoxalyl substituted dithiolato nickel has the absorption maximum approaching $1370 \mathrm{~nm}$ in dichloromethane (1440 nm in dimethylsulphoxide), compared to that of unsubstitueted complex at $720 \mathrm{~nm}$ in hexane. The NIR-absorption can also be reversibly switched between the bleached and colored state, respectively ${ }^{72}$. However, introduction of highly electron-rich groups tend to cause some problems, such as photochemical instability, low yield and difficulty in purification, which hampers their applications as NIR electrochromic materials. ${ }^{69}$

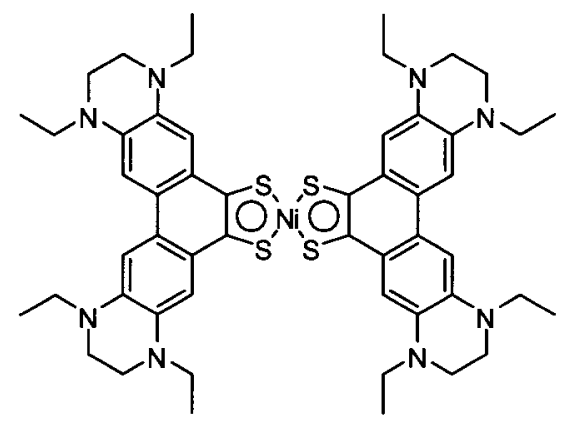

\section{N,N'-diethyl-6,6'-tetrahydroquinoxalyl substituted dithiolato nickel}

A large number of dinuclear complexes with conjugated bridging ligands have been found to have absorption maxima in the NIR region, covering the both telecommunication wavelengths of $1.3 \mu \mathrm{m}$ and $1.55 \mu \mathrm{m}$. Organic dinuclear or multinuclear complexes are more common to be NIR electrochromic, with the lowenergy transition mainly arising from the charge-transfer between metal and ligand (MLCT or LMCT depending on the relative energy levels of empty and occupied orbitals of metals and ligands) or intervalence charge transfer (IVCT) between metals via the bridging ligand.

Speaking on electrochemistry, MLCT or LMCT generally depends on their relative ease to undergo oxidation. Apparently, more easily oxidized ligand should favour 
metal to ligand charge transfer. The MLCT-type example complexes and their spectral data associated with electrochemical reactions are shown in table I.2. The dioxolenebased dinuclear ruthenium complex $[\mathbf{I . 1 1}]^{3+}$ (sq-q) (Table I.2), resulting from ligandcentred oxidation $\left(0.06 \mathrm{~V} \mathrm{vs} \mathrm{Fc} / \mathrm{Fc}^{+}\right)$, displays a transition at $1225 \mathrm{~nm}\left(\varepsilon \sim 4.0 \times 10^{4} \mathrm{M}^{-1}\right.$ $\mathrm{cm}^{-1}$ ), which is ascribed to Ru(II) to sq-q MLCT transitions. This transition is absent in its fully reduced state $[\mathbf{I . 1 1}]$ and fully oxidized state $[\mathbf{I . 1 1}]^{4+74}$. The derivate of I.11 with larger size of dendric hexahydroxytriphenylene (I.12) as bridging ligand appears less favorable to achieve high contrast in the NIR region. $[\mathbf{I . 1 2}]^{3+}$ (sq-sq-sq) has large overlapping in absorption with other two oxidized states, $[\mathbf{I . 1 2}]^{4+}$ (sq-sq-q) and [I.12 $]^{5+}$ (sq-q-q) over $800 \mathrm{~nm}$. It has to undergo a 3e-oxidization to convert to $[\mathbf{I . 1 2}]^{6+}$ (q-q-q) to minimize the overlapping at $1170 \mathrm{~nm}$ and a high driving potential of $1.03 \mathrm{eV}$ vs. SCE is required $^{75}$. On the other hand, more easily oxidized metal should favour ligand to metal charge transfer. In dinuclear tris(pyrazolyl)-borate-molybdenum complexes, metal molybdenum is easier to be oxidized, resulting in highly intense ligand to metal charger transfer (LMCT) transition. A variety of biphenolate bridging ligands have shown intense NIR absorption at Mo(V)/Mo(VI) states mainly due to Mo(VI) to ligand $\mathrm{LMCT}^{76}$. The most remarkable complex among them is 4,4'-[2,2'-bithiophene]-5,5'-diylbiphenolate bridged product $[\mathbf{I . 1 3}]^{+}$which has a very intense transition at $1360 \mathrm{~nm}\left(\varepsilon \sim 3.0 \times 10^{4} \mathrm{M}^{-1}\right.$ $\mathrm{cm}^{-1}$ ), close to one of the telecommunication wavelengths. This transition is absent in its $[\mathrm{I.13}]^{0}(\mathrm{Mo}(\mathrm{V}) / \mathrm{Mo}(\mathrm{V}))$ state. A solution-based optical attenuator with this product reaches a high dynamic range of $50 \mathrm{~dB}$ with a good reversibility ${ }^{77}$, although the switching time is as long as in minutes. 
Table I.2. Examples of dinuclear metal complexes with MLCT and LMCT-related NIR absorption.

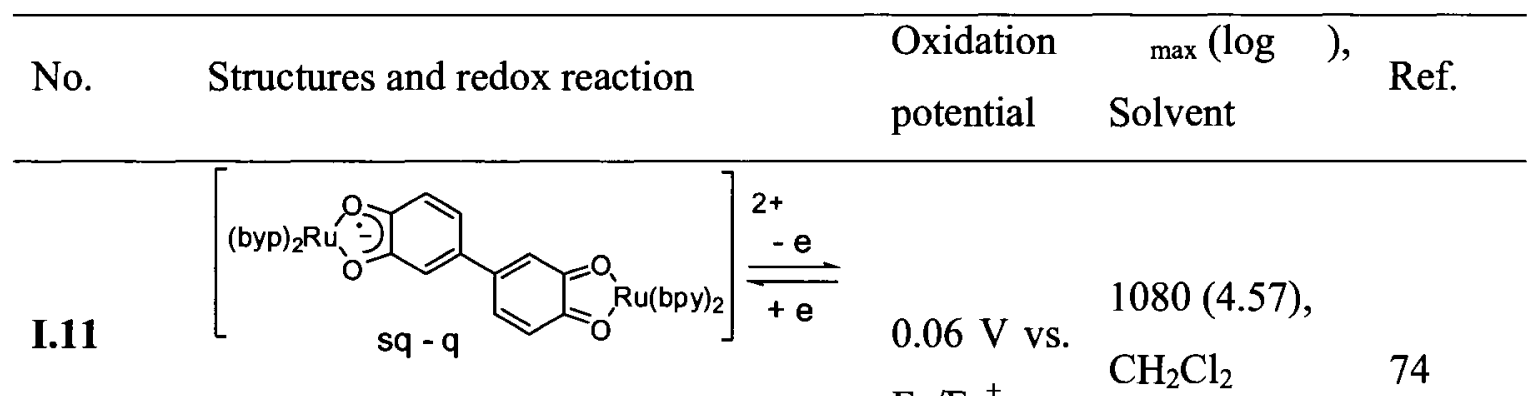

$\mathbf{I . 1 2}$

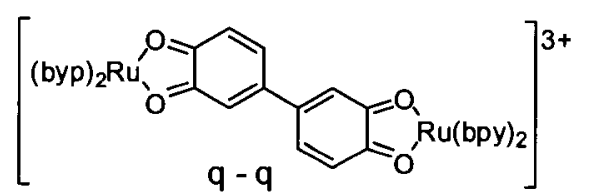

$\mathrm{Fc} / \mathrm{Fc}^{+}$

$\mathrm{CH}_{2} \mathrm{Cl}_{2}$

$1.03 \mathrm{~V}$ vs. $1170(4.60)$,

SCE $\quad$ ACN

75

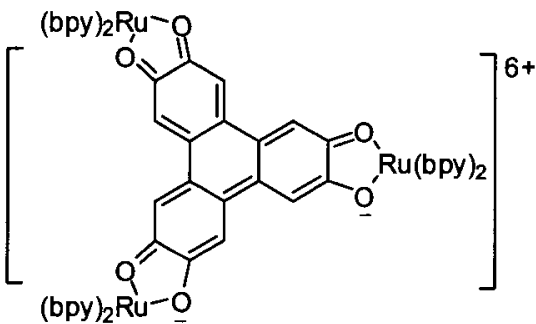

$0.44 \mathrm{~V}$ vs. $1,360(3.47)$,

$\mathbf{I . 1 3}$

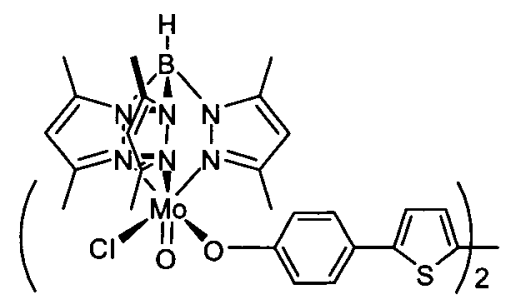

$\mathrm{Fc} / \mathrm{Fc}^{+} \quad \mathrm{CH}_{2} \mathrm{Cl}_{2}$

76

${ }^{\mathrm{a}} \lambda_{\max }$ in $\mathrm{nm}, \varepsilon$ in $\mathrm{M}^{-1} \mathrm{~cm}^{-1}$.

As for the IVCT-related NIR absorption, it is generally seen with dinuclear metal complexes in which the two metals exist in the two different oxidation states with relatively strong electronic interaction. ${ }^{73}$ When there is a strong inner sphere interaction between the two metals, the mixed-valence state is more stable, rather than 
disproportionating to the isovalent states. In addition, IVCT in mixed-valence state, or a charge transfer from metal donor (lower oxidization state) to metal acceptor (higher oxidization state) via the bridging ligand, requires a lower energy compared to the one the isovalent state. Experimentally, the stability of the mixed-valence state can be evaluated by the separation between the redox couples in electrochemistry. Considering a mixed-valence complex $\mathrm{M}^{\mathrm{II}} / \mathrm{M}^{\mathrm{III}}$, the comproportionation constant $K_{c}$ (equilibrium constant) can be expressed by:

$$
K_{c}=\left[\mathrm{M}^{\mathrm{II}} / \mathrm{M}^{\mathrm{III}}\right]^{2} /\left(\left[\mathrm{M}^{\mathrm{II}} / \mathrm{M}^{\mathrm{II}}\right]\left[\mathrm{M}^{\mathrm{III}} / \mathrm{M}^{\mathrm{III}}\right]\right) .
$$

$K_{c}$ is determined from electrochemical data according to the Nernst equation:

$$
\Delta G=-\mathrm{RT}\left(\ln K_{c}\right)=-\mathrm{nF}(\Delta E),
$$

where $\Delta E$ is the separation between the two redox potentials, $\mathrm{R}$ is universal gas constant, $\mathrm{F}$ is Faraday constant, $\mathrm{n}$ is the number of electrons transferred in the cell reaction or halfreaction. It is apparent that a large potential separation will lead to the more stable mixedvalence state. On the other hand, the magnitude of interaction, or coupling constant $(J)$, is largely determined by the true electron-transfer distance ( $r$ in $\AA$ ), as well as the extinction coefficient of the IVCT band ( $\varepsilon$ in $\left.\mathrm{M}^{-1} \mathrm{~cm}^{-1}\right)$, the width at half-height of the IVCT band $\left(v_{1 / 2}\right.$ in $\left.\mathrm{cm}^{-1}\right)$ and the energy of the IVCT band maximum $\left(E\right.$ in $\left.\mathrm{cm}^{-1}\right)$, which is generally expressed as ${ }^{78,79}$ :

$$
J=2.05 \times 10-1\left(\varepsilon \cdot v_{1 / 2} \cdot E\right)^{0.5} / r .
$$

As pointed out by Ward, the energy of IVCT relies largely on $K_{\mathrm{c}}$ and $J$ : when the interaction $(J)$ is high and $K_{\mathrm{c}}$ is large, the IVCT appears at low energy with high intensity. 
Table I.3. Examples of dinuclear metal complexes with IVCT-related NIR absorption.

\begin{tabular}{|c|c|c|c|c|c|}
\hline No. & Structures & $\begin{array}{l}\max (\quad) \\
\text { Solvent }\end{array}$ & $K_{c}$ & $\begin{array}{c}J \\
\left(\mathrm{~cm}^{-1}\right)\end{array}$ & Ref. \\
\hline I.14 & & $\begin{array}{c}1570(3.70) \\
\text { D2O }\end{array}$ & $3 \times 10^{6}$ & 3300 & 80 \\
\hline I.15 & & $\begin{array}{c}1500(3.62), \\
\text { D2O }\end{array}$ & $8 \times 10^{4}$ & 855 & $\begin{array}{l}84 \\
85\end{array}$ \\
\hline I.16 ${ }^{\mathrm{b}}$ & & $\begin{array}{c}2000(4.15) \\
\mathrm{CH}_{2} \mathrm{Cl}_{2}\end{array}$ & 350 & 830 & 81 \\
\hline $\mathbf{I . 1 7 ^ { \mathrm { c } }}$ & & $\begin{array}{l}1520, \\
\mathrm{ACN}\end{array}$ & $1 \times 10^{5}$ & 3200 & 82 \\
\hline $\mathrm{I.18}^{\mathrm{c}}$ & $\mathrm{n}=0$ & $\begin{array}{c}1936(4.34), \\
\text { ACN }\end{array}$ & 690 & 1020 & \\
\hline $1.19^{c}$ & $\mathrm{n}=1$ & $\begin{array}{c}1650(3.82) \\
\mathrm{ACN}\end{array}$ & 16 & 600 & 89 \\
\hline $1.20^{c}$ & $\mathrm{n}=2$ & $\begin{array}{c}12 \text { 14(3.34), } \\
\text { ACN }\end{array}$ & 6 & 330 & \\
\hline
\end{tabular}

${ }^{\mathrm{a}} \lambda_{\max }$ in $\mathrm{nm}, \varepsilon$ in $\mathrm{M}^{-1} \mathrm{~cm}^{-1}$.

${ }^{\mathrm{b}}$ Tterpy $=$ 4'-(4-tolyl)-2,2':6',2"-terpyridine.

' byp $=2,2$ '-bipydidyl 
Since the discovery of $\left[\left(\mathrm{NH}_{3}\right)_{5} \mathrm{Ru} \text {-pyrazine- } \mathrm{Ru}\left(\mathrm{NH}_{3}\right)_{5}\right]^{5+}$ by Creutz and Taube (Creutz-Taube ion) ${ }^{80}$, a great number of dinuclear ruthenium complexes with low-energy IVCT at mixed-valence states have been prepared $^{73}$. Some active in the range of telecommunication wavelengths are selected and listed in table I.3. All the complexes in table I.3 show relatively strong low-energy transition over $1220 \mathrm{~nm}$ in the mixed-valence state. Among them, $[\mathbf{I . 1 6}]^{3+}$ displays the lowest energy transition around $2000 \mathrm{~nm}$ with the highest extinction coefficient $\left(=14000 \mathrm{M}^{-1} \mathrm{~cm}^{-1}\right)^{81}$. The Creutz-Taube ion $\left([\mathbf{I . 1 4}]^{5+}\right)$ and 2,3,5,6-tetra-2-pyridinylpyrazine bridged dinuclear ruthenium complex $[\text { I.17 }]^{5+}$ displays absorption maxima around $1550 \mathrm{~nm}$ with very high coupling constant $\left(3200-3300 \mathrm{~cm}^{-1}\right)^{82}$, which are more considered as valence-delocalized complexes (Robin and Day class III) ${ }^{73,83}$. With the extension of the length of pyrazine bridge, e.g. by insertion S-S bond between two pyridines in $\mathbf{I} .15^{84,85}$, the metal-metal interaction drops to a much lower value (from 3200 to 855 ) which is accompanied with the decrease in comproportionation constant and a blue shift of the low-energy transition. This trend is more clearly shown in a series of dinuclear ruthenium complexes I.18, I.19 and I.20 ${ }^{86}$. With the separation of the two metals further by inserting phenyl rings, both coupling constant and comproportionation constant decrease to lower values with optical transition being shifted to a higher energy. As pointed by Ward, the change in metal-metal interaction (1020 to 330, 3 folds) seems to be less affected by the increase of the distance than the change in comproportionation constant (690 to 6,115 folds).

L.21 (Figure I.6) represents another type of mixed-valence dinuclear ruthenium complexes. It was first prepared Kaim et al.$^{87}$ and further developed by Desjardins et al. from our lab ${ }^{88}$. $[\mathbf{L . 2 1}]^{2+}$ is simply prepared from the reaction of cis- $\mathrm{Ru}(\mathrm{bpy})_{2} \mathrm{Cl}_{2} \cdot 2 \mathrm{H}_{2} \mathrm{O}$ 
and a dicarbonylhydrazine (dch) ligand in a basic condition and easily separated by column chromatography. It can undergo two reversible one-electron oxidation reactions result in $[\mathbf{L . 2 1}]^{3+}$ and $[\mathbf{L . 2 1}]^{4+}$ with a large $\Delta E>0.45 \mathrm{~V}\left(K_{c}>5 \times 10^{7}\right)$. The mixedvalence $[\mathbf{L . 2 1}]^{3+}$ complexes display intense $\left(\varepsilon>7000 \mathrm{M}^{-1} \mathrm{~cm}^{-1}\right)$ and broad (half-width $>$ $1250 \mathrm{~cm}^{-1}$ ) absorption in the NIR region, which is absent when reduced to $[\mathbf{L . 2 1}]^{3+}$ state or further oxidized to $[\mathbf{L . 2 1}]^{4+}$ state. Their IVCT is little solvent dependent but highly substituent dependent. An electron donor causes a blue shift of the transition, while an electron acceptor brings a red shift to the transition. By finely tuning the substituents, e.g. $\mathrm{R}=\mathrm{CH}_{3}$, an intense $\left(\varepsilon=9300 \mathrm{M}^{-1} \mathrm{~cm}^{-1}\right)$ IVCT band at $1550 \mathrm{~nm}$ can be achieved, which matches one of the telecommunication wavelengths. Not useful only for tuning the optical transition, the change of $\mathrm{R}$ group gives a possibility to introduce other functional groups for polymerization. These features, plus the stability in the air and towards thermal degradation, have made DCH-based dinuclear ruthenium complexes attractive electrochromic materials for NIR optical attenuation and other applications.
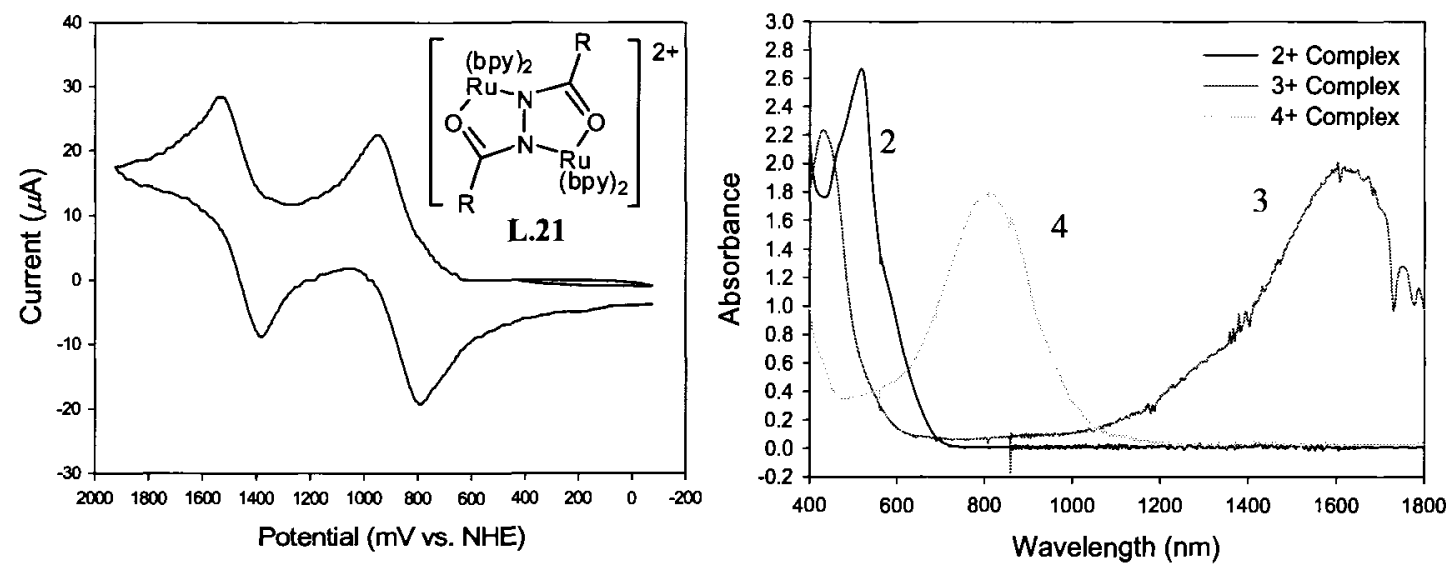

Figure I.6. $\left[\left\{R u(b p y)_{2}\right\}_{2} \mu-P h_{2} d c h\right]^{2+}$ (L.21): general structure, typical CV and absorption spectra in three different oxidation states. 


\section{I.5. Electrochromic Variable Optical Attenuator (ECVOA)}

Electrochromic (EC) materials that change the absorption in the NIR region, in particular at telecommunication wavelengths, are useful for applications in optical communication, such as variable optical attenuators (VOA). A VOA is a device that can attenuate the intensity or power level of an input optical beam to produce an output optical beam with controlled intensity. It is an essential component in telecommunication system involving the wavelength-division multiplexing (WDM) technology because it can flatten signal variations caused by changes in source power, amplifier gain and other components $^{89-91}$. Various types of VOA devices have been developed and operate in different mechanisms, such as sliding-block mechanical devices ${ }^{89}$ and thermo-optic systems $^{90,91}$.

A new concept transmissive VOA has been proposed ${ }^{92}$, which is based on the use of NIR electrochromic materials to absorb or attenuate the NIR light and thus called electrochromic variable optical attenuator (ECVOA, Figure I.7). It composes one NIR electrochromic material coated on a transparent electrode like indium doped tin oxide (ITO) glass with opposite electrochromic behavior $\left(\mathrm{DCH}-\mathrm{Ru}\right.$ and $\left.\mathrm{WO}_{3}\right)$, separated by a thin layer of gel electrolyte. When electrons are injected to the catholically electrochromic material $\left(\mathrm{WO}_{3}\right)$, it will under to reduction to turn "colored" at $1550 \mathrm{~nm}$. At the same time, the anodically electrochromic material (DCH-Ru) will undergo oxidation to become "colored" and thus the light will be absorbed or attenuated. By switching the bias, both materials change to the "bleached" states and the light will then be allowed to pass. Compared to some known VOAs, advantages of ECVOA include possible integration with other optical devices on one planar substrate, low-cost 
fabrication, low operation voltage (e.g., $2 \mathrm{~V}$ ) and large dynamic range of attenuation (e.g., 10-50 dB). For commercial application of ECVOA, electrochromic materials should have the following features: high contrast ratio (percent transmittance change between bleached and colored state) at the telecommunication wavelengths, high color efficiency, low cost in preparation, good processibility, fast switching time and long-time stability.

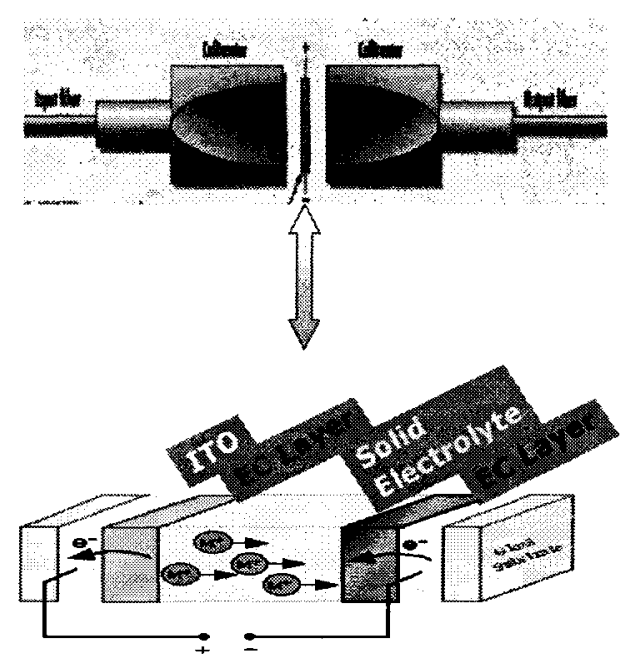

Figure I.7. Concept design of transmissive ECVOA.

\section{I.6. Rationale and Objectives}

Although the DCH-based dinuclear ruthenium complexes have shown some good properties as NIR electrochromic materials, they are still not suitable for application in solid devices. Thus, by incorporating DCH-Ru active component in the film-forming polymers, applications of these NIR electrochromic materials in solid devices should be realized. Accordingly, this research will mainly focus on exploration of different ways of incorporating the DCH-Ru complexes into various polymeric systems. Three strategies for making $\mathrm{DCH}-\mathrm{Ru}$ film-forming materials can be envisioned: doping $\mathrm{DCH}-\mathrm{Ru}$ into crosslinked polymer host, complexation with DCH-containing polymers and 
polymerization of functionalized DCH-Ru monomers. Therefore, the objectives of this research are:

1. To prepare $[\mathrm{G}]-1$ dendric $\mathrm{DCH}$ ligands and their ruthenium complexes with a higher ruthenium content in order to improve the extinction coefficient at $1550 \mathrm{~nm}$ and to study the electronic/optical properties-structure relationships;

2. To evaluate the attenuation performance of ECVOA based on [G]-1 dendric DCH$\mathrm{Ru}$ complexes;

3. To prepare and study polymeric $\mathrm{DCH}-\mathrm{Ru}$ complexes though polymeric ligand containing hydrazinedicarboxamide (-NH-DCH-NH-);

4. To synthesize the $\mathrm{DCH}-\mathrm{Ru}$ polymers from $\mathrm{A}-\mathrm{B}$ and AA-BB types of monomers and to evaluate optical attenuation of the resulting polymers at $1550 \mathrm{~nm}$. 


\section{References}

1. Yang, R. Q.; Tian, R. Y.; Yan, J. A.; Zhang, Y.; Yang, J.; Hou, Q.; Yang, W.; Zhang, C.; Cao, Y. Macromolecules 2005, 38, 244.

2. Brabec, C. J.; Winder, C.; Sariciftci, N. S.; Hummlen, J. C.; Dhanabalan, A.; van Hal, P. A.; Janssen, R. A. J. Adv. Funct. Mater. 2002, 12(10), 709.

3. McDonagh, M. A.; Bayly, S. R.; Riley, D. J.; Ward, M. D.; McCleverty, J. A.; Cowin, M. A.; Morgan, C. N.; Varrazza, R.; Penty, R. V.; White, I. H. Chem. Mater. 2000, 12, 2523.

4. Hilderbrand, S. A.; Kelly, K. A.; Weissleder, R.; Tung, C. H. Bioconjugate Chem. 2005, 16, 1275.

5. Chandrasekhar, P.; Zay, B. J.; McQueeney, T.; Scara, A.; Ross, D.; Birur, G. C.; Haapanen, S.; Kauder, L.; Swanson, T.; Douglas, D. Synth. Met. 2003, 135-136, 23.

6. Tung, C.; Lin, Y.; Moon, W.; Weissleder, R. ChemBioChem 2002, 3, 784.

7. Greenberg, C. B. Thin Solid Films 1994, 251, 81.

8. Anaissi, F. J.; Demets, G. J. F.; Toma, H. E. ElectroChem. Commun. 1999, 1, 332.

9. Wang, Z. Y.; Zhang, J. D.; Wu, X. G.; Birau, M.; Yu, G. M.; Yu, H. A.; Qi, Y. H.; Desjardins, P.; Meng, X. S.; Gao, J. P.; Todd, E.; Song, N. H.; Bai, Y. W.; Beaudin, A. M. R.; LeClair, G. Pure Appl. Chem. 2004, 76(7-8), 1435.

10. Monk, P. M. S.; Mortimer, R. J.; Rosseinsky, D. R. Electrochromism: Fundamentals and Application, VCH Weinheim, 1995.

11. Somani, P. R.; Radhakrishnan, S. Mater. Chem. Phys. 2002, 77, 117.

12. Wolff, J. J.; Wortmann, R. Adv. Phys. Org. Chem. 1999, 32, 121.

13. Mortimer, R. J. Chem. Soc. Rev. 1997, 26, 147. 
14. Mortimer, R. J. Electrochim. Acta 1999, 44, 2971.

15. Mortimer, R. J.; Dyer, A. L.; Reynolds, J. R. Displays 2006, 27, 2.

16. Hünig, S.; Kemmer, M.; Wenner, H.; Perepichka, I. F.; Bäuerle, P.; Emge, A.; Gescheid, G. Chem. Eur. J. 1999, 5(7), 1969.

17. Lambert, C.; Nöll, G. J. Am. Chem. Soc. 1999, $121,8434$.

18. Lambert, C.; Nöll, G. Chem. Eur. J. 2002, 8(15), 3467.

19. Lee, C.; Lee, Y. M.; Moon, M. S.; Park, S. H.; Park, J. W.; Kim, K. G.; Jeon, S. H. J. Electroanal. Chem. 1996, 416, 139.

20. Penneau, J. F.; Stallman, B. J.; Kasai, P. H.; Miller, L. L. Chem. Mater. 1991, 3, 791.

21. Almlof, J.; Jozefiak, T. H.; Feyereisen, M. W.; Miller, L. L. J. Am. Chem. Soc. 1990, 112, 1206.

22. Fiedler, J.; Zali, S. T.; Klein, A.; Hornung, F.; Kaim, W. Inorg. Chem. 1996, 35, 3039.

23. Demol, F.; De Backer, M. G.; Levillain, E.; Sauvage, F. X. Spectrochim. Acta A 2001, 57, 1611 .

24. Ichimura, A. S.; Xie, Q.; Szajek, L. P.; Lema, J.; Burns, A.; Huang, R. H.; Jackson, J. E.; Dye, J. L.; Demol, F.; Sauvage, F. X.; De Backer, M. G. J. Phys. Chem. A 2000, 104, 3038.

25. Fabian, J.; Nakazumi, H.; Matsuka, M. Chem. Rev. 1992, 92, 1197.

26. Fabian, J. J. Prakt. Chem. 1991, 333(2), 197.

27. Bulschel, M.; Ajayaghosh, A.; Arunkumar, E.; Daub, J. Org. Lett. 2003, 5(17), 2975. 
28. Perepichka, D. F.; Bryce, M. R; Batsanov, A. S.; McInnes, E. J. L.; Zhao, J. P.; Farley, R. D. Chem. Eur. J. 2002, 8(20), 4656.

29. Lenhard, J. R.; Hein, B. R. J. Phys. Chem. 1996, 100, 17287.

30. Miller, L. L.; Zhong, C. J.; Kasai, P. J. Am. Chem. Soc. 1993,115, 5982.

31. Ichimura, A. S.; Xie, Q.; Szajek, L. P.; Lema, J.; Burns, A.; Huang, R. H.; Jackson, J. E.; Dye, J. L.; Demol, F.; Sauvage, F.-X.; DeBacker, M. G. J. Phys. Chem. A 2000, 104, 3038.

32. Lenhard, J. R.; Parton, R. L. J. Am. Chem. Soc. 1987, 109, 5808.

33. Parton, R. L.; Lenhard, J. R. J. Org. Chem. 1990, 55, 49.

34. Lenbard, J. R.; Cameron, A. D. J. Phys. Chem. 1993, 97, 4916.

35. Akahoshl, H.; Toshlma, S.; Itaya, K. J. Phys. Chem. 1981, 85, 818.

36. Zhang, S. S.; Sha, Q. Q. Solid State lonics 1993, 59, 179.

37. Ryu, J.-H.; Shin, D.-O.; Suh, K.-D. J. Polym. Sci., Part A: Polym. Chem. 2005, 43, 6562.

38. Nakano, T.; Yade, T. Chem. Lett. 2008, 37(3), 258.

39. Moliton, A.; Hiorns, R. C. Polym. Int. 2004, 53, 1397.

40. Unur, E.; Jung, J. H.; Mortimer, R. J.; Reynolds, J. R. Chem. Mater. 2008, 20, 2328.

41. Kumar, A.; Welsh, D. M.; Morvant, M. C.; Piroux, F.; Abboud, K. A.; Reynolds, J. R. Chem. Mater. 1998, 10, 896.

42. Sapp, S. A.; Sotzing, G. A.; Reynolds, J. R. Chem. Mater. 1998, 10, 2101.

43. Thompson, B. C.; Schottland, P.; Zong, K.; Reynolds, J. R. Chem. Mater. 2000, 12, 1563.

44. Sonmez, G.; Meng, H.; Wudl, F. Chem. Mater. 2003, 15, 4923. 
45. Roncali, J. Chem. Rev. 1997, 97, 173.

46. Sonmez, G.; Shen, C. K. F.; Rubin, Y.; Wudl, F. Angew. Chem. Int. Ed. 2004, 43 1497.

47. Hyodo, K. Electrochim. Acta 1994, 39(2), 265.

48. Somani, P.; Mandale, A. B.; Radhakrishnan, S. Acta Mater. 2000, 48, 2859.

49. Mortimer, R. J; Sonmez, G. Chem. Commun. 2005, 5251.

50. Li, Y. F.; Yan, B. Z.; Yang, J.; Cao, Y.; Qian, R. Y. Synth. Met. 1988, 25, 79.

51. Monkman, A. P.; Bloor, D.; Stevens, G. C.; Stevens, J. C. H.; Wilson, P. Synth. Met. 1989, 29(1), E277.

52. Watanabe, A.; Mori, K.; Iwabuchi, A.; Iwasaki, Y.; Nakamura, Y.; Ito, S. Macromolecules 1989, 22, 3521.

53. Mortimer, R. J. J. Muter. Chem. 1995, 5, 969.

54. Chung, T. C.; Kaufman, J. H.; Heeger, A. J.; Wudl, F. Phys. Rev. B 1984, 30(2), 702.

55. Tourillon, G.; Garnier, F. J. Electrochem. Soc. 1983, 130(10), 2042.

56. Leclerc, M.; Faid, K. Adv. Maier. 1997, 9(14), 1087.

57. Chan, H. S. O.; Ng, S. C. Prog. Polym. Sci. 1998, 23(7), 1167.

58. Reference 9a in Groenendaal, L. B.; Jonas, F.; Freitag, D.; Pielartzik, H.; Reynolds, J. R. Adv. Mater. 2000, 12(7), 481.

59. Kanazawa, K. K.; Diaz, A. F.; Gill, W. D.; Grant, P. M.; Street. G. B.; Gardini, G. P.; Kwak, J. F. Synth. Met. 1986, 3, 329.

60. Gaupp, C. L.; Zong, K.; Schottland, P.; Thompson, B. C.; Thomas, C. A.; Reynolds, J. R. Macromolecules 2000, 33, 1132. 
61. Schottland, P.; Zong, K.; Gaupp, C. L.; Thompson, B. C.; Thomas, C. A.; Giurgiu, I.; Hickman, R.; Abboud, K. A.; Reynolds, J. R. Macromolecules 2000, 33, 7051.

62. Reference 27, 28 in Walczak, R. M.; Reynolds, J. R. Adv. Mater. 2006, 18, 1121.

63, Walczak, R. M.; Reynolds, J. R. Adv. Mater. 2006, 18, 1121.

64. Roncali, J. Macromol. Rapid Commun. 2007, 28, 1761.

65. Bundgaard, E.; Krebs, F. C. Sol. Energy Mater. Sol. Cells 2007, 91, 954.

66. Durmus, A.; Gunbas, G. E.; Toppare, L. Chem. Mater. 2007, 19, 6247.

67. Groenendaal, L. B.; Jonas, F.; Freitag, D.; Pielartzik, H.; Reynolds, J. R. Adv. Mater. 2000, 12(7), 481.

68. Schrauzer, G. N.; Mayweg, V. P. J. Am. Chem. Soc. 1962, 84, 3221.

69. Mueller-Westerhof, U. T.; Vance, B.; Yoon, D. I. Tetrahedron 1991, 47, 909.

70. Aragoni, M. C.; Arca, M.; Cassano, T.; Denotti, C.; Devillanova, F. A.; Isaia, F.; Lippolis, V.; Natali, D.; Nitti, L.; Sampietro, M.; Tommasi, R.; Verani, G. Inorg. Chem. Commun. 2002, 5, 869.

71. Robertson, N.; Cronin, L. Coord. Chem. Rev. 2002, 227, 93.

72. Deplano, P.; Mercuri, M. L.; Pintus, G.; Trogu, E. F. Comments Inorg. Chem. 2001, 22(6), 353.

73. Ward, M. D. Chem. Soc. Rev. 1995, 24, 121.

74. Joulié, L. F.; Schatz, E.; Ward, M. D.; Weber, F.; Yellowlees, L. J. J. Chem. Soc. Dalton Trans. 1994, 799.

75. Barthram, A. M.; Cleary, R. L.; Kowallick, R.; Ward, M. D. Chem. Commun. 1998, 2695.

76. Bayly, S. R.; Humphrey, E. R.; de Chair, H.; Paredes, C. G.; Bell, Z. R.; Jeffery, J. 
C.; McCleverty, J. A.; Ward, M. D.; Totti, F.; Gatteschi, D.; Courric, S.; Steele, B. R.; Screttas, C. G. J. Chem. Soc., Dalton Trans. 2001, 1401.

77. McDonagh, A.; Bayly, S. R.; Riley, D. J.; Ward, M. D.; McCleverty, J. A.; Cowin, M. A.; Morgan, C. N.; Varrazza, R.; Penty, R. V.; White, I. H. Chem. Mater. 2000, $12,2523$.

78. Allen, C. C.; Hush, N. S. Prog. Inorg. Chem. 1967, 8, 357.

79. Hush, N. S. Prog. Inorg. Chem. 1967, 8, 391.

80. Creutz, C.; Taube, H. J. Am. Chem. Soc. 1973, 95, 1086.

81. Laye, R. H.; Couchman, S. M.; Ward, M. D. Inorg. Chem. 2001, 40, 4089.

82. Colin, J.-P.; Lainé, P.; Launay, J.-P.; Sauvage, J.-P.; Sour, A. J. Chem. Soc. Chem. Commun. 1993, 434.

83. Fürholz, U.; Joss, S.; Bürgi, H. B.; Ludi, A. Inorg.Chem. 1985, 24, 943.

84. Moreira, I. S.; Franco, D. W. J. Chem. Soc. Chem. Commun. 1992, 450.

85. Moreira, I. S.; Franco, D. W. Inorg. Chem. 1994, 33, 1607.

86. Beley, M.; Chodorowski-Kimmes, S.; Collin, J.-P.; Lainé, P.; Launay, J.-P.; Sauvage, J.-P. Angew Chem. Int. Ed. Eng. 1994, 33, 1775.

87. Kaim, W.; Kasack, V.; Binder, H.; Roth, E.; Jordanov, J. Angew. Chem., Int. Ed. Eng. 1988, 27, 1174.

88. Qi, Y. H.; Desjardins, P.; Wang, Z. Y. J. Opt. A Pure Appl. Opt. 2002, 4, S273.

89. Barber, B.; Giles, C. R.; Askyuk, V.; Ruel, R.; Stulzl, L.; Bishop, D. IEEE Photonics Technol. Lett. 1998, 10, 1262.

90. Kawai, T.; Koga, M.; Okuno, M.; Kitoh, T. Electron. Lett. 1998, 34, 264.

91. Jin, Y. S.; Lee, S. S.; Son, Y. S. Electron. Lett 1999, 35, 916. 
92. Qi, Y. H.; Wang, Z. Y. Macromolecules 2003, 36, 3146. 


\section{Chapter II Design, Synthesis and Application of [G]-1 DCH-Ru Complexes}

\section{II.1 Introduction}

A variable optical attenuator (VOA) is a device that can attenuate the intensity of an input optical beam to produce an output optical beam with controlled intensity ${ }^{1-3}$. It's a key component in wavelength-division multiplexing (WDM) technology, in which multiple wavelengths are multiplexed on a single optical fiber. Development of VOA operated in the NIR region, especially at $1310 \mathrm{~nm}$ and $1550 \mathrm{~nm}$, has drawn a great deal of research in fibre-optic telecommunications, in which silica fibers are used to transmit optical data with a minimal optical loss. NIR VOA devices have been fabricated based on various mechanisms such as electrochromic ${ }^{4}$, micro-electro mechanic ${ }^{5,6}$, liquid crystal $^{7-9}$ and thermo-optic ${ }^{10,11}$ attenuators. Among these VOA devices, electrochromic VOA (ECVOA) has the advantages of low driving voltage, ease of fabrication, ease of integration in optical fiber system and a minimum amount of moving parts, which can meet the current challenges to fabricate low-power consuming, flexible, lightweight and inexpensive VOA devices.

EC materials which are active in the NIR region are thus of interest to be explored. Due to the low density, higher color contrast, thermal stability and electrochemical stability upon cycling, NIR-active organic EC materials, typically conducting polymers like poly(3,4-ethylenedioxythiophene) (PEDOT) and its derivatives, can well serve this purpose. However, most interest in EC materials has been directed to optical change in the visible region with the applications as tunable windows ${ }^{12}$, variable-reflectance 
mirrors $^{13}$ and EC displays ${ }^{14}$, etc. Only recently did the PEDOT-based ECVOA begin to be reported from our group and other groups ${ }^{15-17}$.

As one group of NIR-active materials, metal complexes, especially dinuclear and polynuclear complexes, also received much attention in this field for several reasons. Firstly, reversible electrochromism is the intrinsic feature for most metal complexes. Secondly, they exhibit high color contrast in the NIR region upon oxidation or reduction. Thirdly, their redox potentials are generally lower than 3 V. Fourthly, the absorption band can be well controlled by structural modification. Finally, they can form high-quality thin films, with proper structural modification or polymerization, on electrodes. The reported NIR electrochromic metal complexes include ruthenium dioxolene complexes ${ }^{18}$, tris(pyrazolyl)borato-molybdenum complexes ${ }^{19}$ and mixed-valence dinuclear ruthenium complexes $^{20-22}$

It's known that dinuclear metal complexes with a significant metal-metal electronic coupling can show an intervalence charge transfer (IVCT) transition, or metalto-metal charge transfer (MMCT) transition, from the metal donor to the metal acceptor ${ }^{23}$. This transition often occurs in the long-wavelength region due to the low energy transition. The early work by Kaim et al. shows that the mixed-valence dinuclear ruthenium complexes based on dicarbonylhydrazine (DCH) and 2,2'-bipyridine (bpy) ligands are highly electrochromic in the NIR region ${ }^{20,21}$, which makes them excellent candidates for use as NIR electrochromic materials in devices. Extensive studies on the novel dinuclear ruthenium complexes (DCH-Ru) have been carried out in our group in the past few years. A series of dinuclear DCH-Ru complexes bearing various donor and acceptor groups have been prepared ${ }^{24}$. DCH-Ru complexes with weak electron-donating 
substituents (e.g., phenyl, alkyl, and phenoxy) are proposed to be the most promising materials for use in variable optical attenuator (VOA) for their strong electrochromism at the telecommunication band of $1550 \mathrm{~nm}$.

In this chapter, a series of [G]-1 (hexanuclear) DCH-Ru complexes having a benzene core are proposed. The synthesis, property and ECVOA application of a series of [G]-1 DCH-Ru complexes are described. Some advantages are expected from the dendric structure. The most desirable feature of such a dendric structure should be the capability to undergo cross-linking reaction to produce good films with high resistance to solvent and thermal degradation if a reacting group is attached to each end. A slightly higher molar extinction coefficient is expected compared to monomeric dinuclear ruthenium species due to the slightly higher ratio of ruthenium content to the overall molecular weight. In addition, rapid ion transportation is expected in a crosslinked film due to its larger free volume, which will allow for a faster switching in VOA.

\section{II.2 Synthesis and Characterization of [G]-1 DCH-Ru complexes}

The [G]-1 ligands II.1-5 were synthesized according to a previous procedure, ${ }^{25}$ from the reaction of 1,3,5-benzenetricarboxylic acid trichloride with three equivalents of the corresponding hydrazides in 53-85\% yield (Table II.1). The corresponding hexanuclear ruthenium complexes were prepared using the similar procedure in literature ${ }^{21}$, by reacting $c i s-\mathrm{Ru}(\mathrm{bpy})_{2} \mathrm{Cl}_{2} \cdot 2 \mathrm{H}_{2} \mathrm{O}$ with a $[\mathrm{G}]-1$ ligand under a basic condition in methanol/water (Table II.1). The complexes were purified by column chromatography on acidic aluminum oxide with acetonitrile as the eluent and $45-56 \%$ yield was obtained. 
Table II.1. Syntheses of 1,3,5-benzenetris(2'-substituted carbohydrazides) II.1-5 and the corresponding DCH-Ru complexes II.(1-5)-Ru.

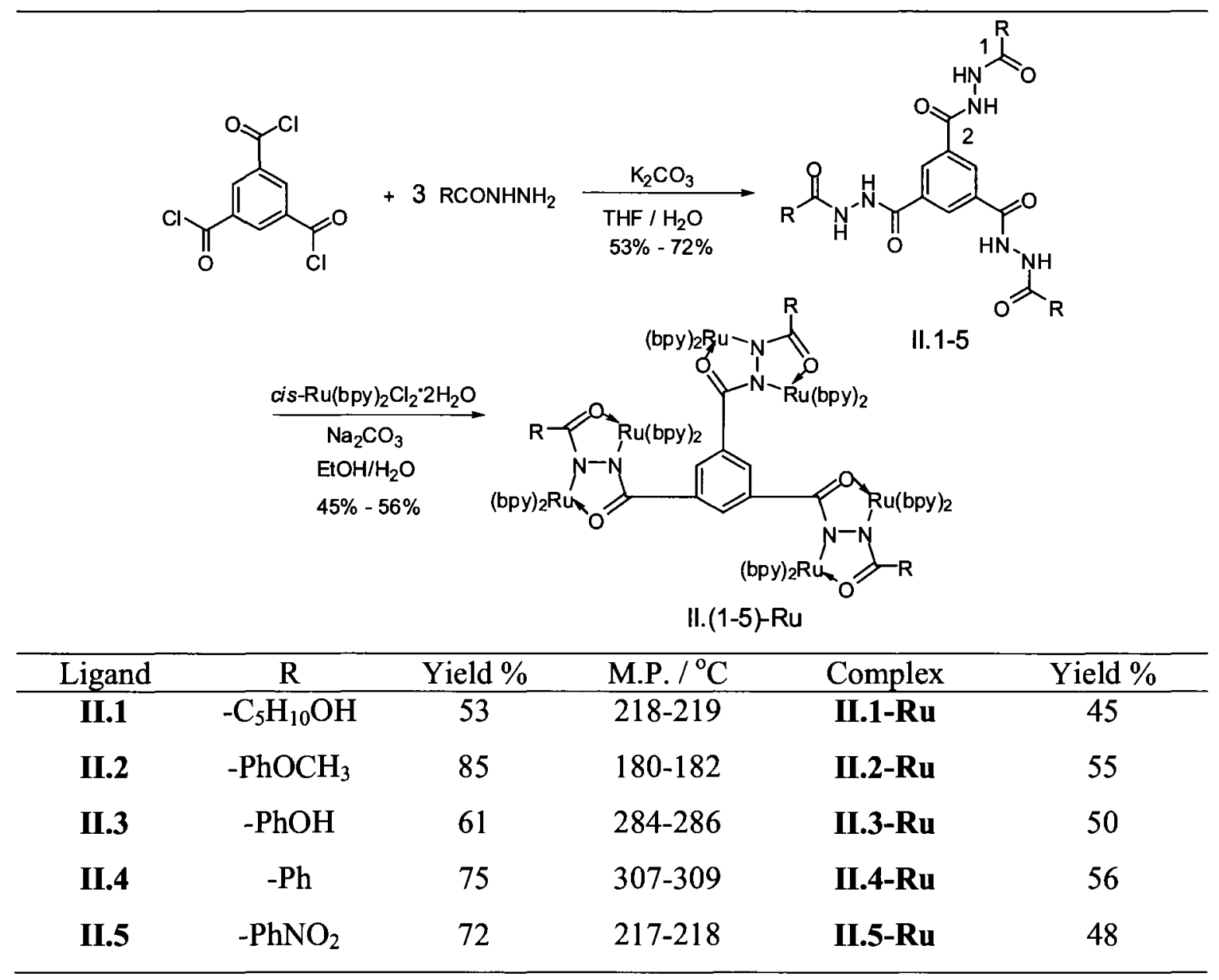

The structures of the ligands were characterized by IR, ${ }^{1} \mathrm{H}$ NMR and ${ }^{13} \mathrm{C}$ NMR. As shown in figure II.1, the IR bands at around $3250 \mathrm{~cm}^{-1}, 1650 \mathrm{~cm}^{-1}$ and $1600-1500$ $\mathrm{cm}^{-1}$ are assigned to $\mathrm{N}-\mathrm{H}, \mathrm{C}=\mathrm{O}$ and aromatic $\mathrm{C}=\mathrm{C}$, respectively. The IR spectra of the corresponding ruthenium complexes show the absence of the N-H stretch at $3250 \mathrm{~cm}^{-1}$. The new band at $840 \mathrm{~cm}^{-1}$ is from the P-F stretching vibration of the $\mathrm{PF}_{6}{ }^{-}$counter ion. The peaks of carbonyl carbons of these ligands in the ${ }^{13} \mathrm{C}$ NMR spectra appear in the range 171.1 - $164.9 \mathrm{ppm}$ and the chemical shift of C-2 in ligand II.1 (structures in Table II.1) 
exhibits a strong dependence on the nature of the substituent $R$. Due to the highest electron-donating ability, the $\mathrm{C}-2$ has the highest chemical shift at $171.1 \mathrm{ppm}$.

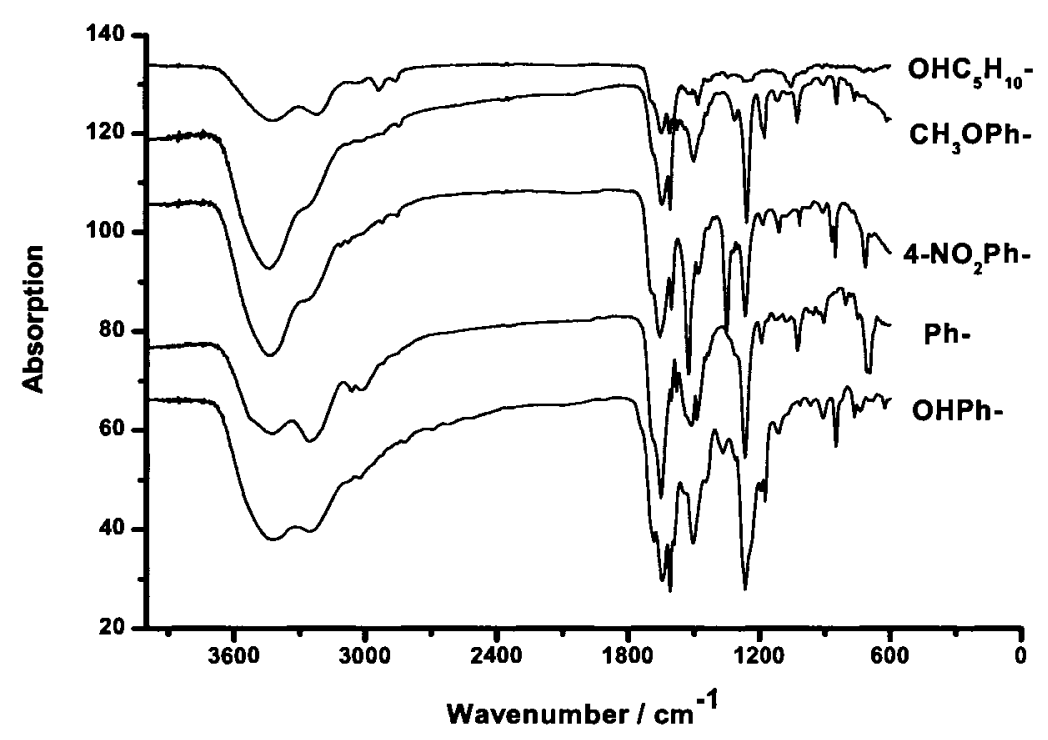

Figure II.1. IR spectra of ligands II.1-5 (KBr pallets).

\section{II.3 Electrochemical Properties}

$\mathrm{CV}$ experiments were performed in $0.1 \mathrm{M} \mathrm{TBAH} /$ acetonitrile solution at a scanning rate of $200 \mathrm{mV} / \mathrm{s}$ and the representive result of II.4-Ru was shown in figure II.2. The electrochemical data for the DCH-Ru complexes, along with comproportionation constants $K_{c}$ are given in table II.2, and a representative cyclic voltamogram (CV) of II.4$\mathbf{R u}(\mathrm{R}=\mathrm{Ph})$ is shown in figure II.2. Each dendritc complex exhibits two quasi-reversible redox couples in the positive potential region like a dinuclear DCH-Ru complex, which can be assigned to two three-electron oxidation steps: $3\left(\mathrm{Ru}^{\mathrm{II}} / \mathrm{Ru}^{\mathrm{II}}\right) \rightarrow 3\left(\mathrm{Ru}^{\mathrm{II}} / \mathrm{Ru}^{\mathrm{III}}\right) \rightarrow$ $3\left(\mathrm{Ru}^{\mathrm{III}} / \mathrm{Ru}{ }^{\mathrm{III}}\right)$. This result suggests there is no electron delocalization among the three dinuclear-complex moieties. As the average donor strength of the substituent decreases, both the first $\left(E_{1}\right)$ and second half-wave oxidation potentials $\left(E_{2}\right)$ shift anodically. The 
difference between two oxidation potentials $(\Delta E)$, also an indicator of the stability of the mixed-valence species, is not greatly affected by the substituents because of the synchronous shifts of $E_{1}$ and $E_{2}$. However, $\Delta E$ values do show a dropping trend over the series with the increasing donor strength.

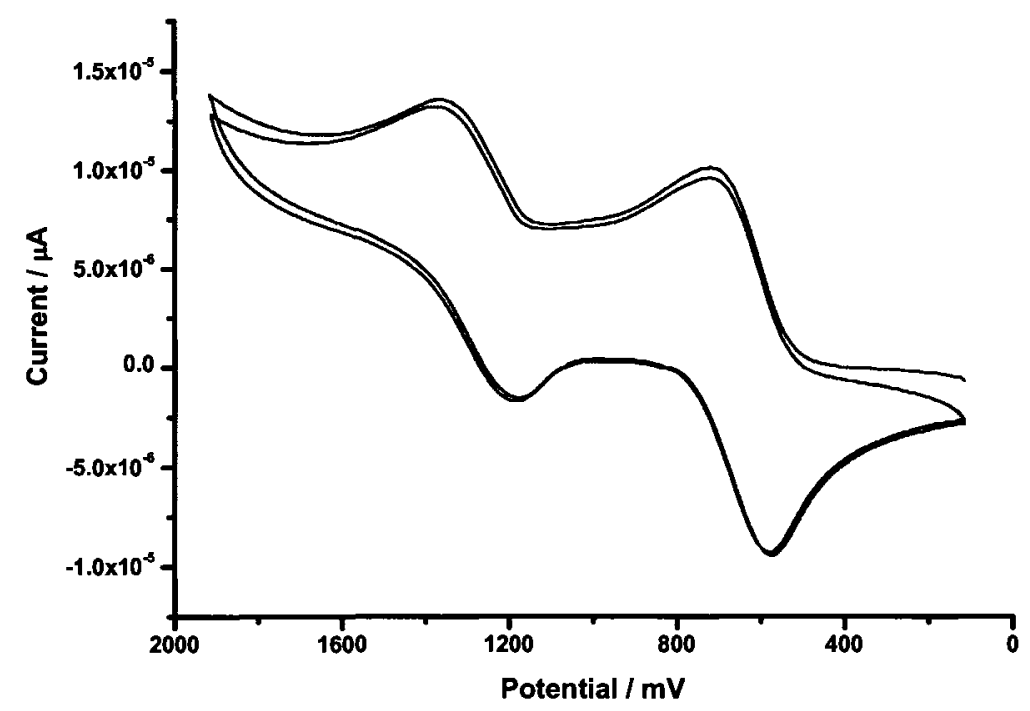

Figure II.2. CV of II.4-Ru $(\mathrm{R}=\mathrm{Ph})$ in 0.1 M TBAH/ACN (scanning rate of $200 \mathrm{mv} / \mathrm{s})$.

Table II.2. Electrochemical oxidative potentials of complexes in 0.1M TBAH/ACN solution (scanning rate of $200 \mathrm{mv} / \mathrm{s}$ ).

\begin{tabular}{ccccccc}
\hline Complex & $R$ & $E_{1} / \mathrm{mV}$ & $E_{2} / \mathrm{mV}$ & $\Delta E / m V$ & $K_{c}{ }^{a}$ & $\delta^{*}$ \\
\hline II.1-Ru & $\mathrm{C}_{5} \mathrm{H}_{10} \mathrm{OH}$ & 597 & 1183 & 586 & $8.1 \times 10^{9}$ & -0.18 \\
II.2-Ru & $p$-PhOMe & 620 & 1182 & 562 & $3.1 \times 10^{9}$ & -0.09 \\
II.3-Ru & $p$-PhOH & 631 & 1235 & 604 & $1.6 \times 10^{10}$ & -0.06 \\
II.4-Ru & $\mathrm{Ph}$ & 645 & 1238 & 593 & $1.1 \times 10^{10}$ & -0.02 \\
II.5-Ru & $p$-PhNO & 747 & 1369 & 622 & $3.2 \times 10^{10}$ & 0.25 \\
\hline${ }^{\mathrm{a}} K_{c}=10^{16.91 \Delta E}$ & & & & & \\
\hline
\end{tabular}


The relationship between the oxidation potential and the electron-donating strength of constituents can be depicted by employing the Hammett parameter as it provides a direct measurement of the strength of an electron donor ${ }^{26}$. The Hammett parameters are calculated according to the following equation:

$$
\sigma^{*}={ }^{1} \sigma_{p}+{ }^{2} \sigma_{p}
$$

where ${ }^{1} \sigma_{p}$ and ${ }^{2} \sigma_{p}$ are the Hammett parameters of the substituent R and R', respectively. As approximation, the phenyl core was served as one substituent. The calculated $\sigma^{*}$ values are listed in table 2 and the plots of $\sigma^{*}$ value vs $E_{l}$ and $E_{2}$ are shown in figure II.3. The plot clearly shows a linear dependence of the electrochemical properties of $[\mathrm{G}]-1$ $\mathrm{DCH}-\mathrm{Ru}$ complexes on Hammett parameters like dinuclear DCH-Ru complexes ${ }^{24}$. Hence, by selecting proper substituent, the [G]-1 DCH-Ru complex with the desired $A E$ can be achieved.

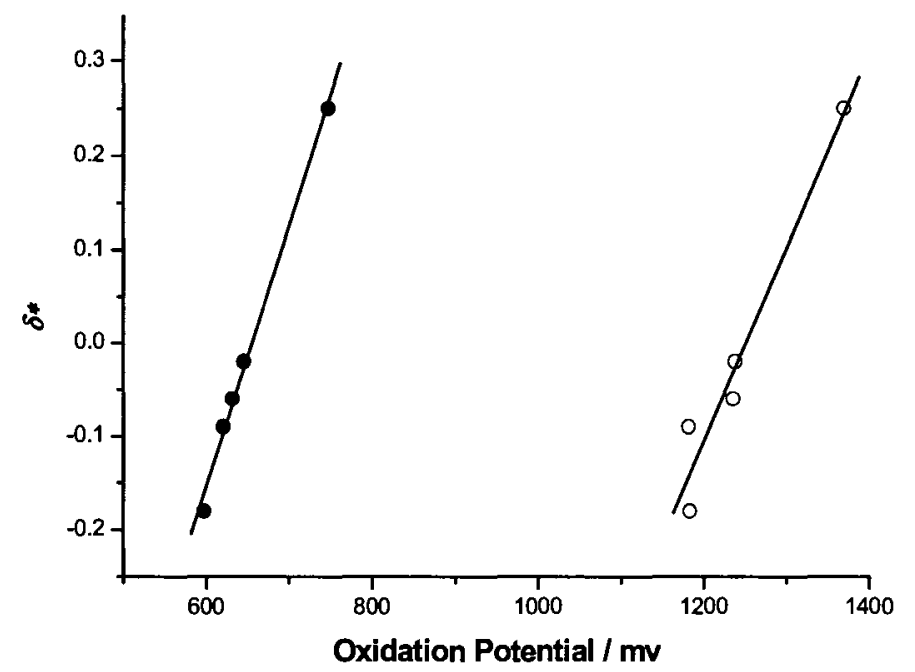

Figure II.3. Relationship between the total Hammett parameter and redox potentials $\left(\bullet E_{1}, \circ E_{2}\right)$. 


\section{II.4 UV-vis-NIR Spectroscopic Properties}

The electronic spectra of a representative [G]-1 DCH-Ru complex (II.4-Ru) at different oxidation states in acetonitrile (ACN) with tetra-n-butylammonium hexafluorophosphate (TBAH) as supporting electrolyte are shown in figure II.4, and the spectroelectrochemical data of the five complexes are listed in table II.3.

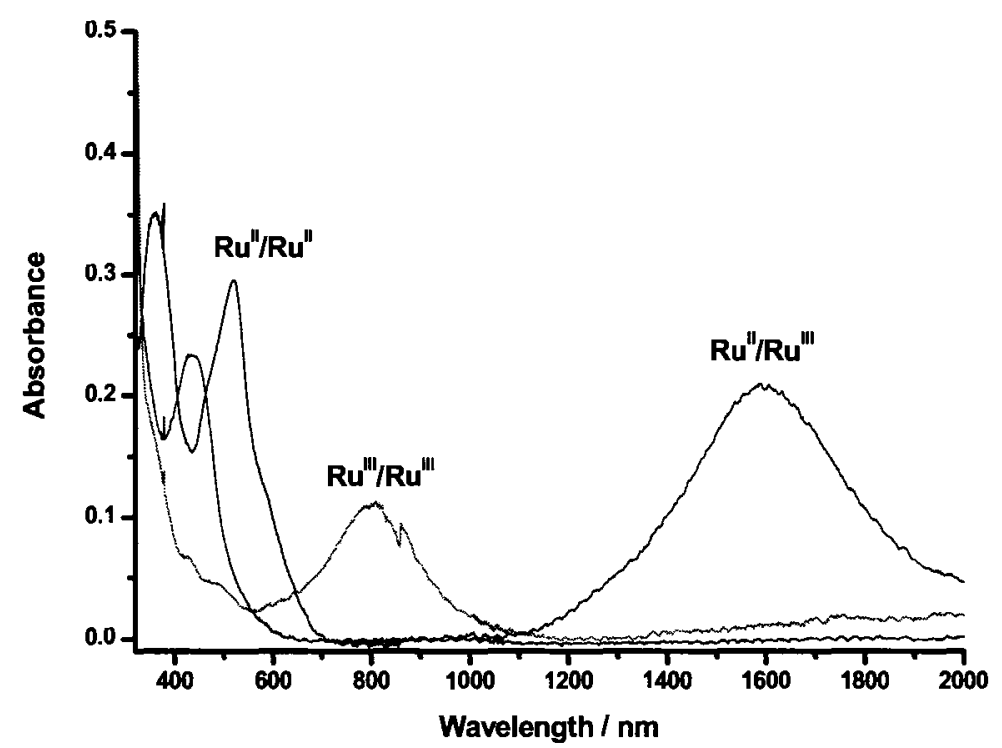

Figure II.4. UV-vis-NIR spectra of DCH-Ru complex $2 \mathrm{~d}(\mathrm{R}=\mathrm{Ph})$ at different oxidation states in 0.1 M TBAH/ACN.

$\mathrm{At}^{\mathrm{Ru}} / \mathrm{Ru} \mathrm{u}^{\mathrm{II}}$ state, the absorption bands around $350 \mathrm{~nm}$ and $510 \mathrm{~nm}$ are assigned to $d\left(\mathrm{Ru}^{\mathrm{II}}\right) \rightarrow \pi^{*}(\mathrm{bpy})$, metal-to-ligand charge transfer (MLCT) transitions. When oxidized to $\mathrm{Ru}^{\mathrm{II}} / \mathrm{Ru}^{\mathrm{III}}$, a broad (from $1000 \mathrm{~nm}$ to over $2000 \mathrm{~nm}$ ) and intense $\left(10^{4} \mathrm{M}^{-1} \mathrm{~cm}^{-1}\right.$ ) appears with peak values ranging from 1540 to $1616 \mathrm{~nm}$, which is attributed to the intervalence transitions, either from metal-to-metal charge transfer (MMCT) transition (localized situation) or different combinations of metal-centered molecular orbitals (delocalized situation) ${ }^{21}$. Due to the little bathochromic shift and high intensity of the NIR band, this transition has been largely attributed to a delocalized situation ${ }^{21}$. It is also 
noticed that the absorption maximum of this band shifts to a shorter wavelength upon increasing the donor effect of the substituent, which can be explained by the hole transfer mechanism proposed by Kaim ${ }^{21}$. The effect of increasing the electron density in the bridge is to destabilize $\mathrm{Ru}^{\mathrm{II}}$ and stabilize $\mathrm{Ru}{ }^{\mathrm{III}}$, resulting in the increase of the energy gap between donor and acceptor metals. At $\mathrm{Ru}^{\mathrm{III}} / \mathrm{Ru}^{\mathrm{III}}$ state, the bands around $800 \mathrm{~nm}$ are assigned to $\mathrm{DCH}$-centred $\pi(\mathrm{DCH})^{2-} \rightarrow d\left(\mathrm{Ru}^{\mathrm{III}}\right)$, ligand-to-metal charge transfer (LMCT) transition.

As shown in table II.3, the DCH-Ru complexes with weak donating-strength substituent (II.1-5) can all be considered as the suitable materials for use in ECVOA as the maxima of their MMCT bands are close to the telecommunication wavelength of $1550 \mathrm{~nm}$.

Table II.3. Optical data of complexes at different oxidative states.

\begin{tabular}{ccccc}
\hline Complex & $\mathrm{R}$ & $\mathrm{Ru}^{\mathrm{II}} / \mathrm{Ru}^{\mathrm{II}}$ & $\begin{array}{c}\lambda_{\max } / \mathrm{nm}\left(\log \left[\varepsilon / \mathrm{M}^{-1} \mathrm{~cm}^{-1}\right]\right) \\
\mathrm{Ru}^{\mathrm{II}} / \mathrm{Ru}^{\mathrm{III}}\end{array}$ & $\mathrm{Ru}^{\mathrm{III}} / \mathrm{Ru}^{\mathrm{III}}$ \\
\hline II.1-Ru & $\mathrm{C}_{5} \mathrm{H}_{10} \mathrm{OH}$ & $353(4.42), 510(4.36)$ & $448(4.20), 1540(4.10)$ & $804(4.10)$ \\
II.2-Ru & $p$-PhOMe & $362(4.50), 502(4.37)$ & $456(4.30), 1579(4.12)$ & $817(3.96)$ \\
II.3-Ru & $p$ - $\mathrm{PhOH}$ & $354(4.42), 505(4.31)$ & $428(4.21), 1600(4.12)$ & $809(3.99)$ \\
II.4-Ru & $\mathrm{Ph}$ & $353(4.49), 517(4.39)$ & $450(4.32), 1590(4.17)$ & $809(3.99)$ \\
II.5-Ru & $p-\mathrm{PhNO}_{2}$ & $354(4.43), 497(4.37)$ & $455(4.28), 1616(4.12)$ & $793(3.84)$ \\
\hline
\end{tabular}

\section{II.5 NIR Electrochromic Variable Optical Attenuator}

\section{II.5.1 Single-Layer Device}

Compared to previously studied dinuclear DCH-Ru complexes ${ }^{24},[\mathrm{G}]-1 \mathrm{DCH}-\mathrm{Ru}$ complexes have some similar properties such as strong NIR absorption around $1550 \mathrm{~nm}$, 
large $K_{c}\left(\sim 1 \times 10^{10}\right)$ and relative low potential $(450-600 \mathrm{mv}$ vs NHE) for the first oxidation. They possess relatively higher molar extinction coefficient and are capable of forming a crosslinked network, which make them readily applicable in a solid device.

A simple single-layer ECVOA device was fabricated by cross-linking II.1-Ru with triisocyanate to form a film on an ITO electrode. The crosslinked film was inert to common organic solvents such as acetone, acetonitrile and DMF without noticeable leaching after 24 hours. The crosslinked film (thickness $=400 \pm 10 \mathrm{~nm}$ ) displays the same electrochemical and electrochromic behaviors as its dendritic complex. In a cell, the crosslinked film coated on ITO glass was switched between $+700 \mathrm{mv}$ to $+1200 \mathrm{mv}$ versus silver electrode in $0.1 \mathrm{M}$ TBAH/ACN solution.

Typically, two parameters, attenuation and switching time, are used to evaluate the performance of an ECVOA. Attenuation is the transmittance difference between bleached and colored state, which is calculated by the equation (2):

$$
\mathrm{A}=10 \times \log \left(T_{b} / T_{c}\right)
$$

where $\mathrm{A}$ is the attenuation in $\mathrm{dB}, T_{b}$ is the transmittance of the bleached state and $T_{c}$ is the transmittance of the colored or NIR-absorbing state. Switching speed is the time required to achieve the conversion between the two states. At a switching speed of $2 \mathrm{~s}$ for $90 \%$ conversion, a maximum attenuation of $2.0 \mathrm{~dB}$ at $1550 \mathrm{~nm}$ was achieved, which translates to an intrinsic attenuation value of $4.9 \mathrm{~dB} / \mathrm{m}$ for the film. When the switching speed was set at $3 \mathrm{~s}$, a full conversion was reached, leading to a maximum attenuation of $2.7 \mathrm{~dB}$ or $6.8 \mathrm{~dB} / \mathrm{m}$ for the film.

Color efficiency (CE) is another key parameter to evaluate an EC device. It is determined by the injected/ejected charge per unit electrode area $(\Delta Q)$ and the change in 
optical density $(\triangle \mathrm{OD})$ during a redox step of the device. The $\mathrm{CE}$ at the specified wavelength is expressed $\mathrm{as}^{27}$ :

$$
\mathrm{CE}(\lambda)=\Delta \mathrm{OD}(\lambda) / \Delta Q=\log \left(T_{b} / T_{c}\right) / \Delta Q
$$

A high CE value means that the device can provide a large optical modulation with a small charge insertion or ejection. It is a crucial parameter for practical EC devices because long-term cycling stability may be enhanced by using a lower charge insertion or ejection rate. The electrochromic efficiency at $1550 \mathrm{~nm}$ of the crosslinked film was measured to be $238 \mathrm{~cm}^{2} / \mathrm{C}$. This value is higher than some known electrochromic materials ${ }^{28}$.

\section{II.5.2 Hybrid Single-Layer Device}

For practical applications, the attenuation range of a VOA is required to be more than $20 \mathrm{~dB}$. A single layer device based on the film of II.1-Ru is thus not suitable for its low intrinsic attenuation power $(6.8 \mathrm{~dB} / \mu \mathrm{m})$. Although a thicker film can increase the attenuation range, it will result in a lower switching speed due to longer ion diffusion time. A solution is to combine a canthodic coloring material with the anodic [G]-1 DCH$\mathrm{Ru}$ material to form a double-layer device. Tungsten oxide $\left(\mathrm{WO}_{3}\right)$ is a suitable cathodic EC material with a long-term stability, broad NIR absorption and high coloration efficiency ${ }^{29}$. However, the low CE of thin film of [G]-1 DCH-Ru complex can not match the high $\mathrm{CE}$ and high charge density of polycrystalline thin film of $\mathrm{WO}_{3}{ }^{30}$. Hence, we designed a hybrid single-layer device with $\mathrm{WO}_{3}$ on an electrode and the ruthenium complex in an electrolyte solution to solve the problem of mismatch. 


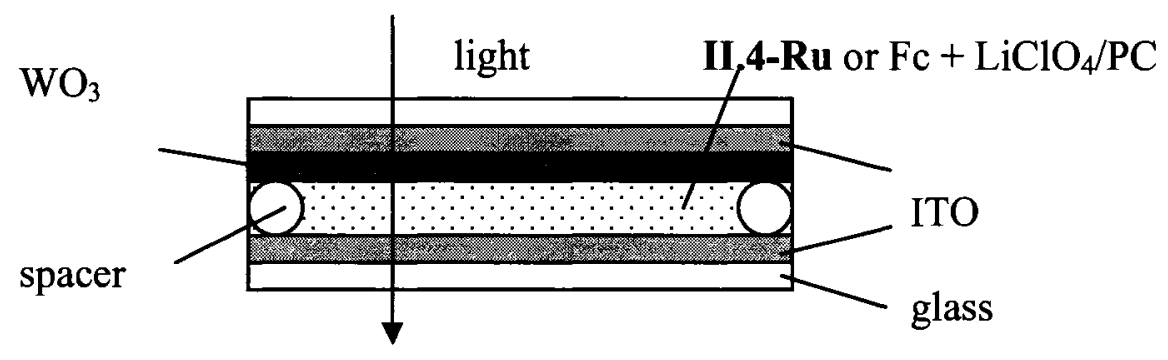

Figure II.5. NIR ECVOA device configuration.

The configuration of the hybrid ECVOA device is shown in figure II.5. Complex II.4-Ru was selected for its highest molar extinction coefficient $\left(1.41 \times 10^{4} \mathrm{M}^{-1} \mathrm{~cm}^{-1}\right)$. The electrolyte solution was made of $0.1 \mathrm{M} \mathrm{LiClO}_{4}$ in propylene carbonate (PC). For a comparison, a NIR-inactive EC material, ferrocene $(\mathrm{Fc})$, was also used in another ECVOA device. The $\mathrm{WO}_{3}$ film can be made by electrodepostion, sol-gel, CVD, vacuum vapor deposition and sputtering methods ${ }^{31}$. The $\mathrm{WO}_{3}$ coated ITO glass was made by vacuum vapor deposition. Figure II.6 shows the X-ray pattern of $\mathrm{WO}_{3}$ on ITO glass and blank ITO glass. The three peaks at $21.3^{\circ}, 30.3^{\circ}$ and $35.3^{\circ}$ belong to the (200), (201), (221) planes of $\mathrm{WO}_{3}$ film, which is in line with reference for polycrystalline $\mathrm{WO}_{3}{ }^{32}$.

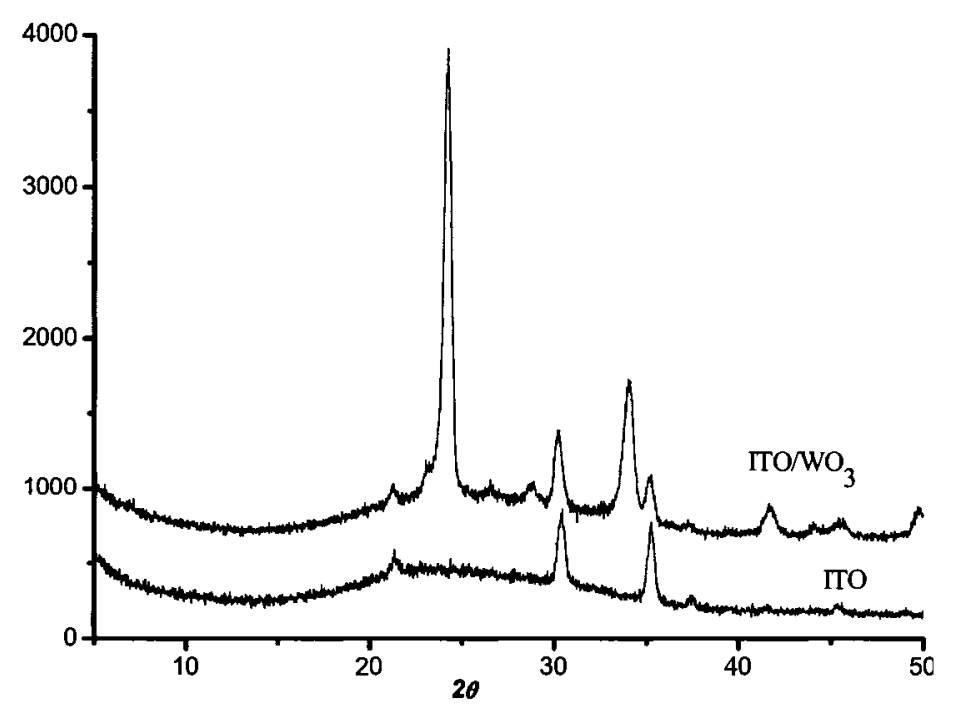

Figure II.6. The X-ray pattern of ITO/ $\mathrm{WO}_{3}$ and blank ITO glass. 


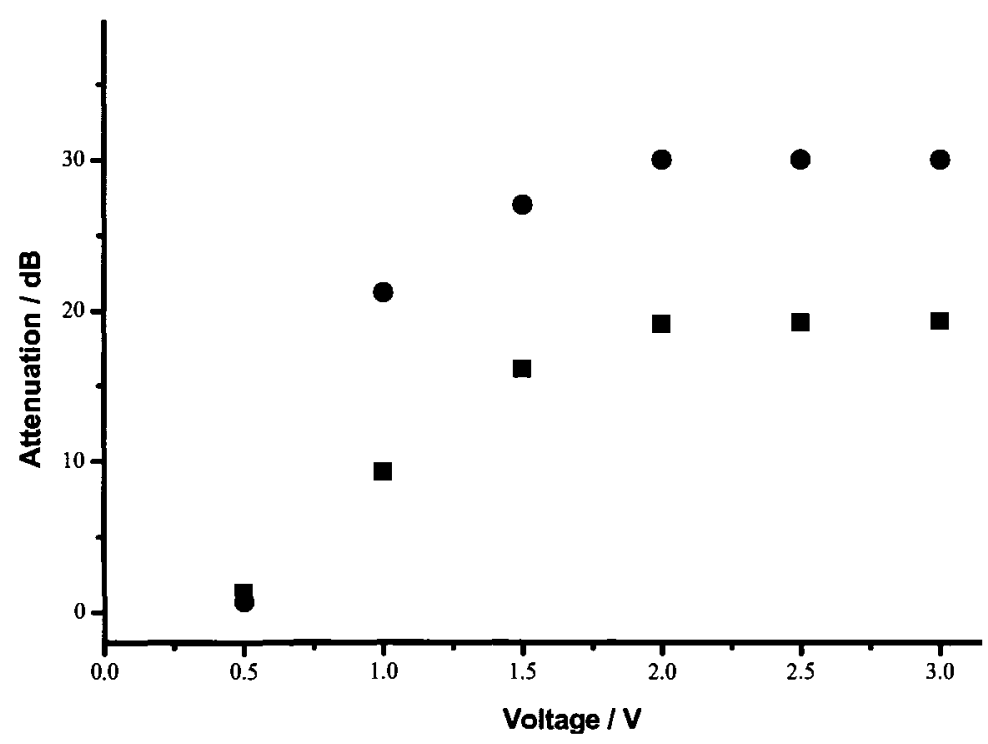

Figure II.7. The relation between the applied voltage and attenuation at $1550 \mathrm{~nm}$ of device A: ITO / $\mathrm{WO}_{3}$ / Fc / ITO (ロ) and B: ITO / $\mathrm{WO}_{3}$ / DCH-Ru / ITO $(\bullet)$.

Figure II.7 illustrates the relation between the applied voltage and the optical attenuation at $1550 \mathrm{~nm}$ of devices A (ITO / $\left.\mathrm{WO}_{3} / \mathrm{Fc} / \mathrm{ITO}\right)$ and $\mathrm{B}\left(\mathrm{ITO} / \mathrm{WO}_{3} / \mathrm{DCH}-\right.$ $\mathrm{Ru} / \mathrm{ITO}$ ). Ferrocene was used as a blank reference to show the effect of DCH-Ru on device performance because it has no NIR absorption. Under $0.5 \mathrm{~V}$, the attenuation of devices $\mathrm{A}$ and $\mathrm{B}$ is $1.3 \mathrm{~dB}$ and $0.7 \mathrm{~dB}$, respectively. They are almost the same because under $0.5 \mathrm{~V}$, the [G]-1 DCH-Ru complex can not be electrochemically oxidized to its $\mathrm{Ru}^{\mathrm{II}} / \mathrm{Ru}{ }^{\mathrm{III}}$ state that has NIR absorption at $1550 \mathrm{~nm}$. When the applied voltage is higher than $0.5 \mathrm{~V}$, the attenuation ranges of both devices increase with the increase of voltage until they reach a plateau above $2.0 \mathrm{~V}$ where the attenuations of device A and B are 19.1 $\mathrm{dB}$ and $30.0 \mathrm{~dB}$, respectively. These results demonstrate that the operation voltage of the device should not be lower than $2.0 \mathrm{~V}$ and the attenuation power of device $\mathrm{B}$ is about $50 \%$ larger than that of the ferrocene-containing device A. The transmittance vs time 
curves of devices $\mathrm{A}$ and $\mathrm{B}$ under $2.0 \mathrm{~V}$ are shown in figure II.8. Both devices reach full response within $100 \mathrm{~s}$ and give the attenuation of $19.1 \mathrm{~dB}$ and $30.0 \mathrm{~dB}$, respectively. The response times for both devices to reach $90 \%$ of total conversion are $2.5 \mathrm{~s}$ and $5.4 \mathrm{~s}$, respectively.

The injected charge was measured to be $7.81 \times 10^{-2} \mathrm{C}$ and $2.97 \times 10^{-2} \mathrm{C}$ for devices $\mathrm{A}$ and $\mathrm{B}$, respectively. With the active area of $1.2 \mathrm{~cm}^{2}$ for each device, the charge densities are calculated to be $6.51 \times 10^{-2} \mathrm{C} / \mathrm{cm}^{2}$ and $2.48 \times 10^{-2} \mathrm{C} / \mathrm{cm}^{2}$ for devices $\mathrm{A}$ and B, respectively. Accordingly, with the measured $\triangle \mathrm{OD}$ (at $1550 \mathrm{~nm}$ ) of 1.91 and 3.01, the color efficiency of devices A and B are calculated to be $29.2 \mathrm{~cm}^{2} / \mathrm{C}$ and $121.2 \mathrm{~cm}^{2} / \mathrm{C}$, respectively. This shows that the ruthenium complex as a counter electrode NIR EC material contributes to larger optical attenuation and higher color efficiency in device B. The stability and reversibility of device $\mathrm{B}$ is evaluated by the long-term attenuating ability. After 18 cycles, the dynamic attenuation range dropped $9 \%$, but kept steady afterwards.

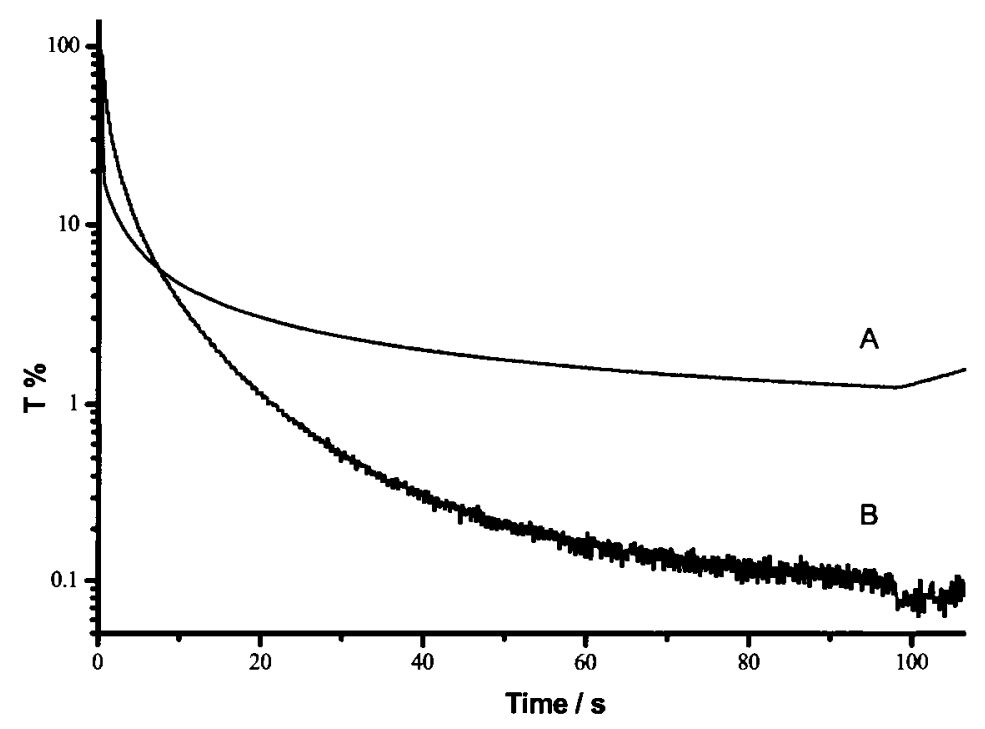

Figure II.8. The transmittance vs time curves of devices A and B under 2.0V. 
Because the electrochemical reduction of DCH-Ru complex is faster than electrochemical oxidation for this "rechargeable battery type of device", the reduction voltage should be lower than the oxidation voltage. Otherwise, the time for electrochemical oxidation or NIR-color bleaching will be very long (several hours) and the device will show a poor reversibility.

\section{II.6 Conclusion}

In this work, a series of [G]-1 DCH-Ru complexes with excellent NIR electrochromic $(\sim 1550 \mathrm{~nm})$ properties have been obtained. A fine tuning of the electrochemical and optical properties of the complexes has been achieved by changing the electron-donating nature of the substituents. The electrochemical properties that are affected by the substituents are correlated well using the Hammett parameters. Two electrochromic VOA devices (simple and hybrid single-layer devices) have been demonstrated. The higher dynamic range of optical attenuation of the hybrid device indicates that the mismatch of the charge density between $\mathrm{WO}_{3}$ and the crosslinked DCH-Ru complex film can be largely reduced by using relatively high concentration of DCH-Ru complex in solution. In a hybrid ECVOA, a dynamic attenuation range as high as $30 \mathrm{~dB}$ has been obtained.

\section{II.7 Experimental Section}

\section{Materials}

All the chemicals were purchased from Sigma-Aldrich Canada Ltd. and used as supplied. Spectroscopic grade acetonitrile was used in the UV-vis-NIR spectroscopicy 
and cyclic voltammetric measurements. Cis- $\mathrm{Ru}(\mathrm{bpy})_{2} \mathrm{Cl}_{2} \cdot 2 \mathrm{H}_{2} \mathrm{O}$ was prepared according to the literature method. ${ }^{33}$ ITO glass was purchased form Delta Technology Company.

\section{Synthesis of 6-Hydroxyhexanoic Hydrazide}

To a solution of hydrazine hydrate $(5 \mathrm{~mL}, 0.1 \mathrm{~mol})$ in DMF $(5 \mathrm{~mL})$ was added $\varepsilon$ caprolactone $(5.5 \mathrm{~mL}, 0.05 \mathrm{~mol})$ dropwise at room temperature. After stirring for $1 \mathrm{~h}$, the resultant white precipitate was collected by filtration and washed with hot acetone twice to give a white powder $\left(5.8 \mathrm{~g}, 81 \%\right.$ yield). $\mathrm{mp} 115-116{ }^{\circ} \mathrm{C} ;{ }^{1} \mathrm{H}$ NMR (200 MHz, DMSO$\left.d_{6}\right): \delta / \mathrm{ppm} 8.90(\mathrm{~s}, 1 \mathrm{H}), 4.35($ tri, $1 \mathrm{H}, \mathrm{J}=6.6 \mathrm{~Hz}), 4.12(\mathrm{~s}, 2 \mathrm{H}), 3.36($ tri, $2 \mathrm{H}), 1.98($ tri, $2 \mathrm{H}, \mathrm{J}=7.5 \mathrm{~Hz}), 1.42-1.26(\mathrm{~m}, 6 \mathrm{H}) . \mathrm{IR}(\mathrm{KBr}, \mathrm{cm}-1): 3311\left(v_{\mathrm{N}-\mathrm{H}}\right), 1642\left(v_{\mathrm{C}=0}\right), 1536.6$ $\left(\mathfrak{K}_{\mathrm{N}-\mathrm{H}}\right) ; \mathrm{MS}(\mathrm{ESI}, \mathrm{m} / \mathrm{z})$ found (nature of the peak, relative intensity): $147\left(\mathrm{M}+\mathrm{H}^{+}, 44\right)$.

\section{General procedure for the preparation of [G]-1 ligands II.1-5}

To a solution of one of the acid hydrazides $(0.03 \mathrm{~mol})$ and potassium carbonate $(4.2 \mathrm{~g}, 0.03 \mathrm{~mol})$ in $160 \mathrm{ml}$ of water-THF (3:1) was added a solution of $1,3,5-$ benzenetricarboxylic acid trichloride $(2.66 \mathrm{~g}, 0.01 \mathrm{~mol})$ in THF $(20 \mathrm{~mL})$ with stirring. The reaction mixture was stirred for $1-3 \mathrm{~h}$. The resulting solid was collected by filtration, washed with water and dried. Recrystallization from dimethylsulfoxide-water $(1: 1$ in volume) gave the products as white powders.

\section{1,3,5-Benzenetricarboxylic tris[2-(6-hydroxyhexano)hydrazide)] (II.1)}

IR $\left(\mathrm{KBr}, \mathrm{cm}^{-1}\right): 3221\left(v_{\mathrm{N}-\mathrm{H}}\right), 2937,2862\left(v_{\mathrm{C}-\mathrm{H}}\right), 1649\left(v_{\mathrm{C}=\mathrm{O}}\right), 1612\left(v_{\mathrm{C}=\mathrm{C}}\right), 1055\left(v_{\mathrm{C}-\mathrm{O}}\right)$; ${ }^{1} \mathrm{HNMR}\left(300 \mathrm{MHz}, \mathrm{DMSO}-d_{6}\right)$ 8/ppm: 10.57 (s, 3H), 9.98 (s, 3H), 8.50 (s, 3H), 4.37 (s, 
3H), 3.39 (tri, $6 \mathrm{H}, \mathrm{J}=6 \mathrm{~Hz}), 2.20($ tri, $6 \mathrm{H}, \mathrm{J}=6 \mathrm{~Hz}), 1.56(\mathrm{~m}, 6 \mathrm{H}), 1.44(\mathrm{~m}, 6 \mathrm{H}), 1.35(\mathrm{~m}$, $6 \mathrm{H}) ;{ }^{13} \mathrm{C}$ NMR (100 MHz, DMSO- $\left.d_{6}\right) \delta / \mathrm{ppm}: 171.9,164.9,133.8,130.0,61.1,33.8,32.7$, 25.6, 25.5; MS (ESI, $\mathrm{m} / \mathrm{z}$ ) found (nature of the peak, relative intensity): $595\left(\mathrm{M}+\mathrm{H}^{+}\right.$, 1.2).

\section{1,3,5-Benzenetricarboxylic tris[2-(4-Methoxybenzoyl)hydrazide)] (II.2)}

IR $\left(\mathrm{KBr}, \mathrm{cm}^{-1}\right): 3255\left(v_{\mathrm{N}-\mathrm{H}}\right), 1647\left(v_{\mathrm{C}=\mathrm{O}}\right), 1608,1500\left(v_{\mathrm{C}=\mathrm{C}}\right), 1259\left(v_{\mathrm{C}-\mathrm{o}}\right) ;$ m.p. $;{ }^{1} \mathrm{HNMR}$ $\left(300 \mathrm{MHz}, \mathrm{DMSO}-d_{6}\right) \delta / \mathrm{ppm}: 10.78(\mathrm{~s}, 3 \mathrm{H}), 10.51(\mathrm{~s}, 3 \mathrm{H}), 8.64(\mathrm{~s}, 3 \mathrm{H}), 7.94(\mathrm{~d}, 6 \mathrm{H}, \mathrm{J}=9$ $\mathrm{Hz}), 7.07(\mathrm{~d}, 6 \mathrm{H}, \mathrm{J}=9 \mathrm{~Hz}), 3.84(\mathrm{~s}, 9 \mathrm{H}) ;{ }^{13} \mathrm{C}$ NMR $\left(100 \mathrm{MHz}, \mathrm{DMSO}-d_{6}\right) \delta / \mathrm{ppm:} \mathrm{165.7,}$ $165.5,162.6,134.1,130.1,129.9,125.0,114.2,55.9 ; \mathrm{MS}(\mathrm{ESI}, \mathrm{m} / \mathrm{z})$ found (nature of the peak, relative intensity): $655\left(\mathrm{M}+\mathrm{H}^{+}, 0.2\right)$.

\section{1,3,5-Benzenetricarboxylic tris[2-(4-hydroxybenzoyl)hydrazide)] (II.3)}

IR $\left(\mathrm{KBr}, \mathrm{cm}^{-1}\right): 3254\left(v_{\mathrm{N}-\mathrm{H}}\right), 1647\left(v_{\mathrm{C}=\mathrm{O}}\right), 1608,1502\left(v_{\mathrm{C}=\mathrm{C}}\right), 1267\left(v_{\mathrm{C}-\mathrm{N}}\right) ;{ }^{1} \mathrm{HNMR}(300$ MHz, DMSO-d $\left.{ }_{6}\right) \delta / \mathrm{ppm}: 10.73(\mathrm{~s}, 3 \mathrm{H}), 10.38(\mathrm{~s}, 3 \mathrm{H}), 10.25(\mathrm{~s}, 3 \mathrm{H}), 8.63(\mathrm{~s}, 3 \mathrm{H}), 7.82(\mathrm{~d}$, $6 \mathrm{H}, \mathrm{J}=6 \mathrm{~Hz}), 6.86(\mathrm{~d}, 6 \mathrm{H}, \mathrm{J}=6 \mathrm{~Hz}) ;{ }^{13} \mathrm{C} \mathrm{NMR}\left(100 \mathrm{MHz}, \mathrm{DMSO}-d_{6}\right) \delta / \mathrm{ppm}: 165.9$, $165.5,161.2,134.1,130.1,130.0,123.5,115.5 ; \mathrm{MS}(\mathrm{ESI}, \mathrm{m} / \mathrm{z})$ found (nature of the peak, relative intensity): $613\left(\mathrm{M}+\mathrm{H}^{+}, 0.7\right)$.

\section{1,3,5-Benzenetricarboxylic tris[2-benzoylhydrazide)] (II.4)}

IR $\left(\mathrm{KBr}, \mathrm{cm}^{-1}\right): 3255\left(v_{\mathrm{N}-\mathrm{H}}\right), 1649\left(v_{\mathrm{C}=\mathrm{O}}\right), 1608,1502\left(v_{\mathrm{C}=\mathrm{C}}\right), 1267\left(v_{\mathrm{C}-\mathrm{N}}\right) ;{ }^{1} \mathrm{HNMR}(300$ MHz, DMSO- $\left.d_{6}\right) \delta / p p m: 10.87(\mathrm{~s}, 3 \mathrm{H}), 10.67(\mathrm{~s}, 3 \mathrm{H}), 8.66(\mathrm{~s}, 3 \mathrm{H}), 7.96(\mathrm{~d}, 6 \mathrm{H}, \mathrm{J}=7.2$

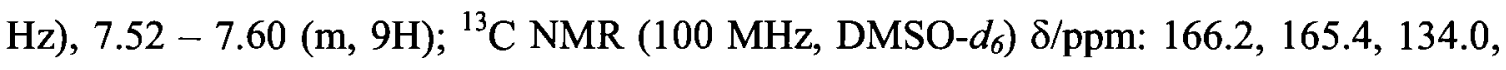


$132.9,132.4,130.2,129.0,128.0 ; \mathrm{MS}(\mathrm{ESI}, \mathrm{m} / \mathrm{z})$ found (nature of the peak, relative intensity): $565\left(\mathrm{M}+\mathrm{H}^{+}, 2.3\right)$.

\section{1,3,5-Benzenetricarboxylic tris[2-(4-nitrobenzoyl)hydrazide)] (II.5)}

IR $\left(\mathrm{KBr}, \mathrm{cm}^{-1}\right): 3254\left(v_{\mathrm{N}-\mathrm{H}}\right), 1653\left(v_{\mathrm{C}=\mathrm{O}}\right), 1600\left(v_{\mathrm{C}=\mathrm{C}}\right), 1525,1350\left(v_{\mathrm{N}-\mathrm{O}}\right), 1263\left(v_{\mathrm{C}-\mathrm{N}}\right)$;

${ }^{1} \mathrm{HNMR}\left(300 \mathrm{MHz}\right.$, DMSO-d $d_{6}$ ) $\delta / \mathrm{ppm}: 11.03$ (s, 6H), 8.67 (s, 3H), 8.40 (d, 6H, J = $9 \mathrm{~Hz}$ ), $8.18(\mathrm{~d}, 6 \mathrm{H}, \mathrm{J}=9 \mathrm{~Hz}) ;{ }^{13} \mathrm{C}$ NMR $\left(100 \mathrm{MHz}, \mathrm{DMSO}-d_{6}\right) \delta / \mathrm{ppm}: 165.3,164.7,149.9$, $138.5,130.4,129.5,124.3 ; \mathrm{MS}(\mathrm{ESI}, \mathrm{m} / \mathrm{z})$ found (nature of the peak, relative intensity): not found.

\section{General procedure for the preparation of [G]-1 DCH-Ru complexes II.(1-5)-Ru}

To a solution of [G]-1 ligand $(0.063 \mathrm{mmol})$ and sodium carbonate $(50 \mathrm{mg}, 0.5$ mmol) in a mixture of water/ethanol (5/1 v:v, $80 \mathrm{ml})$ were added 3 equivalents of cis$\mathrm{Ru}(\mathrm{bpy})_{2} \mathrm{Cl}_{2} \cdot 2 \mathrm{H}_{2} \mathrm{O}(0.20 \mathrm{~g}, 0.38 \mathrm{mmol})$ with stirring. The solution was heated to reflux for $48 \mathrm{~h}$ under argon. After cooling to room temperature, $1.00 \mathrm{~g}$ of ammonium hexafluorophosphate in $40 \mathrm{~mL}$ of water was added to afford red dark precipitate. The precipitate was filtered off, redissolved in acetone $(20 \mathrm{~mL})$ and precipitated into diethyl ether. The product was further purified by column chromatography with acetonitrile on acidic alumina and dried under vacuum. 


\section{Measurements}

The NMR spectra were obtained at room temperature on a Varian Gemini 200 and a Bruker AMX-400 NMR spectrometer, using deuterated dimethylsulfoxide (DMSO$\mathrm{d}_{6}$ ) as solvents with $1 \%$ tetramethylsilane (TMS) as an internal standard. The chemical shifts were reported in $\delta(\mathrm{ppm})$ to TMS. IR spectra were recorded using $\mathrm{KBr}$ pellets of the compound and collected with an ABB Bomem Michelson-100 FT-IR spectrometer.

Cyclic voltammetry (CV) was performed using a BAS100B/W electrochemical station interfaced and monitored with a PC computer. The standard three-electrode configuration was composed by a platinum as working electrode, a platinum wire as counter electrode, and a silver wire as reference electrode. The silver pseudo-reference electrode was calibrated with a ferrocene/ferrocenium $\left(\mathrm{Fc} / \mathrm{Fc}^{+}\right)$redox couple, and the potentials were reported respect to the normal hydrogen electrode (NHE). tetra- $n$ butylammonium hexafluorophosphate $(\mathrm{TBAH})$ in acetonitrile $(0.1 \mathrm{M})$ as a supporting electrolyte was used for all electrochemical measurements. All the solutions were deoxygenated with argon prior to electrochemical measurements.

Spectroelectrochemical measurements were carried out by combinating the electrochemical station with a Perkin Elmer Lambda 900 UV-vis-NIR spectrometer. The optical attenuation was monitored at $1550 \mathrm{~nm}$. Spectroelectrochemistry in solutions was performed using an OTTLE cell. ${ }^{34}$

\section{Fabrication of Hybrid and Single-layer ECVOA Devices}

The $\mathrm{WO}_{3}$ film was vacuum deposited onto clean ITO glass under dynamic vacuum of $10^{-4} \mathrm{~Pa}$. The film thickness is controlled by quartz oscillator to be about 300 
$\mathrm{nm}$. Then the film was annealed at $450^{\circ} \mathrm{C}$ for 30 minutes to form a polycrystalline film. The structure of film was characterized by X-ray diffraction.

The optical attenuator is of transmittance type and fabricated as follows: The ITO/ $\mathrm{WO}_{3}$ glass and a clean ITO glass were assembled together with clips and a $125 \mu \mathrm{m}$ polyethylene sheet as spacer. Then the solution of ferrocene ( $\mathrm{Fc})$ or ruthenium complex $(1.0 \mathrm{mM})$ was injected into the cell gap. The ECVOA device was characterized using BAS100B/W electrochemistry workstation and Perkin Lambda 900 UV-vis-NIR spectrometer. The spectrometer was used to measure the change of transmittance of the device under square wave or constant voltage applied by electrochemistry workstation. 


\section{References}

1. Kawai, T.; Koga, M.; Okuno, M.; Kitoh, T. Electron. Lett. 1998, 34, 263.

2. Barber, B.; Giles, C. R.; Askyuk, V.; Ruel, R.; Stulzl, L.; Bishop, D. IEEE Photo. Techno.l Lett. 1998, 10, 1262.

3. Jin, Y. S.; Lee, S. S.; Son, Y. S. Electron. Lett. 1998, 35, 916.

4. Cowin, M. A.; Varrazza, R.; Morgan, C.; Penty, R. V.; White, I. H.; McDonagh, A. M.; Bayly, S.; Riley, J.; Ward, M. D.; McCleverty, J. A. Trends Opt. Photonics 2001, 54, WR6/1.

5. Barber, B.; Giles, C. R.; Askyuk, V.; Ruel, R.; Stalz, L.; Bishop, D. IEEE Photon. Technol. Lett. 1998, 10, 1262.

6. Ford, J. E.; Walker, J. A.; Greywall, D. S.; Goossen, K. W. J. Lightwave Technol. 1998, 16, 1663.

7. Fan, Y. H.; Lin, Y. H.; Ren, H.; Gauza, S.; Wu, S. T. Appl. Phys. Lett. 2004, 84, 1233.

8. Wu, Y. H.; Lin, Y. H.; Lu, Y. Q.; IDE, M.; Suguro, A.; Hosaka, Y.; Katsunuma, A.; Takahashi, K.; Shiraishi, A. Opt. Review 2004, 11, 132.

9. Ren, Q. W.; Fan, Y. H.; Wu, J. R.; Wu, S. T. Proc. SPIE 2005, 5936, 59360J/1.

10. Kawai, T.; Koga, M.; Okuno, M.; Kitoh, T. Electron. Lett. 1998, 34, 264.

11. Lee, S. S.; Jin, Y. S.; Son, Y. S. J. Lightwave Technol. 1999, 17, 2556.

12. Cui, H. N. ; Costa, M. F.; Teixeira, V.; Porqueras, I.; Bertran, E. Surf. Sci. 2003, 532,1127

13. Mortimer, R. J. Chem. Soc. Rev. 1997, 26,147.

14. Pages, H.; Topart, P.; Lemordant, D. Electrochim Acta 2001, 46, 2137. 
15. Zhang, J. D.; Yu, H. A.; Wu, X. G.; Wang, Z. Y. Opt. Mater. 2004, 27, 265.

16. Vergaz, R.; Barrios, D.; Sanchez-Pena, J. M.; Vazquez, C. Pozo-Gonzalo, C.; Mecerreyes, D.; Pomposo, J. Proc. SPIE 2005, 5840, 389.

17. Grenier, C. R. G.; Reynolds, J. R. Adv. Funct. Mater. 2007, 17, 1480.

18. Joulié, L. F.; Schatz, E.; Ward, M. D.; Weber, F.; Yellowlees, L. J. J. Chem. Soc. Dalton Trans. 1994, 5, 799

19. Harden, N. C.; Humphrey, E. R.; Jeffery, J. C.; Lee, S. M.; Marcaccio, M.; McCleverty, J. A.; Rees, L. H.; Ward, M. D. J. Chem. Soc. Dalton Trans. 1999, 15 , 2417

20. Kaim, W.; Kasack, V.; Binder, H.; Roth, E.; Jordanov, J. Angew. Chem., Int. Ed. Engl. 1988, 27, 1174.

21. Kasack, V.; Kaim, W.; Binder, H.; Jordanov, J.; Roth, E. Inorg. Chem. 1995, 34, 1924.

22. Ward, M. D. Chem. Soc. Rev. 1995, 24, 121.

23. Creutz, C.; Taube, H. J. Am. Chem. Soc. 1973, 95, 1086.

24. Qi, Y.; Desjardins, P.; Wang, Z. Y. J. Opt. A: Pure Appl. Opt. 2002, 4, S273.

25. Tashtoush, H.; Subaihi, R.; Al-Talib, M. Magn. Reson. Chem. 1997, 35, 549.

26. Hansch, C.; Leo, A. and Taft, R. W. Chem. Rev. 1991, 91, 165.

27. Bange, K.; Gambke, T. Adv. Mater. 1990, 2, 10.

28. Schwendeman, I.; Hwang, J.; Welsh, D. M.; Tanner, D. B.; Reynolds, J. R. $A d v$. Mater. 2001, 13, 634 .

29. Wang, Z. Y.; Zhang, J.; Wu, X.; Birau, M.; Yu, G.; Yu, H.; Qi, Y.; Desjardins, P.; Meng, X.; Gao, J. P.; Todd, E.; Song, N.; Bai, Y.; Beaudin, A. M. R.; LeClair, G. 
Pure Appl. Chem. 2004, 76, 1435.

30. Qi, Y. H.; Wang, Z. Y., Macromolecules 2003, 36, 3146.

31. Granqvist, C. G. Electrochimica Acta 1999, 44, 3005.

32. Sun, H. T.; Cantalini, C.; Lozzi, L.; Passacantando, M.; Santucci, S.; Pelino, M. Thin Solid Films 1996, 287, 258.

33. Sullivan, B.; Salmon, D.; Meyer, T. Inorg. Chem. 1978, 17, 3334.

34. Kejecik, M.; Danek, M.; Hartl, H. J. Electroanal. Chem. 1991, 317, 179. 


\section{Chapter III Synthesis and Characterization of Biurea-Ruthenium Complex Monomers, Dimers and Polymers}

\section{III.1 Introduction}

A ligand polymer refers to a linear or branched polymer that is able to form complexes with metals. By complexation of ligand polymers, the complex polymers will have the physical, chemical and mechanical properties imparted by the metal complex and the polymer. Depending on the position of the ligand fragment in polymer, metal complexes can be introduced into a polymer chain as part of the main chain or pendent groups $^{1}$. As incorporation of metal complex in polymer main chain will greatly change photophysical properties of the polymer, the metal complex polymers generally find applications in optoelectronics such as OLED, transistors and solar cells.

As the complexation of a metallic compound with a ligand polymer can be conducted in the same manner as that to form a small complex, much effort of the research on this type of polymers has focused on the design of ligand polymers. The well known ligand has is widely used in metal-containing polymers is 2,2 '-bipyridyl. Some of 2,2'-bipyridyl ligand polymers are shown in scheme III. $^{2-6}$. Bipyridyl ruthenium complexes are widely used and incorporated into polymers.

As for the DCH ligand we are interested in, it can be found as a component in a large number of potential ligand polymers, such as polyhydrazides ${ }^{7,8}$ and polybiureas ${ }^{9}$. The former can be prepared by treating the same molar equivalents of hydrazine or a dihydrazide and an acid chloride in n-methyl-2-pyrrolidone (NMP); the latter can be prepared from hydrazine and a diisocyanate (Scheme III.2). 


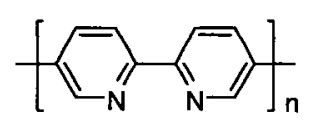

(a)

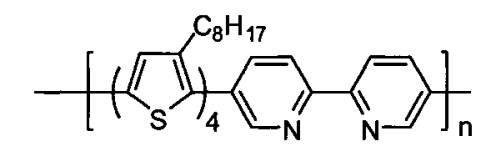

(b)

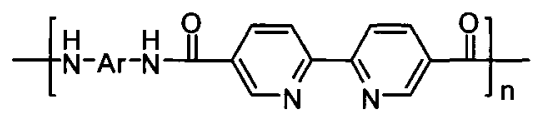

(d)

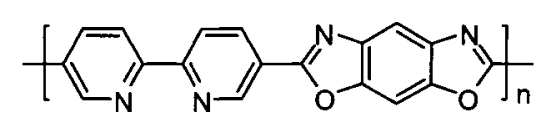

(c)

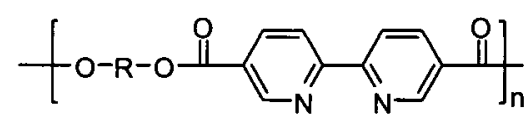

(e)

Scheme III.1. (a) Poly(2,2'-bipyridine-5,5'-diyl), ${ }^{2}$ (b) Copolymer with quarter(3octylthiophene), ${ }^{3}$ (c) Copolymer with benzobisoxazole, ${ }^{4}$ (d) Polyamides, ${ }^{5}$ (e) Polyesters. ${ }^{6}$

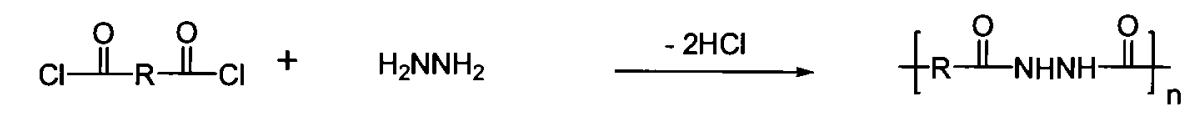

(a)

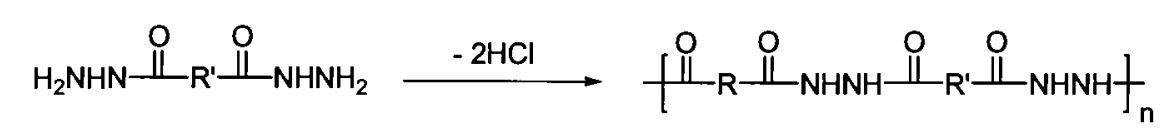$$
\mathrm{OCN}-\mathrm{R}-\mathrm{NCO}+\mathrm{H}_{2} \mathrm{NNH}_{2} \longrightarrow \mathrm{fHN}_{\mathrm{R}-\mathrm{NH}} \stackrel{\mathrm{O}}{-} \mathrm{NHNH}-\stackrel{\mathrm{O}}{f_{n}}
$$

(b)

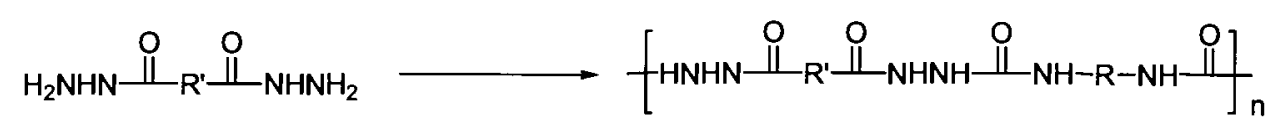

Scheme III.2. General reaction routes to prepare (a) polyhydrazides and (b) polybiurea.

Aliphatic DCH-Ru polymers have been prepared from polyhydrazides in our lab ${ }^{10}$. Good films and high color efficiencies have been achieved from those polymers. However, due to their aliphatic structures, their thermal decomposition temperatures $(5 \%$ wt. loss) are below $210^{\circ} \mathrm{C}$, which limits the use of these materials in high-temperature applications. 
In this thesis work, the ligand polymers based on the aromatic biurea unit will be investigated (Scheme III.2). By design, the complex polymers are expected to have high thermal stability than those based on aliphatic hydrazides. Second, the fragment between each two DCH-Ru units may be oxidized to a conjugated bridge for electron/charge delocalization. Third, oxidation of the central diaminophenylene bridge may produce another electrochromic moiety in the product. Such potential properties make biureacontaing atomic polymers highly interesting to be explored. In addition to the polymer ligand, two model compounds, the monomer and dimer complexes were also designed.

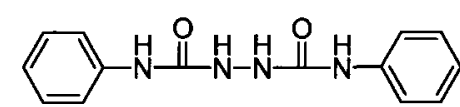

III.1

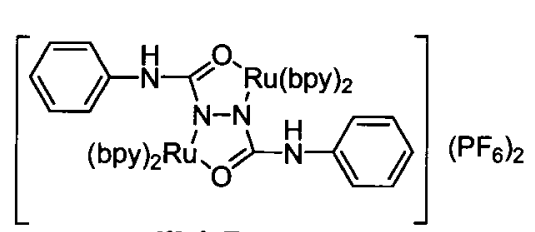

III.1-Ru

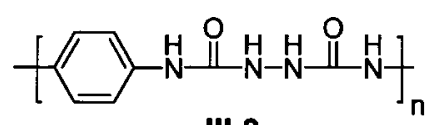

III.3

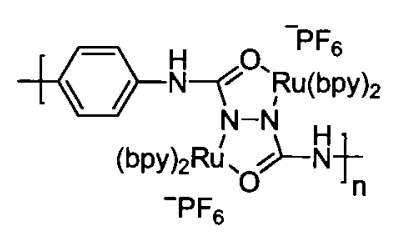

III.3-Ru

Polymer

Monomer

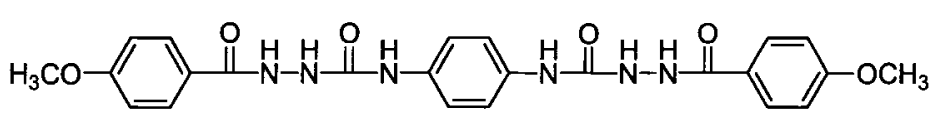

III.2

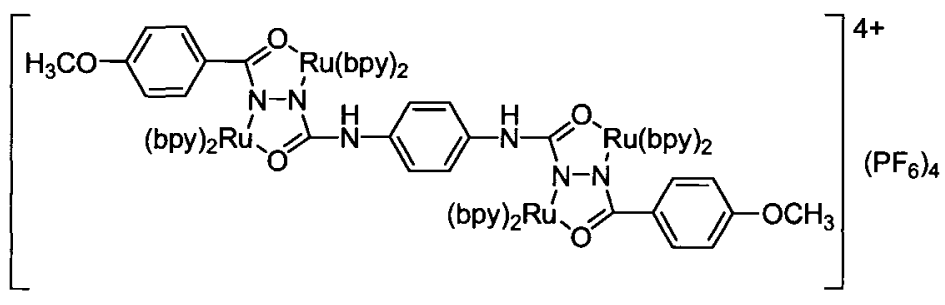

III.2-Ru

Dimer

Scheme III.3. Structures of monomeric, dimeric and polymeric complexes and their Ligands. 


\section{III.2 Results and Discussion}

\section{III.2.1 Complex Monomer}

\section{III.2.1.1 Synthesis and Characterization}

The ligand, 1,6-diphenylbiurea, was synthesized by reacting two equivalents of phenyl isocyanate with 1 equivalent of hydrazine hydrate in THF. Its IR spectrum is characterized by strong bands at 3298 and $3222 \mathrm{~cm}^{-1}$ due to the two different NH groups. The $\mathrm{C}=\mathrm{O}$ bending mode is found at $1670 \mathrm{~cm}^{-1}$. In the ${ }^{1} \mathrm{H}$ NMR spectrum, the peaks at 8.79 and $7.98 \mathrm{ppm}$ are assigned to the two biurea protons; those at $7.50,7.25$ and 6.95 ppm are ascribed to the protons from benzenes. In addition, five peaks in the ${ }^{13} \mathrm{C} N M R$ spectrum at $156.5,140.1,128.9,122.1$ and $119.0 \mathrm{ppm}$ further confirm the structure.

The monomeric complex was prepared and purified following the procedure described previously. This complex appeared to be easily oxidized in the air, resulting in a low yield $(10 \%)$ for the product in the $\mathrm{Ru}^{\mathrm{II}} / \mathrm{Ru}^{\mathrm{III}}$ state. Its ${ }^{\mathrm{l}} \mathrm{N}$ NMR spectrum was not obtained due to the existence of the paramagnetic $\mathrm{Ru}^{\mathrm{III}}$ species.

\section{III.2.1.2 Electrochemical Properties}

The electrochemical properties were examined by cyclic voltammetry (CV). The CV in figure III. 1 reveals three oxidation couples. The first two quasi-reversible couples at 0.22 and $0.78 \mathrm{~V}$ (vs. NHE) are assigned to the successive one-electron oxidation of the $\mathrm{Ru}^{\mathrm{II}} / \mathrm{Ru}^{\mathrm{II}}$ to $\mathrm{Ru}^{\mathrm{III}} / \mathrm{Ru}^{\mathrm{III}}$. Because of the presence of two electron donors, oxidation potentials of the $\mathrm{DCH}-\mathrm{Ru}$ moiety are quite low, making their $\mathrm{Ru}^{\mathrm{II}} / \mathrm{Ru}^{\mathrm{II}}$ and $\mathrm{Ru} \mathrm{u}^{\mathrm{II}} / \mathrm{Ru} \mathrm{u}^{\mathrm{III}}$ states unstable under ambient conditions. The one at the highest potential $(\sim 1.0 \mathrm{~V})$ is due to the oxidation of the NH groups attached to benzenes. This value is comparable to the 
oxidation potential of the amino group in diphenylamine ( 0.63 vs. SCE). This suggests that unlike the amide's $\mathrm{NH}$, the $\mathrm{NH}$ adjacent to the DCH-Ru fragment has some characteristic of the amino group ${ }^{11}$. As the radical cation of the $\mathrm{NH}$ is not stabilized, this redox process is almost irreversible.

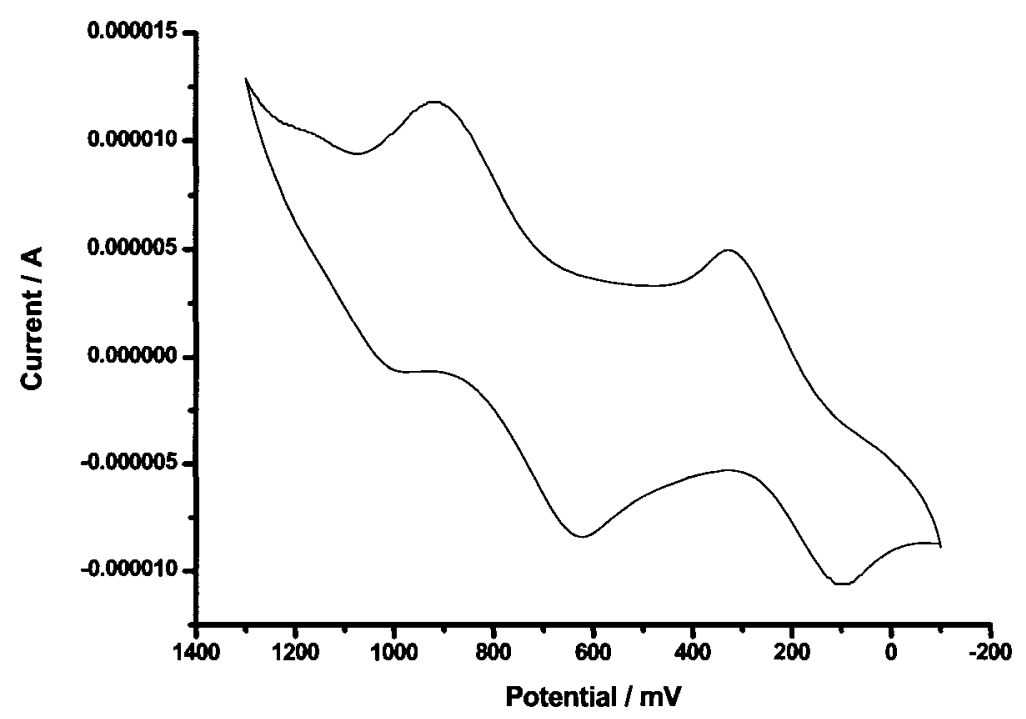

Figure III.1. Cyclic voltammogram of monomer complex (III.1-Ru) in 0.1 M TBAH/ACN (200 mV/s).

\section{III.2.1.3 Spectroelectrochemical Properties}

The UV-vis-NIR absorption of the monomeric complex at different oxidation states was measured in an OTTLE cell. Similar to other DCH-Ru complexes ${ }^{12}$, at the $\mathrm{Ru}^{\mathrm{II}} / \mathrm{Ru}{ }^{\mathrm{II}}$ state III.1-Ru has the two absorption bands at $502 \mathrm{~nm}$ and $389 \mathrm{~nm}$ which are assigned to $d\left(\mathrm{Ru}^{\mathrm{II}}\right) \rightarrow \pi^{*}$ (bpy) MLCT transitions (Figure III.2). Oxidation to the $\mathrm{Ru}^{\mathrm{II}} / \mathrm{Ru}^{\mathrm{III}}$ state (potential $=300 \mathrm{mV}$ ) shifts the bpy centred MLCT transition and results in the appearance of a broad NIR band $\left(\lambda_{\max }=1273 \mathrm{~nm}\right)$ from intervalence transitions. At 
the $\mathrm{Ru}^{\mathrm{III}} / \mathrm{Ru}^{\mathrm{III}}$ state (potential $=900 \mathrm{mV}$ ), an intense band at $840 \mathrm{~nm}$ was observed, which is assigned to the DCH-centred $\pi(\mathrm{DCH})^{2-} \rightarrow d \mathrm{Ru}^{\mathrm{III}}$ LMCT transition.

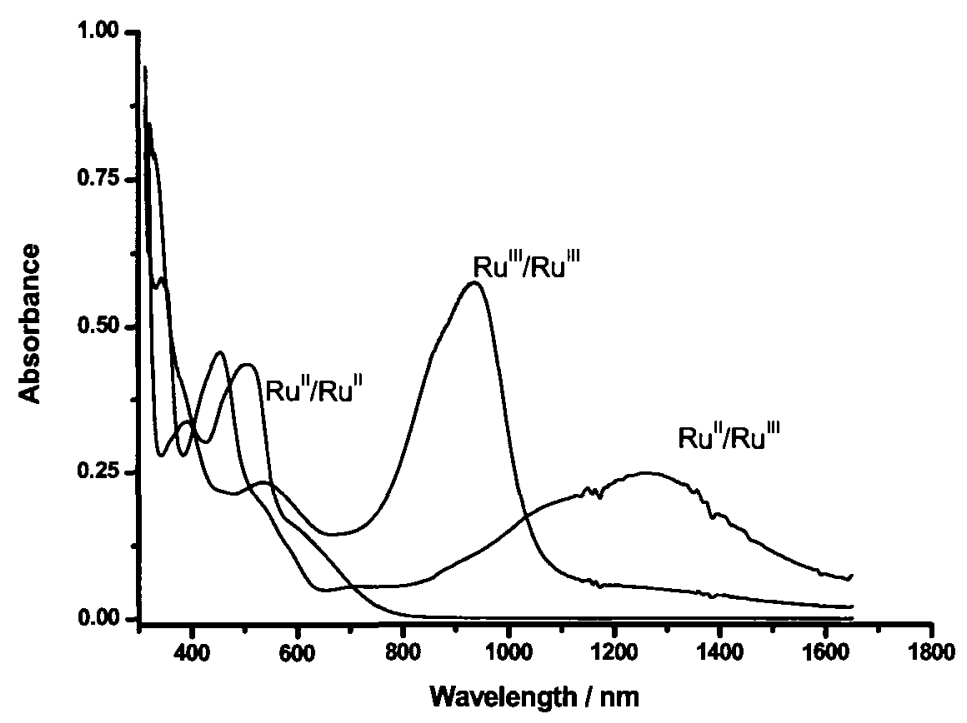

Figure III.2. Spectroelectrochemical spectrum of monomer complex (III.1-Ru) in 0.1M TBAH/ACN solution.

\section{III.2.2 Complex Dimer}

To better evaluate the contribution of the central bridge ( $p$-phenylenediamine) to the band gap and electronic communication during redox reactions, a dimeric ligand (III.2) is designed. With an aniline fragment attached to the ends of the DCH moiety, it would be an ideal dimeric ligand. However, the absence of two electron-donating $\mathrm{NH}$ moieties will increase the oxidation potentials of the complex dimer, making it less unstable and easier to be purified. 


\section{III.2.2.1 Synthesis and Characterization}

The dimeric ligand was synthesized in one step by reacting 2 equivalents of 4 methoxybenzohydrazide with 1 equivalent of 1,4-phenylenediisocyanate in anhydrous THF at room temperature. The product showed high purity and could be used without further purification. The complex dimer was prepared following the method described before, resulting in a yield of $40 \%$ after purification by column chromatography.

In the IR spectra (Figure III.3), the absorption of $\mathrm{N}-\mathrm{H}$ stretching mode appears as a shoulder of the broad band from water, locating at $3274 \mathrm{~cm}^{-1}$. The $\mathrm{C}=\mathrm{O}$ and $\mathrm{C}=\mathrm{C}$ stretching modes are found at $1664 \mathrm{~cm}^{-1}$ and $1500 \sim 1600 \mathrm{~cm}^{-1}$, respectively. The structure was further confirmed by ${ }^{1} \mathrm{H}$ and ${ }^{13} \mathrm{C}$ NMR spectra as shown in figure III.4 and all the protons and carbons were assigned.

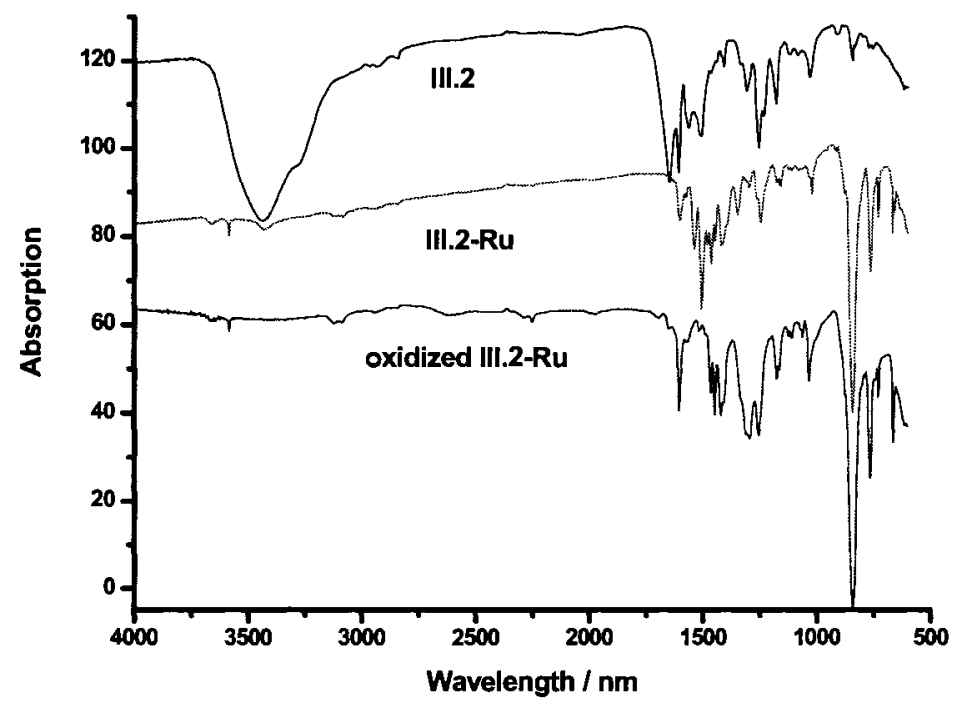

Figure III.3. IR spectra of dimeric ligand (III.2) and its complex (III.2-Ru).

The complex dimer was prepared following the procedure described previously. As shown by the IR spectra, the carbonyl absorption band at $1664 \mathrm{~cm}^{-1}$ from the dimer ligand disappears from its ruthenium complex (III.2-Ru) due to the electron 
delocalization on $[\mathrm{DCH}]^{2-}$ moieties. Upon oxidation $\left(10 \% \mathrm{H}_{2} \mathrm{O}_{2}\right)$, the $\mathrm{N}-\mathrm{H}$ bending mode at $1537 \mathrm{~cm}^{-1}$ in III.2-Ru disappears. The results suggest the NH groups on central bridge are prone to oxidation under proper conditions.
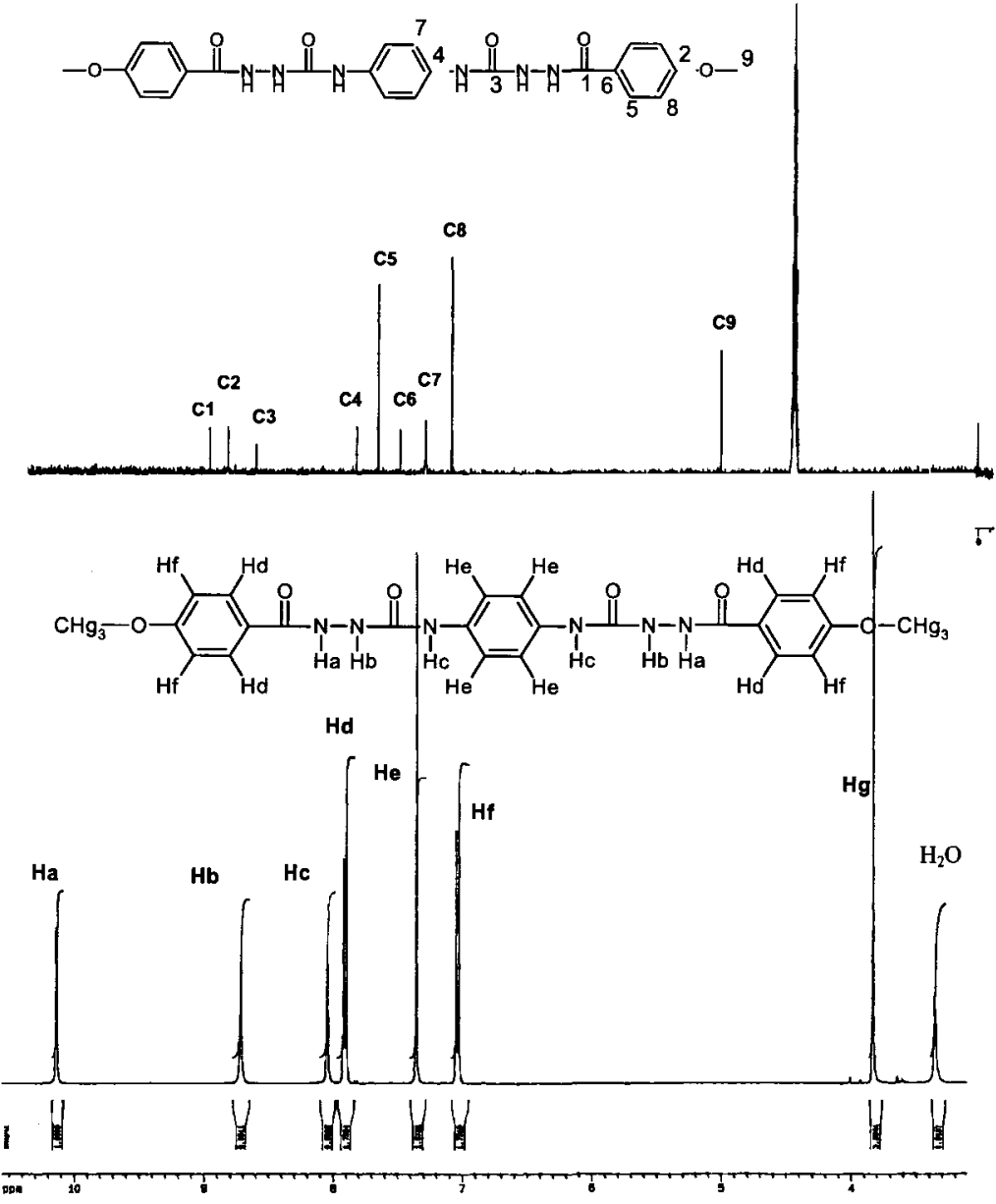

Figure III.4. ${ }^{1} \mathrm{H}$ and ${ }^{13} \mathrm{C}$ NMR spectra of dimer ligand (III.2).

The ${ }^{1} \mathrm{H}$ NMR spectrum of the complex dimer shows highly overlapped peaks for aromatic protons and $\mathrm{N}-\mathrm{H}$ protons due to the coexistence of several stereoisomers, making them very difficult to be assigned. The integral ratio of those protons to the protons on the methoxy groups was calculated to be $13.2: 1$, which is close to the expected value of 13:1. In addition, the peak from the methoxy protons in the complex 
was found to shift to a lower filed ( $\delta=3.82 \mathrm{ppm})$ than that in the ligand $(\delta=2.05 \mathrm{ppm})$, indicating a weaker electron acceptor of the DCH-Ru moiety than the DCH counter part in the dimeric ligand.

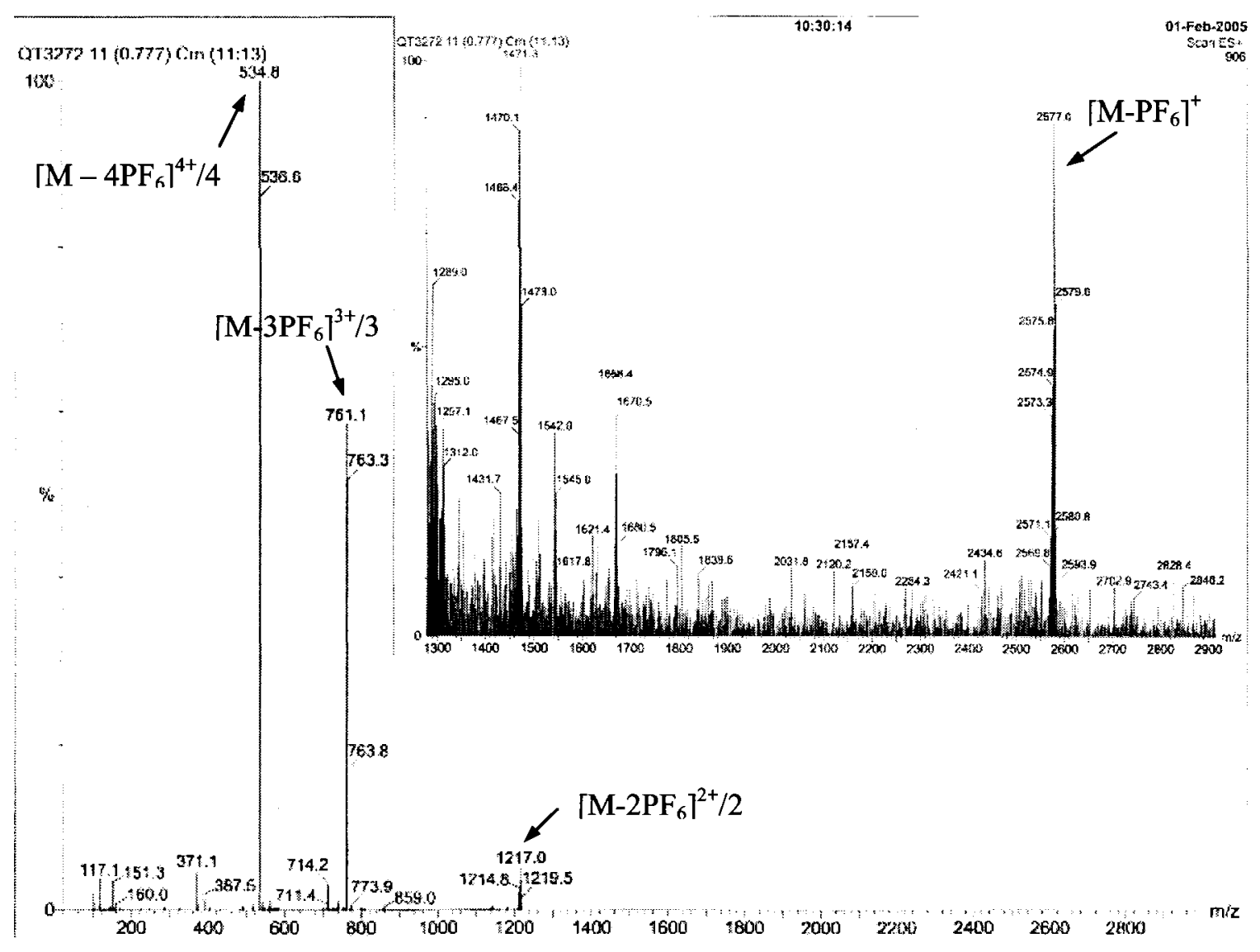

Figure III.5. ESI-MS spectrum of complex dimer (III.2-Ru).

The formation of the target dimer complex is supported by the results of electrosray ionisation mass spectrometry (ESI-MS) (Figure III.5), in which the expected signals of monocation $\left(\left[\mathrm{M}-\mathrm{PF}_{6}\right]^{+}, \mathrm{m} / \mathrm{z}=2257.0\right)$, dicationa $\left(\left[\mathrm{M}-2 \mathrm{PF}_{6}\right]^{2+}, \mathrm{m} / \mathrm{z}=1217.0\right)$, trication $\left(\left[\mathrm{M}^{-} 3 \mathrm{PF}_{6}\right]^{3+}, \mathrm{m} / \mathrm{z}=761.1\right)$ and tetracation $\left(\left[\mathrm{M}-4 \mathrm{PF}_{6}\right]^{4+}, \mathrm{m} / \mathrm{z}=534.8\right)$ are well resolved. The purity of the dimer complex was evaluated by inductively coupled plasma (ICP) analysis. The content of ruthenium in the complex was found to be $13.8 \%$ which is slightly lower than the expected value of $14.8 \%$. 


\section{III.2.2.2 Electrochemical Properties}

Cyclic voltammogram of complex dimer III.2-Ru shows two reversible oxidation couples as shown in figure III.6. The tiny waves above $1.40 \mathrm{eV}$ are probably from some impurities. If the diaminophenylene bridge and the DCH-Ru units exist as an isolated entity, there should be in total four reversible oxidation couples, or two from each component. However, only two oxidation couples appear.

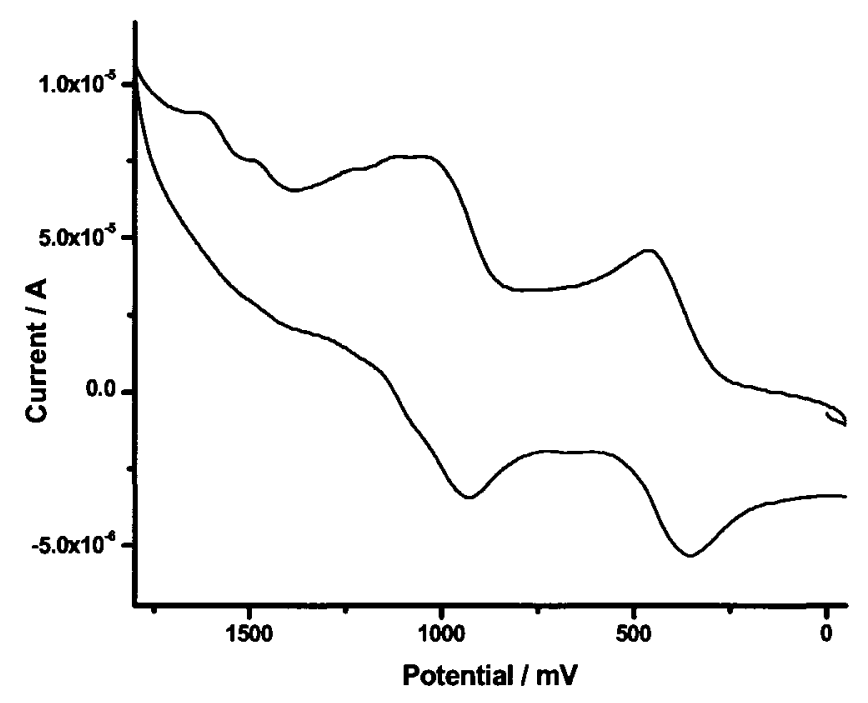

Figure III.6. Cyclic voltammogram of dimer complex (III.2-Ru) in 0.1M TBAH/ACN solution.

Considering the amino characteristic of the amide groups in the complex dimer, $N, N^{\prime}$-diphenyl-1,4-phenylenediamine (PDA) was taken as a reference for comparison. The first $\left(E_{1}\right)$ and the second $\left(E_{2}\right)$ half-wave potential and the redox potential splitting $(\Delta E)$ of PDA are $0.32-0.24 \mathrm{~V}, 0.75-0.87$ and $0.43-0.53 \mathrm{~V}$ (vs. NHE), respectively, in ACN with tetraethylammonium perchlorate (TEAP) as supporting electrolyte ${ }^{13,14}$. While the corresponding potentials found in the complex dimer are $0.41 \mathrm{~V}, 0.99 \mathrm{~V}$ and $0.48 \mathrm{~V}$, respectively, which are close to the values of PDA. Therefore, it is reasonable to believe 
that the two types of the redox waves overlap at each oxidation step. If this is true, the anodic shift of the oxidation compared to PDA can be attributed to the stabilization of electron-deficient DCH-Ru moiety during oxidation.

\section{III.2.2.3 Spectroelectrochemical Properties}

This assumption of the oxidation behaviour was supported by the spectroelectrochemical properties of the dimer complexes. Figure III.7 shows the absorption spectra during the electrochemical oxidation of complex dimer III.2-Ru in an OTTLE cell. At zero potential, it displays two intense bands at 338 and $521 \mathrm{~nm}$ which are attributed to $d\left(\mathrm{Ru}^{\mathrm{II}}\right) \rightarrow \pi^{*}$ (bpy) MLCT. The central bridge is expected to absorb below $320 \mathrm{~nm}$, outside of the spectral range of interest. Under an applied potential of $0.40 \mathrm{~V}$, the two DCH-Ru species are expected to oxidize to theo $\mathrm{Ru}^{\mathrm{II}} / \mathrm{Ru}^{\mathrm{III}}$ states according to $\mathrm{CV}$ data. A broad band appears in the NIR region $\left(\lambda_{\max }=1312 \mathrm{~nm}\right)$, which is assigned to the MMLC of the DCH-Ru moiety. In addition, a shoulder accompanying the NIR band around $850 \mathrm{~nm}$ is assigned to the IVCT of the partially formed radical cations of $p$ phenylenediamine. For PDA, this absorption shows at about $710 \mathrm{~nm}^{13}$. The red shift is attributed to the decreased donor effect of the DCH-Ru moieties when oxidized to the $\mathrm{Ru}^{\mathrm{II}} / \mathrm{Ru}$ III state. The similar trend has been reported in the PDA-type of compounds substituted with the electron-withdrawing groups ${ }^{13}$. With the further increase of the potential but lower than the potential to oxidize $\mathrm{DCH}-\mathrm{Ru}$ to the $\mathrm{Ru} / \mathrm{III} / \mathrm{Ru}$ III state, the absorption maximum of the NIR band shifted slightly to a higher wavelength (1345 nm) without changing the intensity, which is attributed to the decrease of the electrondonating strength of the oxidized NH groups. The position of the shoulder did not change, 
but the intensity increased. These results suggest that the oxidation of the central bridge occurs at a relatively higher potential than the $\mathrm{DCH}-\mathrm{Ru}^{\mathrm{II}}$ unit.

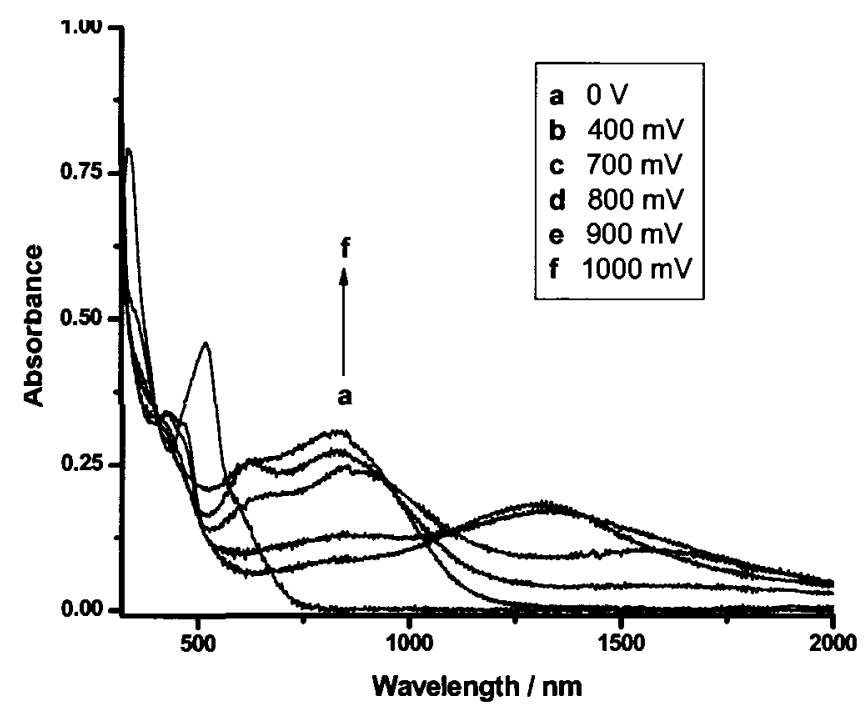

Figure III.7. Spectroelectrochemical spectra of complex dimer (III.2-Ru) in 0.1M TBAH/ACN solution.

The oxidation mechanism of the NH groups could be argued. As proposed by Desjardins $^{15}$, at the $\mathrm{Ru}^{\mathrm{II}} / \mathrm{Ru}^{\mathrm{III}}$ state, the $\mathrm{NH}$ group in $\left[\left\{\mathrm{Ru}(\mathrm{bpy})_{2}\right\}_{2} \mu-\mathrm{Ph}, \mathrm{NH}\left(\mathrm{C}_{3} \mathrm{H}_{7}-\mathrm{n}\right)-\right.$ $\mathrm{dch}]\left(\mathrm{PF}_{6}\right)_{2}$ can be reversibly oxidized by the neighboured $\mathrm{Ru}^{\mathrm{III}}$, resulting in the formation of $\mathrm{C}=\mathrm{N}$ double bond and reduced $\mathrm{Ru}{ }^{\mathrm{II}} / \mathrm{Ru}^{\mathrm{II}}$ (Scheme III.4). However, this is not the case for the complex dimer, because Otherwise, the IVCT band from the delocalized radical cation of the central bridge would have been observed. 

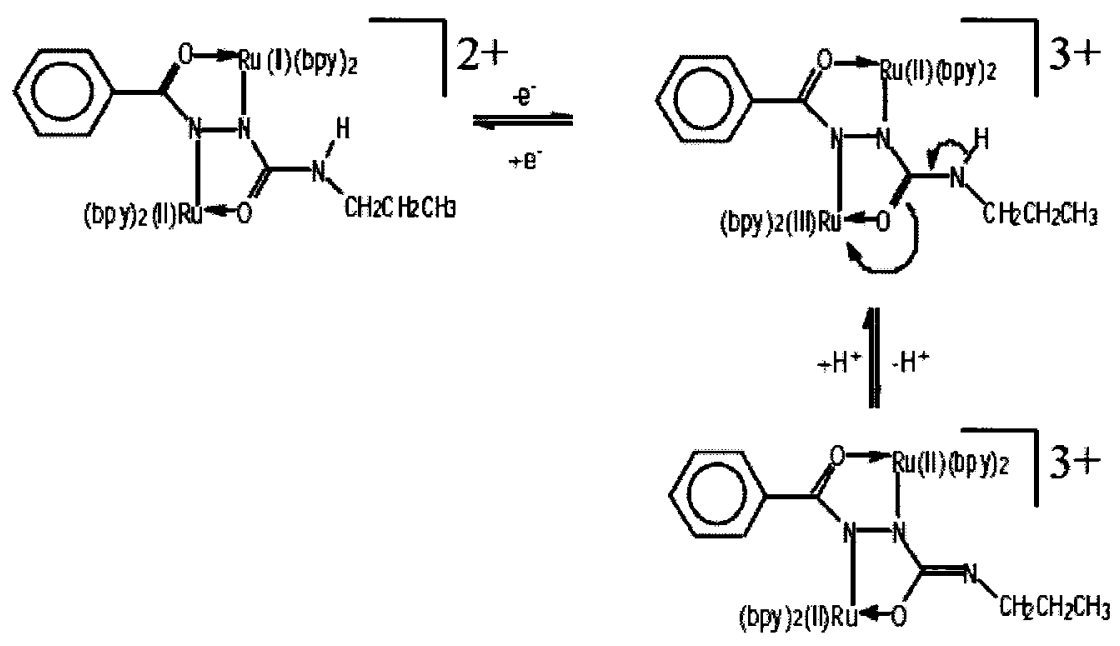

\section{Scheme III.4. Proposed oxidation mechanism of $\mathrm{NH}$ group in $\left[\left\{\mathrm{Ru}(\mathrm{bpy})_{2}\right\}_{2} \mu-\mathrm{Ph}\right.$, $\left.\mathbf{N H}\left(\mathrm{C}_{3} \mathrm{H}_{7}-\mathrm{n}\right) \mathrm{dch}\right]\left(\mathrm{PF}_{6}\right)_{2}$.}

When the potential increased to $800 \mathrm{mV}$, the intensity of the NIR band sarted to drop, indicating that the oxidation reaction from the $\mathrm{Ru}^{\mathrm{II}} / \mathrm{Ru}^{\mathrm{III}}$ to $\mathrm{Ru}{ }^{\mathrm{III}} / \mathrm{Ru}^{\mathrm{III}}$ states began to take place. The NIR band shifted to a longer wavelength of $1610 \mathrm{~nm}$ due to the further decrease of the electron-donating strength of the central bridge. Under this intermediate state, the absorption band at $870 \mathrm{~nm}$ can be attributed to two portions. One is from $\pi(\mathrm{DCH})^{2-} \rightarrow d\left(\mathrm{Ru}^{\mathrm{III}}\right)$, or LMCT, around $800-900 \mathrm{~nm}$ for typical DCH-Ru complexes ${ }^{13}$. The other is from the unconverted radical cationic bridge, observed at $640 \mathrm{~nm}$ as a shoulder. When the potential reaches $1.00 \mathrm{~V}$, the NIR band disappeared and the intensity of the LMCT got further increase, indicating a complete conversion from the $\mathrm{Ru}^{\mathrm{II}} / \mathrm{Ru}{ }^{\mathrm{III}}$ to $\mathrm{Ru}^{\mathrm{III}} / \mathrm{Ru}{ }^{\mathrm{III}}$ state. The LMCT band also shifted to a lower wavelength of $840 \mathrm{~nm}$ from 800 $\mathrm{mV}$ to $900 \mathrm{mV}$, which can be ascribed to the increased electron-deficiency of dicationic bridge. This change is consistent to the substituent effect observed in dinuclear DCH-Ru systems $^{12}$ and our dendric complexes discussed in chapter 2 . The shoulder at $\sim 650 \mathrm{~nm}$ 
shifted slightly to $630 \mathrm{~nm}$ and reached its maximum intensity at $0.90 \mathrm{~V}$, still about 100 $\mathrm{nm}$ longer compared to that in the dicationic PDA.

Based on the results from CV and spectroelectrochemistry, the oxidation process of the dimer complex can be described as two reversible three-electron steps as shown in scheme III.4. At each oxidation step, DCH-Ru and $p$-phenylenediamine moiety take place nearly simultaneously. The electrochemical and spectroelectrochemical data of complex monomer (III.1-Ru) and dimer (III.2-Ru) are summarized in tables III.1 and III.2.

$$
\text { (nu }
$$

Scheme III.5. Proposed redox process of complex dimer (III.2-Ru).

Table III.1. Electrochemical data of monomer and dimer complexes.

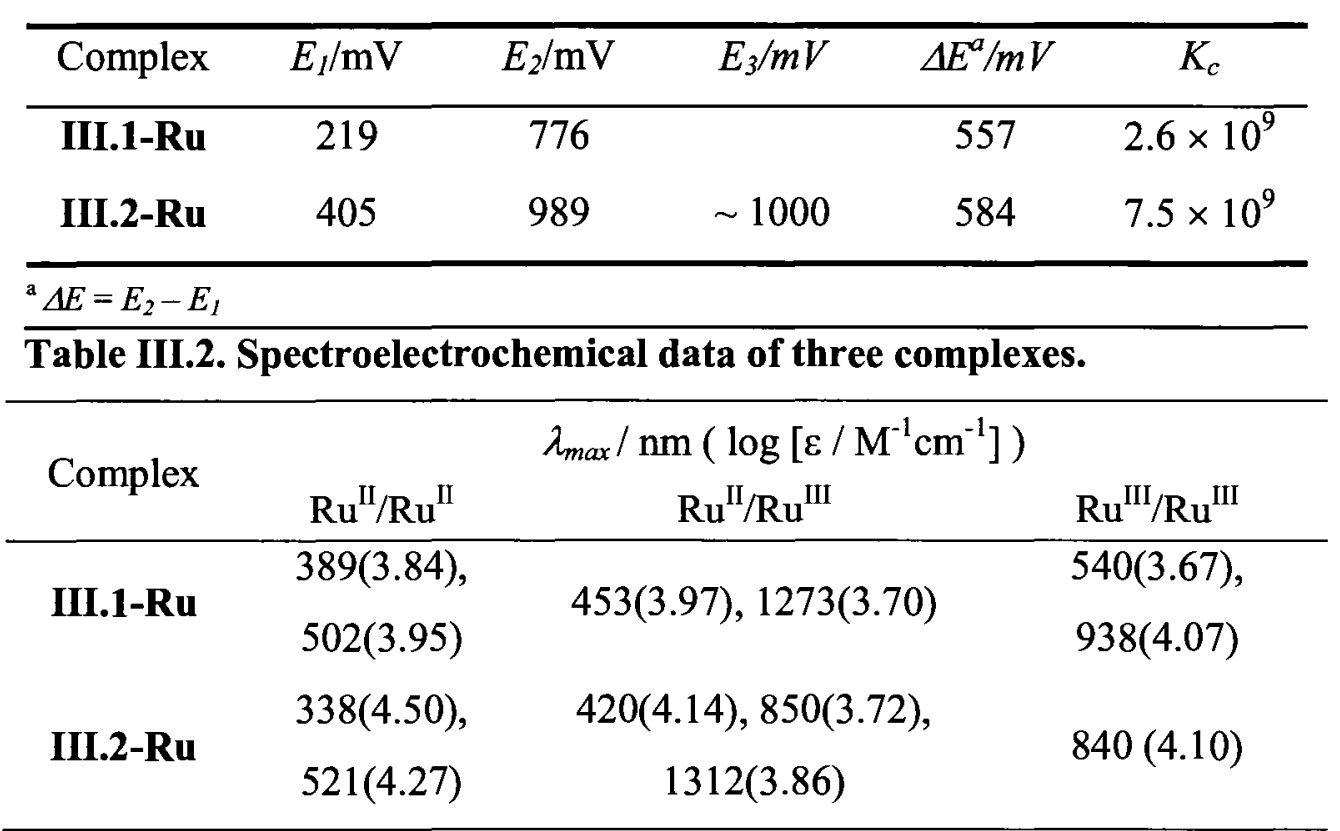




\section{III.2.3 Polymer Complex}

\section{III.2.3.1 Synthesis and Characterization}

The polybiurea ligand was prepared in DMSO by treating stoichiometric quantities of $p$-phenylenediisocyanate with hydrazine hydrate. The resulting product appeared to be a gel in the solvent due to the strong interchain hydrogen-bonding interactions. The IR spectrum of the product appears similar to that of ligand monomer, showing N-H stretching at $3240 \mathrm{~cm}^{-1}$ and $\mathrm{C}=\mathrm{O}$ stretching at $1664 \mathrm{~cm}^{-1}$.

For each repeating unit, three major peaks at $8.66,7.87$ and $7.37 \mathrm{ppm}$ are found in the ${ }^{1} \mathrm{H}$ NMR spectrum (Figure III.8) and assigned to the two identical protons on the NH groups between the two carbonyl groups and the two identical protons on $\mathrm{NH}$ groups attached to benzene, and the four identical protons on benzene, respectively. In the ${ }^{13} \mathrm{C}$ NMR spectrum, three peaks are found at 156.1, 134.1 and $119.2 \mathrm{ppm}$, which are attributed to the two identical carbons from the carbonyl groups, two identical carbons on benzene attached to the NH groups and four identical carbons on benzene, respectively.

It is also noticed that two small peaks appearing in the ${ }^{1} \mathrm{H}$ NMR spectrum. One is close to the peak of water and the other one is located beside the peaks from the biurea group. They are highly possible from the hydrazide groups at the ends of polymer chains. The difference between the integral ratio between the actual value (1:1.5) and the expected value (1:2) is largely due to the incomplete integration of the $\mathrm{NH}_{2}$ groups as part of the peak is shielded by the broad peak from water. According to the integral ratio of the protons on repeating unit and the protons from end groups, the number-average molecular $\left(M_{n}\right)$ weight of the product could be calculated for low-molecular-weight polymers. Assuming that the polymer chains have the same hydrazide group at the chain 
ends, the average degree of polymerization is calculated to be about 11 , equal to a $M_{n}$ of $2.1 \times 10^{3}$. However, this molecular weight does not represent the whole sample, because the sample is only partially dissolved in the solvent (DMSO- $d_{6}$ ). Even at a higher temperature $(330 \mathrm{~K})$ during the NMR experiment, a large amount of the sample remained insoluble.
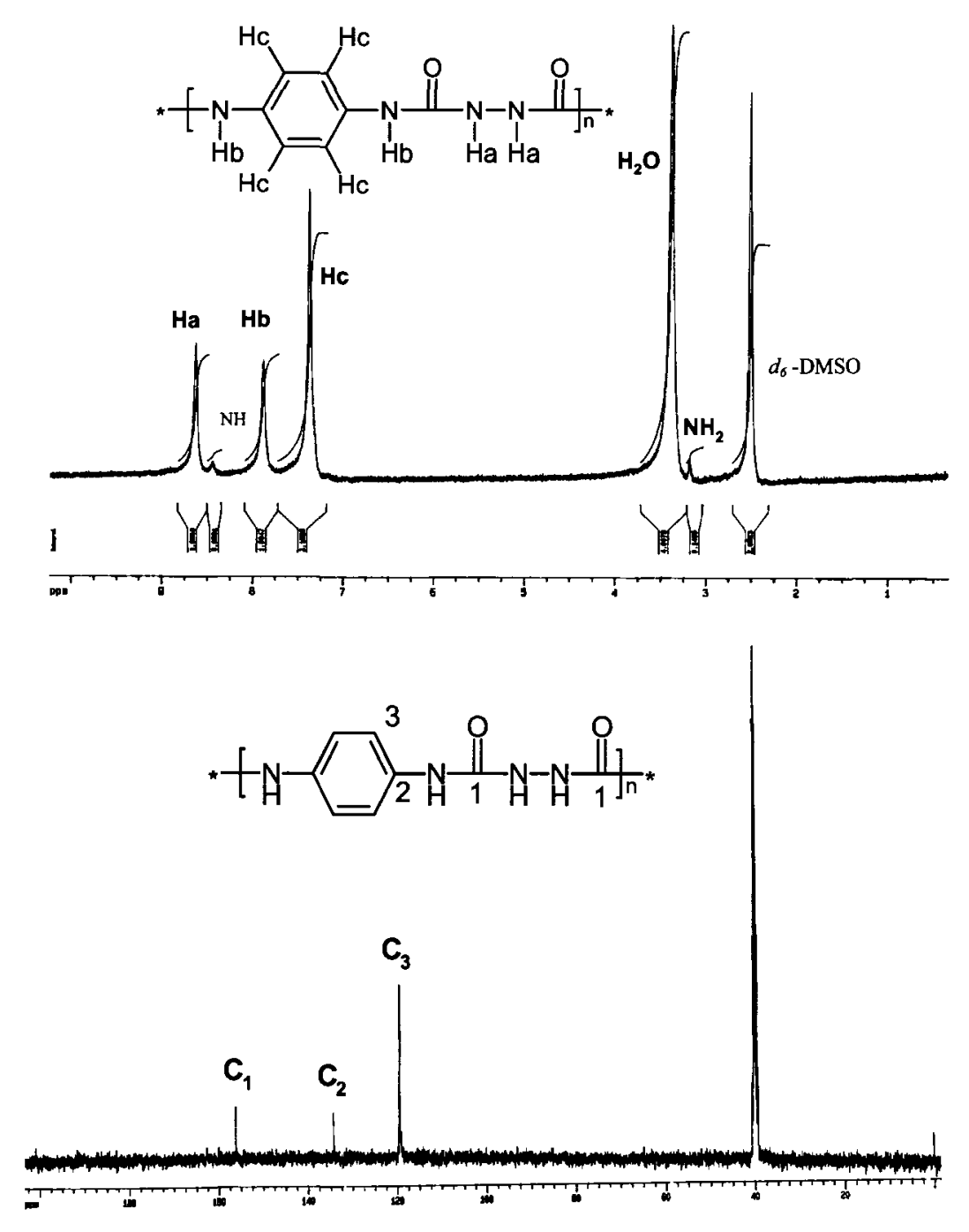

Figure III.8. ${ }^{1} \mathrm{H}$ NMR and ${ }^{13} \mathrm{C}$ NMR spectra of polymer ligand (III.3).

Thermal properties of the ligand polymer were analyzed by differential scanning calorimetry (DSC) and thermogravimetry (TG). Due to its highly rigid structure, no 
glass-transition temperature was found. The onset temperature for $5 \%$ weight loss was found to be $320^{\circ} \mathrm{C}$ for the ligand polymer by TG, indicating a relatively high thermal stability.

The complexation reaction of the ligand polymer with a ruthenium complex was carried out in DMF, in order to fully solve the ligand polymer. The final product was precipitated in water containing $\mathrm{NH}_{4} \mathrm{PF}_{6}$ salt. Like the complex monomer, the complex polymer appeared to be readily oxidized in the air during workup. The product as dark blue solids could not be purified by column chromatography as it is strongly absorbed by alumina.

\section{III.2.3.2 Electrochemical Properties}

As shown by CV (Figure III.9), the product did not achieve the desired ratio of complexation since the oxidation waves from DCH-Ru moieties (less than $1000 \mathrm{mV}$ ) are weak. The ruthenium content analyzed by ICP is only $11.8 \%$, which is lower than the expected value of $15.5 \%$. The oxidation around $1.00 \mathrm{~V}$ is likely from the single nuclear ruthenium complex incorporated into the polymer backbone. The reason for incomplete complexation is mainly due to the stiffness of the polymer chains. As the each incorporation will increase the rigidity of the polymer chain, the lack of rotation just prevent the polymer chain from further complexation. 


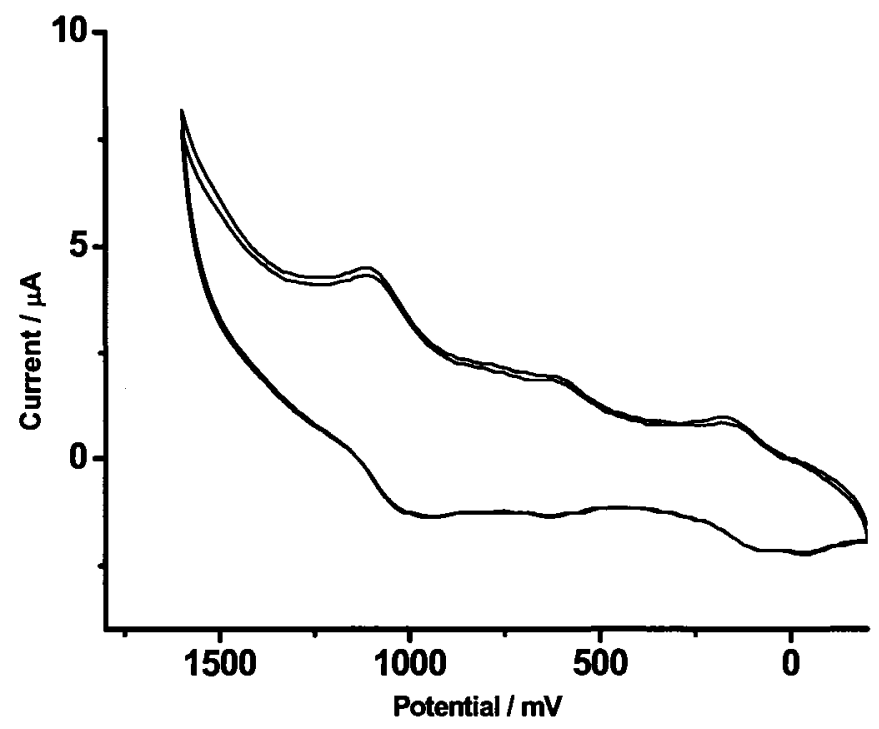

Figure III.9. Cyclic voltammogram of complex polymer (III.3-Ru) in 0.1M TBAH/ACN solution.

\section{III.3 Conclusion}

We have designed and synthesized three biurea-containing ligands, in the forms of monomer, dimer and polymer. The complex dimer serves as a good model to study the electrochemical property related to the structural details. As predicted, the NH group shows some amino characteristics after the complexation of the $\mathrm{DCH}$ moieties. The electrochemical properties of the central diaminophenylene bridge and the DCH-Ru moiety are quite similar and can still be successfully explored and studies by spectroelectrochemistry. The complexation of the ligand polymer could not produce the fully complexed polymers, due to the stiffness of the polymer backbone. Therefore, a new method is needed to make $\mathrm{DCH}-\mathrm{Ru}$-containing polymers. 


\section{II.4 Experimental Section}

\section{Materials}

All reagents and solvents utilized in synthesis and measurement were used as received. cis- $\mathrm{Ru}(\mathrm{bpy})_{2} \mathrm{Cl}_{2} \cdot 2 \mathrm{H}_{2} \mathrm{O}$ was prepared according to the literature method. ${ }^{17}$

\section{Measurements}

${ }^{1} \mathrm{H}$ and ${ }^{13} \mathrm{C}$ NMR spectra were recorded on Brucker AMX-400 and Varian 300 MHz NMR spectrometers using deuterated dimethylsulfoxide (DMSO- $\mathrm{d}_{6}$ ) as solvents with $1 \%$ tetramethylsilane (TMS) as an internal standard. The chemical shifts were reported in $\delta(\mathrm{ppm})$ to TMS. IR spectra were taken on an ABB Bomem MB-100 FTIR in $\mathrm{KBr}$

UV-vis-NIR spectroscopic and electrochemical measurements were taken using spectroscopic grade acetonitrile (ACN) or N.N-dimethylformamide (DMF) on a Perkin Elmer Lambda 900 UV-vis-NIR and BAS 100 B/W, separately.

Inductively coupled plasma (ICP) analysis of ruthenium was done at the Institute of Chemistry, Chinese Academy of Sciences, Beijing, China.

$N, N^{\prime}$-diphenyl-1,2-Hydrazinedicarboxamide (III.1)

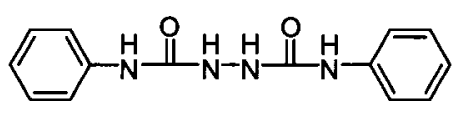

To a solution of phenylisocyanate $(1.19 \mathrm{~g}, 10.0 \mathrm{mmol})$ in THF $(20 \mathrm{~mL})$ was added dropwise a solution of hydrazine hydrate $(55 \%, 0.30 \mathrm{~g}, 5.0 \mathrm{~mol})$ in THF $(5 \mathrm{~mL})$ with stirring. The solution was kept stirring for $1 \mathrm{~h}$ after the completion of addition. The resulting precipitate was collected by filtration, washed with water and dried to give 
white powder $\left(0.98 \mathrm{~g}, 73 \%\right.$ yield). M. p. $240-241^{\circ} \mathrm{C}$; IR $\left(\mathrm{KBr}, \mathrm{cm}^{-1}\right): 3298,3222\left(\mathrm{w}_{\mathrm{N}-\mathrm{H}}\right)$, $3095\left(v_{\mathrm{C}-\mathrm{H}}\right), 1670\left(v_{\mathrm{C}=0}\right), 1596,1546,1448\left(v_{\mathrm{NC}=\mathrm{C}}\right) ;{ }^{1} \mathrm{H}$ NMR $\left(300 \mathrm{MHz}, \mathrm{DMSO}-d_{6}\right)$ : $8.79(\mathrm{~s}, 2 \mathrm{H}), 7.98(\mathrm{~s}, 2 \mathrm{H}), 7.50(\mathrm{~d}, 4 \mathrm{H}, \mathrm{J}=7.2 \mathrm{~Hz}), 7.25(\mathrm{t}, 4 \mathrm{H}, \mathrm{J}=7.2 \mathrm{~Hz}), 6.95(\mathrm{t}, 2 \mathrm{H}$, $\mathrm{J}=7.2 \mathrm{~Hz}) ;{ }^{13} \mathrm{C}$ NMR $\left(100 \mathrm{MHz}\right.$, DMSO- $\left.d_{6}\right) \delta / \mathrm{ppm}: 156.5,140.1,128.9,122.1,119.0$; MS (ESI, $\mathrm{m} / \mathrm{z}$ ) found (nature of the peak, relative intensity): $271\left(\mathrm{M}+\mathrm{H}^{+}, 2.3\right)$.

$N, N^{\prime}$-(1,4-phenylene)bis(4-methoxybenzoylsemicarbazide) (III.2)

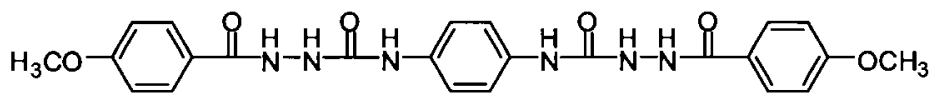

To a solution of 4-methoxybenzohydrazide $(0.83 \mathrm{~g}, 5.0 \mathrm{mmol})$ in THF $(20 \mathrm{~mL})$ was added dropwise a solution of 1,4-phenylene diisocyanate $(0.40 \mathrm{~g}, 2.5 \mathrm{~mol})$ in anhydrous THF ( $5 \mathrm{~mL}$ ) with stirring. The solution was kept stirring for $2 \mathrm{~h}$ after the completion of addition. The resulting precipitate was collected by filtration, washed with water and dried to give white powder $(1.17 \mathrm{~g}, 95 \%$ yield $) . \mathrm{T}_{\mathrm{d}}>330^{\circ} \mathrm{C}$; IR $\left(\mathrm{KBr}, \mathrm{cm}^{-1}\right)$ : $3274\left(v_{\mathrm{N}-\mathrm{H}}\right), 1664\left(v_{\mathrm{C}=0}\right), 1606,1564,1506\left(v_{\mathrm{C}=\mathrm{C}}\right) ;{ }^{1} \mathrm{H}$ NMR $\left(300 \mathrm{MHz}\right.$, DMSO- $\left.d_{6}\right)$

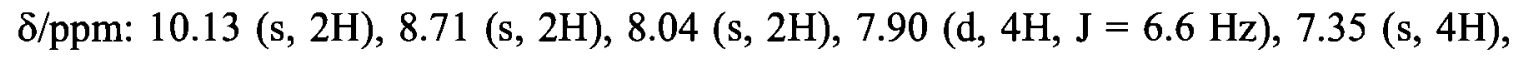
$7.03(\mathrm{~d}, 4 \mathrm{H}, \mathrm{J}=6.6 \mathrm{~Hz}), 3.82(\mathrm{~s}, 6 \mathrm{H}) ;{ }^{13} \mathrm{C}$ NMR $\left(100 \mathrm{MHz}\right.$, DMSO-d $\left.{ }_{6}\right) \delta / \mathrm{ppm}: 165.8$, $161.8,155.8,134.0,129.3,124.6,119.0,113.5 ; \mathrm{MS}(\mathrm{ESI}, \mathrm{m} / \mathrm{z})$ found (nature of the peak, relative intensity): $494\left(\mathrm{M}+\mathrm{H}^{+}, 0.6\right)$.

Poly(1,4-phenylene-1,6-biurea) (III.3)

To a solution of 1,4-phenylene diisocyanate $(1.60 \mathrm{~g}, 10 \mathrm{mmol})$ in DMSO $(15 \mathrm{ml})$ was added dropwise a solution of hydrazine hydrate $(55 \%, 0.58 \mathrm{~g}, 10 \mathrm{mmol})$ in DMSO (5 $\mathrm{mL}$ ). The solution was kept stirring after the completion of addition. The resulting 
product was precipitated in methanol, filtered, washed with methanol and dried to give white powder $(1.88 \mathrm{~g}, 98 \%$ yield $) . \mathrm{Td}>320^{\circ} \mathrm{C}$; IR $\left(\mathrm{KBr}, \mathrm{cm}^{-1}\right): 3240\left(\mathrm{~h}_{\mathrm{N}-\mathrm{H}}\right), 1664\left(v_{\mathrm{C}=\mathrm{O}}\right)$, $1514\left(v_{\mathrm{C}=\mathrm{C}}\right) ;{ }^{1} \mathrm{H}$ NMR $\left(300 \mathrm{MHz}, \mathrm{DMSO}-d_{6}\right): 8.66(\mathrm{~s}, 2 \mathrm{H}), 7.87(\mathrm{~s}, 2 \mathrm{H}), 7.37(\mathrm{~s}, 4 \mathrm{H}) ;{ }^{13} \mathrm{C}$ NMR; (100 MHz, DMSO- $\left.d_{6}\right) \delta /$ ppm: 156.1, 134.1, 119.2.

\section{General procedure for the preparation of DCH-Ru complexes}

The ruthenium complexes were synthesized via the procedure of Kaim. ${ }^{16}$ The general synthetic procedure was to combine $0.38 \mathrm{mmol}(200 \mathrm{mg}) \mathrm{Ru}(\mathrm{bpy})_{2} \mathrm{Cl}_{2} \cdot 2 \mathrm{H}_{2} \mathrm{O}$ with $0.19 \mathrm{mmol}$ of the dicarboxylhydrazine fragment and $40 \mathrm{mg} \mathrm{NaOH}$ or $100 \mathrm{mg} \mathrm{Na} 2 \mathrm{CO} 3$ in $80 \mathrm{~mL}$ of $5: 1 \mathrm{H}_{2} \mathrm{O} / \mathrm{EtOH}(\mathrm{v}: \mathrm{v})$. The mixture was then refluxed for approximately 14 hours under argon. After cooling to room temperature, $1.00 \mathrm{~g}$ of tetra- $n$-butylammonium hexafluorophosphate (TBAH) in $40 \mathrm{~mL}$ of water was added to afford red dark precipitate. The precipitate was filtered off, redissolved in acetone $(20 \mathrm{~mL})$ and precipitated into diethyl ether. The product was further purified by column chromatography with acetonitrile on acidic alumina and dried under vacuum.

$\left[\left\{\mathrm{Ru}(\mathrm{bpy})_{2}\right\}_{4} \mu-\left(N, N^{\prime}-(1,4-\right.\right.$ phenylene $)$ bis(4-methoxybenzoylsemicarbazide $\left.\left.)\right)\right]\left(\mathrm{PF}_{6}\right)_{4}$

(III.2-Ru)

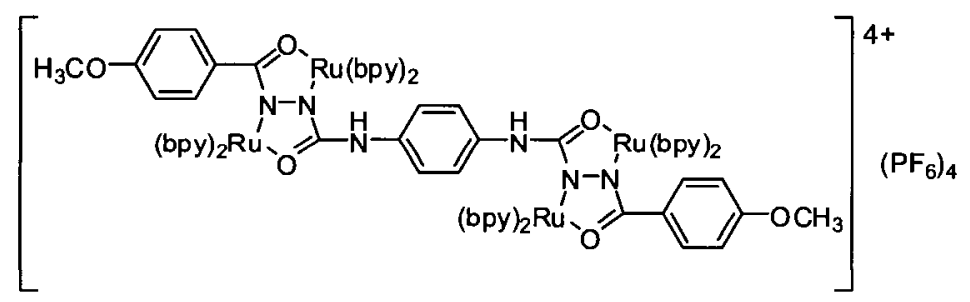

IR $\left(\mathrm{KBr}, \mathrm{cm}^{-1}\right): 1602,1506\left(v_{\mathrm{C}=\mathrm{C}}\right) ; 1539\left(\mathrm{~N}_{\mathrm{N}-\mathrm{H}}\right) ;{ }^{1} \mathrm{H}$ NMR (300 MHz, DMSO- $\left.d_{6}\right): 9.22-$ $5.51,(\mathrm{~m}, 78 \mathrm{H}), 2.85(\mathrm{~s}, 6 \mathrm{H})$; MS (ESI, $\mathrm{m} / \mathrm{z})$ found (nature of the peak, relative intensity): 
$2257.0\left(\left[\mathrm{M}-\mathrm{PF}_{6}\right]^{+},<0.1\right), 1217.0\left(\left[\mathrm{M}-2 \mathrm{PF}_{6}\right]^{2+}, 5.10\right), 761.1\left(\left[\mathrm{M}-3 \mathrm{PF}_{6}\right]^{3+}, 58.50\right), 534.8$ $\left(\left[\mathrm{M}-4 \mathrm{PF}_{6}\right]^{4+}, 0.32\right)$. 


\section{References}

1. Ciardelli, F.; Tsuchida, E.; Wöhrle, D. Macromolecule-Metal Complexes, SpringerVerlag, 1996.

2. Yamamoto, T.; Yoneda, Y.; Maruyama, T. J. Chem. Soc. Chem. Commun. 1992, 1652.

3. Trouillet, L.; De Nicola, A.; Guillerez, S. Chem. Mater. 2000, 12, 1611.

4. Yu, S. C.; Gong, X.; Chan, W. K. Macromolecules 1998, 31, 5639.

5. Yu, S. C.; Chan, W. K. Macromol. Rapid. Commun. 1997, 18, 213.

6. Yu, S. C.; Chan, W. K. Macromolecules 2000, 33, 3259.

7. Frazer, A. H.; Wallenberger, F. T. J. Polym. Sci. Part A: Polym. Chem. 1964, 2, 1137.

8. Frazer, A. H.; Wallenberger, F. T. J. Polym. Sci. Part A: Polym. Chem. 1964, 2, 1147.

9. Campbell, T. W.; Foldi, V. S.; Farago, J. J. Appl. Polym. Sci. 1959, 11(5), 155.

10. Desjardins, P.; Wang, Z. Y. ACS Symp. Ser. 2005, 888, 51.

11. D'Aprano, G.; Leelerc, M.; Zotti, G. Synth. Met. 1996, 82, 59.

12. Kasack, V.; Kaim, W.; Binder, H.; Jordanov, J.; Roth, E. Inorg. Chem. 1995, 34, 1924.

13. Nishiumi, T.; Nomura, Y.; Chimoto, Y.; Higuchi, M.; Yamamoto, K. J. Phys. Chem. B 2004, 108, 7992;

14. Aprano, G. D.;1 Leclerc, M.; Zotti, G. Synth. Metals 1996, 82, 59.

15. Desjardins, P. Synthesis and Characterization of Novel Organometallic and Organic Electrochromic Materials, PhD dissertation, Carleton University, 2001, 91.

16. Kaim, W.; Kasack, V. Inorg. Chem. 1990, 29, 4696. 
17. Sullivan, B.; Salmon, D.; Meyer, T. Inorg. Chem. 1978, 17, 3334. 


\section{Chapter IV Ru-Containing Polymers by Suzuki Cross-Coupling Polymerization}

\section{IV.1 Introduction}

The Suzuki reaction, also called Miyaura-Suzuki reaction, is the palladium(0)catalysed cross-coupling between an aryl- or vinyl- boronic acid and an aryl- or vinylhalide in the presence of a base, which was first discovered by Akira Suzuki et al in $1979^{1}$. The accepted mechanism is shown in scheme IV.1, which involves oxidative addition of the halide substrate to give a $\mathrm{Pd}$ (II) intermediate, followed by a transmetallation, and a final reductive elimination that regenerates the catalyst $\mathrm{s}^{2-4}$. The transmetallation is thought to be facilitated by base-mediated formation of the tetracoordinate boronate anion which is more electrophilic than the free boronic acid ${ }^{5}$.

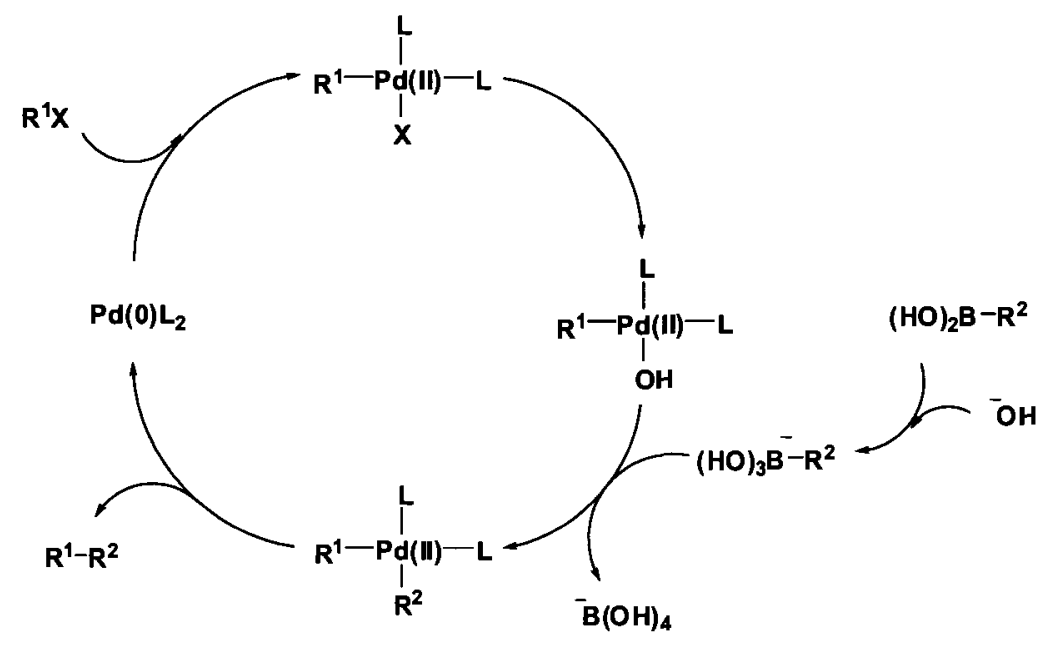

\section{Scheme IV.1. Accepted mechanism of Suzuki-coupling reaction.}

This reaction is not restricted to boronic acids (or their esters) and halides. Potassium trifluoroborates ${ }^{6,7}$, organoboranes ${ }^{8-11}$ and fluorosulfonates ${ }^{12}$ can also be used in place of boronic acids. Some pseudohalides, for example triflates ${ }^{13-16}$ may also be used as coupling partners. Several reviews on the Suzuki reaction have been published. ${ }^{17-21}$ 
Because of low catalyst loading (typically $0.5 \mathrm{~mol} \%$ ), potential recycling of the catalyst, high productivity, low energy consumption, mild conditions, low waste production, and safe solvents, the application of the Suzuki reaction has been widespread from the synthesis of small molecular, natural products ${ }^{22,23}$ and pharmaceutical drugs ${ }^{24,25}$ to various polymers ${ }^{26,27}$.

As stated above, the Suzuki reaction offers several advantages to make it satisfy the requirements for condensation polymerization. If the two starting materials contain bifunctional bromo and boronic acid (or boronic acid ester) groups, the cross-coupling reaction can in principle lead to the formation of a linear polymer. Thus, such a reaction can be deemed to be a Suzuki cross-coupling polymerization (also called as Suzuki polycondensation, SPC), which is a typical step-growth polymerization, as shown in scheme IV.2. The boronic acid or boronic acid ester and the halide can be present in the same monomer (AB-type) or in different monomers (AA/BB-type). In 1988, the Suzuki cross-coupling reaction was successfully applied in making poly(p-2,5-di-nhexylphenylene) (PPP derivate) by the Schlüter group at the Max-Planck Institute for Polymer Research in Mainz ${ }^{26}$. Since then, much effort has been made to utilize this reaction as a powerful synthetic tool in modern polymer chemistry. A variety of aromatic polymers have been prepared through this cross-coupling polymerization, such as chelating polymers ${ }^{28-29}$, hyperbranched polymers $^{30-36}$, dendrimers ${ }^{37,38}$, amphiphilic copolymers $^{39-41}$, polyelectrolytes ${ }^{42,43}$, main-chain chiral polymers ${ }^{44-47}$, poly(arylene vinylene)s and poly(arylene ethynylene) $\mathrm{s}^{48-51}$. 


\section{AABB-approach}

$$
\begin{aligned}
& \left(\mathrm{R}_{1} \mathrm{O}\right)_{2} \mathrm{~B}-\mathrm{X}-\mathrm{B}(\mathrm{OR})_{2}+\mathrm{R}_{2}-\mathrm{Y}-\mathrm{R}_{2} \underset{\mathrm{Bd}]}{\stackrel{[\mathrm{Pase}}{\longrightarrow}}+\mathrm{X}-\mathrm{Y} \mathrm{f}_{\mathrm{n}} \\
& \mathrm{R}_{1}=\mathrm{H} \text {, alkyl, cycloalkyl } \quad \mathrm{R}_{2}=\mathrm{Br}, \mathrm{l}, \mathrm{TfO}
\end{aligned}
$$

AA-Monomer BB-Monomer

\section{AB-approach}

$$
\left(\mathrm{R}_{1} \mathrm{O}\right)_{2} \mathrm{~B}-\mathrm{x}-\mathrm{R}_{2} \underset{\text { Base }}{\stackrel{[\mathrm{Pd}]}{\longrightarrow}}+\mathrm{x} \mathrm{t}_{\mathrm{n}}
$$

\section{AB-Monomer}

\section{Scheme IV. 2. General representation of SPC with the AA/BB-type or AB-type polymerization. $X$ and $Y$ represent aromatic units, typically benzene derivatives.}

The Suzuki cross-coupling polymerization is also useful in producing metalcontaining polymers with the luminescent and redox-active properties typically through AA/BB-type approach ${ }^{52-55}$. An example is the alternating copolymer containing a ruthenium-bipyridine metal complex and 1,4-phenylene unit produced by the Klemm group (Scheme IV.3) ${ }^{56}$.

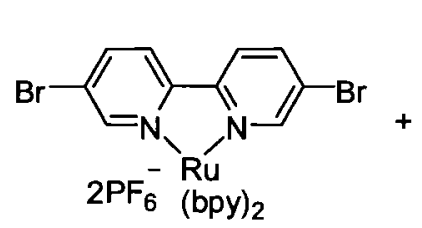

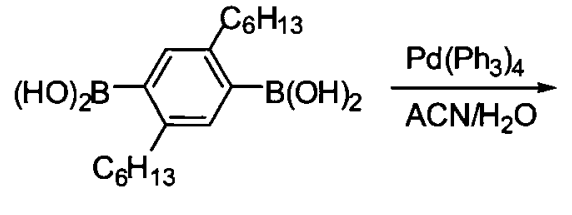

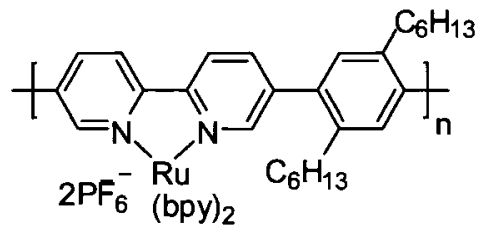

\section{Scheme IV.3. Synthesis of Ru-containing polymer by Suzuki cross-coupling Polymerization.}

In this chapter, two synthetic approaches, i.e., $\mathrm{AB}-$ and AA-BB-type polymerizations are described for the synthesis of a novel series of polymers containing a 
dinuclear ruthenium complex moiety by SPC. In addition, polymer modification is described through the introduction of short poly(ethylene glycol) fragments in order to increase the ion transport property of the $\mathrm{Ru}$-containing polymer and other properties.

\section{IV.2 Design and Synthesis of AB monomers}

\section{IV.2.1 DCH-based AB-type Monomer}

The simplest AB ligand based on 1,2-dicarbonylhydrazide (DCH) should have the structure of IV.2 or IV.3 (Scheme IV.4) with bromophenyl and borophenyl attached to the DCH separately.

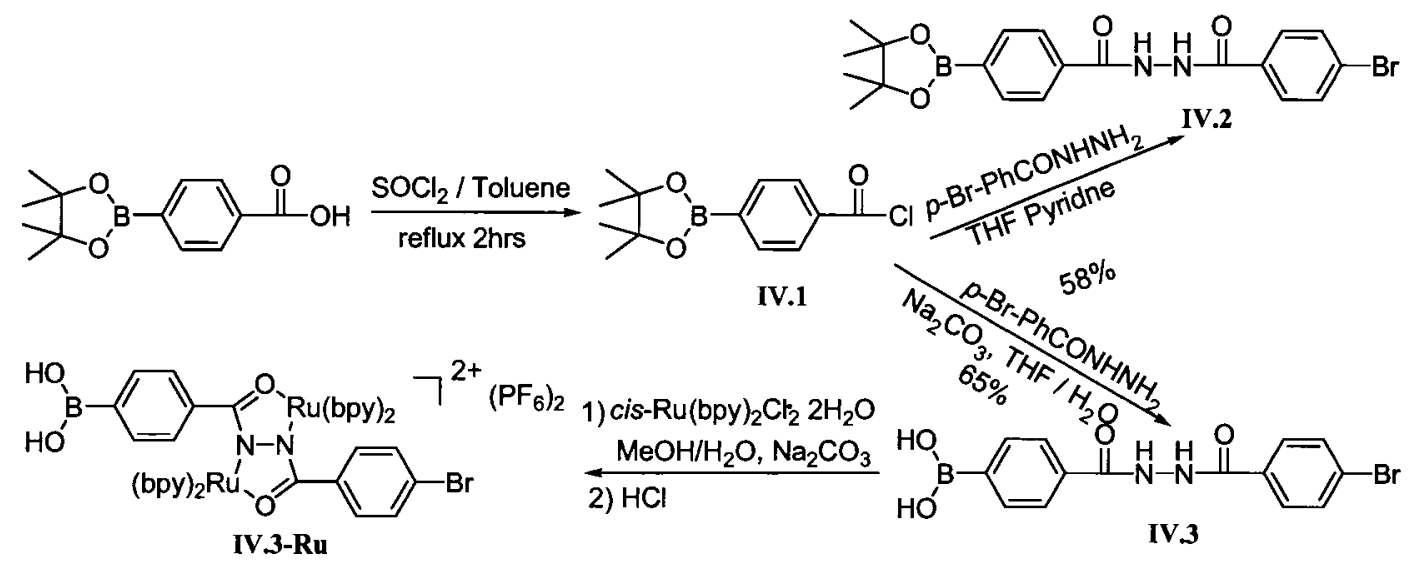

\section{Scheme IV.4. Synthesis of AB ligand and the complex}

As shown in scheme IV.4, this ligand can be prepared by reacting 4bromobenzhydrazide and 4-bromobenzoyl chloride (IV.1 $)^{57}$. Moreover, the product obtained in an aqueous medium is different from the one under anhydrous condition. The latter kept the boronic acid ester group from the reactant with a m.p. of $249-251^{\circ} \mathrm{C}$, while the former was a hydrolyzed boronic acid product (no m.p. detected owing to the decomposition). The structural difference in the product is elucidated by IR and ${ }^{1} \mathrm{H}$ NMR. 
In figure IV.1, the absorption band of the methyl group at $\sim 2900 \mathrm{~cm}^{-1}$ from IV.3 disappears for IV.2. In comparison of the ${ }^{1} \mathrm{H}$ NMR spectra of these two products (Figure IV.2), the missing of the methyl peaks at $1.37 \mathrm{ppm}$ for IV.2 indicates a nearly complete hydrolysis of the boronic acid ester under aqueous conditions.

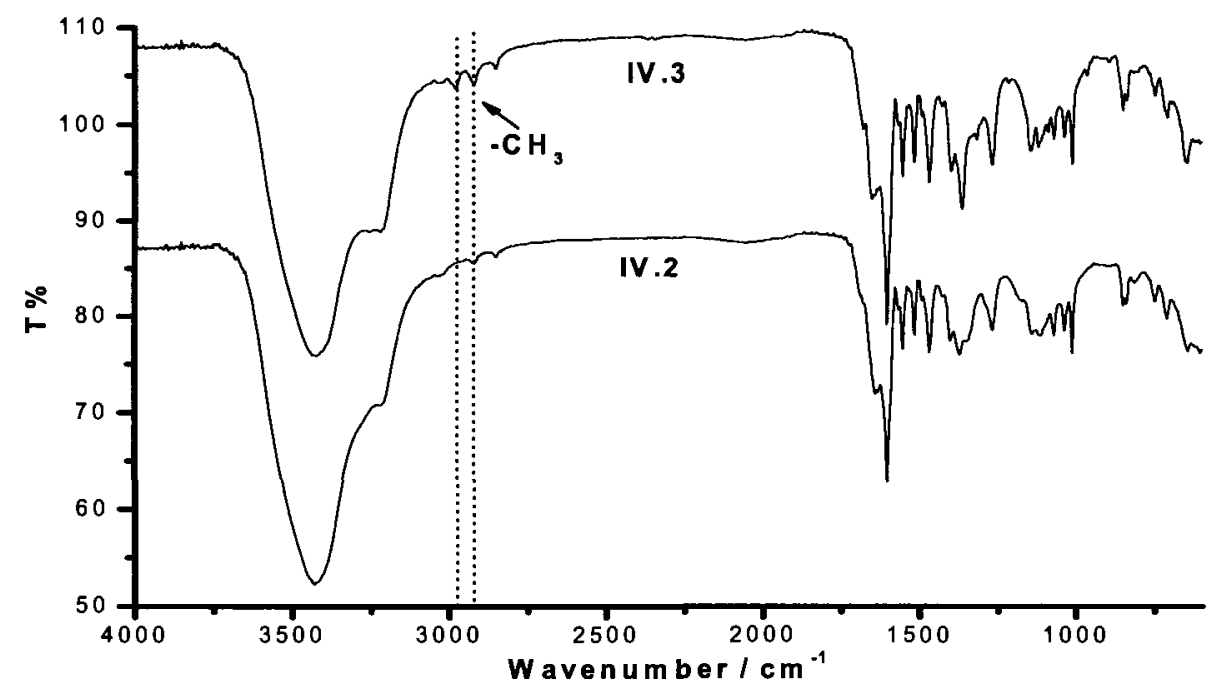

Figure IV.1. IR spectra of ligands IV.2 and IV.3 (KBr pellet).

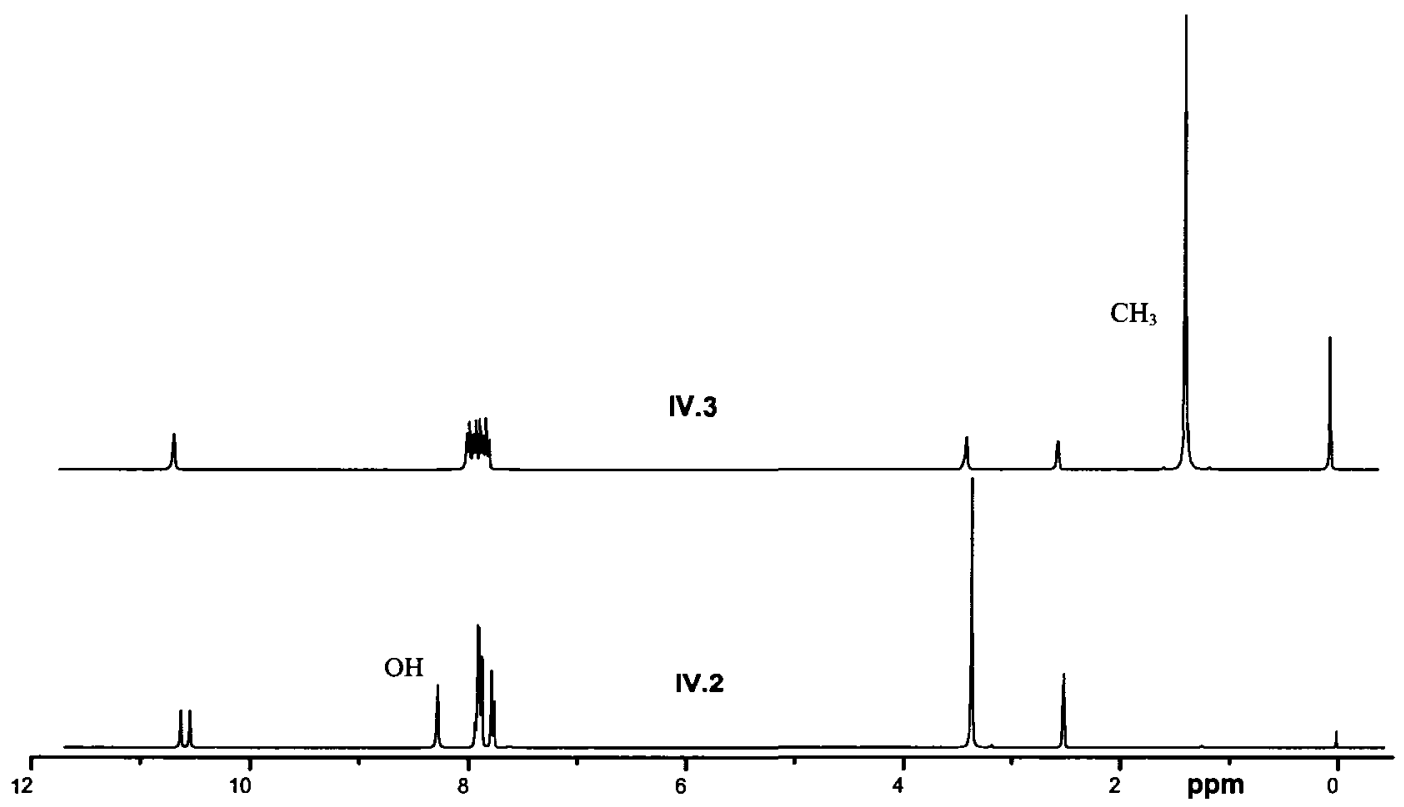

Figure IV.2. ${ }^{1}$ H NMR spectra of IV.2 and IV.3 in DMSO-d $d_{6}$ 
The corresponding complexes IV.2-Ru and IV.3-Ru were prepared according to the procedure of $\mathrm{Kaim}^{58}$, reacting cis- $\mathrm{Ru}(\mathrm{bpy})_{2} \mathrm{Cl}_{2} \cdot 2 \mathrm{H}_{2} \mathrm{O}$ with ligands IV.2 and IV.3 separately under a basic condition in the mixture of methanol/water. During the purification of the complexes derived from this AB-type ligand by column chromatography on basic aluminum oxide, the ester also tends to be hydrolyzed to the acid. Thus, IV.3-Ru should be a better choice for polymerization. However, the SPC of IV.3-Ru didn't produce high molecular weight polymer according to the low viscosity $\left(\eta_{\text {inh }}=0.08 \mathrm{dL} / \mathrm{g}, \mathrm{c}=0.5 \mathrm{~g} / \mathrm{dL}\right)$ of the product.

The unsuccessful polymerization is likely to be caused by the steric hindrance instead of the reactivity of the monomer complex. In the catalytic cycle of Suzuki reaction, oxidative addition is generally a rate-determining step $^{17}$. Considering the electron-withdrawing nature of the DCH fragment in ligand IV.3, the corresponding Ru complex should be ready to undergo oxidative addition. According to the calculated geometric structure of $\left[\left\{\boldsymbol{R} u(b p y)_{2}\right\}_{2} \mu-P h_{2} d c h\right]^{2+}$ (a model compound for [IV.3-Ru $]^{2+}$ ) presented in figure IV.3, the phenyl ring and bipyridyl group is almost face-to-face parallel, which is likely to cause more steric hindrance when the two pheny rings are connected. Thus, structural modification of ligand IV.3 is necessary by pushing phenyl rings away from the dipyridyl groups. 


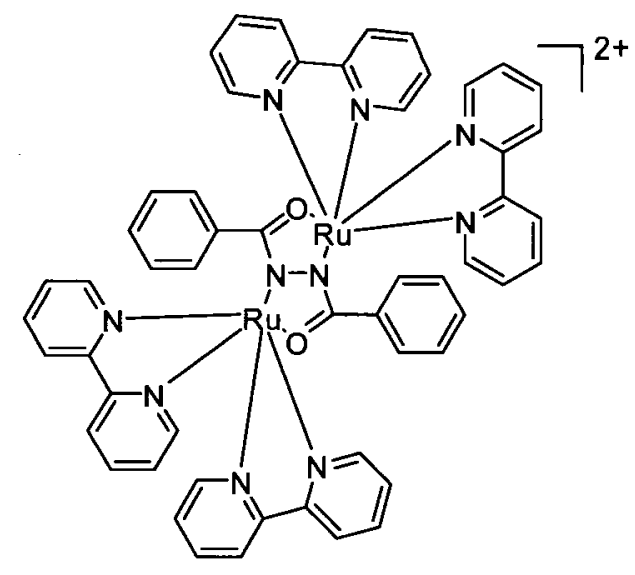

$\left\lceil\{R u(b p v)\},, \mu-P h,\left.d c h\right|^{2+}\right.$

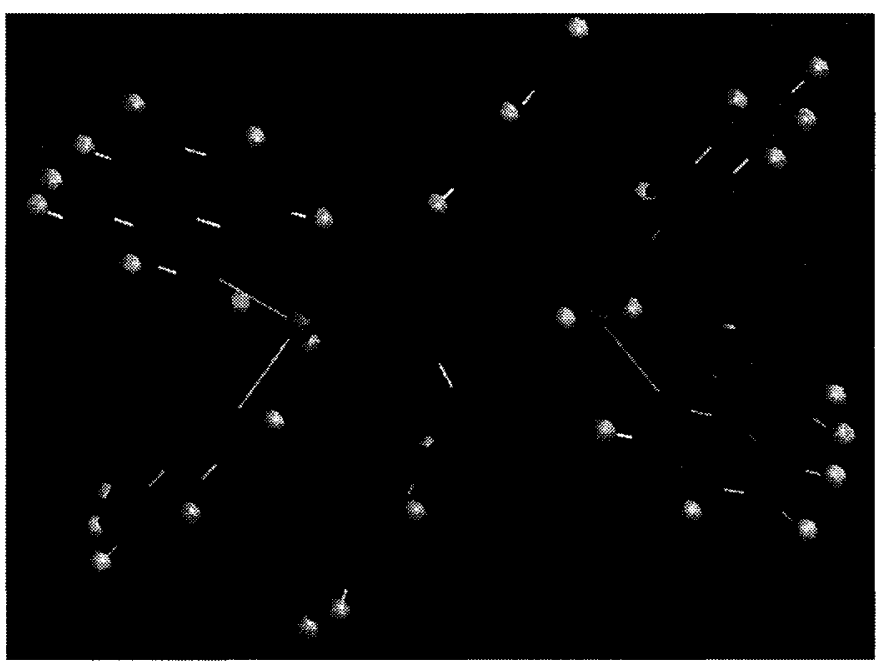

Figure IV.3. Calculated geometric structure of $\left[\left\{R u(b p y)_{2}\right\}_{2} \mu-P h_{2} d c h\right]^{2+}$ by Spartan ES as a model compound for [IV.3-Ru $]^{2+}$.

\section{IV.2.2 Biurea-based AB-type Monomer}

Compared to ligand IV.2, the only change in ligand IV.10 (Scheme IV.5) is the insertion of the $-\mathrm{NH}$ - moiety between the $\mathrm{DCH}$ and phenyl groups, aiming at reducing steric hindrance from the dipyridyl groups. Another purpose is to alter the redox property of the complex polymer. Compound IV.6 was prepared according to a known procedure ${ }^{59}$, starting from 4-bromoaniline (IV.4). After deprotection by the $\mathrm{Pd} / \mathrm{C}$ catalyzed hydrogenation, the boronic acid salt (IV.5) was then converted to its ester (IV.6) through a solid phase reaction with pinacol followed by the formation of the urethane (IV.7) with pheny chloroformate ${ }^{60}$. Upon reacting with excess hydrazine hydrate, compound IV.8 was obtained in $69 \%$ yield, which was then reacted with 4- bromophenyl isocyanate to afford IV.10. The corresponding IV.10-Ru was prepared by using the same procedure as for ligand IV.3. 


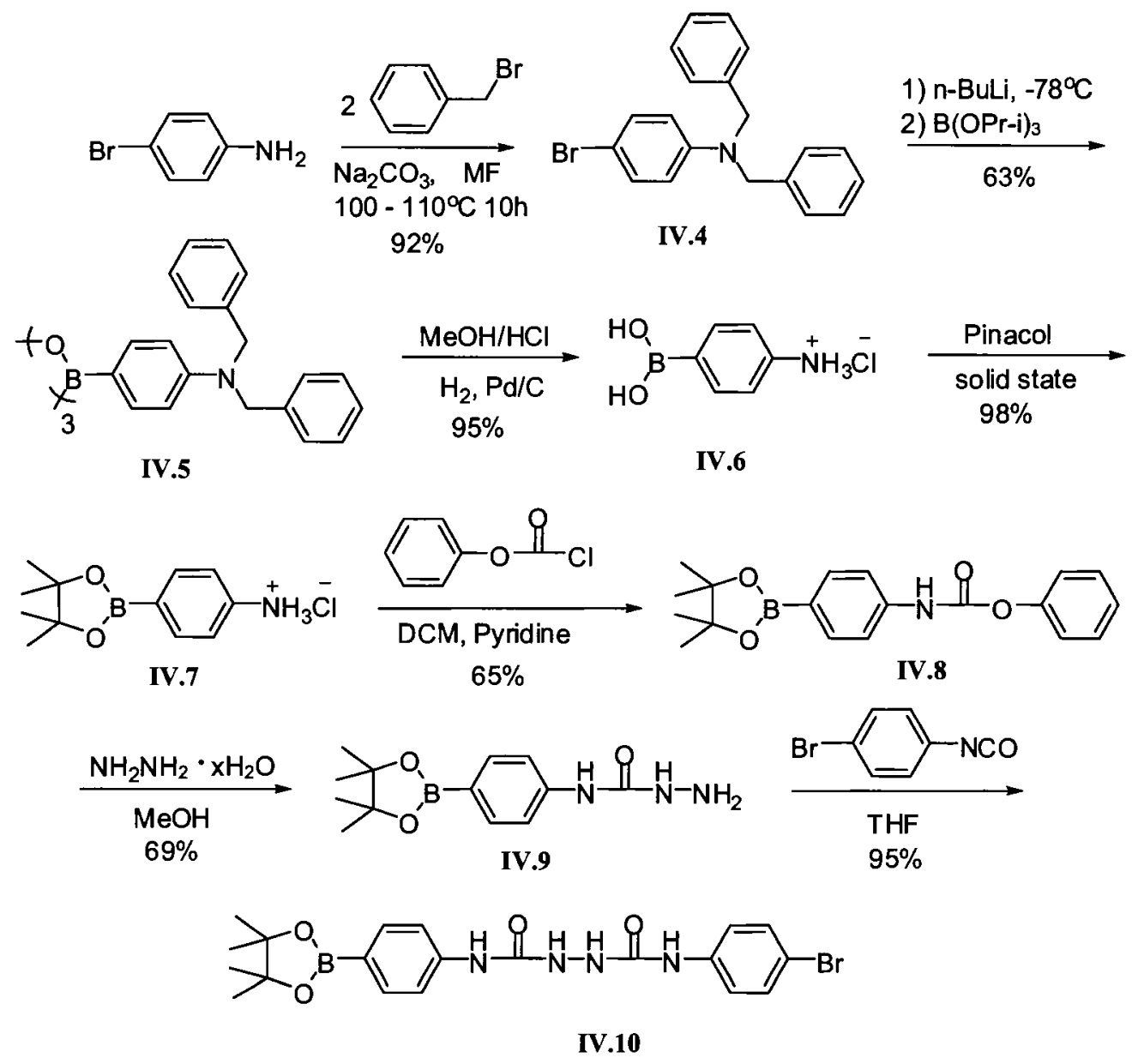

Scheme IV.5. Synthesis of Biurea-based AB-type ligand.

As shown in figure IV.4, the phenyl groups in the calculated geometric structure of $\left[\left\{R u(b p y)_{2}\right\}_{2} \mu-(N H P h)_{2} d c h\right]^{2+}$ (a model compound for [IV.10-Ru] ${ }^{2+}$ ) are not parallel to any of the bipyridyl group, and they stick out more compared to those in $\left[\left\{\boldsymbol{R} u(b p y)_{2}\right\}_{2}\right.$ $\left.\boldsymbol{\mu}-\boldsymbol{P} \boldsymbol{h}_{2} \boldsymbol{d c h}\right]^{2+}$. Such difference should reduce the steric hindrance of IV.10-Ru during polymerization. But, the viscosity of the product didn't give any increase against the starting monomer even when the reaction time was extended to $24 \mathrm{hrs}$. The low reactivity of IV.10-Ru may be caused by the relatively high electron-donating effect of the -NH- 
group attached to the phenyl ring. As we have discussed in previous chapter, after the formation of complex, the withdrawing ability of the carbonyl group is highly reduced to leave the -NH- group with high electron density, which makes IV.10-Ru less active in the step of oxidative-addition compared to electron-withdrawing group ${ }^{17}$.

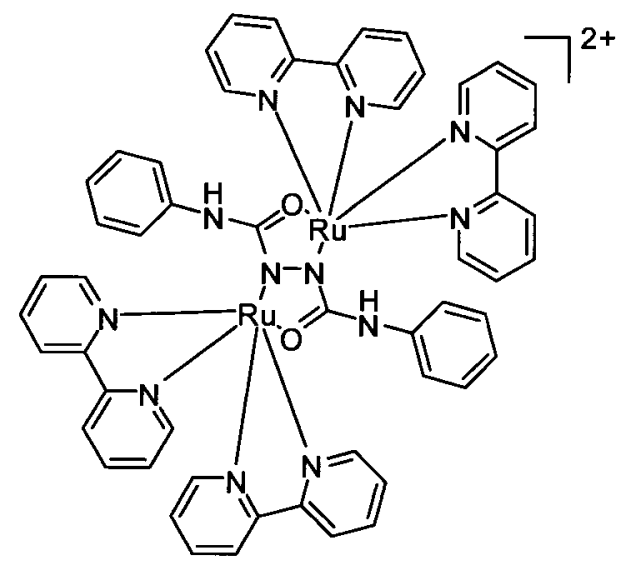

$\left[\{\boldsymbol{R u}(\mathrm{bpv})\},, \mu-(\mathrm{NHPh}),\left.d c h\right|^{2+}\right.$

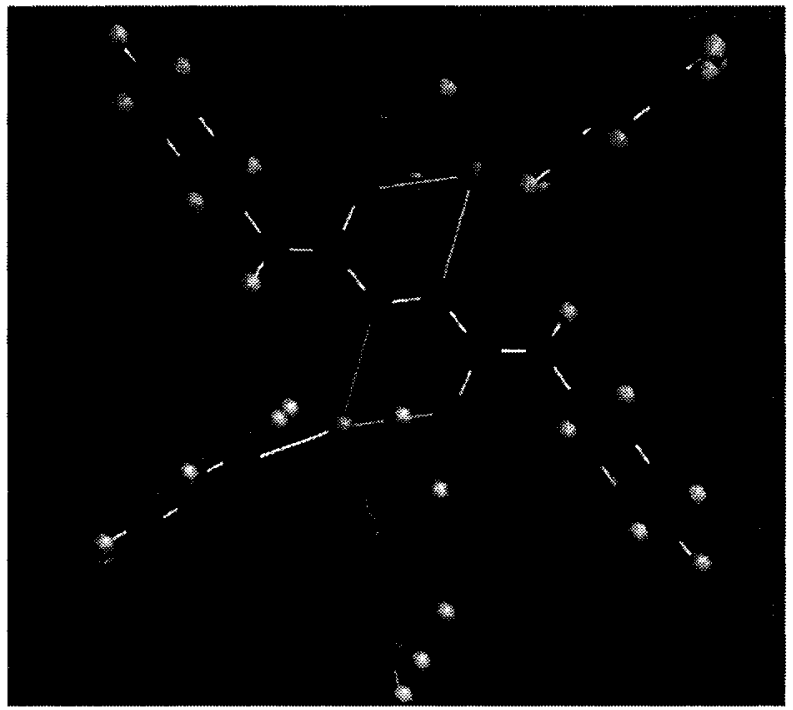

Figure IV.4. Calculated geometric structure of $\left[\left\{\mathrm{Ru}(\mathrm{bpy})_{2}\right\}_{2} \mu-(\mathrm{NHPh})_{2} d c h\right]^{2+}$ as a model compound for [IV.10-Ru $]^{2+}$ by Spartan ES.

\section{IV.3 AA-BB copolymers}

In the $\mathrm{AA} / \mathrm{BB}$ approach, the $\mathrm{DCH}-\mathrm{Ru}$ monomer can start with dibromo- or diboronic acid functional groups. However, it will take extra steps to synthesize a diboronic DCH ligand than a dibromo- DCH ligand. In addition, the relative inert biromo- DCH-Ru complex is easier to be purified by column chromatography. Thus, in the AA/BB approach, we decided to polymerize a dibromo- $\mathrm{DCH}-\mathrm{Ru}$ monomer with other diboronic acid or ester monomers, not the inverse. 


\section{IV.3.1 Synthesis and Characterization of Poly(DCH-Ru-alt-triglycol)}

DCH-Ru monomer IV.11-Ru was prepared from the complexation of AA ligand (IV.11) with $c$ is- $\mathrm{Ru}(\mathrm{bpy})_{2} \mathrm{Cl}_{2} \cdot 2 \mathrm{H}_{2} \mathrm{O}$ according to the method by $\mathrm{Kaim}^{58}$ in $73 \%$ yield after purification by column chromatography (Scheme IV.14). The TLC result on alumina plate only gave one spot (elueant: $\mathrm{ACN}$ ).

2

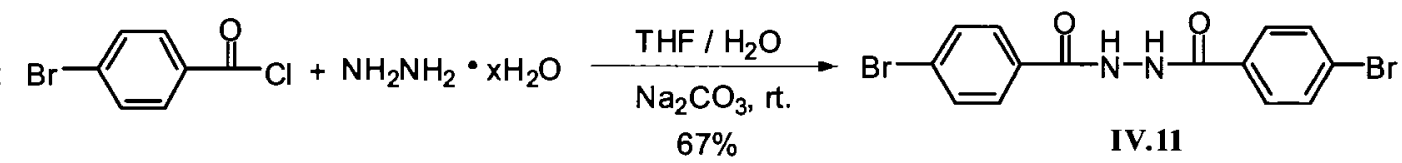

1) cis-Ru(bpy) ${ }_{2} \mathrm{Cl}_{2} \cdot 2 \mathrm{H}_{2} \mathrm{O}$ $\mathrm{EtOH} / \mathrm{H}_{2} \mathrm{O}, \mathrm{Na}_{2} \mathrm{CO}_{3}$

2) $\mathrm{NH}_{4} \mathrm{PF}_{6}$ $73 \%$

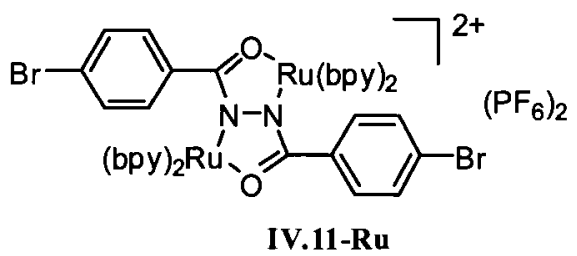

2 Br

$\mathrm{Br}-\mathrm{OH}+\mathrm{Cl}-\mathrm{KOH} / \mathrm{BuOH}$

$75 \%$

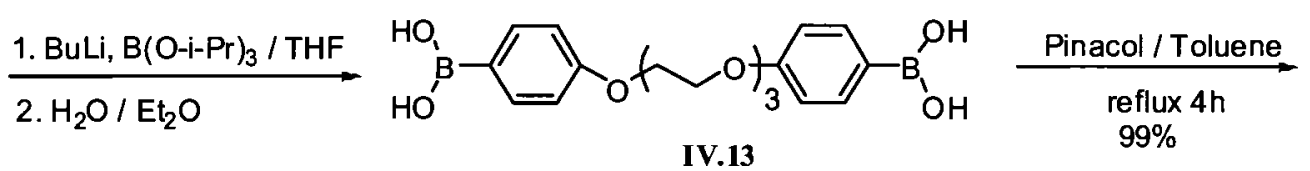<smiles>CC1(C)OB(c2ccc(OCCOc3ccc(B4OC(C)(C)C(C)(C)O4)cc3)cc2)OC1(C)C</smiles>

IV.14<smiles>Brc1ccc(OCCOc2ccc(Br)cc2)cc1</smiles>

IV.12

Scheme IV.6. Synthesis of monomer IV.11-Ru complex and BB monomer IV.14.

By comparing the IR spectra (Figure IV.5) of the complex (IV.1-Ru) to its ligand (IV.11), the major difference is the disappearance of the $\mathrm{N}-\mathrm{H}$ band at $3200 \mathrm{~cm}^{-1}$ and the appearance of a P-F band at $841 \mathrm{~cm}^{-1}$. The ${ }^{13} \mathrm{C}$ NMR spectrum of IV.11-Ru (Figure IV.6) shows 29 peaks with 2 different carbonyl peaks at 175.2 and 175.0 ppm separately, which 
indicates the presence of two diastereomers. In the dinuclear DCH-Ru complex, ruthenium metal center can possess right-handed or left-handed chirality $(\Delta$ or $\Lambda)$, respectively. For a symmetrical DCH-Ru complex, there exist a meso $(\Delta \Lambda)$ and two enantiomeric isomers $(\Delta \Delta$ and $\Lambda \Lambda)$. For each diasteromer, there will be 25 resonance peaks in the ${ }^{13} \mathrm{C}$ NMR spectrum. As a result, there should be totally 42 peaks in the ${ }^{13} \mathrm{C}$ NMR spectrum. Due to the signal overlapping, only 39 peaks are seen in figure IV.6. This finding is consistent to that of its structural isomer of oxamide-Ru complexes studied in our $1 b^{61}$.

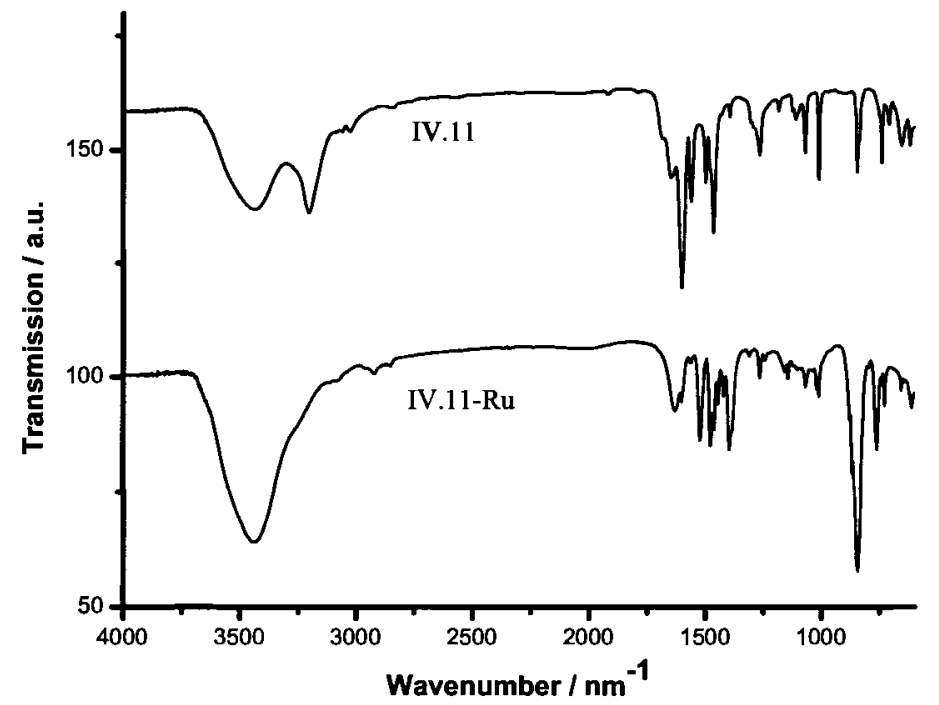

Figure IV.5. IR spectra of compound IV.11 and its complex IV.11-Ru.

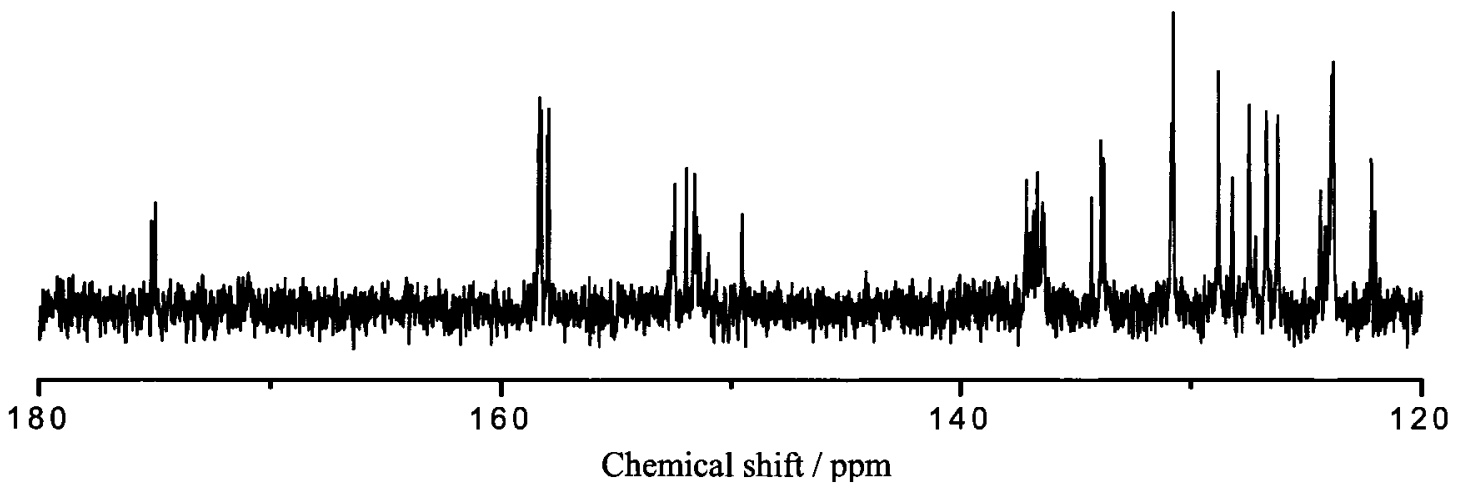

Figure IV.6. ${ }^{13} \mathrm{C}$ NMR spectrum of monomer IV.11-Ru. 
Compound IV.14 is the ester derivative of its boronic acid IV.13 that was synthesized according to a known procedure ${ }^{62}$ from its precursor IV.12 and purified by flash column chromatography (eluant: hexane/ether $=2 / 1)($ Scheme IV.14). Compound IV.12 was obtained in 75\% yield by refluxing 4-bromophenol with 1,2-bis(2chloroethoxy)ethane in n-butanol with the presence of $\mathrm{KOH}^{63}$. Refluxing IV.13 and pinacol in toluene gave the BB monomer IV.14 in quantitative yield.

The polymerization was carried out in degassed DMF at $100{ }^{\circ} \mathrm{C}$ with $\mathrm{K}_{2} \mathrm{CO}_{3}$ as a base and $\mathrm{Pd}\left(\mathrm{PPh}_{3}\right)_{4}$ as a catalyst (Scheme IV.7). The inherent viscosity of the polymerization product was found to be $0.25 \mathrm{dL} / \mathrm{g}(\mathrm{c}=5 \mathrm{mg} / \mathrm{mL})$, suggesting the formation of an oligomer. The IR spectrum of this product shows a band at $840 \mathrm{~cm}^{-1}$ for the P-F stretching from $\mathrm{PF}_{6}^{-}$, a band at $1631 \mathrm{~cm}^{-1}$ from $-\mathrm{CON}-\left(18 \mathrm{~cm}^{-1}\right.$ lower than the carbonyl group in the ligand), two bands at $2925 \mathrm{~cm}^{-1}$ and $2861 \mathrm{~cm}^{-1}$ for the methylene moiety and a band at $1264 \mathrm{~cm}^{-1}$ for the ether linkage from monomer IV.14. The boronaryl absorbance at $1144 \mathrm{~cm}^{-1}$ in the starting compound IV.14 $4^{64}$ was not observed in the product. The integrals of its ${ }^{1} \mathrm{H}$ NMR spectrum give the expected numbers of the different protons: 48 protons between 6.36 and $9.34 \mathrm{ppm}$ from all the benzene rings, 4 protons at 4.15, 3.80 and $3.66 \mathrm{ppm}$ for each methylene moieties. The cyclic voltammogram spectrum of the oligomer shows two reversible pairs of oxidation couples starting at $0.45 \mathrm{~V}$ and $1.00 \mathrm{~V}$ which is $50 \mathrm{mV}$ lower than those of the starting monomer IV.11-Ru. 

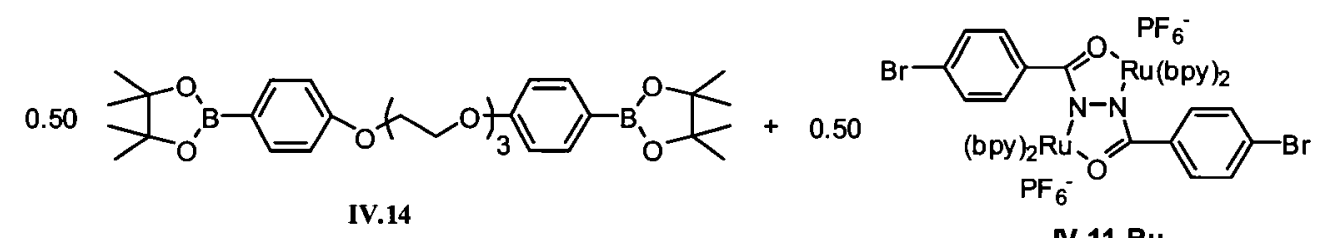

N.11-Ru

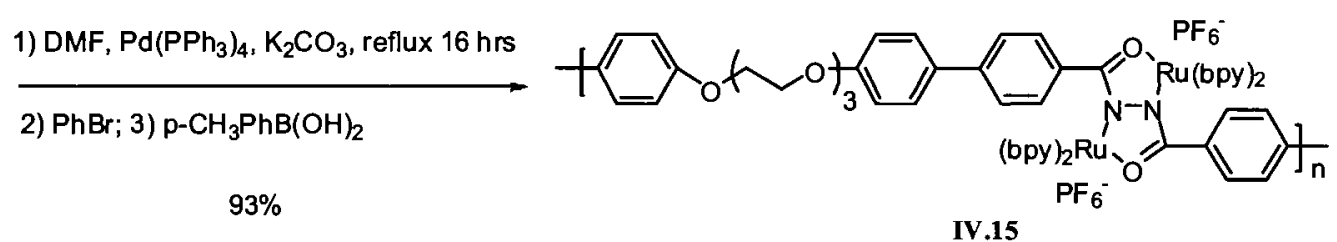

Scheme IV.7. Suzuki cross-coupling polymerization of IV.11-Ru and IV.14.

\section{IV.3.2 Synthesis and Characterization of Poly(fluorene-co-DCH-Ru)}

Poly(9-alkylfluorene)s are highly fluorescent in solution and in the solid-state ${ }^{65}$. Rigid-rod polyfluorene has a tendency to form excimer aggregates, which leads to a redshifted emission to long wavelength $(>500 \mathrm{~nm})^{66}$. Its emission spectrum overlaps well with the MLCT absorption (360 - 520 nm) of DCH-Ru, thus the copolymers could be a good model for energy-transfer study. Herein, we chose commercially available 9,9dioctylfluorene-2,7-bis(trimethylborate) (IV.16) as a monomer and 9,9-dioctyl-2,7dibromofluorene (IV.17) and DCH-Ru monomer IV.11-Ru (Scheme IV.8). The two octyl side chains in IV.16 are expected to impart the solubility to the polymers. The molar feed ratios of IV.11-Ru to the total starting monomers are $0.50,0.44,0.22$ and 0.11 , respectively. Except for the ratio at 0.11 , the polymerization at all the other feed ratios produced high-molecular-weight copolymers according to the viscosity data. Polyfluorene is non-polar and soluble in toluene, chloroform and THF. When the molar feed ratio to the total starting monomers is lower than 0.22 , the product was not polar enough to be soluble in DMF, which was obtained only in low molecular weight. 
0.50

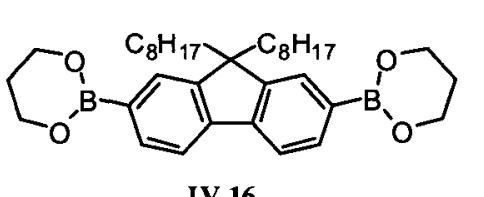

IV.16

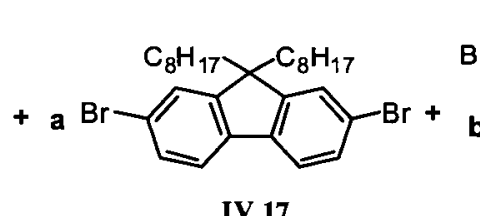

IV.17

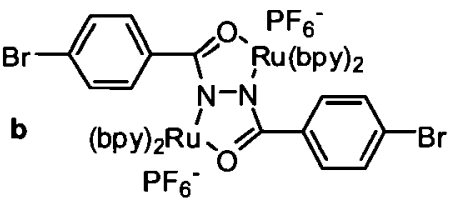

IV.11-Ru

$\mathrm{K}_{2} \mathrm{CO}_{3}$, reflux $16 \mathrm{hrs}$

1) $D M F, P d\left(P P h_{3}\right)_{4}, K_{2} \mathrm{CO}_{3}$, reflux $16 \mathrm{hrs}$

2) $\mathrm{PhBr} ; 3) \mathrm{p}-\mathrm{CH}_{3} \mathrm{PhB}(\mathrm{OH})_{2}$

$97 \%$

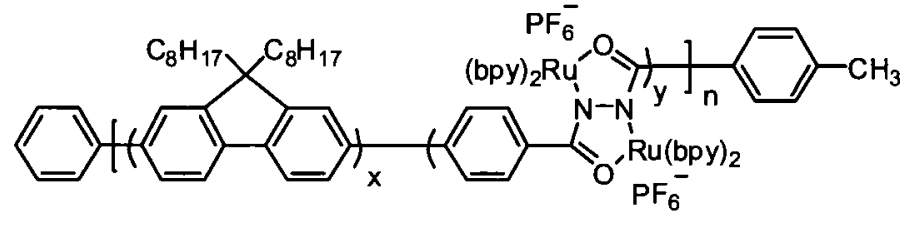

$a=0.28, b=0.22:$ IV.18 $(x=0.77, y=0.23)$,

$a=0.06, b=0.44$ : IV.19 $(x=0.56, y=0.44)$,

$a=0 \quad, b=0.50: N .20(x=0.50, y=0.50)$

Scheme IV.8. Preparation of poly(fluorene-co-DCH-Ru) by Suzuki cross-coupling polymerization.

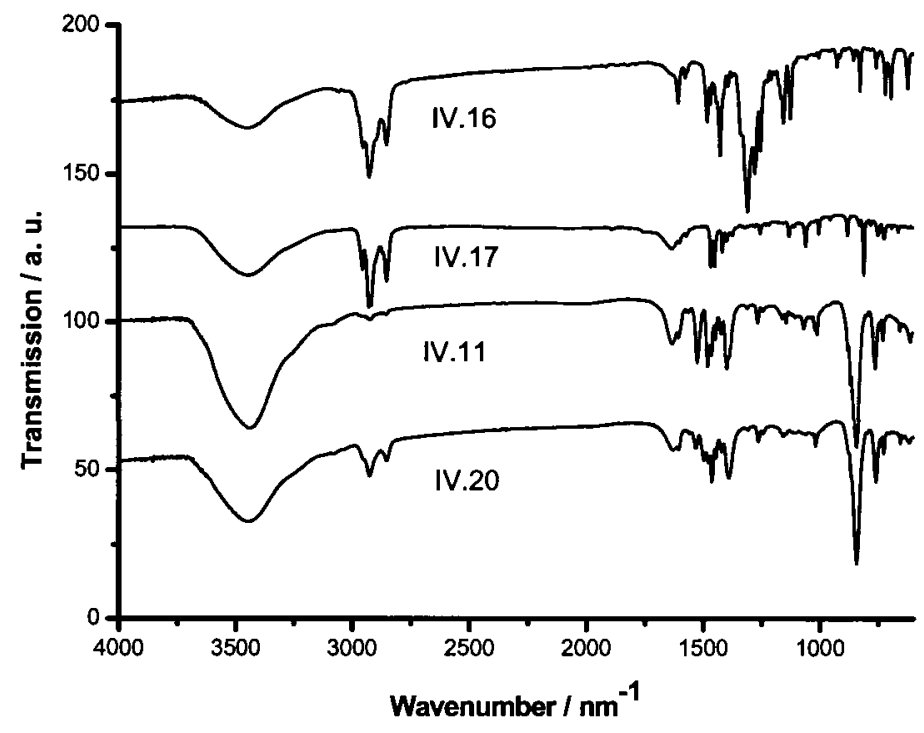

Figure IV.7. IR spectra of starting monomers IV.16, IV.17 and IV.11-Ru and product IV.20 in KBr.

The polymer structures were characterized by IR and ${ }^{1} \mathrm{H}$ NMR. The broad band from $3700 \mathrm{~cm}^{-1}$ to $3100 \mathrm{~cm}^{-1}$ in the IR spectrum is from the water in the $\mathrm{KBr}$ pellet. By comparing the IR spectra (Figure IV.7) of the product (IV.20) and the starting monomers 
(IV.11-Ru, IV.16 and IV.17), we can see that for the product, the band at 2848 - 2952 $\mathrm{cm}^{-1}\left(v_{\mathrm{C}-\mathrm{H}}\right)$ is from IV.16 and IV.17, and the bands at $1633 \mathrm{~cm}^{-1}\left(v_{\mathrm{C}=\mathrm{O}}\right)$ and $844 \mathrm{~cm}^{-1}\left(v_{\mathrm{P}-\mathrm{F}}\right)$ are from IV.11-Ru. The ${ }^{1} \mathrm{H}$ NMR spectrum of IV.20 in figure IV.8 shows the aromatic protons from fluorene and DCH-Ru moieties at $6.38-9.44 \mathrm{ppm}(\mathrm{m}, 46 \mathrm{H})$ and aliphatic protons at $2.13 \mathrm{ppm}(\mathrm{s}, 3 \mathrm{H}), 1.04 \mathrm{ppm}(\mathrm{s}, 21 \mathrm{H})$ and $0.62 \mathrm{ppm}(\mathrm{s}, 10 \mathrm{H})$. The integrals of the ${ }^{1} \mathrm{H}$ NMR spectra of IV.19 and IV.20 also give the numbers of protons close to the calculated values according to the feed ratios. Unfortunately, it's difficult to use the ${ }^{1} \mathrm{H}$ NMR data to calculate the degree of polymerization for these polymers due to the overlaps of the resonance signals of the methyl end-capped group and the octyl groups at $\sim 2.4 \mathrm{ppm}$.

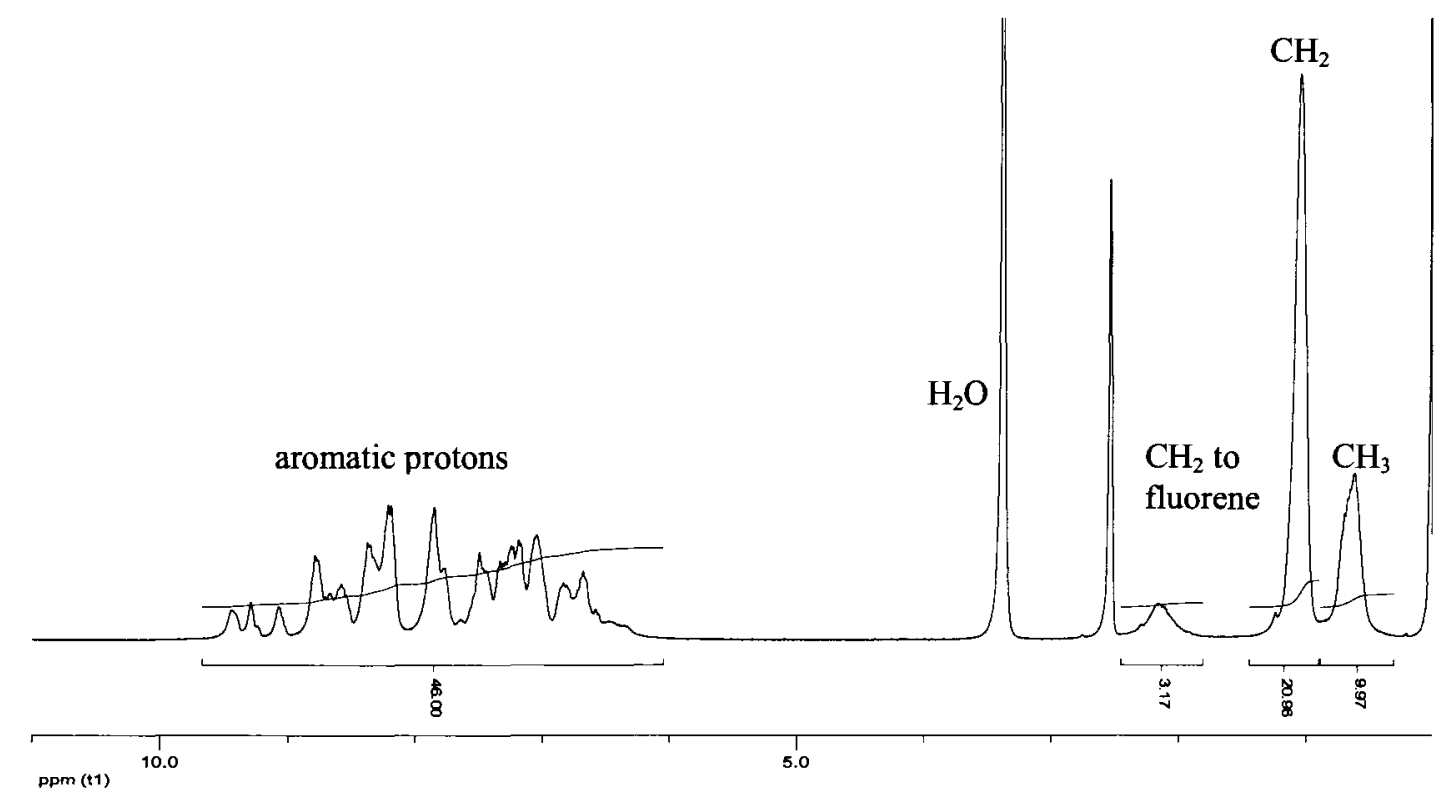

Figure IV.8. ${ }^{1}$ H NMR spectrum (300 MHz, DMSO- $d_{6}$ ) of IV.20. 


\section{IV.3.3 Solution Property}

In the polymer backbone, each DCH-Ru unit bears two positive charges. Therefore, these polymers were expected to behave like polyelectrolytes. The reduced viscosities, $\eta_{\text {red, }}$ of polymers IV.18I, V.19I and V.20 containing a different amount of DCH-Ru were measured at $30^{\circ} \mathrm{C}$ and shown in figure IV.9 as a function of polymer concentration in DMF. For each polymer solution without the addition of salt $\left(\mathrm{NH}_{4} \mathrm{PF}_{6}\right)$, we observed a pronounced polyelectrolyte effect, i.e., the reduced viscosity increases with the decrease of concentration, because of the long-range electrostatic interactions. Under low ionic strength conditions, this observed increase of the reduced viscosity upon dilution can be described by the Fuoss-Strauss equation ${ }^{67}$ :

$$
\eta_{\text {red }}^{-1}=\mathrm{c} / \eta_{\mathrm{sp}}=1 /[\eta]+(\mathrm{B} /[\eta]) \mathrm{c}^{1 / 2}
$$

where, $\mathrm{c}$ is concentration, $\eta_{\mathrm{sp}}$ is specific viscosity, $[\eta]$ is intrinsic viscosity, and B is a constant reflecting the interaction of polyelectrolytes. This equation can be used to estimate intrinsic viscosity $([\eta])$ by plotting $\left(\mathrm{c} / \eta_{\mathrm{sp}}\right)$ vs. $\mathrm{c}^{1 / 2}$. A more accurate way to measure $[\eta]$ is to add salt to the polyelectrolyte solution to suppress the polyelectrolyte effect by screening out electrostatic interactions. In the presence of $0.01 \mathrm{M} \mathrm{NH}_{4} \mathrm{PF}_{6}$, the reduced viscosity of each polymer solution can be fitted by a straight line. Thus, the intrinsic viscosities are $0.69,1.06$ and $0.70 \mathrm{~mL} / \mathrm{g}$ for polymer IV.18, IV.19 and IV.20, respectively (Table IV.1). 


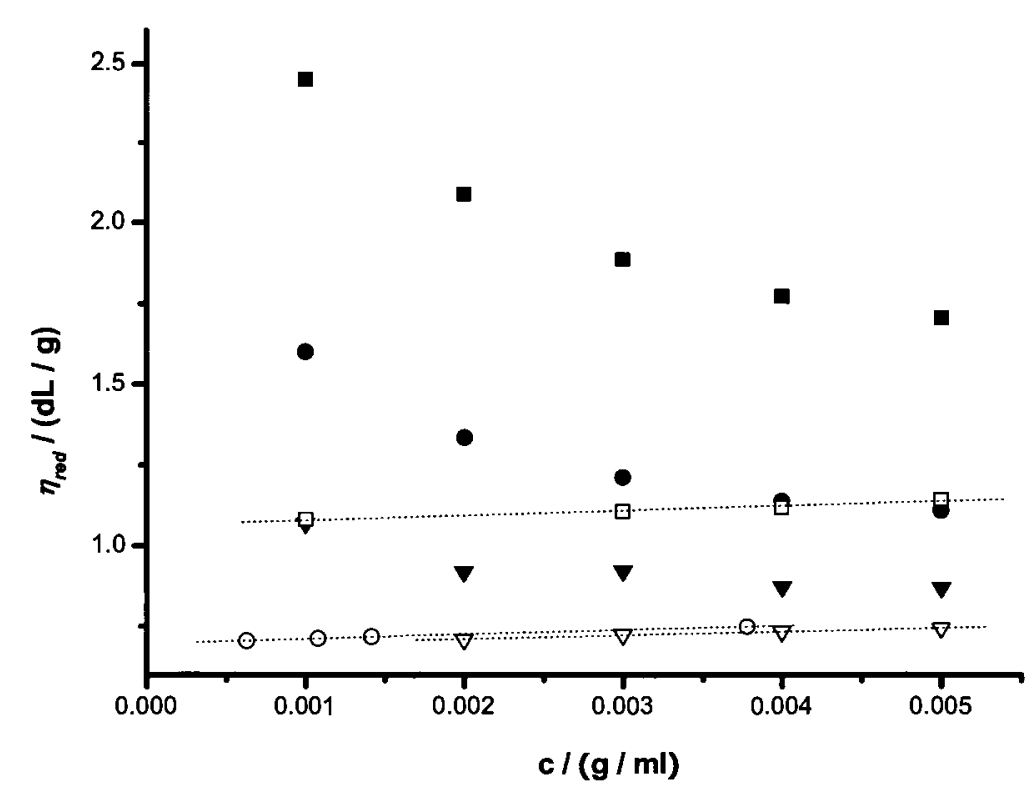

Figure IV.9. Reduced viscosities as a function of polymer concentration in DMF without or with salt $\left(0.01 \mathrm{M} \mathrm{NH}_{4} \mathrm{PF}_{6}\right)$ at $30^{\circ} \mathrm{C}$ : (B) IV.18, salt free; (X) IV.18, with salt; (!) IV.19, salt free; ( $\forall$ ) IV.19 with salt; (,) IV.20, salt free; (-) IV.20, with salt.

Table IV.1. Intrinsic viscosity and GPC data $^{\mathrm{b}}$ of copolymers IV.18, IV.19 and IV.20.

\begin{tabular}{ccccc}
\hline Compound & {$[\boldsymbol{\eta}]^{\mathrm{a}} /(\mathrm{dL} / \mathrm{g})$} & $\bar{M}_{w} / \mathrm{kD}$ & $\bar{M}_{n} / \mathrm{kD}$ & PDI \\
\hline IV.18 & 0.69 & 45660 & 20310 & $2.25(95.0 \%)^{\mathrm{c}}$ \\
IV.19 & 1.06 & 2640 & 2360 & $1.12(5.0 \%)^{\mathrm{c}}$ \\
IV.20 & 0.70 & 4490 & 2840 & $1.58^{\mathrm{c}}$ \\
\hline
\end{tabular}

${ }^{a}$ intrinsic viscosity. ${ }^{b}$ DMF solvent relative to polystyrene standards. ${ }^{c}\left[\mathrm{NH}_{4} \mathrm{PF}_{6}\right]=2 \mathrm{mM}$.

The molecular weight measurement was carried out on gel permeation chromatography (GPC) with polystyrene as standards. Unfortunately, under the normal conditions, elution with $\mathrm{CHCl}_{3}$ or $\mathrm{DMF}$, often gives uninterpretable results for polyelectrolytes, especially for those containing charged metals, due to the strong interaction between these polymers and the packing materials in GPC column (e.g., 
polystyrene/divinyl benzene crosslinked beads). Addition of a salt in the eluent is proven to be effective to break up such interaction and useful in obtaining the more realistic chromatogram for metal-containing polymers ${ }^{68}$.

The GPC traces of the copolymers are illustrated in figure IV.10. We first used 1 $\mathrm{mM} \mathrm{NH}_{4} \mathrm{PF}_{6}$ in DMF as an eluent. This solvent system could only elute polymer IV.18 which has the lowest total metal charges among the three polymers. When the concentration of $\mathrm{NH}_{4} \mathrm{PF}_{6}$ was increased to $2 \mathrm{mM}$, copolymer IV.19 and IV.20 were also able to be eluted. The GPC data are shown in Table IV.1. For copolymer IV.18, the small shoulder peak at longer retention time indicates the presence of low molecular weight oligomers with a portion of $5.00 \%$ according to the integral of the peak. Because of the significant structural difference between the Ru-containing copolymers and polystyrene standard, only the apparent molecular weights of a series of polymers with similar structures can be obtained ${ }^{69}$, in addition to the polydispersity index (PDI). PDI is defined by the ratio of $\bar{M}_{w} / \bar{M}_{n}$, where $\bar{M}_{w}$ and $\bar{M}_{n}$ are the weight- and number-average molecular weight of the sample, respectively. By comparing the PDI data of the three polymers in table IV.1, IV.20 turns out to have the lowest polydispersity index and also the lowest $\bar{M}_{w}$. 


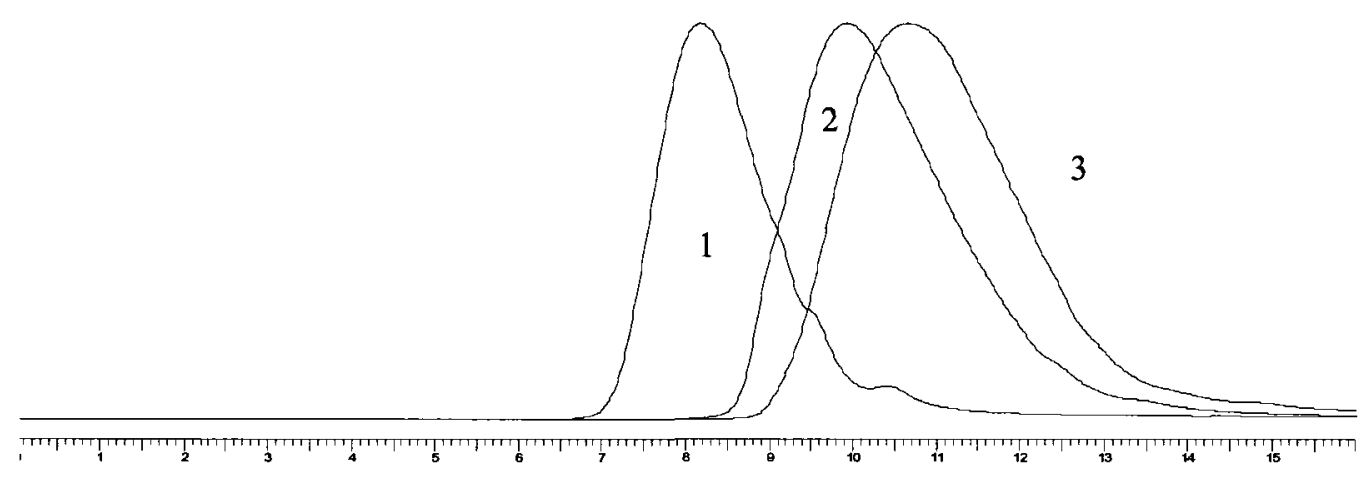

Retention Time / min

Figure IV.10. GPC traces of DCH-Ru copolymers using $2 \mathrm{mM} \mathrm{NH}_{4} \mathrm{PF}_{6}$ in DMF as an eluant : 1) IV.18, 2) IV.19, 3) IV.20.

\section{IV.3.4 Electrochemical characterization}

The cyclic voltammograms of the monomers (IV.11-Ru and IV.16) and copolymers IV.18, IV.19 and IV.20 were illustrated in figure IV.11 and the electrochemistry data are presented in Table IV.2. The cyclic voltammogram of lowmolecular-weight IV.20 (trace 3 in Figure IV.11) bears two pairs of reversible oxidation peaks owing to the dinuclear $\mathrm{Ru}$ component and one irreversible peak from the fluorene part. The $1^{\text {st }}$ redox couple is assigned to $\mathrm{Ru}^{\mathrm{II}} / \mathrm{Ru}^{\mathrm{II}} \leftrightarrow \mathrm{Ru}^{\mathrm{II}} / \mathrm{Ru}^{\mathrm{III}}$, and the $2^{\text {nd }}$ redox couple is assigned to $\mathrm{Ru}^{\mathrm{II}} / \mathrm{Ru}^{\mathrm{III}} \leftrightarrow \mathrm{Ru}^{\mathrm{III}} / \mathrm{Ru}{ }^{\mathrm{III}}$. The oxidation potentials of these two couples are very close to those of the starting monomer IV.11-Ru, which suggests that the interaction between two dinuclear units through fluorene moiety is too weak, and there is no conjugation through the fluorene spacer. Therefore, the three polymers show only two redox couples from the DCH-Ru fragment and the positions are very close in cyclic voltammograms despite their different chain structures. Meanwhile, the oxidation potential of the fluorene part is anodically shifted with respect to the starting monomer IV.16 ( $1.56 \mathrm{~V}$ vs. $1.49 \mathrm{~V}$ vs. NHE). This is because the electron-deficient $\mathrm{Ru}^{\mathrm{III}} / \mathrm{Ru}^{\mathrm{III}}$ 
moiety tends to lower both the HOMO and LUMO of fluorene, making it more difficult to oxidize. Like other polyelectrolytes, the solubility of these polymers decreases with the increase of the ionic strength, which makes it difficult to carry out the electrochemical studies in a $0.1 \mathrm{M}$ electrolyte/ACN or DMF solution for those high-molecular-weight polymers. Thus, these polymers were coated on a Pt-disc electrode $(1 \mathrm{~mm}$ diameter) for electrochemical work. The two cycles of CV for copolymer IV.18 are fully repeatable, while for copolymer IV.19 and IV.20, compared to the $1^{\text {st }}$ cycle of CV, the $2^{\text {nd }}$ cycle shows a large drop regarding the current intensity due to partial dissolution of the coated polymers in the electrolyte solution.

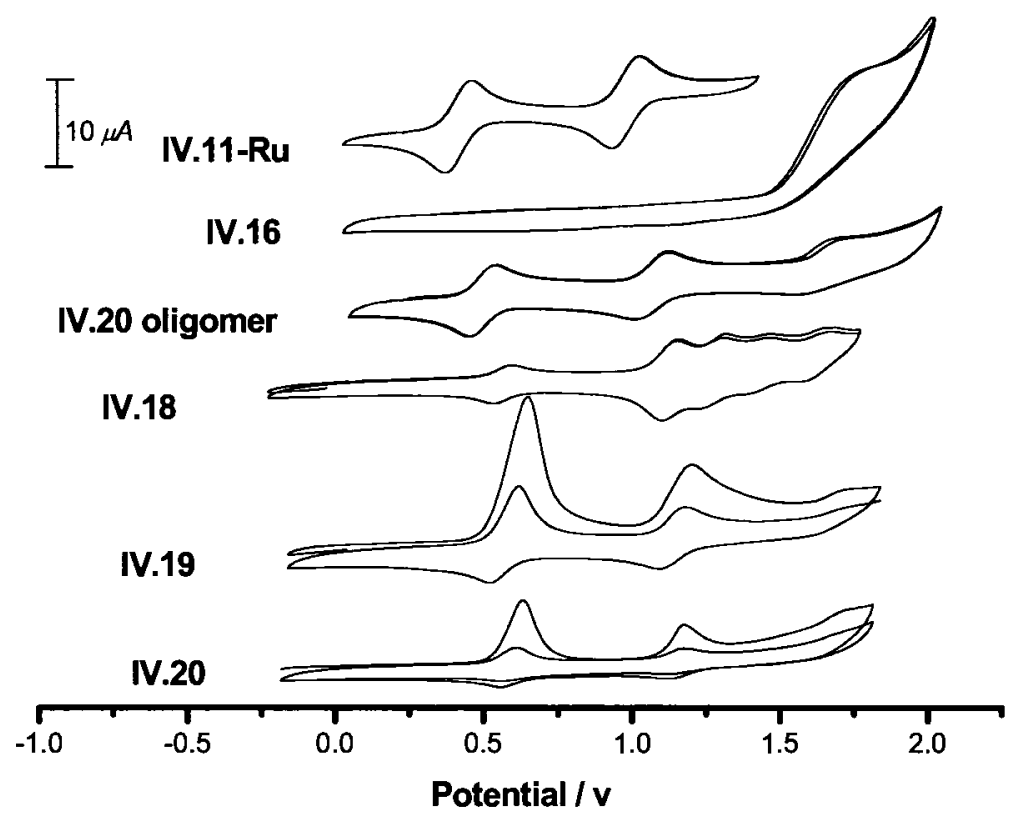

Figure IV.11. Cyclic voltammograms of monomers and copolymers IV.18, IV.19 and IV.20 in 0.1M TBAH/ACN solution at room temperature (polymers are coated on electrode).

Unlike IV.19 and IV.20, each showing only one oxidation peak for the fluorene moiety in $\mathrm{CV}$ at a relatively higher oxidation potential $(\sim 1.60 \mathrm{~V})$, polymer IV.18 shows multiple oxidation peaks for its fluorene fragments at lower potentials $(1.24-1.57 \mathrm{~V})$. This 
difference can be attributed to the formation of relative longer oligofluorene fragments on the polymer chains. Compared to single fluorene molecule, the HOMO energy level is higher in fluorene oligomers, making it easier to oxidize.

Table IV.2. Electrochemistry data ${ }^{\mathrm{a}}$ of monomers and copolymers taken in $0.1 \mathrm{M}$ TBAH/ACN.

\begin{tabular}{|c|c|c|c|c|c|}
\hline compound & $\mathrm{E}_{1}^{\mathrm{ox}} / \mathrm{V}$ & $\mathrm{E}_{2}{ }^{\mathrm{ox}} / \mathrm{V}$ & $E_{3}{ }^{\text {ox }} / V$ & $\Delta \mathrm{E}_{2-1} / \mathrm{V}$ & $k_{\mathrm{c}}^{\mathrm{c}}$ \\
\hline IV.16 & 1 & 1 & 1.45 & 1 & 1 \\
\hline IV.11-Ru & 0.52 & 1.05 & 1 & 0.55 & $2.0 \times 10^{9}$ \\
\hline $\begin{array}{c}\text { IV.20 } \\
\text { oligomer }\end{array}$ & 0.48 & 1.05 & 1.60 & 0.57 & $4.35 \times 10^{9}$ \\
\hline IV.18 & 0.50 & 1.06 & $1.24-1.57$ & 0.56 & $3.0 \times 10^{9}$ \\
\hline IV.19 & 0.51 & 1.06 & 1.61 & 0.55 & $2.0 \times 10^{9}$ \\
\hline IV.20 & 0.51 & 1.06 & 1.60 & 0.55 & $2.0 \times 10^{9}$ \\
\hline
\end{tabular}

\section{IV.3.5 UV-vis-NIR Spectroscopic Study}

Figure IV.12 shows the UV-vis spectra of monomer IV.11-Ru and three copolymers in acetonitrile and the data are presented in Table IV.3. For monomer IV.11$\mathbf{R u}$, the strong absorption band at about $300 \mathrm{~nm}$ is attributed to the intraligand $\pi \rightarrow \pi^{*}$ (bpy) transitions. The broad absorption bands at $357 \mathrm{~nm}$ and $524 \mathrm{~nm}$ are assigned to typical spin-allowed metal-to-ligand charge-transfer (MLCT) transitions. For copolymer IV.18, IV.19 and IV.20, they all show two absorption peaks at about $300 \mathrm{~nm}$ and $525 \mathrm{~nm}$, while the absorption peak around $360 \mathrm{~nm}$ is blue-shifted for IV.19 and IV.20 and red-shifted 
for IV.18 due to different spectral overlapping. Fluorene monomer has strong UV absorption lower than $320 \mathrm{~nm}$, while the absorption maximum of polyfluorene is around $380 \mathrm{~nm}$. In IV.19 and IV.20, the polymer chain structure is close to alternating to make the spectral overlapping happen between the DCH-Ru and the fluorene moieties, resulting in a blue-shift to $\sim 345 \mathrm{~nm}$. For copolymer IV.18, there exists longer oligofluorene fragments, which make the spectral overlapping between the DCH-Ru and the oligofluorenes red-shift to $375 \mathrm{~nm}$.

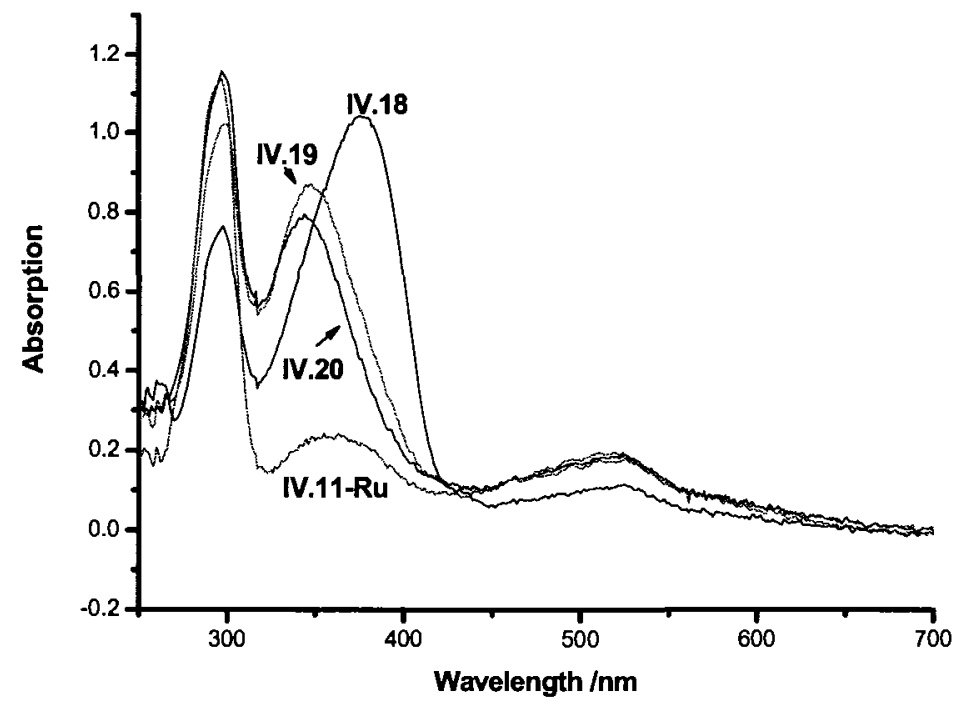

Figure IV.12. UV-vis-NIR spectra of starting monomers and copolymer products. in $\mathrm{ACN}$ at a concentration of $0.020 \mathrm{mg} / \mathrm{ml}$.

As the intensity of the absorption band at $525 \mathrm{~nm}$ is associated with MLCT of $\mathrm{DCH}-\mathrm{Ru}$ fragment and the position is almost the same in both the monomer complex and the copolymers, it's feasible to use a colorimetric method for the detection of the Ru content in polymers. Within a $3 \%$ error, the measured data (Table IV.4) are in a good agreement with those as calculated from the feed ratios. 
Table IV.3. Photophysical properties of monomer 11 and three copolymers in ACN.

\begin{tabular}{|c|c|c|c|c|}
\hline \multirow{2}{*}{ Compound } & \multirow{2}{*}{$\begin{array}{c}\text { Absorption } \\
\lambda_{\max } / \mathrm{nm}\left[\log \left(\varepsilon / \mathrm{M}^{-1} \mathrm{~cm}^{-1}\right]\right.\end{array}$} & \multirow[b]{2}{*}{ Assignment } & \multicolumn{2}{|c|}{ Emission $\lambda_{\max } / \mathrm{nm}$} \\
\hline & & & $\lambda_{\mathrm{ex}}=320 \mathrm{~nm}$ & $\lambda_{\mathrm{ex}}=560 \mathrm{~nm}$ \\
\hline \multirow{2}{*}{ IV.11-Ru } & $297(4.76)$ & $\pi \rightarrow \pi^{*}$ & \multirow{2}{*}{790} & \multirow{2}{*}{418} \\
\hline & 357 (IV.24), 524 (4.17) & MLCT & & \\
\hline \multirow{2}{*}{ IV.18 } & $298(4.36)$ & $\pi \rightarrow \pi^{*}$ & \multirow{2}{*}{790} & \multirow{2}{*}{408} \\
\hline & $375(4.49), 525(3.54)$ & MLCT & & \\
\hline \multirow{2}{*}{ IV.19 } & $298(4.62)$ & $\pi \rightarrow \pi^{*}$ & \multirow{2}{*}{790} & \multirow{2}{*}{403} \\
\hline & 347 (IV.55), 525 (3.87) & MLCT & & \\
\hline \multirow{2}{*}{ IV.20 } & $297(4.70)$ & $\pi \rightarrow \pi^{*}$ & \multirow{2}{*}{790} & \multirow{2}{*}{418} \\
\hline & $345(4.54), 525(3.92)$ & MLCT & & \\
\hline
\end{tabular}

Table IV.4. Measured Ru content by colorimetric method.

\begin{tabular}{cccc}
\hline copolymer & $\begin{array}{c}\text { molar ratio in feed } \\
\text { IV.11-Ru:IV.16: IV.17 }\end{array}$ & $\begin{array}{c}\text { Calculated Ru } \\
\text { wt\% }\end{array}$ & $\begin{array}{c}\text { Measured Ru } \\
\text { wt\% }\end{array}$ \\
\hline IV.18 & $0.22: 0.50: 0.28$ & 7.4 & 7.9 \\
\hline IV.19 & $0.44: 0.50: 0.06$ & 11.0 & 11.0 \\
\hline IV.20 & $0.50: 0.50: 0$ & 11.6 & 11.6 \\
\hline
\end{tabular}

\section{IV.3.6 Photoluminescent and Electroluminescent Properties}

The photoluminescent spectra $\left(\lambda_{\mathrm{ex}}=320 \mathrm{~nm}\right)$ of the three copolymers (IV.18, IV.19 and IV.20) were obtained in ACN at a concentration of $2.14 \times 10^{-5} \mathrm{M}$ for each and are shown in figure IV.13. For IV.20, its maximum quantum yield in solution was obtained at a concentration of $2.14 \times 10^{-5} \mathrm{M}$ by adjusting the concentration, which suggests that at a lower concentration, the quenching of the PL is mainly through intrachain energy transfer; while at a higher concentration, both intrachain and interchain 
energy transfer will take place. Quantum yields of the copolymers, relative to poly $\left(9,9^{\prime}-\right.$ dioctylfluorene) (PFO), were determined by the following equation ${ }^{70}$ :

$$
\phi_{2}=\phi_{I}\left(I_{2} / I_{1}\right)\left(n_{2} / n_{1}\right)^{2}\left(1-10^{-A I}\right) /\left(1-10^{-A 2}\right)
$$

where $\phi$ is the emission quantum yield of an unknown or a reference compound, $I$ is the integral of the emission intensity (area under the emission maximum), $A$ is the absorbance at $\lambda_{\mathrm{ex}}$ in a $1-\mathrm{cm}$ cell, and $\mathrm{n}$ is the refractive index of the solvent.

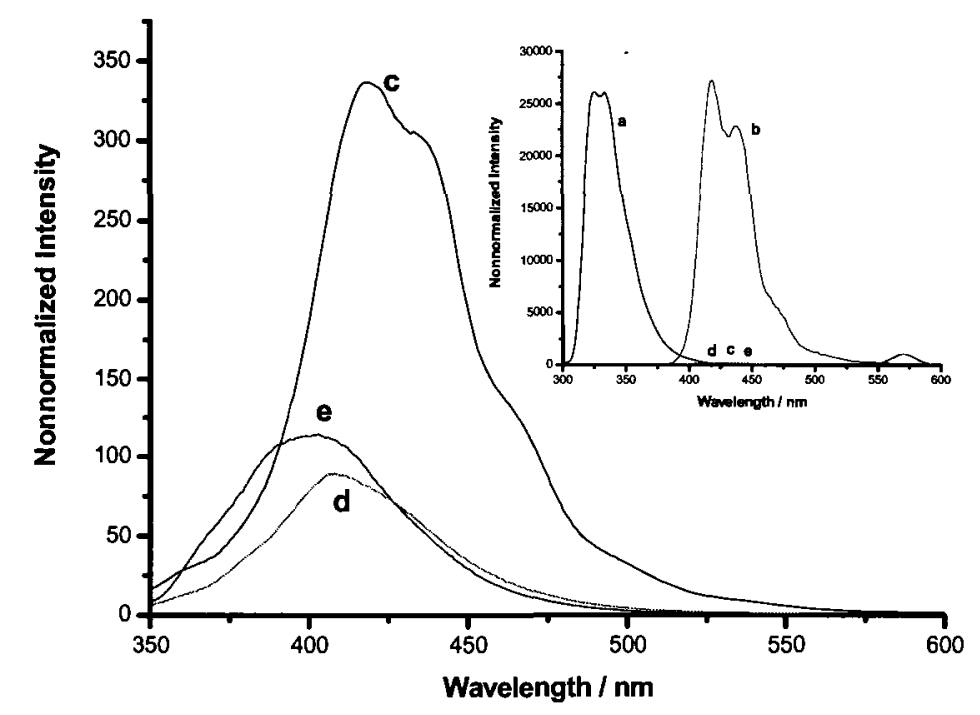

Figure IV.13. Fluorescent spectra of fluorene $\left(\lambda_{e x}=280 \mathrm{~nm}\right.$, inserted figure $)$ and PFO (inserted figure, $\lambda_{e x}=330 \mathrm{~nm}$ ) in toluene and Ru copolymers in $\mathrm{ACN}$ at $\mathrm{c}=2.14 \times 10^{-5} \mathrm{M}\left(\lambda_{e x}=330 \mathrm{~nm}\right)$ : (a) fluorene; (b) PFO; (c) IV.18; (d) IV.19; (e) IV.30.

It's clear that in comparison with PFO (inserted figure in Figure 3.13), the fluorescent quenching is evident even at the lowest loading of monomer IV.11-Ru for IV.18 which has a relative quantum yield of $1.58 \%$ to PFO. For IV.20 in which the molar ratio of fluerene to DCH-Ru is 1:1, its relative quantum yield to PFO in ACN 
drops to $0.53 \%$. In addition, the PL spectra of the copolymers show a blue-shift with the increase of DCH-Ru content in polymer. This is because with a higher Ru content, the polyfluorene segments become shorter. When the fluorene content is equal to that of $\mathrm{DCH}-\mathrm{Ru}$, the PL of the fluorene segments will be similar to that of fluorene alone at 330 $\mathrm{nm}$ (trace a in Figure IV.13), since there is no conjugation between fluorene units through DCH-Ru units. Thus, the emission at about $400 \mathrm{~nm}$ from both IV.19 and IV.20 is most likely from the tailing of fluorene unit. Due to the strong intra- and interchain quenching, no PL at around $400 \mathrm{~nm}$ was detected in the solid state for all the three polymers. Copolymer IV.18 gave nearly a complete emission from oligofluorene fragments in the polymer chain with a maximal emission at $419 \mathrm{~nm}$. According to the relationship between the wavelength of the maximal fluorescent and the length of oligofluorenes ${ }^{71}$, the average length of the oligofluorene in copolymer IV.18 is $5 \sim 6$ repeating units.

As a chromophore in the polymer, the DCH-Ru unit can also emit when being excited at the wavelength of its MLCT band. The room-temperature PL spectra obtained at the excitation wavelength of $560 \mathrm{~nm}$ are depicted in figure IV.14. All the copolymers give the same maximal peaks as the monomer complex IV.11-Ru at $780 \mathrm{~nm}$, which is assigned to a spin-forbidden metal-to-ligand charge-transfer $\left({ }^{3} \mathrm{MLCT}\right) \operatorname{transition}^{72,73}$. 


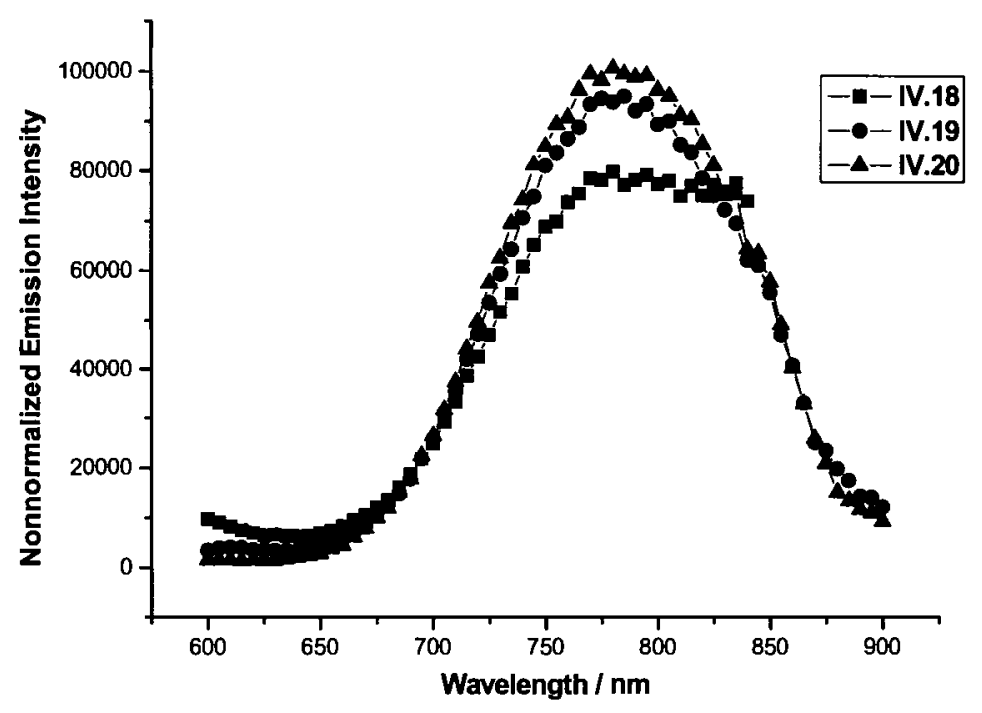

Figure IV.14. PL spectra of three copolymers in $\mathrm{ACN}$ at $\mathrm{c}=0.10 \mathrm{mg} / \mathrm{mL}$.

For the potential application in light-emitting diodes (LEDs), both the PL and EL (electroluminescence) properties are required for the device design. The EL of Ru(II) complexes is ascribed to electro-generated chemiluminescence (ECL) with a process described as the following equations ${ }^{74}$ :

$$
\begin{gathered}
{\left[\mathrm{Ru}^{\mathrm{II}}(\mathrm{L})_{3}\right]^{2+} \rightarrow\left[\mathrm{Ru}^{\mathrm{III}}(\mathrm{L})_{3}\right]^{3+}+e,} \\
{\left[\mathrm{Ru}^{\mathrm{II}}(\mathrm{L})_{3}\right]^{2+}+e \rightarrow\left[\mathrm{Ru}^{\mathrm{II}}\left(\mathrm{L}^{-}\right)(\mathrm{L})_{2}\right]^{+},} \\
{\left[\mathrm{Ru}^{\mathrm{III}}(\mathrm{L})_{3}\right]^{3+}+\left[\mathrm{Ru}^{\mathrm{II}}\left(\mathrm{L}^{-}\right)(\mathrm{L})_{2}\right]^{+} \rightarrow *\left[\mathrm{Ru}^{\mathrm{III}}\left(\mathrm{L}^{-}\right)(\mathrm{L})_{2}\right]^{2+}+\left[\mathrm{Ru}^{\mathrm{II}}(\mathrm{L})_{3}\right]^{2+} \rightarrow 2\left[\mathrm{Ru}^{\mathrm{II}}(\mathrm{L})_{3}\right]^{2+}+h v .}
\end{gathered}
$$

In a ECL device, holes are injected from the anode into the $t_{2 g}$ orbital of $\mathrm{Ru}$, while electrons are injected from the cathode into the $\pi^{*}$ orbital of the ligands. These electrogenerated species hop through the film, until they meet in a single molecule and form excited cations. The deactivation of these radical cations results in the generation of light.

With the functions of an efficient hole/electron transporter and a light-emitter, a single-layer ECL device can be fabricated from $\mathrm{Ru}^{\mathrm{II}}$ complex ${ }^{75}$. The electrochemical 
process in the ECL device leaves it independent of the work functions of the electrodes. Thus, more air-stable metal like Au can be used as an electrode.

To demonstrate EL of the three complex copolymers, a simple single-layer diode device was fabricated with the structure of ITO/copolymer/Au. All the copolymers can form good films with a thickness of $80 \sim 100 \mathrm{~nm}$ on ITO anode by spin-coating. A layer of gold $(130 \mathrm{~nm})$ as a cathode is deposited onto the polymer layer under a pressure of $3 \times$ $10^{-7}$ Torr. The EL spectra shown in figure IV.15 for all the copolymers are similar to their PL spectra with a maximal peak at about $790 \mathrm{~nm}$ due to MLCT transition. The temporal evolution of the current and radiance of the device based on IV.20 is shown in figure IV.15 under different forward bias voltages. Upon application of a voltage, the current rapidly increases to a steady-state value, while the radiance initially follows the current but then decays exponentially with time, which is similar to other ruthenium complex based devices reported in the literature ${ }^{76-78}$. Compared to DCH-Ru pendant polymers ${ }^{79}$, the main-chain copolymer IV.20 responds 4 times faster (20s vs 100s) to reach maximum emission under the similar conditions: the voltage (5V), the Ru content (11.6\% vs $10.6 \%)$ and film thickness $(\sim 80 \mathrm{~nm})$. This is likely due to the higher ionic conductivity of IV.20. 


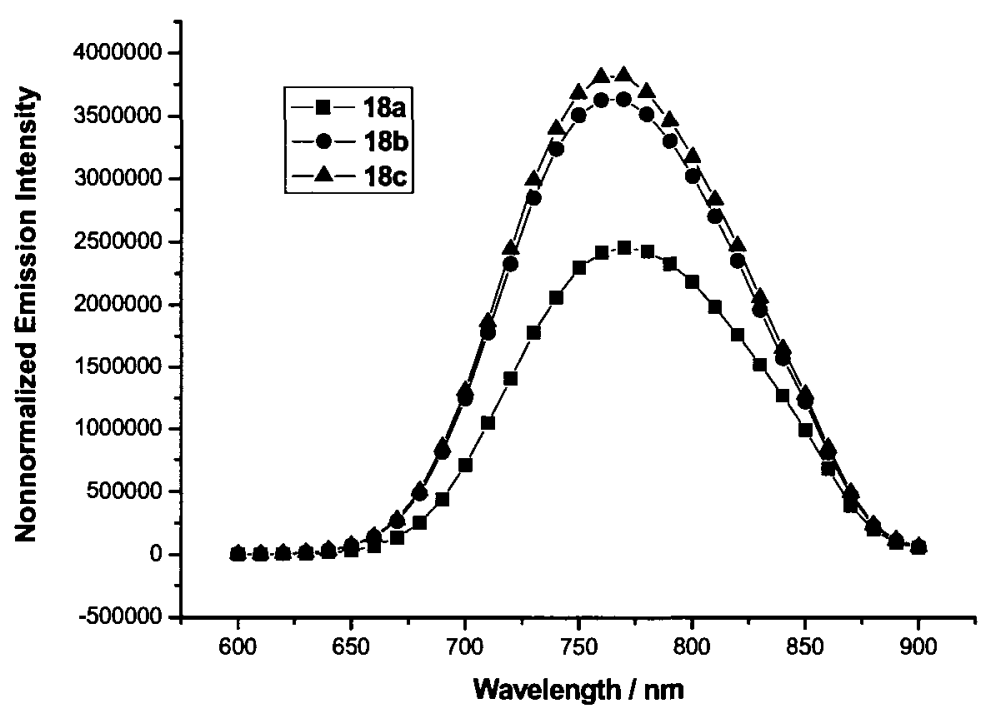

\section{Figure IV.15. EL spectra of LED devices containing polymers IV.18, IV.19 and IV.20 with a configuration of ITO/polymer/Au.}

The solid-state LED devices based on the copolymer IV.20 operate in a mechanism similar to that for electrochemical cells. Unlike organic LED requiring low work function cathodes (e.g., Ca), the devices containing redox ruthenium complex polymers can be made with an air-stable Au cathode. Upon applying a voltage, the counterions $\left(\mathrm{PF}_{6}^{-}\right)$accumulate near the anode and deplete near the cathode, causing a lowering of the barriers for hole and electron injection and thus an increase in the current. When the anion distribution is in equilibrium at the electrodes, as dictated by the applied bias and the Coulombic interactions with the ionic and electronic charge in the device, a steady state is reached. It is believed that in the steady state the applied voltage drops at the contacts, and the holes and electrons move within the device by diffusion only ${ }^{76,77}$. A higher voltage facilitates the accumulation of the $\mathrm{PF}_{6}^{-}$ions at the anode, resulting in a faster device turn-on (Figure IV.16). The previous study ${ }^{79}$ found that the external 
quantum efficiency (EQE) of the devices for polymers with the DCH-Ru groups showed a similar tendency as the EL radiance changed with time. Both the EL radiance and EQE began to decay after the current was up to the steady state and decayed faster under higher voltages. Using copolymers having less ruthenium content (IV.18), much weaker EL was obtained.
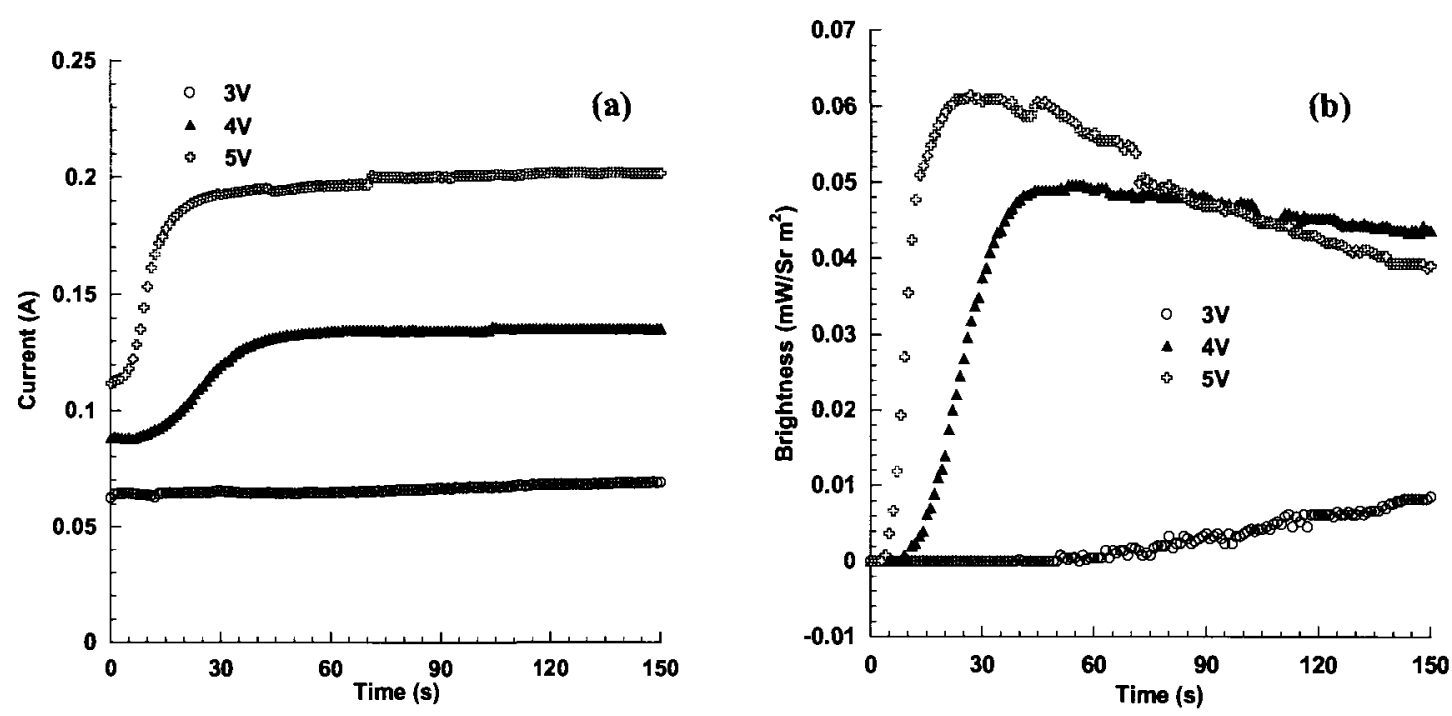

Figure IV.16. EL performance of copolymer IV.20 in film at a chickness of $80 \mathrm{~nm}$ :

(a) current vs time; (b) brightness (radiance) vs time.

\section{IV.3.7 Thermal Properties}

The thermal stability of all the three copolymers and PFO was measured by thermogravimetric analysis (TGA) under nitrogen as assessed by the onset temperature for $5 \%$ weight loss. All the polymers were found to be quite stable at the temperatures up to $405^{\circ} \mathrm{C}$ (Figure IV.17 and Table IV.5). Differential scanning calorimetry (DSC) was also done on the copolymers at a flow rate of $10^{\circ} \mathrm{C} / \mathrm{min}$. No glass transition temperatures were detected for either of the copolymers, indicating the rigidity of the polymer backbone. 


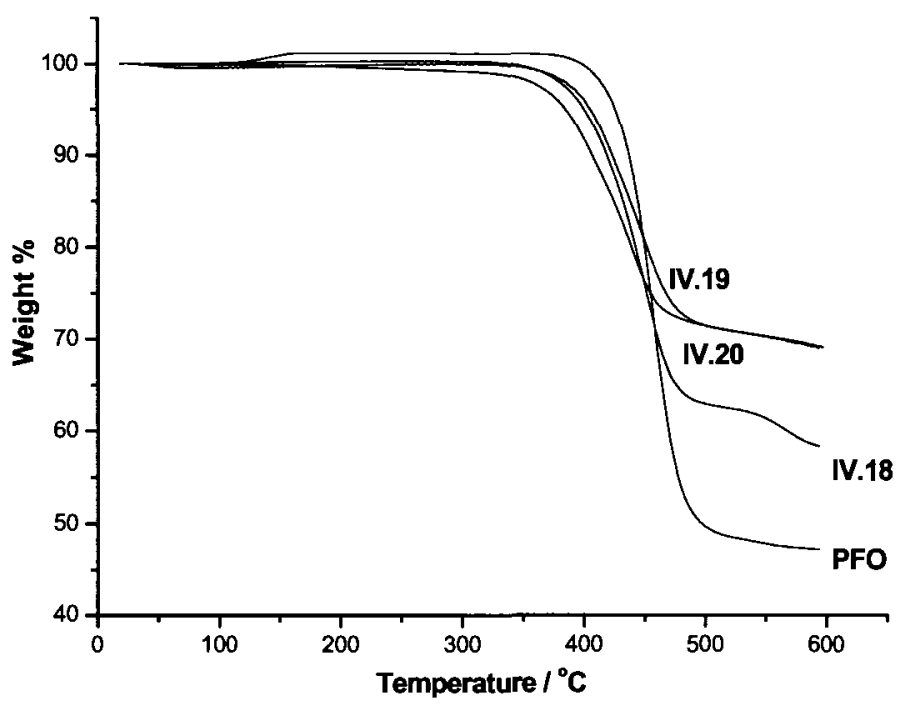

Figure IV.17. TGA traces of PFO and three copolymers.

Table IV.5. Thermal stability results of PFO and three copolymers under $\mathbf{N}_{2}$.

\begin{tabular}{lllll}
\hline Polymer & PFO & IV.18 & IV.19 & IV.20 \\
\hline $\mathrm{T}_{\mathrm{d}} /{ }^{\circ} \mathrm{C}$ & 426 & 400 & 405 & 385 \\
\hline a temperature for $5 \%$ weight loss in nitrogen assessed by TGA with a flow rate of $10^{\circ} \mathrm{C} / \mathrm{min}$
\end{tabular}

\section{IV.3.8 Electrochromic Properties}

The electrochromic (EC) properties of the copolymers were evaluated as a thin film on ITO glasses. With the highest Ru content, polymer IV.20 was expected to achieve the highest optical attenuation at $1600 \mathrm{~nm}$ for a given thickness. In a threeelectrode system, ITO glass acts as a working electrode, Pt as a counter electrode and Ag as a reference electrode. The oxidation and reduction potentials are set at $+600 \mathrm{mv}$ and $600 \mathrm{mv}$, respectively. At a time-based mode, both CV and UV-vis-NIR methods can be used to monitor the redox process of the polymer film (Figure IV.18). For a film with a thickness of $325 \pm 5 \mathrm{~nm}$, the oxidation process was found to be much slower than the reduction process $(20 \mathrm{~s}$ vs $3 \mathrm{~s})$, indicating that the slow oxidation process will prolong the 
time to reach high attenuation degree. This result was also observed for films with lower or higher thickness.

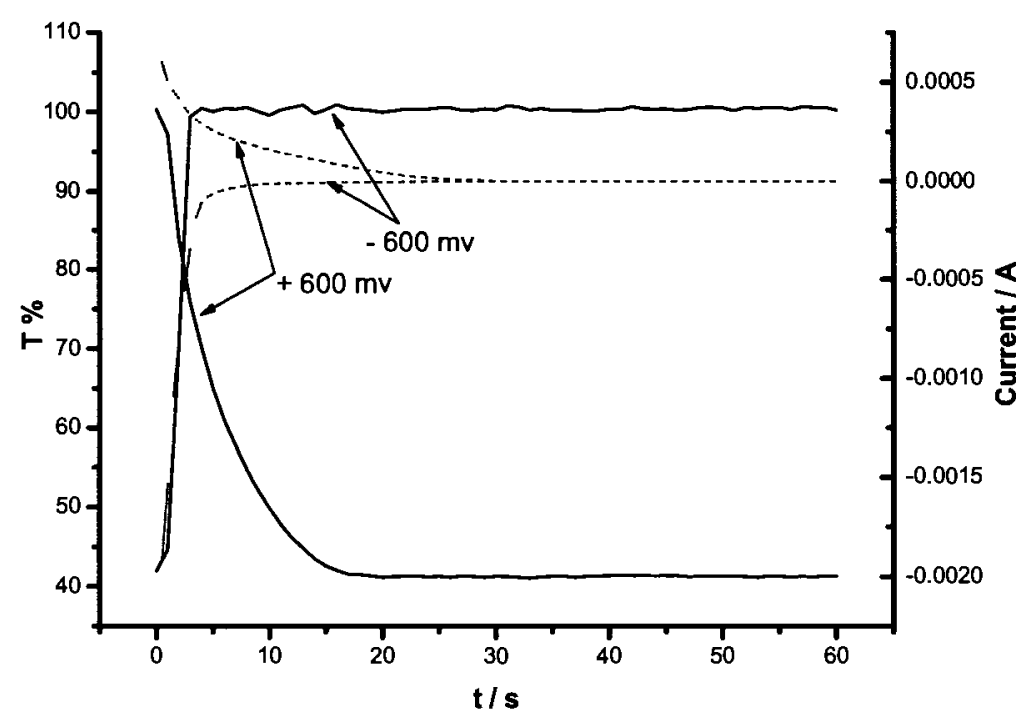

Figure IV.18. Current (dot line) and transmission (solid line) changes of IV.20 film (thickness: $325 \pm 5 \mathrm{~nm}$ ) at $1600 \mathrm{~nm}$ at a constant potential of +600 $\mathrm{mV}$ and $-600 \mathrm{mV}$ in 0.1M TBAH/THF.

According to Street's study on polypyrrole-coated electrode ${ }^{80}$, charge compensation during reduction is favored by diffusion of the electrolyte cation into the polymer and not the anion in the polymer into solution. His study suggests that in our experiment, diffusion of anion $\left(\mathrm{PF}_{6}^{-}\right)$from solution into polymer is much slower than diffusion of cation $\left({ }^{+} \mathrm{NBu}_{4}\right)$ from solution into polymer. The optical attenuation $(\mathrm{dB})$ at $1600 \mathrm{~nm}$ was calculated from the equation:

$$
\text { Attenuation }=10 \log (T b / T c)
$$

where $T b$ and $T c$ are the bleached and colored state of the film, respectively. The measurements were done in a $0.1 \mathrm{M} \mathrm{NH}_{4} \mathrm{PF}_{6} / \mathrm{THF}$ solution under the pulse potentials of \pm $600 \mathrm{mv}$ at different switching speeds. The traces are shown in Figure IV.19. The attenuation ranges were calculated to be $1.27,2.92$ and $3.77 \mathrm{~dB}$ at the switching speeds of 
$5 \mathrm{~s}, 10 \mathrm{~s}$, and $20 \mathrm{~s}$, respectively. The attenuation range at a switching speed of $20 \mathrm{~s}$ corresponds to an intrinsic attenuation value of $11.6 \mathrm{~dB} / \mu \mathrm{m}$. Compared to the thinner film $(200 \pm 5 \mathrm{~nm})$ at the same switching speed (10s), thicker film had a higher attenuation range (2.92 dB vs $1.74 \mathrm{~dB})$, but the attenuation property regarding the thickness is very close $(8.98 \mathrm{~dB}$ vs $8.7 \mathrm{~dB})$. There was no noticeable optical loss for the film at bleached state after 30 cycles at all the three switching speeds.

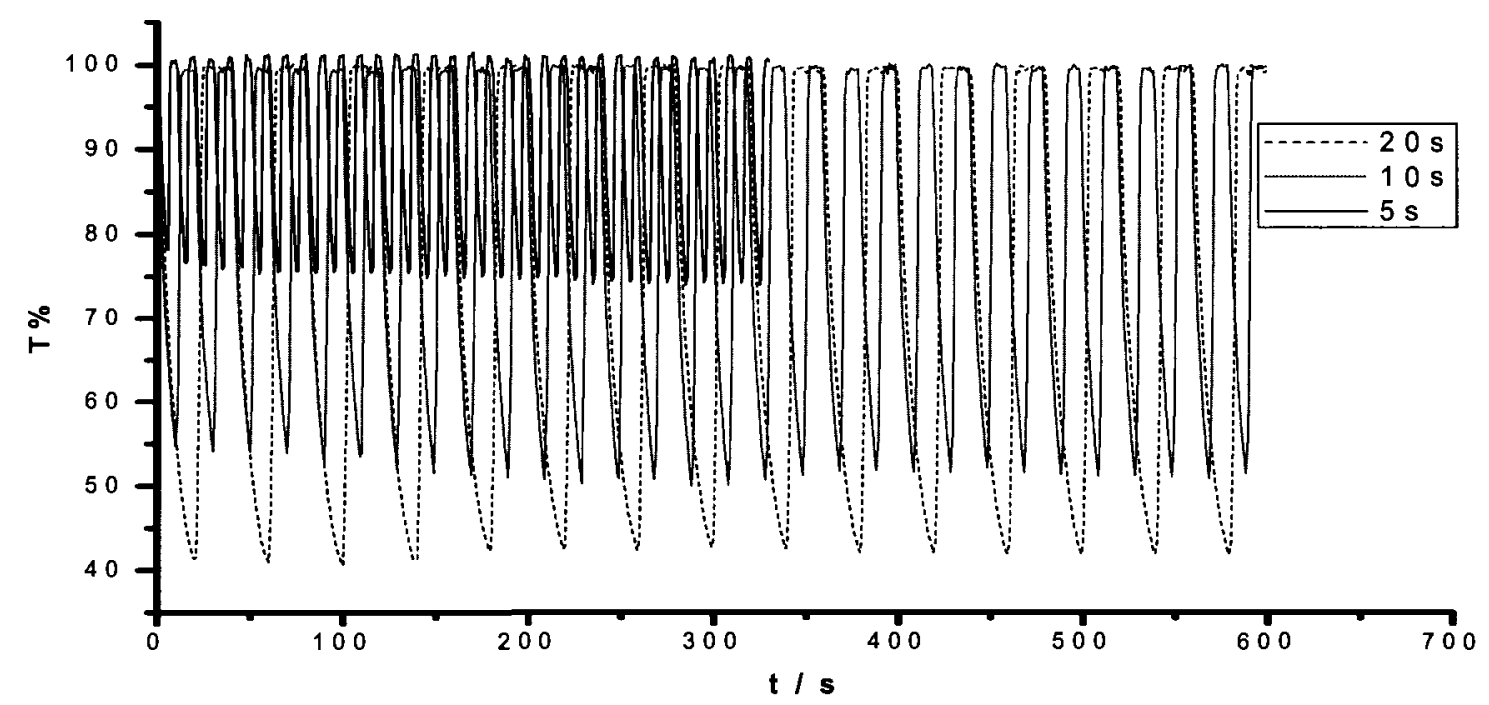

Figure IV.19. Change of transmittance at $1600 \mathrm{~nm}$ of the film of copolymer IV.20 film (thickness: $325 \pm 5 \mathrm{~nm}$ ) coated on ITO glass (electrolyte: $0.1 \mathrm{M}$ $\mathrm{NH}_{4} \mathrm{PF}_{6} / \mathrm{THF}$ ) as a function of switching speed (5s, 10s and 20s); pulse potentials: $\pm 600 \mathrm{mV}$.

\section{IV.4 Conclusion}

In conclusion, we synthesized a series of dinuclear DCH-Ru based main-chain polymers by Suzuki-coupling polymerization through AA/BB approach. These polymers bear both the properties from single molecule DCH-Ru, such as NIR electrochromicity, NIR photoluminescence, NIR electroluminescence, and reversible redox behavior, and 
general polymeric properties like good film formation. These polymers are highly thermally stable and behave like polyelectrolytes in solution. Compared to the method to prepare such DCH-Ru main-chain polymers by complexation of the corresponding DCH polymer ligand and cis-Ru(byp $)_{2} \mathrm{Cl}_{2} \cdot 2 \mathrm{H}_{2} \mathrm{O}$, the current method provided several advantages: (1) easy purification of the polymer products; (2) easy control of the molecular weight by changing the reaction time; (3) easy modification of the polymer structure by choosing proper comonomers. These polymers will be very useful in broad fields, such as reductants detection, NIR marker, NIR electrochromic device, and NIR photovoltaic device, etc.

\section{IV.5 Experimental Section}

\section{Materials}

All reagents and solvents utilized in synthesis and measurement were used as received.

\section{Measurements}

${ }^{1} \mathrm{H}$ and ${ }^{13} \mathrm{C}$ NMR spectra were recorded on Brucker AMX-400 and Varian 300 $\mathrm{MHz}$ NMR spectrometers using deuterated chloroform $\left(\mathrm{CDCl}_{3}\right)$, acetone (acetone-d6) and dimethylsulfoxide (DMSO-d6) as solvents with 1\% tetramethylsilane (TMS) as an internal standard. The chemical shifts were reported in $\delta(\mathrm{ppm})$ to TMS.

IR spectra were taken on an ABB Bomem MB-100 FTIR in $\mathrm{KBr}$ pellets or films coated on a salt plate. Uv-vis-NIR spectrophotometric and electromchemical measurements were taken in spectroscopic grade acetonitrile (ACN) or dimethylformide 
(DMF) using a Perkin Elmer Lambda 900 uv-vis-NIR and BAS 100 B/W, separately. The photoluminescent (PL) tests were done on a Shimadzu RF-1501 fluorescence spectrophotometer with a range of $300 \mathrm{~nm}$ to $800 \mathrm{~nm}$ and a PTI QuantaMaster Bench-top continuous spectrofluorometer with a range from $180 \mathrm{~nm}$ to $1700 \mathrm{~nm}$. The polymer film for PL test is made from casting a DMF solution on an ITO glass.

The EI and ESI mass spectroscopy were performed in the University of Ottawa Regional Mass Spectrometry Centre and reported as $\mathrm{m} / \mathrm{z}(\%$ intensity relative to the base peak). Melting points were measured on a Fisher-Jones melting point apparatus without any correction.

Spectroelectrochemical generation of $\mathrm{Ru} / \mathrm{Ru} u^{\mathrm{III}}$ and $\mathrm{Ru}{ }^{\mathrm{III}} / \mathrm{Ru}^{\mathrm{III}}$ oxidation states of the complexes were completed in an OTTLE cell. The redox potentials were measured vs. NHE with ferrocene as an internal standard.

Viscosity measurements were carried out at $30^{\circ} \mathrm{C}\left( \pm 0.1{ }^{\circ} \mathrm{C}\right)$ using Ubbelohde viscosimeters. Measurements in the presence of added salt were carried out by dissolving the polymer in $0.01 \mathrm{M} \mathrm{NH}_{4} \mathrm{PF}_{6} / \mathrm{DMF}$ solution. Flow times were measured with an accuracy of $( \pm 0.2 \mathrm{~s})$. Every determination was repeated three times to check the reproducibility. GPC measurements were performed on a Perkin Elmer system with an NCI-900 network chromatography interface, an isocratic LC-250 pump, a series 200 refractive index detector, a LC-101 oven and a Polymer Laboratories PLgel $5 \mu m$ MixedD column. The oven temperature was kept at $50^{\circ} \mathrm{C}$ during the tests. A solution of 1.0 and $2.0 \mathrm{mM} \mathrm{NH}_{4} \mathrm{PF}_{6}$ in DMF was used as an eluent at a flow rate of $1.0 \mathrm{~mL} / \mathrm{min}$. Molecular weights were calculated against polystyrene standards. 


\section{General Procedure for Suzuki Cross-Coupling Polymerization}

To a glass tube were added 0.5 part of diboronic acid ester compound, a part of monomer complex IV.11-Ru, b part of dibromo- compound $(0.5+\mathbf{a}+\mathbf{b}=1), 0.4 \%$ part of palliadium $(0)$ catalyst and DMF in a weight/volume ratio of $10 \%$. After the stirred mixture was bubbled by argon for 10 mins, 1.25 parts of $\mathrm{K}_{2} \mathrm{CO}_{3}$ were added to the solution at room temperature. The mixture was kept stirring at $100{ }^{\circ} \mathrm{C}$ overnight under the protection of argon before the reaction was stopped by adding 0.1 part of 4methylphenylboronic acid followed by adding $0.1 \mathrm{~mL}$ of bromobenzene with a interval of $2 \mathrm{hrs}$. Then the mixture was cooled to room temperature, and the product was precipitated in $75 \mathrm{~mL}$ of methanol containing 5 times amount of $\mathrm{NH}_{4} \mathrm{PF}_{6}$. The product was filtered out, washed by methanol and deionic water, and dried at reduced pressure to give polymers in high yields.

4-(4,4,5,5-Tetramethyl-1,3,2-dioxazolidin-2-yl)benzoyl chloride (IV.1)

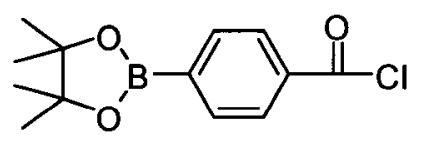

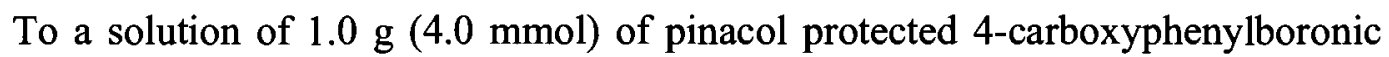
acid in $5 \mathrm{~mL}$ freshly distilled chloroform were added $3.0 \mathrm{~mL}(41 \mathrm{mmol})$ of thionyl chloride and a few drops (about $0.1 \mathrm{~mL}$ ) of N,N-dimethylformamide. The solution was heated to reflux for $2 \mathrm{hrs}$. The reaction solution was then allowed to cool to room temperature and was concentrated on a rotary evaporator under reduced pressure. To the residue was added $8 \mathrm{~mL}$ of chloroform and the resulting solution was concentrated again. This procedure was repeated two more times to remove residual thionyl chloride. The 
crude material was dried under vacuum and was obtained as an off-white solid (1.06 $\mathrm{g}$, $99 \%$ yield). The product was used right away for the next reaction.

4-(2-(4-Bromobenzoyl)hydrazinecarbonyl)phenylboronic acid pinacol ester (IV.2)

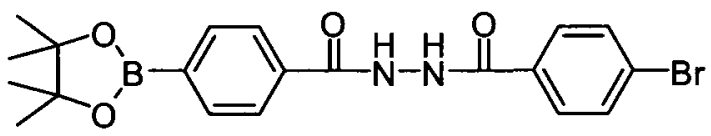

To a solution of $1.08 \mathrm{~g}(0.50 \mathrm{mmol})$ of 4-bromobenzoic hydrazide and $0.40 \mathrm{~g}$ $(0.50 \mathrm{mmol})$ of pyridine in $20 \mathrm{~mL}$ of anhydrous THF was added dropwise $1.33 \mathrm{~g}(0.50$ mmol) of freshly prepared 4-(4,4,5,5-Tetramethyl-1,3,2-dioxaborolan-2-yl)benzoic chloride in $5 \mathrm{~mL}$ of anhydrous THF while stirring. Solvent was removed under reduced pressure after the mixture was kept stirring overnight. The solid was then filtered out, washed by distilled water three times and recrystalized from THF/hexane to provide 1.30 $\mathrm{g}\left(58 \%\right.$ yield) of the product as a white solid. M.p. $249-251{ }^{\circ} \mathrm{C}$; IR ( $\mathrm{KBr}$ pellet, $\left.\mathrm{cm}^{-1}\right)$ : $3423\left(\mathrm{H}_{2} \mathrm{O}\right), 3222\left(v_{\mathrm{N}-\mathrm{H}}\right), 2979,2925,2853\left(v_{\mathrm{C}-\mathrm{H}}\right.$, aliphatic $), 1652\left(v_{\mathrm{C}=\mathrm{O}}\right), 1602,1552$ $\left(v_{\mathrm{C}=\mathrm{C}}\right), 1396\left(v_{\mathrm{C}-\mathrm{N}}\right), 1363\left(\nu_{\mathrm{B}-\mathrm{O}}\right) ;{ }^{1} \mathrm{H}$ NMR (400 MHz, DMSO- $\left.d_{6}\right) \delta / \mathrm{ppm}: 11.01(\mathrm{~s}, 1 \mathrm{H})$, $10.96(\mathrm{~s}, 1 \mathrm{H}), 7.88(\mathrm{~d}, 2 \mathrm{H}, \mathrm{J}=8.0 \mathrm{~Hz}), 7.84(\mathrm{~d}, 2 \mathrm{H}, \mathrm{J}=8.0 \mathrm{~Hz}), 7.68(\mathrm{~d}, 2 \mathrm{H}, \mathrm{J}=8.0 \mathrm{~Hz})$, $7.58(\mathrm{~d}, 2 \mathrm{H}, \mathrm{J}=8.0 \mathrm{~Hz}), 1.29(\mathrm{~s}, 12 \mathrm{H}) ;{ }^{13} \mathrm{C}$ NMR (100 MHz, DMSO- $\left.d_{6}\right) \delta / \mathrm{ppm}: 166.4$, $165.5,135.0,134.6,134.2,132.1,130.0,127.3,126.8,126.2,84.5,25.2$; MS found (nature of the peak, relative intensity): $446\left(\mathrm{M}^{+}\right.$with $\left.{ }^{81} \mathrm{Br}, 0.6\right), 444\left(\mathrm{M}^{+}\right.$with $\left.{ }^{79} \mathrm{Br}, 0.5\right)$, $428\left(\left[\mathrm{M}-\mathrm{H}_{2} \mathrm{O}\right]^{+}\right.$with $\left.{ }^{81} \mathrm{Br}, 99.1\right),\left(\left[\mathrm{M}-\mathrm{H}_{2} \mathrm{O}\right]^{+}\right.$with $\left.{ }^{79} \mathrm{Br}, 98.5\right)$. 
4-(2-(4-Bromobenzoyl)hydrazinecarbonyl)phenylboronic acid (IV.3)

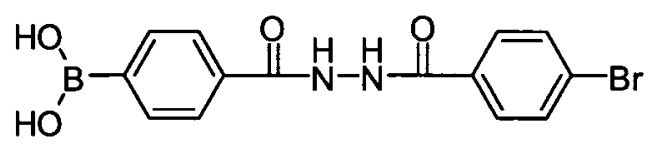

To a solution of $0.82 \mathrm{~g}(3.1 \mathrm{mmol})$ of 4-bromobenzhydrazide in $20 \mathrm{~mL}$ water/THF (3:1) with $0.33 \mathrm{~g}(3.1 \mathrm{mmol}) \mathrm{Na}_{2} \mathrm{CO}_{3}$ were added dropwise a solution of 0.66 $\mathrm{g}(3.1 \mathrm{mmol})$ of freshly prepared 4-(4,4,5,5-tetramethyl-1,3,2-dioxaborolan-2-yl)benzoic chloride in $5 \mathrm{~mL}$ of anhydrous THF while stirring. After addition, the mixture was kept stirring for $4 \mathrm{hrs}$. The solid was then filtered, washed with distilled water and dried under vacuum. The desired product was obtained as a white powder $(0.76 \mathrm{~g}, 65 \%$ yield $) . \mathrm{T}_{\mathrm{d}}>$ $260{ }^{\circ} \mathrm{C}$ (m.p. was not observed); IR (KBr pellet, $\left.\mathrm{cm}^{-1}\right): 3423\left(\mathrm{H}_{2} \mathrm{O}\right), 3222\left(\mathfrak{k}_{\mathrm{N}-\mathrm{H}}\right), 1640$ $\left(v_{\mathrm{C}=\mathrm{o}}\right), 1602,1552\left(v_{\mathrm{C}=\mathrm{C}}\right), 1402\left(v_{\mathrm{C}-\mathrm{N}}\right), 1371\left(v_{\mathrm{B}-\mathrm{O}}\right) ;{ }^{1} \mathrm{H}$ NMR $\left(300 \mathrm{MHz}, \mathrm{DMSO}-d_{6}\right)$

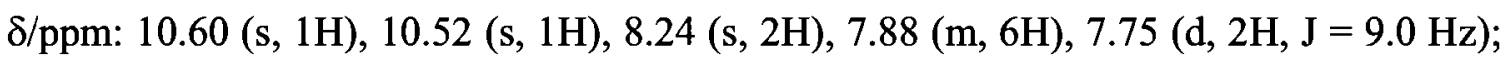

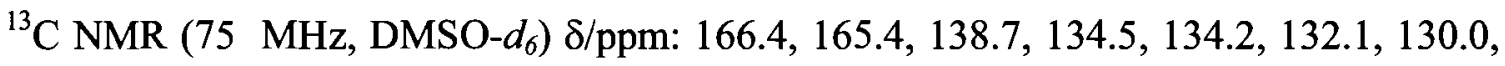
$126.8,126.2 ; \mathrm{MS}(\mathrm{EI}, \mathrm{m} / \mathrm{z})$ not found.

4-Bromo-N,N-dibenzylaniline (IV.4)

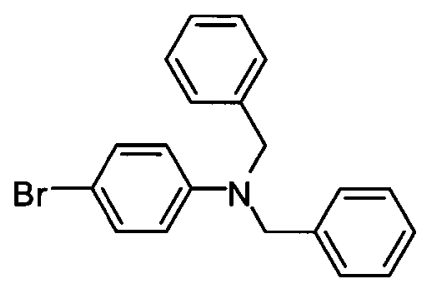

To a mixture of $17.2 \mathrm{~g}(100 \mathrm{mmol})$ of 4-bromoaniline and $16.0 \mathrm{~g}(151 \mathrm{mmol})$ of $\mathrm{Na}_{2} \mathrm{CO}_{3}$ in $100 \mathrm{~mL}$ of DMF was added $35.9 \mathrm{~g}(210 \mathrm{mmol})$ of benzyl bromide dropwise while stirring with the protection of argon. The mixture was kept stirring at $100-100{ }^{\circ} \mathrm{C}$ overnight and then poured into $400 \mathrm{~mL}$ of ice-water, washed with distilled water and cold 
methanol, and dried under reduced pressure at $50{ }^{\circ} \mathrm{C}$. The product was obtained as white crystals in needles $\left(32.3 \mathrm{~g}, 92 \%\right.$ yield). M.p. $126-127^{\circ} \mathrm{C}\left(124-127^{\circ} \mathrm{C}\right)^{90}$; IR (neat, $\mathrm{cm}^{-1}$ ): 3085, 3062, 3028 ( $v_{\mathrm{C}-\mathrm{H}}$, aromatic $), 2925,2861$ ( $v_{\mathrm{C}-\mathrm{H}}$, aliphatic), 1591, 1496, $1450\left(v_{\mathrm{C}=\mathrm{C}}\right)$; ${ }^{1} \mathrm{H}$ NMR $\left(300 \mathrm{MHz}, \mathrm{CDCl}_{3}\right)$ 8/ppm: $7.67(\mathrm{~d}, 2 \mathrm{H}, \mathrm{J}=9.0 \mathrm{~Hz}), 7.38-7.25(\mathrm{~m}, 10 \mathrm{H}), 6.78(\mathrm{~d}$, $2 \mathrm{H}, \mathrm{J}=6.0 \mathrm{~Hz}), 4.70(\mathrm{~s}, 4 \mathrm{H}) ;{ }^{13} \mathrm{C}$ NMR $\left(75 \mathrm{MHz}, \mathrm{CDCl}_{3}\right) \delta / \mathrm{ppm}: 136.4,136.2,128.7$, 127.1, 126.7, 111.7, 83.2, 78.5, 53.8; MS calcd.: $352.3 ; \mathrm{EI} \mathrm{m} / \mathbf{z}$ found (nature of the peak, relative intensity): $351\left(\mathrm{M}^{+}\right.$with $\left.{ }^{81} \mathrm{Br}, 37.4\right), 353\left(\mathrm{M}^{+}\right.$with $\left.{ }^{79} \mathrm{Br}, 36.8\right)$.

Cyclotrimeric 4-(N,N-dibenzylamino)-phenyl-boronic anhydride (IV.5)

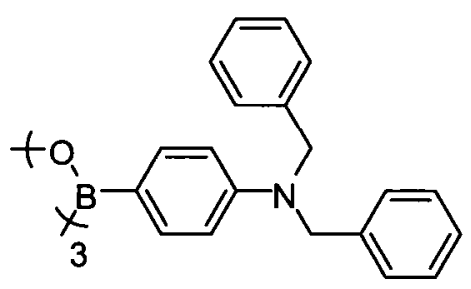

To a solution of $30.0 \mathrm{~g}(85.2 \mathrm{mmol})$ of 4-bromo-N,N-dibenzylaniline in $180 \mathrm{~mL}$ of anhydrous THF cooled to $-78{ }^{\circ} \mathrm{C}$ was added $37.5 \mathrm{~mL}(94.5 \mathrm{mmol})$ of a $2.5 \mathrm{M}$ hexyllithium in hexane solution dropwise in 30 mins with stirring. This solution was transferred to $23.7 \mathrm{~mL}$ of $(102.9 \mathrm{mmol})$ of triisopropyl borate and stirred under $-78^{\circ} \mathrm{C}$ for a further $1 \mathrm{~h}$. The bath was removed and the solution was warmed to room temperature naturally and kept stirring overnight. The concentrated product was mixed with $225 \mathrm{~mL}$ of ethyl acetate and $86 \mathrm{~mL}$ of water. The organic phase was separated, dried over sodium sulfate and concentrated. The solid product was suspended in $50 \mathrm{~mL}$ of hexane, filtered off and washed with $110 \mathrm{~mL}$ of ethyl acetate. The filtrate was concentrated to afford 16.3 $\mathrm{g}(18.0 \mathrm{mmol}, 63 \%)$ desired product as a white solid. M.p. $192-193^{\circ} \mathrm{C}$; IR (neat, $\mathrm{cm}^{-1}$ ): $3420\left(\mathrm{H}_{2} \mathrm{O}\right), 3089,3062,3032$ ( $v_{\mathrm{C}-\mathrm{H}}$, aromatic), 2979, 2929 ( $v_{\mathrm{C}-\mathrm{H}}$, aliphatic), 1600, 1506, 
1451 ( $v_{\mathrm{C}=\mathrm{C}}$, aromatic), 694 ( $\nu_{\mathrm{B}-\mathrm{O}}$, boroxine $)^{91} ;{ }^{1} \mathrm{H} \mathrm{NMR}\left(75 \mathrm{MHz}, \mathrm{CDCl}_{3}\right) \delta / \mathrm{ppm}: 8.05$ (d, $1 \mathrm{H}, \mathrm{J}=9.0 \mathrm{~Hz}), 7.37-7.20(\mathrm{~m}, 11 \mathrm{H}), 6.86-6.77(\mathrm{~m}, 2 \mathrm{H}), 4.77(\mathrm{~s}, 2 \mathrm{H}), 4.71(\mathrm{~s}, 2 \mathrm{H}) ;{ }^{13} \mathrm{C}$ NMR (75 MHz, $\left.\mathrm{CDCl}_{3}\right)$ 8/ppm: 152.2, 138.0, 137.3, 129.3, 128.8, 127.1, 126.7, 111.5, 53.9; MS (ESI, $\mathrm{m} / \mathrm{z}$ ) found (nature of the peak, relative intensity): $1016.4\left(\left[\mathrm{M}+\mathrm{H}_{3} \mathrm{O}\right]^{+}\right.$, $0.10)$.

4-Aminophenylboronic acid hydrochloride (IV.6)<smiles></smiles>

To a solution of $6.28 \mathrm{~g}(7.0 \mathrm{mmol})$ of trimeric $4-(\mathrm{N}, \mathrm{N}$-dibenzylamino)phenylboronic anhydride in $50 \mathrm{~mL}$ of methanol were added $126 \mathrm{mg}$ of $\mathrm{Pd} / \mathrm{C}(10 \%)$ and $1.0 \mathrm{~mL}$ of hydrochloric acid and shaken at room temperature under hydrogen atomosphere (10-40 psi) for $3 \mathrm{hrs}$ until the pressure stopped changing. The catalyst was then filtered off and the filtrate was concentrated at reduced pressure. The desired product was collected as a white solid. ( $3.45 \mathrm{~g}, 95 \%$ yield). This product was used for the next step of reaction without further purification. $\mathrm{Td}>230^{\circ} \mathrm{C}$ (m.p. was not observed).

4-(4,4,5,5-Tetramethyl-1,3,2-dioxaborolan-2-y) aniline hydrochloride (IV.7)<smiles>CC1(C)OB(c2ccc([N])cc2)OC1(C)C</smiles>

To a mortar were added $3.56 \mathrm{~g}(20.5 \mathrm{mmol})$ of 4-aminophenylboronic acid hydrochloride and $2.83(24.2 \mathrm{mmol})$ of pinacol and milled for 10 mins. After heating in vacuum at $52{ }^{\circ} \mathrm{C}$ for $2 \mathrm{hrs}$, the mixture was washed with ethyl ether and dried in vacuum to give the desired product as a white solid $(5.18 \mathrm{~g}, 98 \%$ yield). The sample without $\mathrm{HCl}$ 
used for IR and NMR test was prepared by adding diluted sodium bicarbonate to adjust the $\mathrm{PH}=8$. The precipitate was filtered off and dried in vacuum. $\mathrm{T}_{\mathrm{d}}>300^{\circ} \mathrm{C}$ (m.p. was not observed); IR (neat, $\left.\mathrm{cm}^{-1}\right): 3450,3357\left(w_{\mathrm{N}-\mathrm{H}}\right), 3043\left(v_{\mathrm{C}-\mathrm{H}}\right.$, aromatic), $2974\left(v_{\mathrm{C}-\mathrm{H}}\right.$, aliphatic), $1629\left(v_{\mathrm{N}-\mathrm{H}}\right), 1603\left(\nu_{\mathrm{C}=\mathrm{C}}\right), 1360\left(\nu_{\mathrm{B}-\mathrm{O}}\right.$, ester $) ;{ }^{1} \mathrm{H}$ NMR $\left(150 \mathrm{MHz}, \mathrm{CDCl}_{3}\right)$

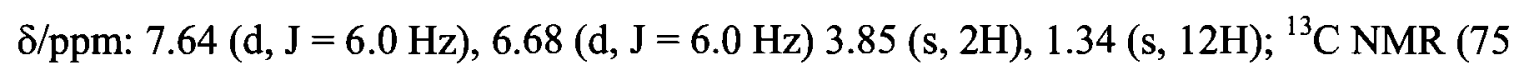
$\mathrm{MHz}, \mathrm{CDCl}_{3}$ ) $\delta / \mathrm{ppm}: 148.0,136.44,114.7,83.4,24.9 ; \mathrm{MS}$ (ESI, m/z) found (nature of the peak, relative intensity): $220.2\left(\left[\mathrm{M}-\mathrm{Cl}^{-}\right]^{+}, 47.2\right)$.

Phenyl 4-(4,4,5,5-tetramethyl-1,3,2-dioxaborolan-2-yl)phenylcarbamate (IV.8)

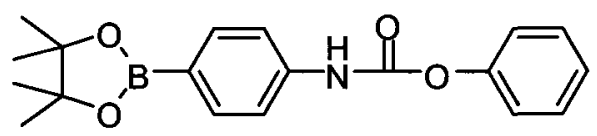

To a mixture of $1.36 \mathrm{~g} \mathrm{(5.3} \mathrm{mmol)} \mathrm{of} \mathrm{4-(4,4,5,5-tetramethyl-1,3,2-dioxaborolan-2-}$ yl)aniline hydrochloride suspended in $150 \mathrm{~mL}$ of anhydrous dichloromethane were added $0.84 \mathrm{~g}(10.6 \mathrm{mmol})$ of pyridine and $0.83 \mathrm{~g}$ of phenyl chloroformate $(5.3 \mathrm{mmol})$. The mixture was stirred overnight till TLC (1:1 = hexane: ether $)$ analysis showed the consumption of all starting materials. The solution was washed with saturated sodium bicarbonate $(20 \mathrm{~mL} \times 3)$, water $(20 \mathrm{~mL} \times 3)$ and brine $(20 \mathrm{~mL} \times 3)$ before it was concentrated. The residue was dried at reduced pressure to give the product as colorless needles $\left(1.17 \mathrm{~g}, 65 \%\right.$ yield). M.p. $184{ }^{\circ} \mathrm{C}$; IR (neat, $\left.\mathrm{cm}^{-1}\right): 3321$ ( $\kappa_{\mathrm{N}-\mathrm{H}}$, amide), 3051 ( $v_{\mathrm{C}-\mathrm{H}}$, aromatic), 2982, $2929\left(v_{\mathrm{C}-\mathrm{H}}\right.$, aliphatic), $1728\left(v_{\mathrm{C}=\mathrm{O}}\right), 1606,1401\left(v_{\mathrm{C}=\mathrm{C}}\right), 1587\left(v_{\mathrm{N}-\mathrm{H}}\right.$, amide), 1361 ( $\nu_{\mathrm{B}-\mathrm{O}}$, ester) 1196, 1142 ( $v_{\mathrm{C}-\mathrm{O}}$, ester); ${ }^{1} \mathrm{H}$ NMR $\left(300 \mathrm{MHz}, \mathrm{CDCl}_{3}\right) \delta / \mathrm{ppm}$ : $7.81(\mathrm{~d}, 2 \mathrm{H}, \mathrm{J}=9.0 \mathrm{~Hz}), 7.43(\mathrm{~m}, 4 \mathrm{H}), 7.28(\mathrm{~d}, 1 \mathrm{H}, \mathrm{J}=9.0 \mathrm{~Hz}), 7.21(\mathrm{~d}, 2 \mathrm{H}, \mathrm{J}=9.0 \mathrm{~Hz})$, 7.08 (s, $1 \mathrm{H}), 1.37$ (s, $12 \mathrm{H}) ;{ }^{13} \mathrm{C}$ NMR $\left(75 \mathrm{MHz}, \mathrm{CDCl}_{3}\right.$ ) $\delta / \mathrm{ppm}: 151.5,150.5,143.0$, 
$140.0,136.0,129.4,125.8,121.7,117.6,83.8,24.9 ; \mathrm{MS}(\mathrm{EI}, \mathrm{m} / \mathrm{z})$ found (nature of the peak, relative intensity): $339\left(\mathrm{M}^{+}, 2.1\right)$.

N-(4-(4,4,5,5-Tetramethyl-1,3,2-dioxaborolan-2-yl)phenyl)-hydrazinecarboxamide (IV.9)<smiles>CC1(C)OB(c2ccc(NC(=O)NN)cc2)OC1(C)C</smiles>

To a solution of $0.27 \mathrm{~g}(7.6 \mathrm{mmol})$ of $85 \%$ hydrazine hydrate in $10 \mathrm{~mL}$ of methanol was added $1.20 \mathrm{~g}(3.5 \mathrm{mmol})$ of compound IV.7. The mixture was heated to reflux for $3 \mathrm{hrs}$ where the complete conversion of the starting compound was checked by TLC $(1: 1=$ hexane: ether $)$. The solution was then cooled down to $0{ }^{\circ} \mathrm{C}$ to promote crystallization. The product was washed by chilled ethyl ether and methanol to give 0.68 g $(69 \%)$ of colorless crystal in needles. M.p. $188^{\circ} \mathrm{C}$; IR (neat, $\left.\mathrm{cm}^{-1}\right): 3347,3317\left(\mathrm{~K}_{\mathrm{N}-\mathrm{H}}\right.$, amide), 3108 ( $v_{\mathrm{C}-\mathrm{H}}$, aromatic), 2979, $2929\left(v_{\mathrm{C}-\mathrm{H}}\right.$, aliphatic), $1682\left(v_{\mathrm{C}=\mathrm{O}}\right), 1606,1511$ $\left(v_{\mathrm{C}=\mathrm{C}}\right), 1580,1534\left(v_{\mathrm{N}-\mathrm{H}}\right.$, amide $), 1397\left(v_{\mathrm{C}-\mathrm{N}}\right), 1360\left(v_{\mathrm{B}-\mathrm{O}}\right.$, ester $) ;{ }^{1} \mathrm{H}$ NMR $(400 \mathrm{MHz}$, DMSO- $\left.d_{6}\right) \delta 8.76(\mathrm{~s}, 1 \mathrm{H}), 7.55(\mathrm{~s}, 4 \mathrm{H}), 7.50(\mathrm{~s}, 1 \mathrm{H}), 4.37(\mathrm{~s}, 2 \mathrm{H}), 1.28(\mathrm{~s}, 12 \mathrm{H}) ;{ }^{13} \mathrm{C} \mathrm{NMR}$ $\left(100 \mathrm{MHz}, \mathrm{DMSO}-d_{6}\right) \delta 157.0,142.8,136.0,135.2,116.9,83.2,24.6 ; \mathrm{MS}(\mathrm{EI}, \mathrm{m} / \mathrm{z})$ found (nature of the peak, relative intensity): $277\left(\mathrm{M}^{+}, 8.2\right)$.

$N$-(4-Bromophenyl)-N'-(4-(4,4,5,5-tetramethyl-1,3,2-dioxaborolan-2-yl)phenyl)-1,2hydrazinedicarboxamide (IV.10)<smiles>CC1(C)OB(c2ccc(NC(=O)NNC(=O)Nc3ccc(Br)cc3)cc2)OC1(C)C</smiles> 
To a stirred solution of $1.35 \mathrm{~g}(4.9 \mathrm{mmol})$ of compound IV.9 in $30 \mathrm{~mL}$ of dry THF was added dropwise $0.97 \mathrm{~g}(4.9 \mathrm{mmol})$ of 4-bromophenyl isocyanate in $10 \mathrm{~mL}$ of dry THF at $0{ }^{\circ} \mathrm{C}$. After stirring at $0{ }^{\circ} \mathrm{C}$ for 30 mins, the mixture was warmed to room temperature and kept stirring for $3 \mathrm{hrs}$. The precipitate was then filtered off, washed by dry THF and dried at reduced pressure to yield $2.2 \mathrm{~g}(96 \%)$ product as white powder. M.p. $243^{\circ} \mathrm{C}$; IR $\left(\mathrm{KBr}, \mathrm{cm}^{-1}\right) 3450\left(\mathrm{H}_{2} \mathrm{O}\right), 3292\left(v_{\mathrm{N}-\mathrm{H}}\right), 3101\left(v_{\mathrm{C}-\mathrm{H}}\right), 2982,2939\left(v_{\mathrm{C}-\mathrm{H}}\right.$, aliphatic), $1670\left(v_{\mathrm{C}=0}\right), 1598,1547,1490\left(v_{\mathrm{C}=\mathrm{C}}\right), 1402\left(v_{\mathrm{C}-\mathrm{N}}\right), 1363\left(\nu_{\mathrm{B}-\mathrm{O}}\right.$, ester $) ;{ }^{1} \mathrm{H}$ NMR $(400 \mathrm{MHz}$, DMSO-d $\left.d_{6}\right) \delta /$ ppm: $8.96(\mathrm{~s}, 1 \mathrm{H}), 8.95(\mathrm{~s}, 1 \mathrm{H}), 8.08(\mathrm{~s}, 1 \mathrm{H}), 8.06(\mathrm{~s}, 1 \mathrm{H}), 7.57(\mathrm{~d}, 2 \mathrm{H}, \mathrm{J}=$ $8.4 \mathrm{~Hz}) 7.51(\mathrm{t}, 4 \mathrm{H}), 7.42(\mathrm{~d}, 2 \mathrm{H}, \mathrm{J}=8.8 \mathrm{~Hz}), 1.27(\mathrm{~s}, 12 \mathrm{H}) ;{ }^{13} \mathrm{C}$ NMR $(100 \mathrm{MHz}$, DMSO- $\left.d_{6}\right) \delta /$ ppm: $155.8,155.64,142.58,139.08,135.96,135.17,121.1,120.4,117.3$, 113.2, 83.2, 24.6; MS (EI, $\mathrm{m} / \mathrm{z})$ found (nature of the peak, relative intensity): $474\left(\mathrm{M}^{+}\right.$ with $\left.{ }^{79} \mathrm{Br}, 0.2\right)$ and $476\left(\mathrm{M}^{+}\right.$with $\left.{ }^{81} \mathrm{Br}, 0.1\right)$.

\section{1,2-Bis(4-bromobenzoyl)hydrazine (IV.11)}

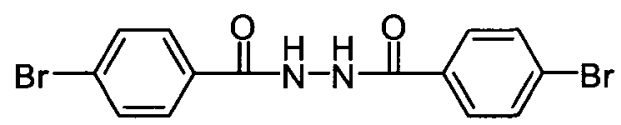

To a solution of $80 \mathrm{~mL}$ of $\mathrm{THF} / \mathrm{H}_{2} \mathrm{O}(1: 1)$ with $0.25 \mathrm{~g}(5.0 \mathrm{mmol})$ of hydrazine monohydrate and $0.53 \mathrm{~g}$ of $\mathrm{Na}_{2} \mathrm{CO}_{3}(5.0 \mathrm{mmol})$ was added $2.20 \mathrm{~g}(10.0 \mathrm{mmol})$ of 4 bromobenzoyl chloride in one portion. The stirring started immediately and continued for $1 \mathrm{hr}$ at room temperature. Then the mixture was heated to $40^{\circ} \mathrm{C}$ and kept stirring for $4 \mathrm{hrs}$ before it's cooled down to room temperature. The solvent was removed at reduced pressure. The white precipitate was collected by filtration and washed with distilled water 3 times. The crude product was purified by recrystallization and the desired product was 
obtained as white crystal in plates $\left(1.32 \mathrm{~g}, 67 \%\right.$ yield). M.p. $286^{\circ} \mathrm{C}\left(\text { lit. } 284-286^{\circ} \mathrm{C}\right)^{92}$; IR $\left(\mathrm{KBr}, \mathrm{cm}^{-1}\right): 3440\left(\mathrm{H}_{2} \mathrm{O}\right), 3203\left(v_{\mathrm{C}=\mathrm{C}}\right), 3024\left(v_{\mathrm{C}-\mathrm{H}}\right), 1647\left(v_{\mathrm{C}=\mathrm{O}}\right), 1601,1560,1499$, 1464( $\left.v_{\mathrm{C}=\mathrm{C}}\right), 1265\left(v_{\mathrm{C}-\mathrm{N}}\right) ;{ }^{1} \mathrm{H}$ NMR (300 MHz, DMSO-d $\left.d_{6}\right) \delta / \mathrm{ppm}: 10.64,(\mathrm{~s}, 2 \mathrm{H}), 7.86(\mathrm{~d}$, $4 \mathrm{H}, \mathrm{J}=9.0 \mathrm{~Hz}$ ), $7.75(\mathrm{~d}, 4 \mathrm{H}, \mathrm{J}=9.0 \mathrm{~Hz}) ;{ }^{13} \mathrm{C}$ NMR $\left(75 \mathrm{MHz}\right.$, DMSO- $\left.d_{6}\right)$ 8/ppm: 165.4, $132.1,132.0,130.0,126.2 ; \mathrm{MS}(\mathrm{EI}, \mathrm{m} / \mathrm{z})$ found (nature of the peak, relative intensity): $380\left(\left[\mathrm{M}-\mathrm{H}_{2} \mathrm{O}\right]^{+}, 79.4\right)$.

$\left[\left\{R u(b p y)_{2}\right\} \mu-(B r P h)_{2}-d c h\right]\left(P F_{6}\right)_{2}(\mathbf{I V . 1 1 - R u})$

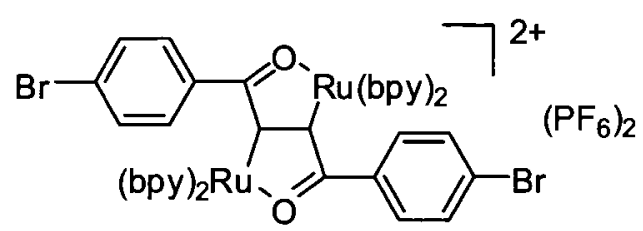

To a solution of $0.40 \mathrm{~g}$ of IV.11 $(1.0 \mathrm{mmol})$ and $0.53 \mathrm{~g}(5.0 \mathrm{mmol})$ of $\mathrm{Na}_{2} \mathrm{CO}_{3}$ in $150 \mathrm{~mL}$ of EtOH$/ \mathrm{H}_{2} \mathrm{O}(1: 2)$ was added $1.04 \mathrm{~g}(2.0 \mathrm{mmol})$ of $c i s-\mathrm{Ru}(\mathrm{bpy})_{2} \mathrm{Cl}_{2} \cdot 2 \mathrm{H}_{2} \mathrm{O}$. The mixture was refluxed overnight under argon and the product was precipitated by adding $5.00 \mathrm{~g}$ of $\mathrm{NH}_{4} \mathrm{PF}_{6}$ in $50 \mathrm{~mL}$ of $\mathrm{H}_{2} \mathrm{O}$ after the solution was cooled to room temperature. The crude product was purified by chromatography with grade III acid alumina as stationary phase and 1:1 acetonitrile:toluene as starting eluent. After the yellow band was washed out of the column, the eluent was changed to $\mathrm{H}_{2} \mathrm{O} /$ acetonitrile (5:95) and the purple band was collected. The solution was concentrated and the product was reprecipitated by adding $\mathrm{NH}_{4} \mathrm{PF}_{6}$ aqueous solution, filled out, washed with water and dried at reduced pressure to give $1.12 \mathrm{~g}(73 \%)$ of desired product. IR $\left(\mathrm{KBr}, \mathrm{cm}^{-1}\right): 3433$ $\left(\mathrm{H}_{2} \mathrm{O}\right), 3055$ ( $v_{\mathrm{C}-\mathrm{H}}$, aromatic), 2952, 2926, $2853\left(v_{\mathrm{C}-\mathrm{H}}\right.$, aliphatic $), 1607\left(v_{\mathrm{C}=\mathrm{N}}\right), 1578,1481$ $\left(v_{\mathrm{C}=\mathrm{C}}\right), 829($ p.- $) ;{ }^{1} \mathrm{H}$ NMR $\left(300 \mathrm{MHz}, \mathrm{DMSO}-d_{6}\right) \delta / \mathrm{ppm}: 9.28(\mathrm{~d}, 1 \mathrm{H}, \mathrm{J}=5.4 \mathrm{~Hz}), 9,17$ 
$(\mathrm{d}, 1 \mathrm{H}, \mathrm{J}=5.1 \mathrm{~Hz}), 8.90(\mathrm{~d}, 1 \mathrm{H}, \mathrm{J}=5.1 \mathrm{~Hz}), 8.73(\mathrm{~d}, 1 \mathrm{H}, \mathrm{J}=8.4 \mathrm{~Hz}), 8.64(\mathrm{~m}, 2 \mathrm{H}), 8.54$ $(\mathrm{d}, 2 \mathrm{H}, \mathrm{J}=8.1 \mathrm{~Hz}), 8.49(\mathrm{~d}, 2 \mathrm{H}, \mathrm{J}=8.1 \mathrm{~Hz}), 8.32-8.08(\mathrm{~m}, 8 \mathrm{H}), 7.81\left(\mathrm{t}, 2 \mathrm{H}, \mathrm{J}_{1}=\mathrm{J}_{2}=7.8\right.$ $\mathrm{Hz}), 7.18-7.12(\mathrm{t}, 4 \mathrm{H}), 6.91-6.82(\mathrm{~m}, 6 \mathrm{H}), 6.47(\mathrm{~d}, 2 \mathrm{H}, \mathrm{J}=8.1 \mathrm{~Hz}), 6.24(\mathrm{~s}, 2 \mathrm{H}) ;{ }^{13} \mathrm{C}$

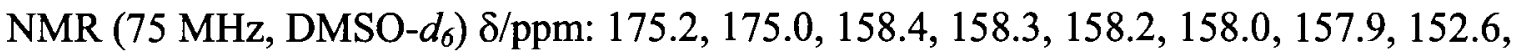
$152.5,152.0,151.6,151.5,151.4,151.0$ (d), 149.5, 137.2, 127.0 (d), 136.7, 136.5, 136.4, $134.3,133.9,133.8,130.9,130.8,128.8,128.2,127.5,127.2,126.8,126.3,124.4,124.2$, 124.0, 123.9, 122.2, 122.0. MS calcd.: $1513.9\left(\mathrm{C}_{54} \mathrm{H}_{40} \mathrm{Br}_{2} \mathrm{~F}_{12} \mathrm{~N}_{10} \mathrm{O}_{2} \mathrm{P}_{2} \mathrm{Ru}_{2}\right) ; \mathrm{ESI} \mathrm{m} / \mathrm{z}$ found (nature of the peak, relative intensity): $1368.8\left(\left[\mathrm{M}-\mathrm{PF}_{6}\right]^{+}, 0.25\right), 612.1\left([\mathrm{M}-2 \mathrm{PF} 6]^{2+} / 2\right.$, 28.83).

\section{1,8-Bis(4-bromophenoxy)-3,6-dioxaoctane (IV.12)}

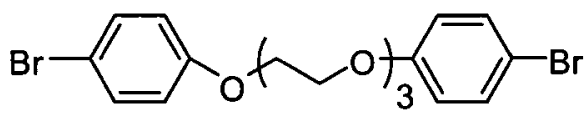

To a solution of $9.34 \mathrm{~g}$ of $p$-bromophenol in $16 \mathrm{~mL}$ of dimethyl sulfoxide (DMSO) was added $2.16 \mathrm{~g}$ of sodium hydroxide and was stirred at $60^{\circ} \mathrm{C}$ for 2 hrs under nitrogen. A solution of $2.25 \mathrm{~g} \mathrm{1,2-bis(2-chloroethoxy)ethane} \mathrm{in} 108 \mathrm{~mL}$ of degassed DMSO was then added dropwise at $60{ }^{\circ} \mathrm{C}$ and the resulting mixture was kept stirring at $90^{\circ} \mathrm{C}$ overnight. When it was cooled to room temperature, $100 \mathrm{~mL}$ of water was added to the mixture to yield a pale brown precipitate. The crude product was isolated by filtration, and recystallized from methanol to yield $4.53 \mathrm{~g}(82 \%)$ of desired product was white crystals. M.p. $73{ }^{\circ} \mathrm{C}$ (lit. $70{ }^{\circ} \mathrm{C}$ ) ${ }^{93}$; IR (neat, $\mathrm{cm}^{-1}$ ): 3096, 3066 ( $v_{\mathrm{C}-\mathrm{H}}$, aromatic), 2929, $2876\left(v_{\mathrm{C}-\mathrm{H}}\right.$, aliphatic), 1591, 1488, $1453\left(v_{\mathrm{C}=\mathrm{C}}\right), 1246,1127,1062$ ( $v_{\mathrm{C}-\mathrm{O}}$, ether $) ;{ }^{1} \mathrm{H}$ NMR $\left(300 \mathrm{MHz}, \mathrm{CDCl}_{3}\right) \delta / \mathrm{ppm}: 7.38(\mathrm{~d}, 2 \mathrm{H}, \mathrm{J}=9.0 \mathrm{~Hz}), 6.81(\mathrm{~d}, 2 \mathrm{H}, \mathrm{J}=9.0 \mathrm{~Hz}), 4.11(\mathrm{t}, 2 \mathrm{H}, \mathrm{J}$ $=3.0 \mathrm{~Hz}), 3.87(\mathrm{t}, 2 \mathrm{H}, \mathrm{J}=3.0 \mathrm{~Hz}), 3,76(\mathrm{~s}, 2 \mathrm{H}) ;{ }^{13} \mathrm{C} \mathrm{NMR}\left(75 \mathrm{MHz}, \mathrm{CDCl}_{3}\right) \delta / \mathrm{ppm}$ : 
$157.9,132,24,116.5,113.1,70.9,68.7,67.7 ; \mathrm{MS}(\mathrm{EI}, \mathrm{m} / \mathrm{z})$ found (nature of the peak, relative intensity): $460\left(\mathrm{M}^{+}, 26.8\right)$.

\section{1,8-Bis(2-(4-(4,4,5,5-tetramethyl-1,3,2-dioxaborolan-2-yl)phenoxy)-3,6-dioxaoctane}

(IV.14)

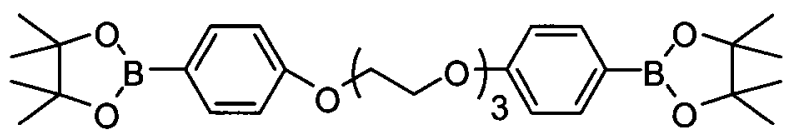

To a stirred solution of $3.68 \mathrm{~g}$ of dibromide compound IV.12 in $100 \mathrm{~mL}$ of anhydrous THF at $-75^{\circ} \mathrm{C}$ under argon was added dropwise $12.8 \mathrm{~mL}(32 \mathrm{mmol})$ of $2.5 \mathrm{M}$ n-butyllithium solution in hexane over 15 mins. After the mixture was maintained for 2 hrs at the same temperature, it was transferred over 15 mins into a $40 \mathrm{~mL}$ of trimethyl borate $(0.352 \mathrm{~mol})$ in $100 \mathrm{~mL}$ of dry THF solution though a tubing bridge at $-75^{\circ} \mathrm{C}$. The temperature was gradually rasied over $3 \mathrm{hrs}$ to room temperature after maintaining at low temperature for another hour. An excess of trimethyl borate was decomposed by the addition of $80 \mathrm{~mL}$ of $2 \mathrm{M} \mathrm{HCl}$ at $0^{\circ} \mathrm{C}$, and then the mixture was stirred at room temperature for $24 \mathrm{hrs}$. The solvent was removed under reduced pressure, and the precipitate was filtered by suction. After washed with $\mathrm{H}_{2} \mathrm{O}(5 \times 80 \mathrm{~mL})$ and hexane $(5 \times$ $50 \mathrm{~mL}$ ), it was recrystallized from methanol-water to afford $2.38 \mathrm{~g}(76 \%)$ of $4,4^{\prime}$-(ethane1,2-diylbis(oxy))bis(4,1-phenylene)diboronic acid (IV.13) as white solid.. The final pinacol-protected product was obtained in $99 \%$ yield by refluxing one equivalent of compound IV.13 and two equivalent of pinacol in toluene for 4 hrs.. M.p. $94-96{ }^{\circ} \mathrm{C}$; IR (neat, $\left.\mathrm{cm}^{-1}\right): 3040\left(v_{\mathrm{C}-\mathrm{H}}\right.$, aromatic), 2977, 2929, $2876\left(v_{\mathrm{C}-\mathrm{H}}\right.$, aliphatic), 1605, $1515\left(v_{\mathrm{C}=\mathrm{C}}\right)$, 1362 ( $\nu_{\mathrm{B}-\mathrm{O}}$, ester), 1249, 1061 ( $\nu_{\mathrm{C}-\mathrm{O}}$, ether), $1146\left(\nu_{\mathrm{B}-\mathrm{C}}\right) ;{ }^{1} \mathrm{H}$ NMR $\left(300 \mathrm{MHz}, \mathrm{CDCl}_{3}\right)$ 


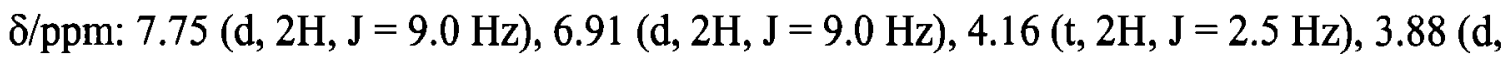
$2 \mathrm{H}, \mathrm{J}=2.5 \mathrm{~Hz}), 3.76(\mathrm{~s}, 2 \mathrm{H}), 1.35(\mathrm{~s}, 12 \mathrm{H}) ;{ }^{13} \mathrm{C} \mathrm{NMR}\left(75 \mathrm{MHz}, \mathrm{CDCl}_{3}\right) \delta / \mathrm{ppm}: 161.4$, $136.5,129.4,114.0,83.56,70.9,69.8,67.3,24.9 ; \mathrm{MS}(\mathrm{EI}, \mathrm{m} / \mathrm{z})$ found (nature of the peak, relative intensity): $554\left(\mathrm{M}^{+}, 21.2\right)$.

Poly(triglycolbiphenyl-alt-DCH-Ru) (IV.5)

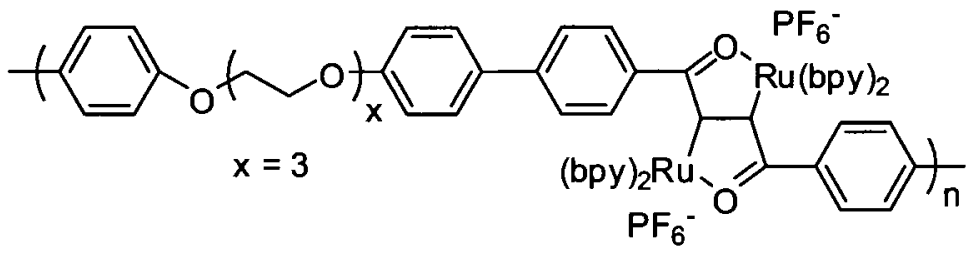

IR (acetonitrile, $\left.\mathrm{cm}^{-1}\right)$ 3078, $3030\left(v_{\mathrm{C}-\mathrm{H}}\right.$, aromatic), 2925, 2868 ( $v_{\mathrm{C}-\mathrm{H}}$, aliphatic), 1602, $1511\left(v_{\mathrm{C}=\mathrm{C}}\right), 1264,1245\left(v_{\mathrm{C}-\mathrm{O}}\right.$, ether $), 840\left(v_{\mathrm{P}-\mathrm{F}}\right) ;{ }^{1} \mathrm{H}$ NMR $\left(300 \mathrm{MHz}\right.$, DMSO- $\left.d_{6}\right) \delta / \mathrm{ppm}$ : 9.43-6.36 (m, 48H), $4.15(\mathrm{~s}, 4 \mathrm{H}), 3.80(\mathrm{~s}, 4 \mathrm{H}), 3.66(\mathrm{~s}, 4 \mathrm{H})$.

poly(fluorene-alt-DCH-Ru) (IV.20)

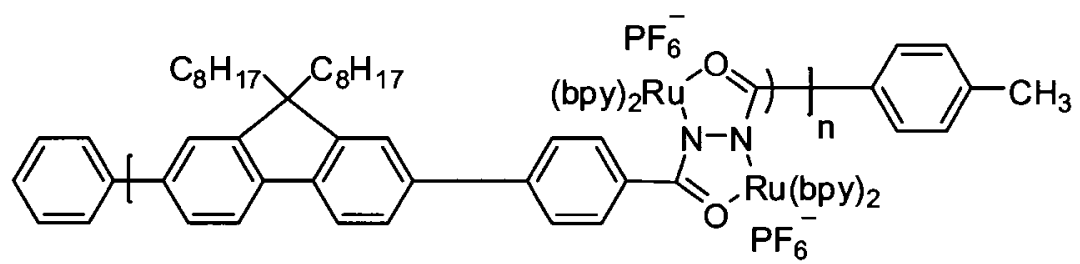

IR (acetonitrile, $\left.\mathrm{cm}^{-1}\right)$ 3078, $3030\left(v_{\mathrm{C}-\mathrm{H}}\right.$, aromatic), 2930, $2853\left(v_{\mathrm{C}-\mathrm{H}}\right.$, aliphatic), 1628 $\left(v_{\mathrm{C}=\mathrm{N}}\right), 1602,1499\left(v_{\mathrm{C}=\mathrm{C}}\right), 840\left(\nu_{\mathrm{P}-\mathrm{F}}\right) ;{ }^{1} \mathrm{H}$ NMR $\left(300 \mathrm{MHz}, \mathrm{DMSO}-d_{6}\right) \delta / \mathrm{ppm}: 6.38-9.44$ $(\mathrm{m}, 46 \mathrm{H}), 2.13(\mathrm{~s}, 3 \mathrm{H}), 1.04(\mathrm{~s}, 21 \mathrm{H})$ and $0.62(\mathrm{~s}, 10 \mathrm{H})$. 


\section{References}

1. Miyaura, Norio; Yamada, Kinji; Suzuki, Akira Tetrahedron Lett. 1979, 20, 3437.

2. Miyaura, N.; Yamada, K.; Suginome, H.; Suzuki, A.; J. Am. Chem. Soc. 1985, 107, 972.

3. Smith,G. B.; Dezeny, G. C.; Hughes, D. L.; King, A. O.; Verhoeven, T. R. J. Org. Chem. 1994, 59, 8151.

4. Moreno-Manas, M.; Pérez, M.; Pleixats, R. J. Org. Chem. 1996, 61, 2346.

5. Martin, A. R.; Yang, Y. Acta Chem. Scand.1993, 47, 221.

6. Molander, G. A.; Bernardi, C. R. J. Org. Chem. 2002, 67, 8424.

7. Molander, G. A.; Dehmel F. J. Am. Chem. Soc. 2004, 126, 10313.

8. Miyaura, N.; Yanagi, T.; Suzuki, A. Synth. Commun. 1981, 11, 513.

9. Miyaura, N.; Suginome, H.; Suzuki, A. Tetrahedron 1983, 39, 3271.

10. Miyaura, N.; Ishiyama, T.; Sasaki, H.; Ishikawa, M.; Sato, M.; Suzuki, A. J. Am. Chem. Soc. 1989, 111, 314.

11. Miyaura, N.; Ishiyama, T.; Ishikawa, M.; Suzuki, A. Tetrahedron Lett. 1986, 27, 6369

12. Roth, G. P.; Fuller, C. E. J. Org. Chem. 1991, 56, 3493.

13. Echavarren, A. M.; Stille, J. K. J. Am. Chem. Joc. 1987, 109, 5478.

14. Martorell, G.; Garcia-Raso, A.; Saa, J. M. Tetrahedron Lett. 1990. 31, 2357.

15. Ohe, T.; Miyaura, N.; Sukuki, A. Synlett 1990, 221.

16. Fu, J. M.; Snieckus, V. Tetrahedron Lett. 1990, 31, 1665.

17. Suzuki, A. Pure Appl. Chem. 1991, 63, 419. 
17. Miyaura, N.; Suzuki, A. Chem. Rev. 1995, 95, 2457.

18. Suzuki, A. J. Organometallic Chem. 1999, 576, 147.

19. Bellina, F.; Carpita, A.; Rossi, R. Synthesis 2004, 15, 2419.

20. Kotha, S.; Lahiri, K.; Kashinath, D. Tetrahedron 2002, 58, 9633.

21. Corbet, J. P.; Mignani, G. Chem. Rev. 2006, 106, 2651.

22. Chemler, S. R.; Trauner, D.; Danishefsky, S. J. Angew. Chem., Int. Ed. 2001, 40, 4544.

23. Nicolaou, K. C.; Bulger, P. G.; Sarlah, D. Angew. Chem., Int. Ed. 2005, 44, 4442.

24. De Vries, J. G.; De Vries, A. H. M.; Tucker, C. E.; Miller, J. A. Innovations in Pharm. Tech. 2001, 01, 125.

25. Yasuda, N. J. Organo. Chem. 2002, 253, 279.

26. Rehahn, M.; Schlüter, A. D.; Wegner, G.; Feast, W. J. Polymer 1989, 30, 1060.

27. Schlüter, A. D. J. Polym. Sci. Part A: Poly. Chem. 2001, 39, 1533.

28. Zhen, H.; Luo, C.; Yang, W.; Song, W. Y.; Du, B.; Jiang, J. X.; Jiang, C. Y.; Zhang, Y.; Cao, Y. Macromolecules 2006, 39, 1693.

29. Zhen, H. Y.; Jiang, C. Y.; Yang, W.; Jiang, J. X.; Huang, F.; Cao, Y. Chem. Eur. J. 2005, 11, 5007.

30. Li, Z. A.; Di, C. A.; Zhu, Z. C.; Yu, G.; Li, Z.; Zeng, Q.; Li, Q. Q.; Liu, Y. Q.; Qin, J. G. Polymer 2006, 47, 7889.

31. Wu, C. W.; Lin, H. C. Macromolecules 2006, 39, 7232.

32. Xin, Y.; Wen, G. A.; Zeng, W. J.; Zhao, L.; Zhu, X. R.; Fan, Q. L.; Feng, J. C.; Wang, L. H.; Wei, W.; Peng, B.; Cao, Y.; Huang, W. Macromolecules 2005, 38, 6755.

33. Liu, X. M.; Lin, T. T.; Huang, J. C.; Hao, X. T.; Ong, K. S.; He, C. B. 
Macromolecules 2005, 38, 4157.

34, Fei, Z. P.; Li, B. S.; Bo, Z. S.; Lu, R. Org. Lett. 2004, 6, 4703.

35. Li, J.; Bo, Z. S. Macromolecules 2004, 37, 2013.

36. Bo, Z. S.; Schlueter, A. D. Chem. Commun. 2003, 18, 2354.

37. Bo, Z. S.; Schluter, A. D. Chem. Eur. J. 2000, 6, 3235.

38. Fu, Y. Q.; Li, Y.; Li, J.; Yan, S. K.; Bo, Z. S. Macromolecules 2004, 37, 6395

39. Bo, Z. S.; Zhang, C. M.; Severin, N.; Rabe, J. P.; Schlueter, A. D. Macromolecules $2000,33,2688$.

40. Kandre, R. M.; Kutzner, F.; Schlaad, H.; Schluter, A. D. Macromol. Chem. Phys. $2005,206,1610$.

41. Li, A. Y.; Chang, J. Y.; Wang, K. Q.; Lu, L. D. Adv. Mater. Res. 2006, 11-12, 371

42. Huang, F.; Hou L. T.; Wu H. B.; Wang X. H.; Shen, H. L.; Cao, W.; Yang, W.; Cao, Y. J. Am. Chem. Soc. 2004, 126, 9845.

43. Huang, F.; Hou, L. T.; Shen, H. L.; Yang, R. Q.; Hou, Q.; Cao, Y. J. Polym. Sci., Part A: Polym. Chem. 2006, 44, 2521.

44. Nehls, B. S.; Galbrecht, F.; Brauer, D. J.; Lehmann, C. W.; Scherf, U.; Farrell, T. J. Polym. Sci., Part A: Polym. Chem. 2006, 44, 5533.

45. Hu, Q. S.; Katayama, H.; Nagao, M.; Nishimura, T.; Matsui, Y.; Fukuse, Y.; Wakioka, M.; Ozawa, F. Macromolecules 2006, 39, 2039.

46. Vitharana, D.; Liu, G. Y.; Jain, V.; Wagaman, M. W.; Zhang, L.; Lee, T. R.; Pu, L. Macromolecules 1996, 29, 1082.

47. Hu, Q. S.; Vitharana, D.; Liu, G. Y.; Jain, V.; Pu, L. Macromolecules 1996, $29,5075$. 48. Grigoras, M.; Antonoaia, N. C. Polymer Int. 2005, 54, 1641. 
49. Zhu, Z. G.; Swager, T. M. J. Am. Chem. Soc. 2002, 124, 9670.

50. Koch, F.; Heitz, W. Macromol. Chem. Phys. 1997, 198, 1531.

51. Bao, Z.; Chen, Y.; Cai, R.; Yu, L. Macromolecules 1993, 26, 5281.

52. Ng, P. K.; Wong, W. T.; Chan, W. K. Macromol. Rapid Comm. 1997, 18, 1009.

53. Pautzsch, T.; Klemm, E. J. Polym. Sci., Part A: Polym. Chem. 2004, 42, 2911.

54. Dinakaran, K.; Chou, C. H.; Hsu, S. L.; Wei, K. H. J. Polym. Sci., Part A: Polym. Chem. 2004, 42, 4838.

55. Liu, S. J.; Zhao, Q.; Chen, R. F.; Deng, Y.; Fan, Q. L.; Li, F. Y.; Wang, L. H.; Huang, C. H.; Huang, W. Chem. Eur. J. 2006, 12, 4351.

56. Frank, W.; Pautzsch, T.; Klemm, E. Macromol. Chem. Phys. 2001, 202, 2535.

57. DiCesare, N.; Lakowicz, J. R. Chem. Commun. 2001, 19, 2022.

58. Kaim, W. and Kasak, V. Inorg. Chem. 1990, 29, 4696.

59. Meudt, A.; Lehnemann, B.; Scherer, S.; Kalinin, A.; Snieckus, V. US7196219.

60. Cui, J. J. WO2004076412.

61. Rastegar, M. F.; Todd, E. K.; Tang, H. D.; Wang, Z. Y. Org. Lett. 2004, 6, 4519.

62. Deng, G; James, Tony D.; Shinkai, S. J. Am. Chem. Soc. 1994,116, 4567.

63. Tashiro, M.; Sumida, T.; Fukata, G. J. Org. Chem. 1980, 45, 1156.

64. Gerrard, W. The Organic Chemistry of Boron; Academic Press: London/New York, 1961.

65. Klämer, G.; Lee, J. I.; Davey, M. H.; Miller, R. D. Adv. Mater. 1999, 11, 115.

66. Bliznyuk, V. N.; Carter, S. A.; Scott, J. C.; Klarner, G.; Miller, R. D.; Miller, D. C. Macromolecules 1999, 32, 361.

67. Fuoss, R. M.; Strauss, U. P. J. Polym. Sci. 1948, 3, 603. 
68. Meier, M. A. R.; Lohmeijer, B. G. G.; Schubert, U. S. Macromol. Rapid Commun. $2003,24,852$.

79. Rader, H. J.; Spickerman, J.; Kreyenschmidt, M.; Mullen, K. Macromol. Chem. Phys. 1996, 197, 3285.

70. Jones, W. E., Jr.; Bignozzi, C. A.; Chen, P.; Meyer, T. J. Inorg. Chem. 1993, 32, 1167.

71. Jo, J.; Chi, C. Y.; Hoger, S.; Wegner, G.; Yoon, D. Y. Chem. Eur. J. 2004, 10, 2681.

72. Constable, E. C.; Housecroft, C. E.; Schofield, E. R.; Encinas, S.; Armaroli, N.; Barigelletti, F.; Flamigni, L.; Figgemeier, E.; Vos, J. G. Chem. Commun. 1999, 10, 869.

73. Benniston, A. C.; Harriman, A.; Lawrie, D. J.; Mayeux, A. Phys. Chem. Chem. Phys. 2004, 6, 51 .

74. Fahnrich, K. A.; Pravda, M.; Guilbault, G. G. Talanta 2001, 54, 531.

75. Elliott, C. M.; Pichot, F.; Bloom, C. J.; Rider, L. S. J. Am. Chem. Soc. 1998, 120, 6781.

76. Kikuchi, D.; Sakaguchi, S.; Ishii, Y.J. Org. Chem. 1998, 63, 6023;

77. Bloxham, J.; Moody, C. J.; Slawin, A. M. Z. Tetrahedron 2002, 58, 3709.

78. Barbieri, A.; Ventura, B.; Barigelletti, F.; Nicola, A.; Quesada, M.; Ziessel, R. Inorg. Chem. 2004, 43, 7359.

79. Wang, S.; Li, X. Z.; Xun, S. D.; Wan, X. H.; Wang, Z. Y. Macromolecules 2006, 39, 7502.

80. Kaufman, J. H.; Kanazawa, K. K.; Street, G. B. Phys. Rev. Lett. 1984, 53, 2461. 


\section{Summary}

In this research we have successfully developed DCH-Ru-containing polymeric materials through the methods of crosslinking dendric DCH-Ru complexes and polymerization of DCH-Ru complex dibromide monomer with other diboronic acid monomers. The resulting products contain the NIR electrochromic properties from DCH$\mathrm{Ru}$ fragments as well as good film-formtion properties because of their high molecular weights, which make them suitable for NIR electrochromic variable optical attenuator in solid device. An intrinsic dynamic attenuation of $11.6 \mathrm{~dB}$ has bee obtained from one of the copolymers, which is comparable to the highest value reported so far in conducting polymers. Also they are easy for purification and quite stable in the ambient condition. A high dynamice attenuation of $30 \mathrm{~dB}$ has also been reached in a single-layer hybrid ECVOA device.

For solid-state DCH-Ru complexes, further improvement of the intrinsic attenuation is still possible from DCH-Ru polymers with higher Ru content than the copolymer we have made. Considering the AA-BB approach, replacing the fluorene fragment in boronic acid with much lower molecular-weight ones like 1,4-phenyl unit can largly increase the Ru content in the final polymeric product. The modification on dipyridyl parts to make them polymerizable could be another approach to increase the $\mathrm{Ru}$ content. In addition, complexes containing metals other than ruthenium with high molar extinguishing coefficient in the NIR region should also be considered for further enhancing the attunation ability and decreasing the high cost of the raw ruthenium complex. Asymmetric Nickel-dithiolenes could be taken as such candidate metal complexes by the introduction of large donating and withdrawing groups at each side, 
which could highly improve the stability of the products to electrochemical reaction and degredation, making them excellent NIR electrochromic materials. 
Appendix

${ }^{1} \mathrm{H}$ and ${ }^{13} \mathrm{C}$ Spectra of Ligands and Complexes 
1,3,5-Benzenetricarboxylic tris[2-(6-hydroxyhexano)hydrazide)] (II.1)
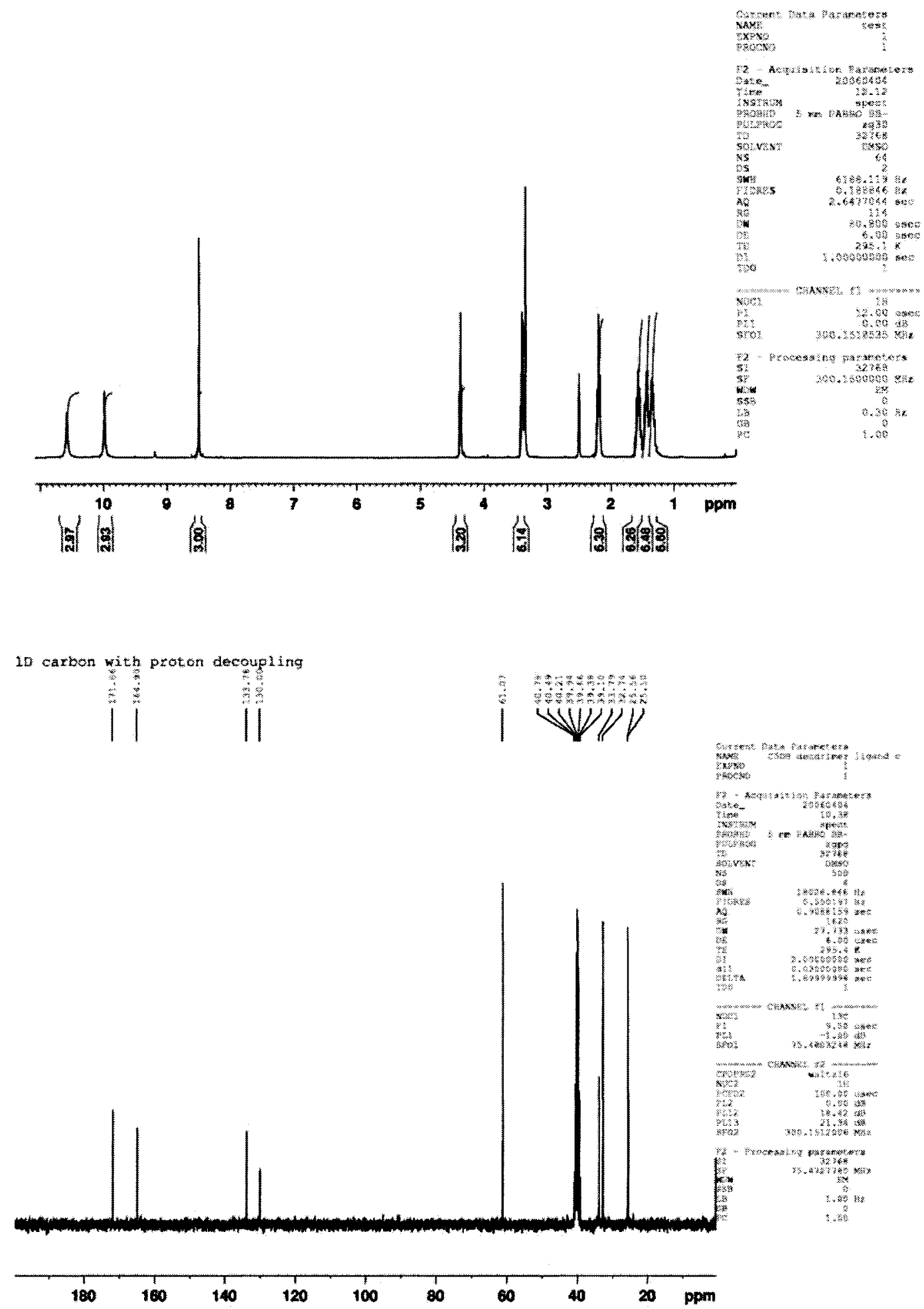
1,3,5-Benzenetricarboxylic tris[2-(4-Methoxybenzoyl)hydrazide)] (II.2)
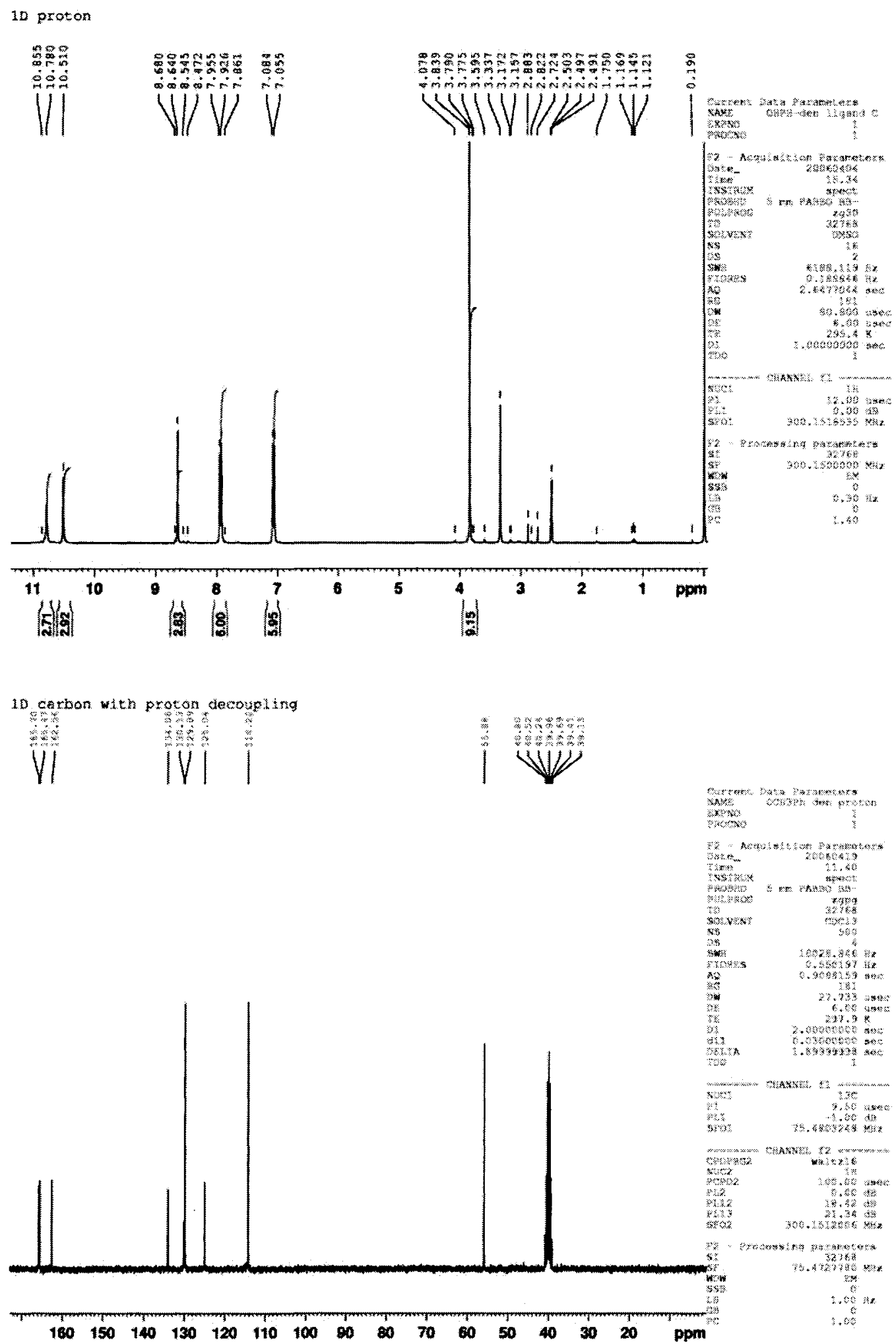
1,3,5-Benzenetricarboxylic tris[2-(4-hydroxybenzoyl)hydrazide)] (II.3)

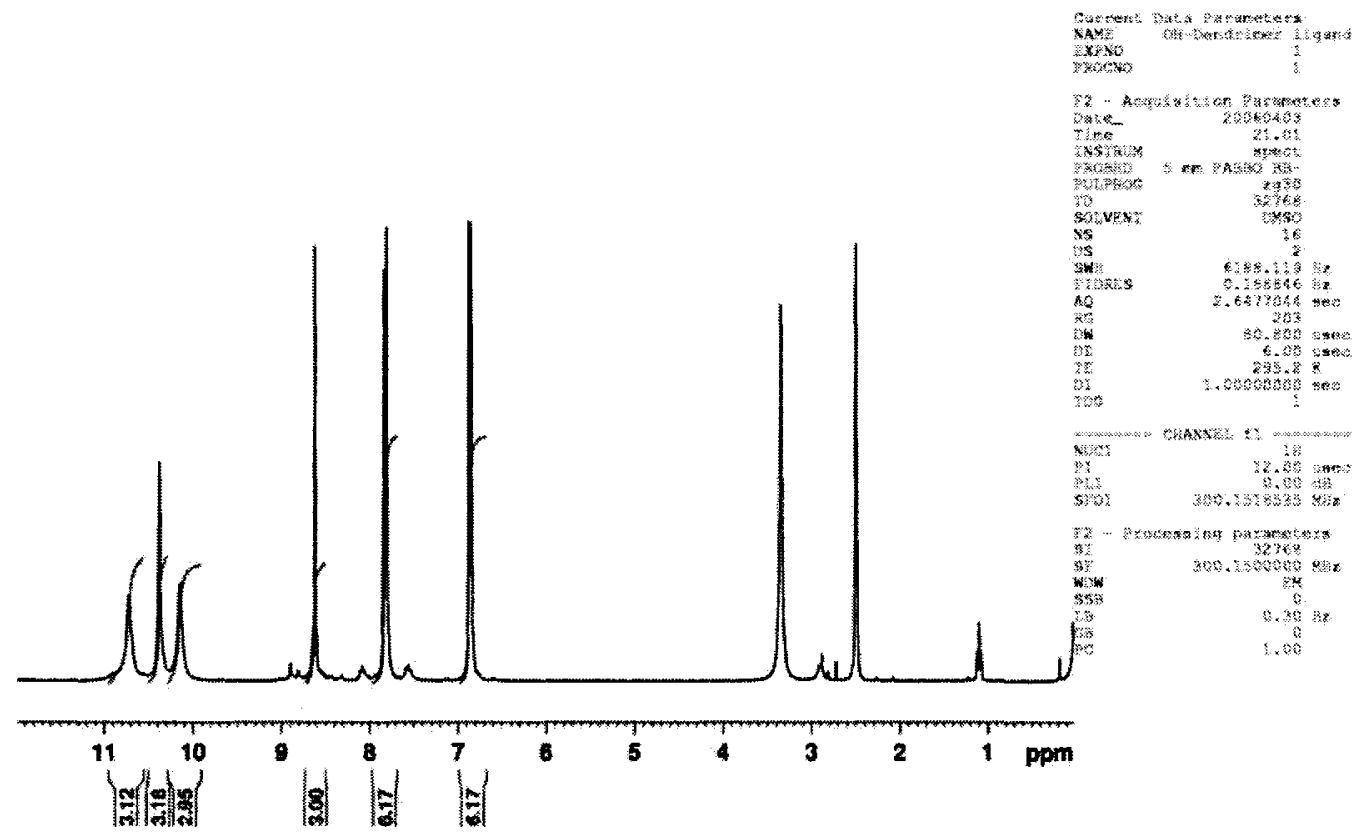

10 carbon wh proton decoupling

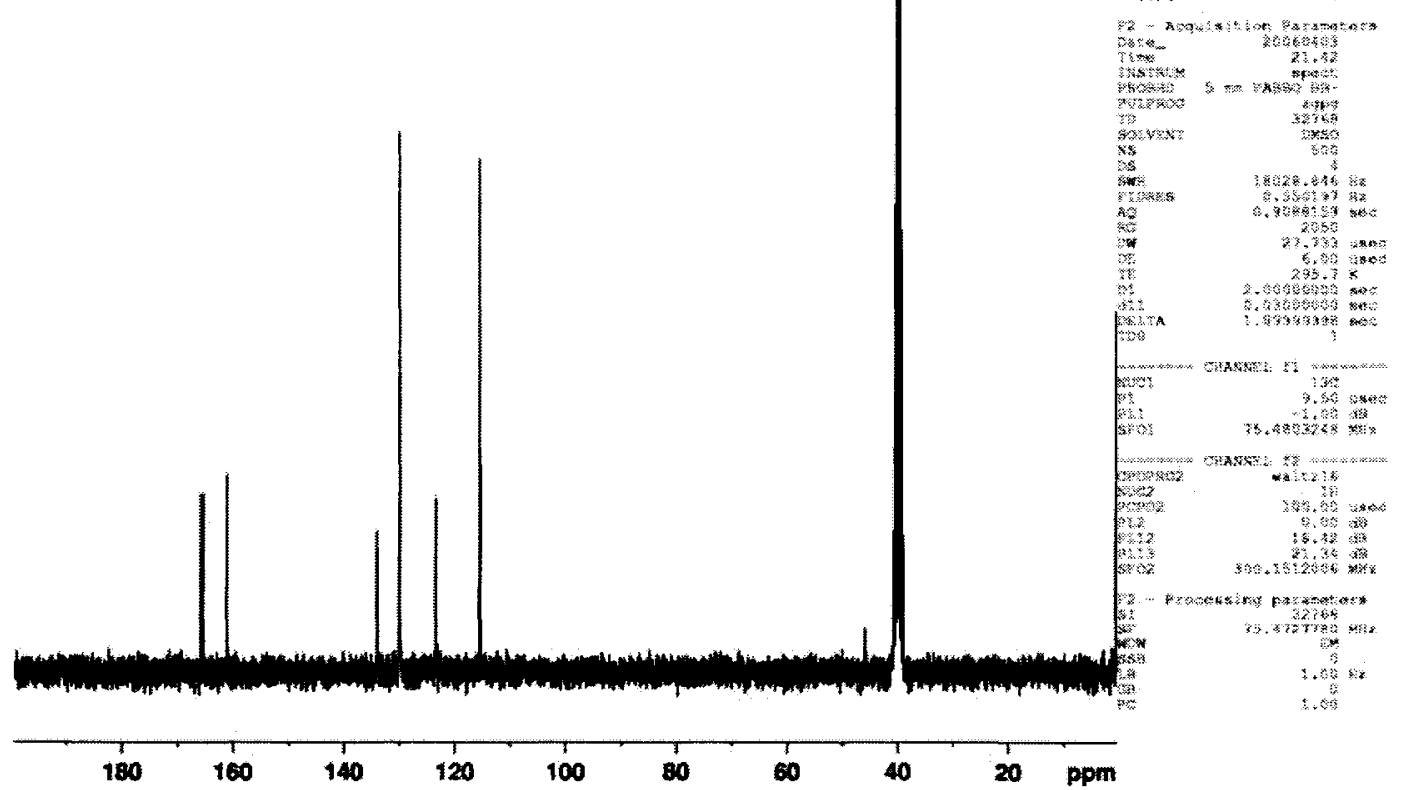



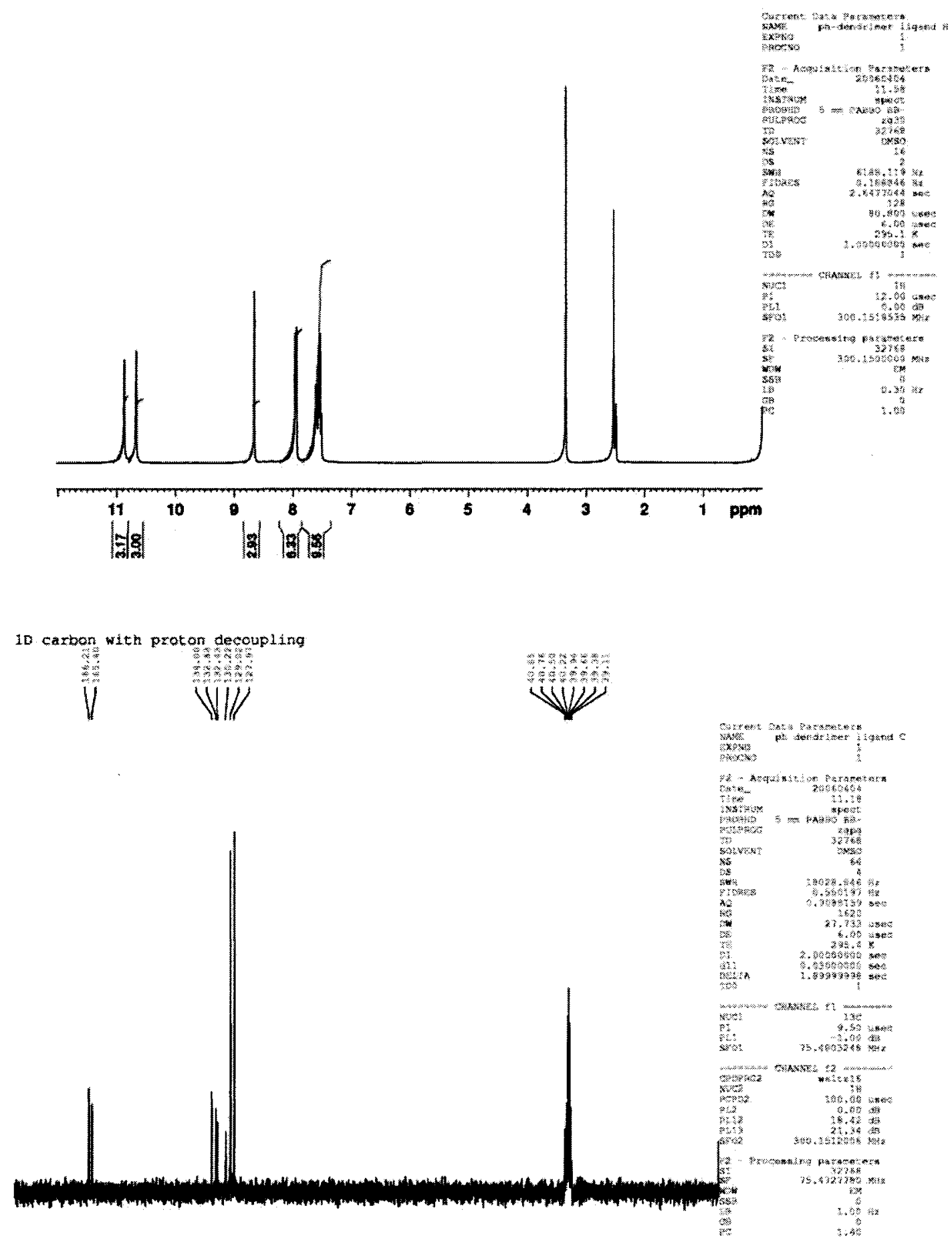

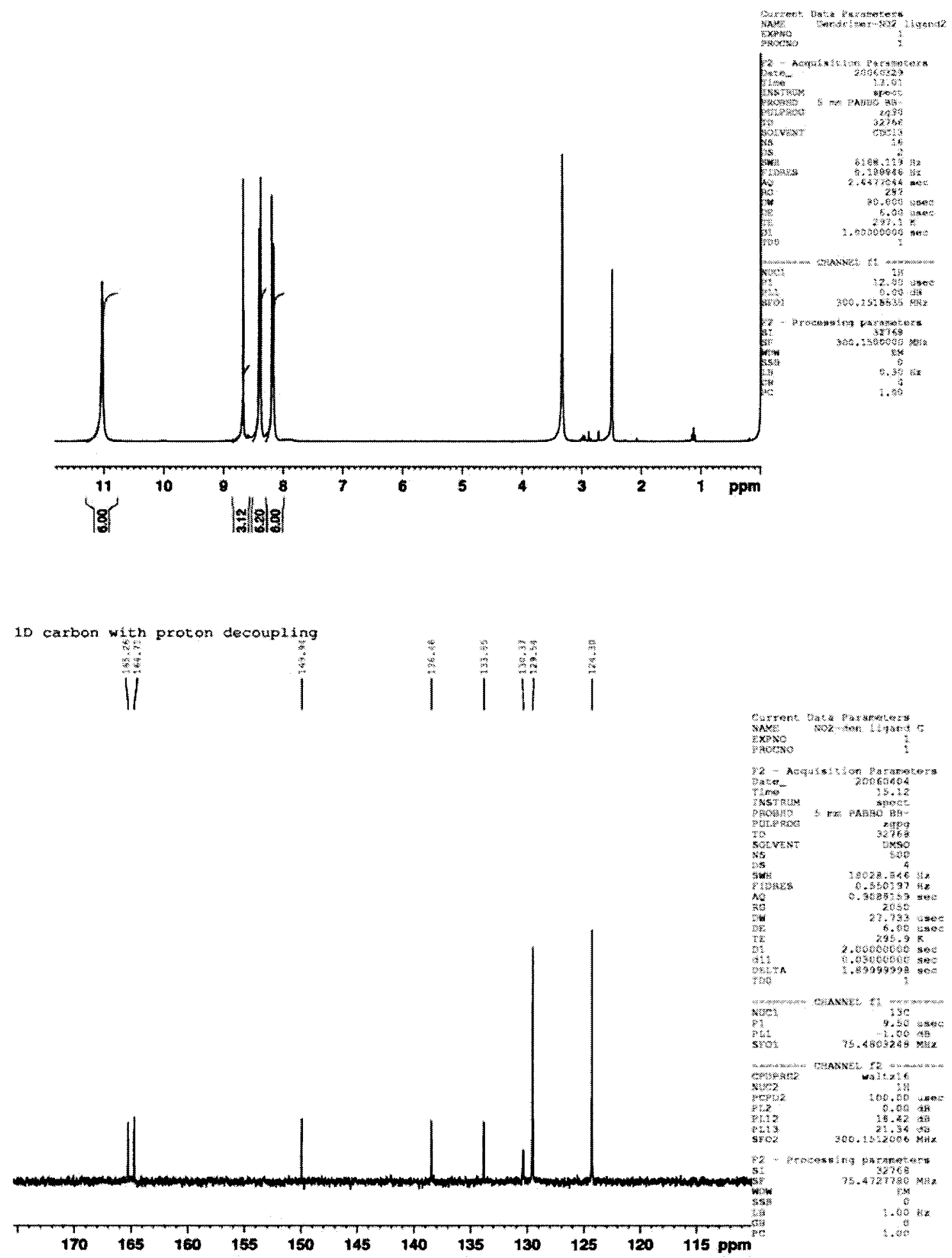
$N, N^{\prime}$-diphenyl-1,2-Hydrazinedicarboxamide (III.1)
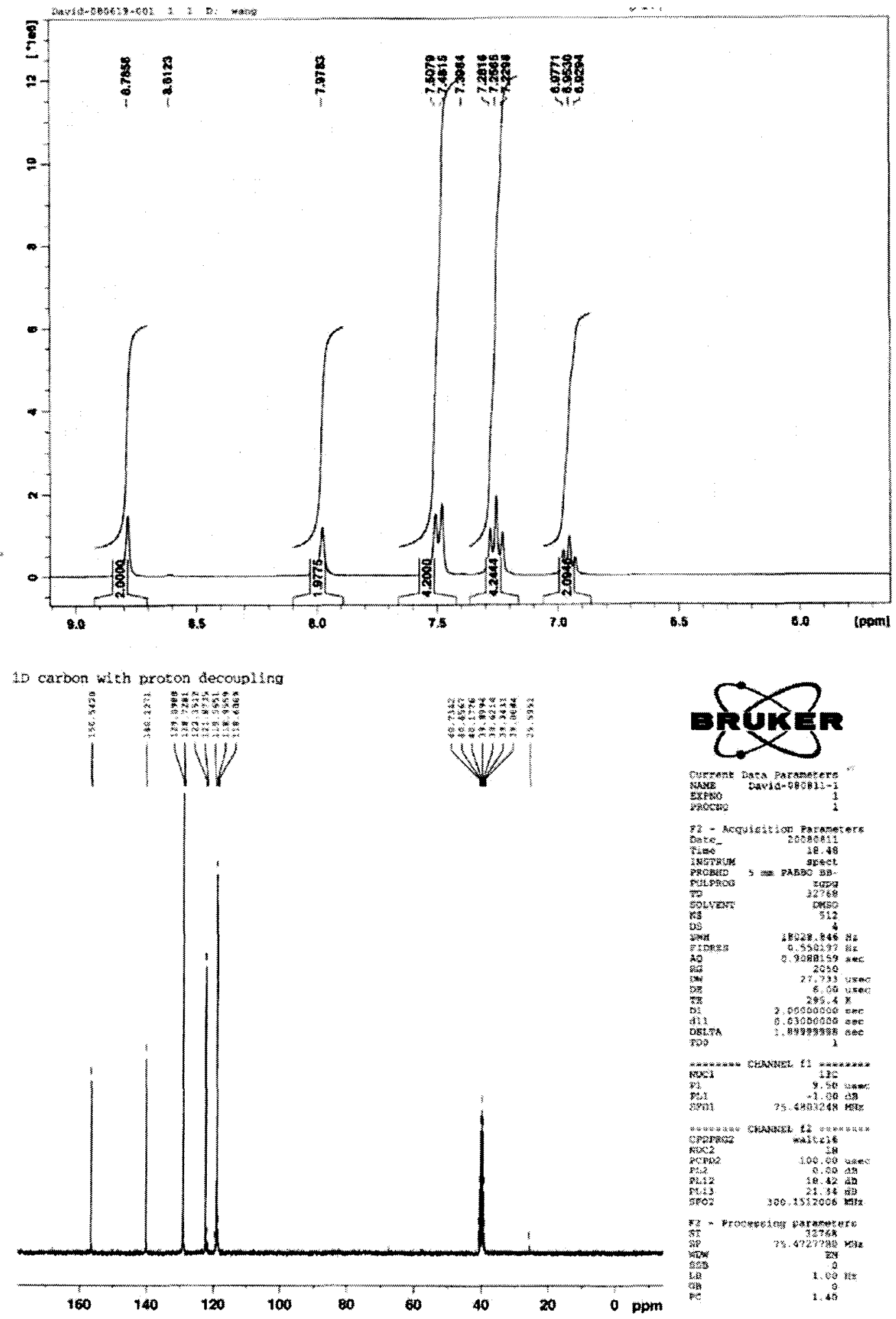

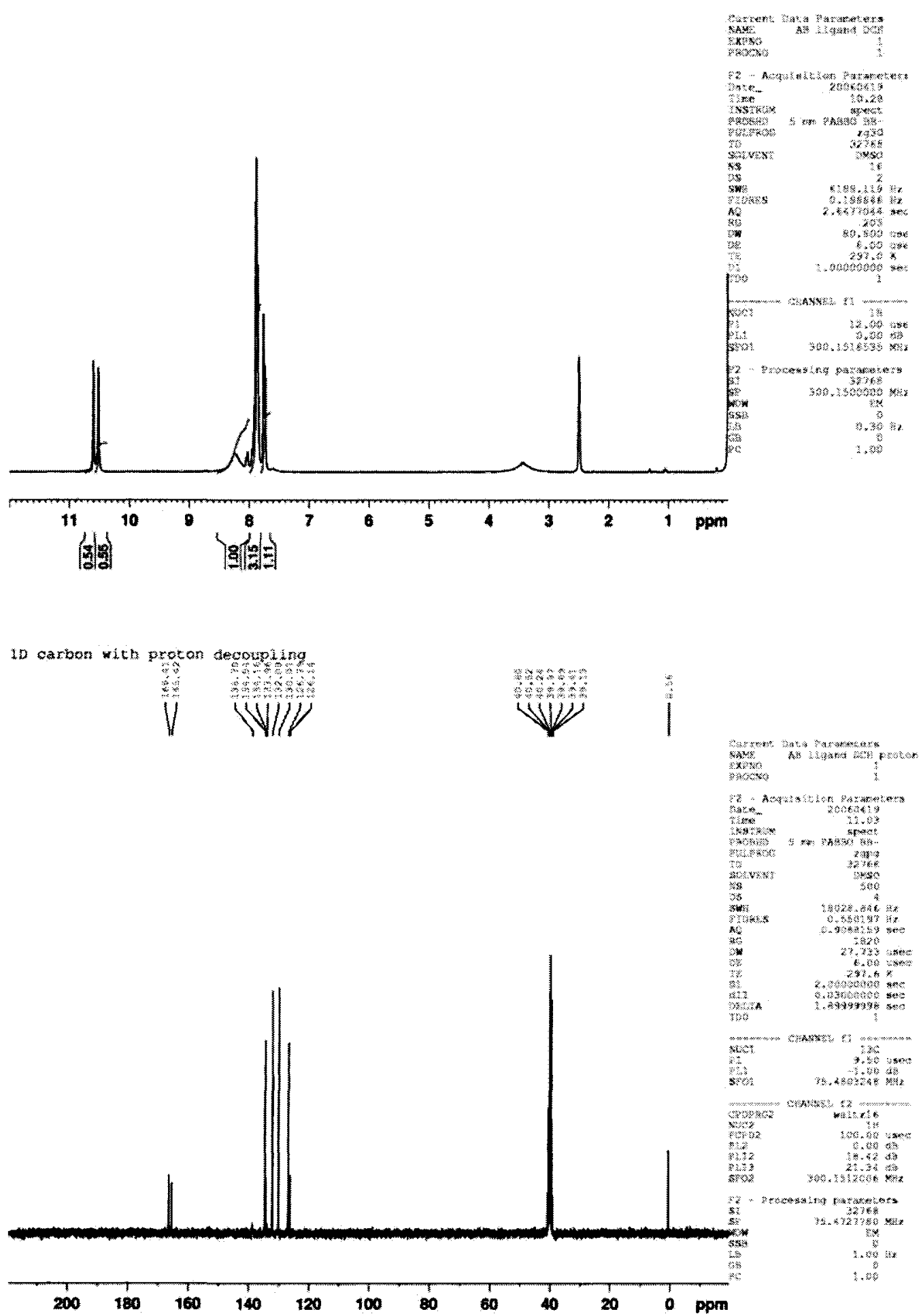
$N$-(4-Bromophenyl)-N'-(4-(4,4,5,5-tetramethyl-1,3,2-dioxaborolan-2-yl)phenyl)-1,2hydrazinedicarboxamide (IV.10)
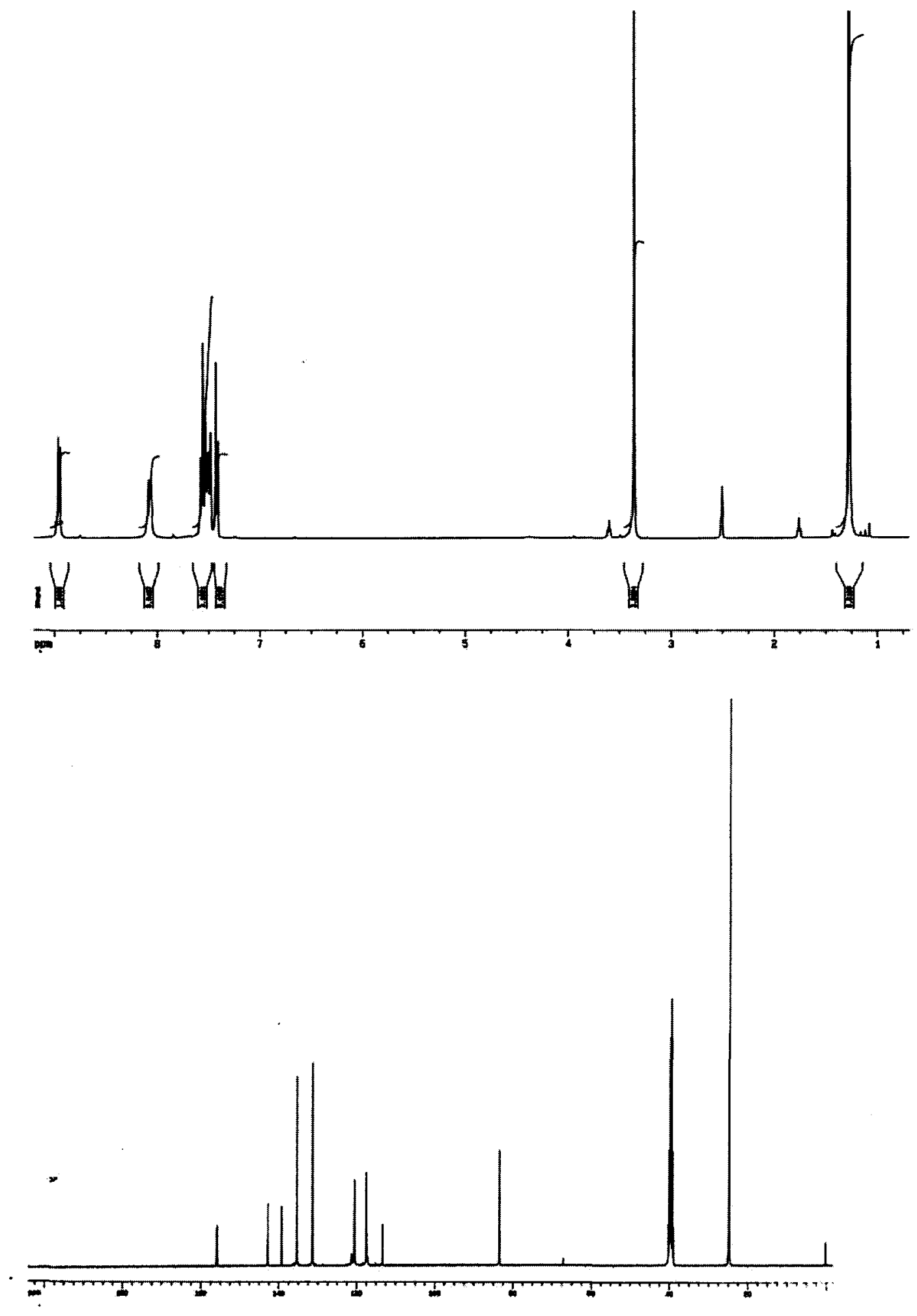


\section{1,2-Bis(4-bromobenzoyl)hydrazine (IV.11)}
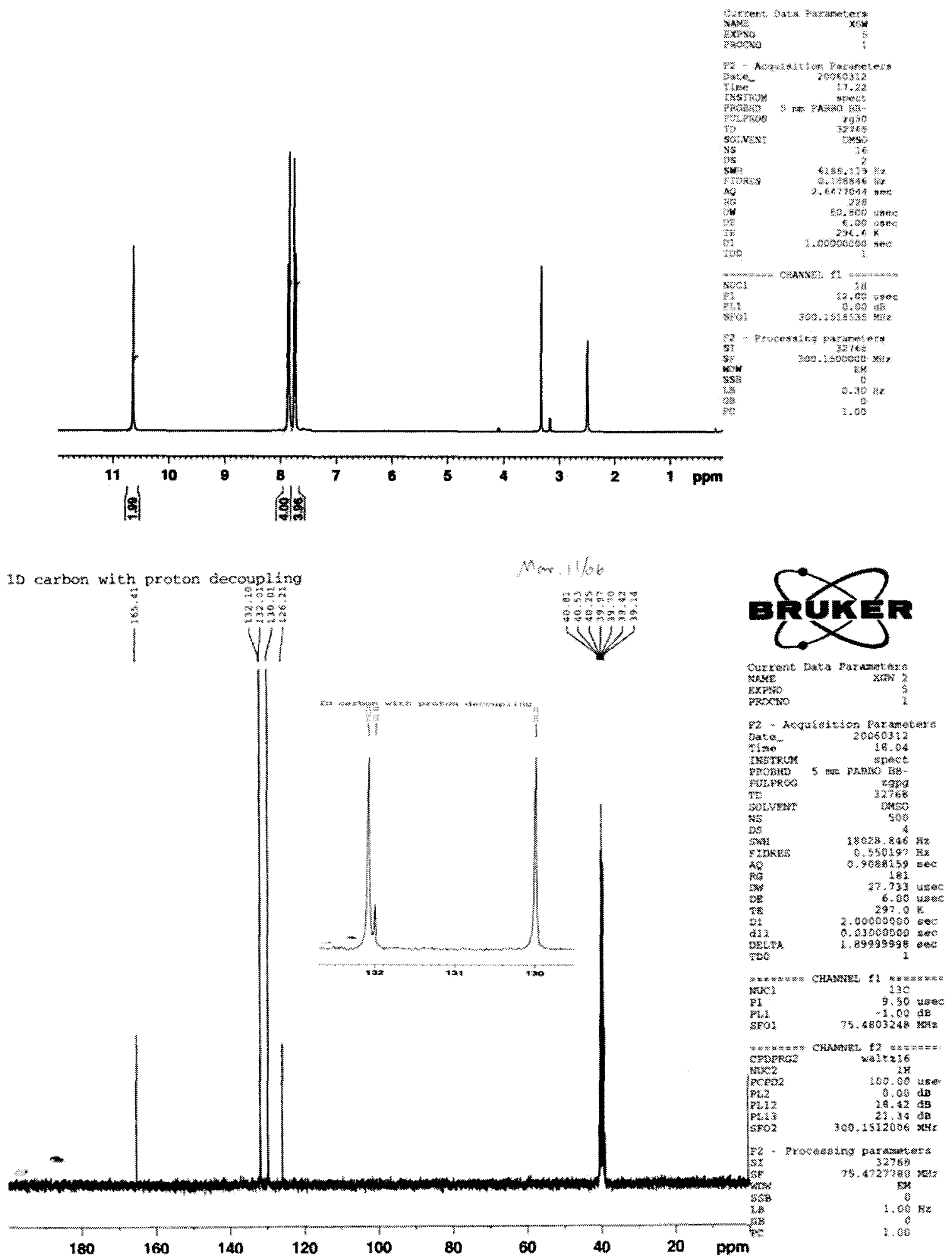
$\left[\left\{R u(b p y)_{2}\right\} \mu-(B r P h)_{2}-d c h\right]\left(P F_{6}\right)_{2}(I V .11-R u)$
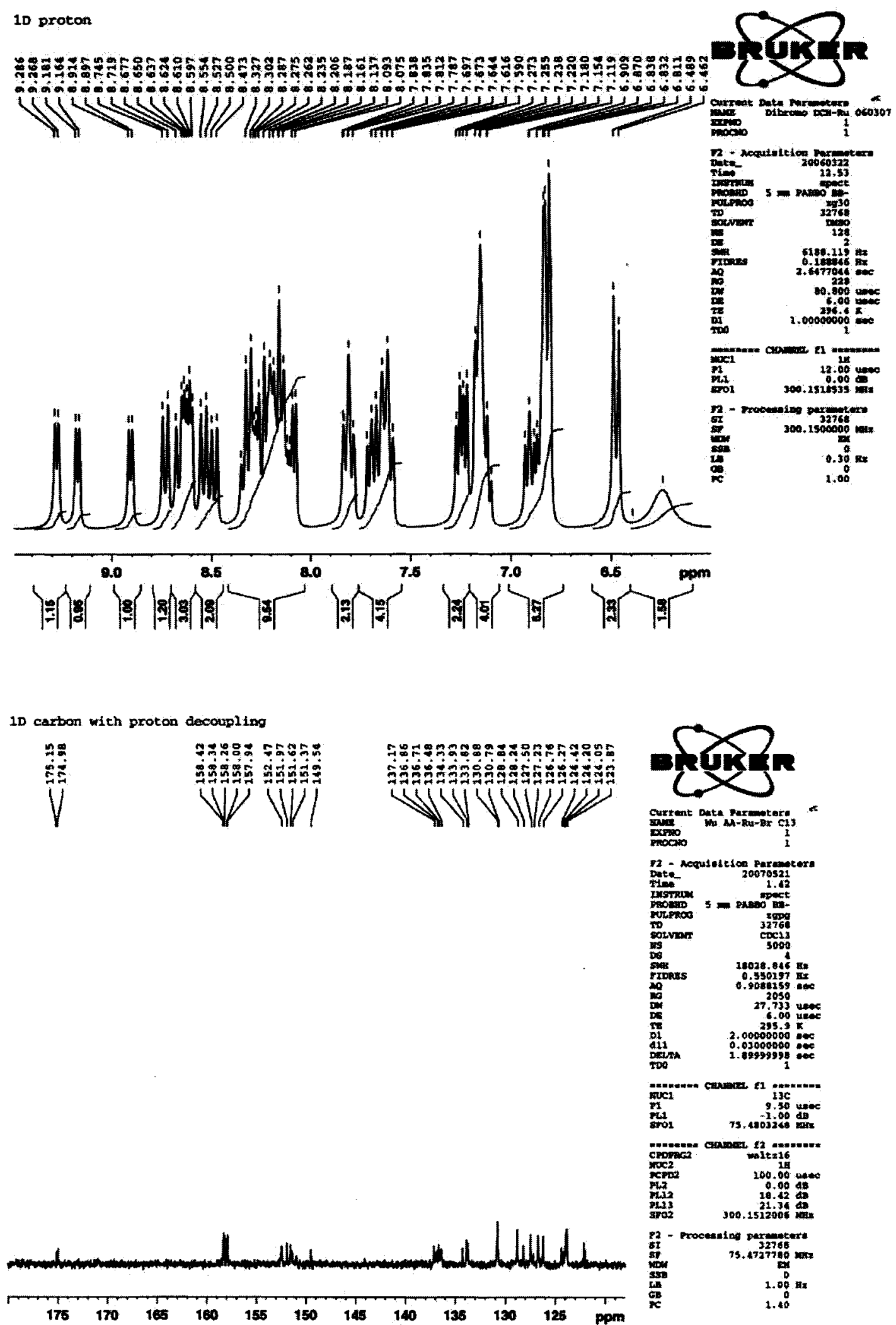